\title{
Soot Optical Diagnostic Development and Application to Turbulent Non-Premixed Buoyant Flames
}

by

\author{
Brian Michael Crosland
}

A thesis submitted to the Faculty of Graduate and Postdoctoral Affairs in partial fulfillment of the requirements for the degree of

\section{Doctor of Philosophy}

In

\section{Mechanical Engineering}

Carleton University

Ottawa, Ontario

(C)2014

Brian Michael Crosland 


\section{Abstract}

This thesis details the development and application of laser-based optical diagnostics capable of measuring soot volume fraction, mean aggregate radius of gyration and primary particle size in turbulent flames. Research focussed on techniques suitable for making instantaneous measurements in turbulent flames, initially investigating a 2D auto-compensating laser-induced incandescence (2DAC-LII) diagnostic prior to developing a unique combined AC-LII and elastic light scattering (ELS) system, which was used in subsequent experiments. Comprehensive Monte Carlo-based uncertainty analyses performed on each system indicated that the imprecise knowledge of soot properties was the largest source of uncertainty for all measurements. Use of a newly-developed ELS calibration method allowed a reduction in uncertainties resulting from calibration and instrument noise. The AC-LII/ELS technique was applied to turbulent buoyant non-premixed flames relevant to solution gas flares used throughout the upstream energy industry, resulting in several important insights. First, the results demonstrate that decreases in soot volume fraction seen near the flame tip are attributable to increased flame intermittency rather than decreases in soot volume fraction within soot-bearing structures, providing support for a recent suggestion from the literature that this could occur in momentum-dominated flames and further extending it to the buoyancydominated flames studied here. Secondly, and contrary to a suggestion in the 
literature for momentum-dominated flames, the current results indicate that soot-bearing structures oxidize very rapidly or not at all, rather than being preferentially oxidized in structures with low soot volume fraction. Thirdly, soot aggregate size was found to vary linearly with residence time, and trends for a wide range of flames collapsed when residence times were offset to account for implied variations in soot inception height. Finally, considering the large range of flow rates and burner diameters investigated, it is significant that measured quantities among all turbulent buoyant flame conditions were well-correlated when scaled in the axial direction by either flame length or residence time. The body of work presented here has provided new insights into the sooting behaviour of turbulent buoyant non-premixed flames and has made significant contributions to the development of diagnostic tools that will facilitate future investigations in a range of flame configurations. 


\section{Acknowledgements}

I would like to thank Professor Matthew Johnson for the advice, support, and motivation he offered during my doctoral studies. He is an inspiring role model \& leader and an all-around good person. I am fortunate to have had the opportunity to work with him for so long.

I would like to thank Dr. Kevin Thomson for his advice \& guidance and for sharing his knowledge and his time with me. He is a thoughtful person, a helpful colleague and a good friend. I am a better person for having worked with him. I would also like to acknowledge the support of various technicians at the National Research Council who helped me at various points along the way: Dan Clavel, Bob Sawchuk, Fazil Baksh, Daniel Gareau and Simon Lafrance.

My doctoral studies would not have been nearly as pleasant without the friends who helped make my time in Ottawa fun and interesting: Derek, Calvin, Karen \& Graham, John \& Janis, Catherine, Carole \& Heine \& the Carleton Toastmasters Club, and all of Matt's other grad students.

The continued support of my mom, dad, and sister has helped reassure me that I'm on the right path, and that with perseverance will come success. Thank you.

Finally, I must thank my wife Catherine for all her love and support through five years of commuting from Blainville to Ottawa, for still loving me once I was back at home 7 days a week, and for only asking a few (dozen) times that terrible, terrible question: are you almost finished?

Yes. 


\section{Table of Contents}

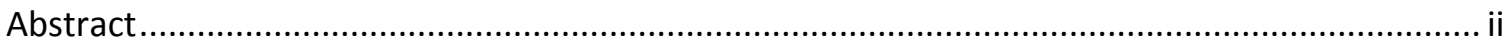

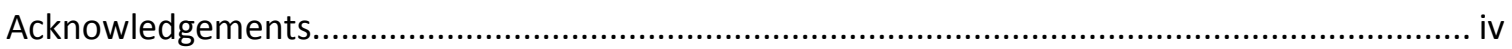

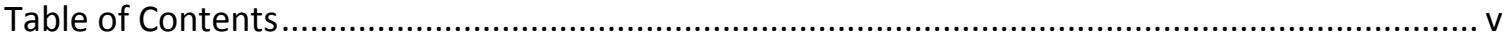

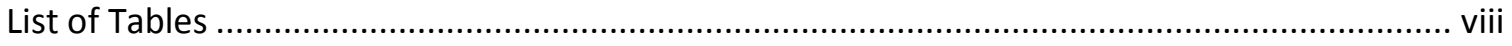

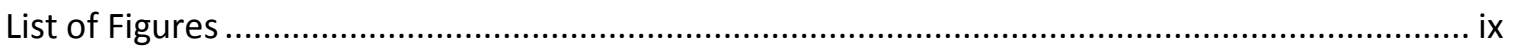

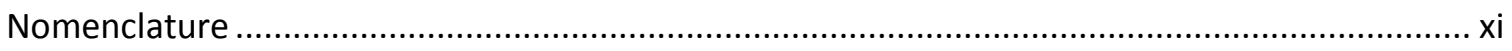

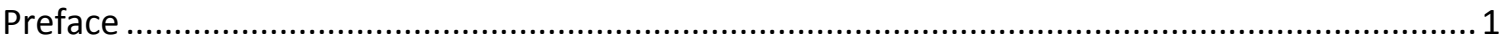

Student Statement Regarding Student Involvement................................................. 3

Supervisor Statement Regarding Student Involvement ................................................. 3

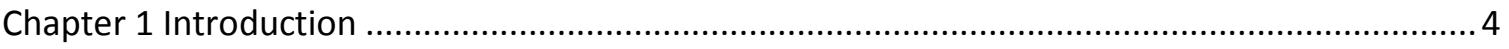

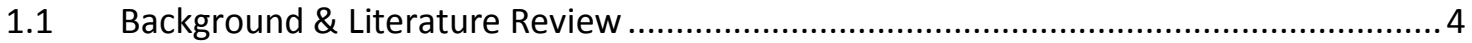

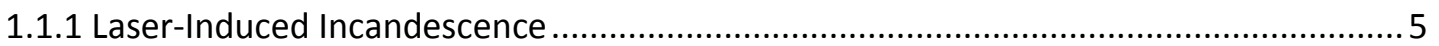

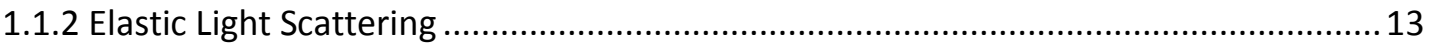

1.1.3 Turbulent Non-Premixed Flames .......................................................... 17

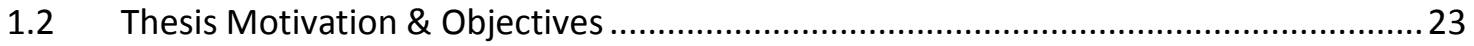

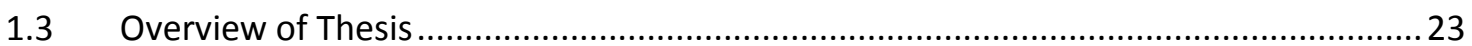

Chapter 2 Analysis of Uncertainties in Two-Dimensional, Auto-Compensating Laser-Induced

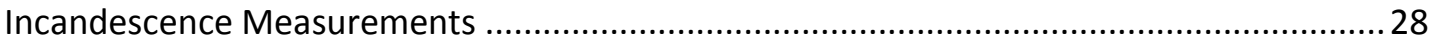

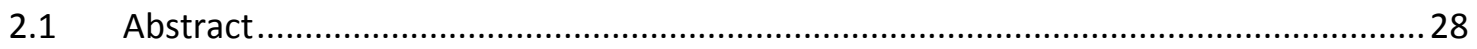

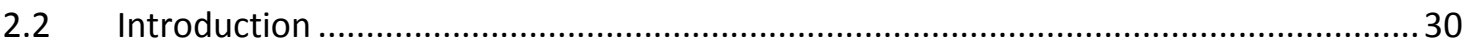

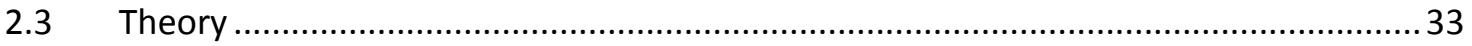

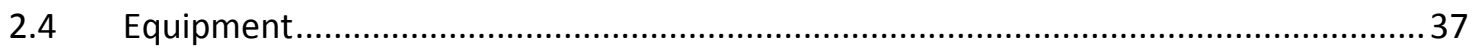

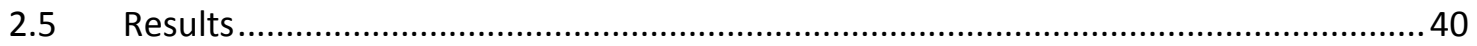

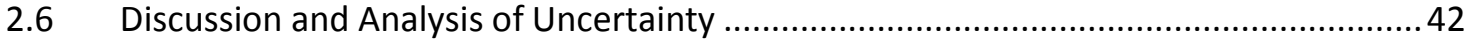

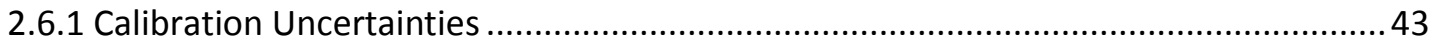

2.6.2 Uncertainties During Data Collection ........................................................ 45

2.6.3 Uncertainties of Instantaneous and Mean $f_{v}$ Measurements Using 2D-AC-LII............51 


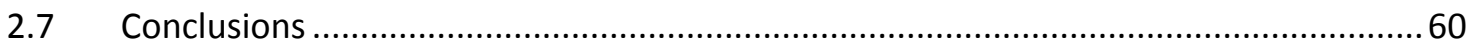

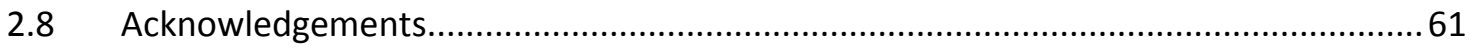

Chapter 3 Diffuse Surface Calibration of Elastic Light Scattering Detectors ................................. 62

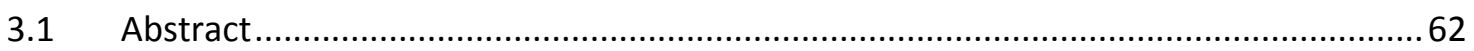

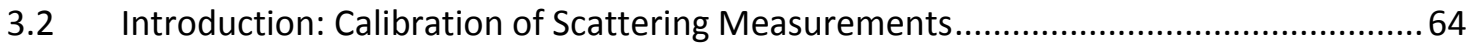

3.3 Calibration Theory and Experimental Methodology ..................................................6 66

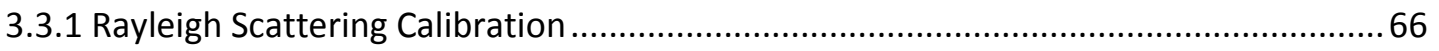

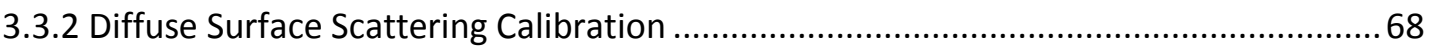

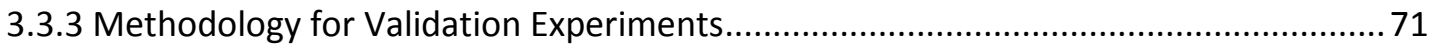

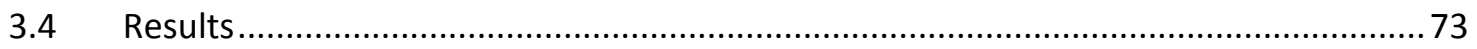

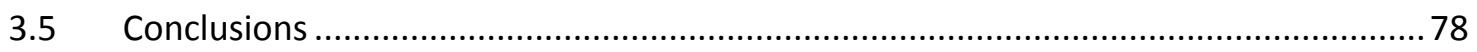

Chapter 4 Simultaneous Measurement of Soot Volume Fraction, Aggregate Size and Primary

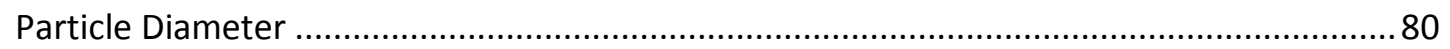

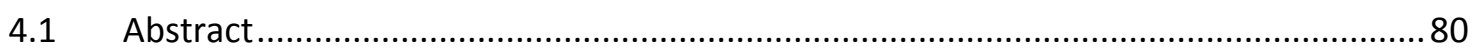

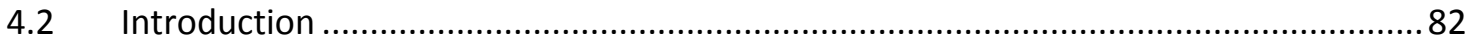

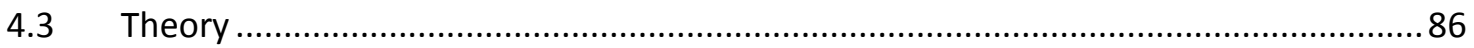

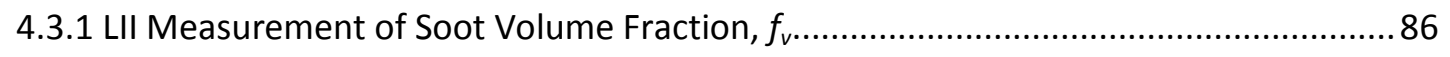

4.3.2 Determination of Soot Mean Aggregate Radius of Gyration........................................ 90

4.3.3 Determination of Primary Particle Diameter .............................................................. 95

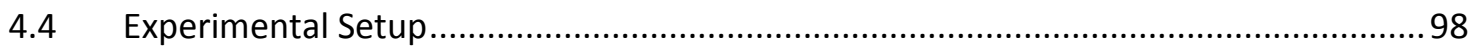

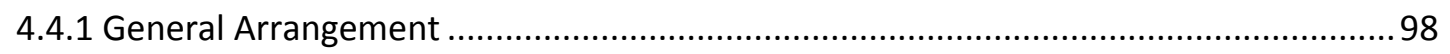

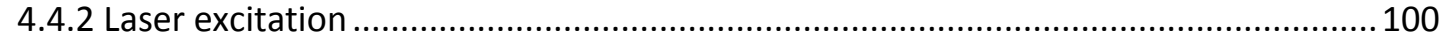

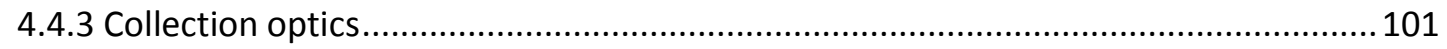

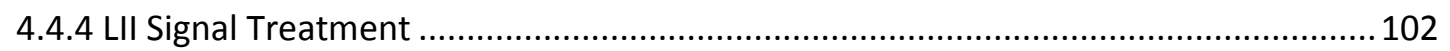

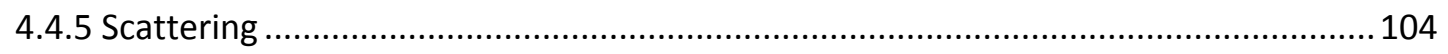

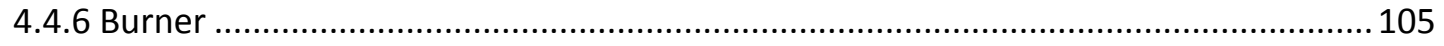

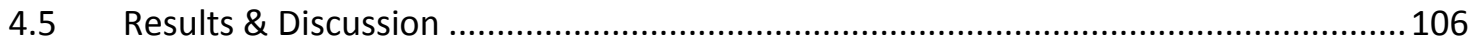

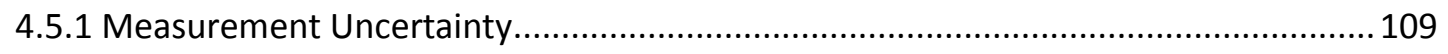

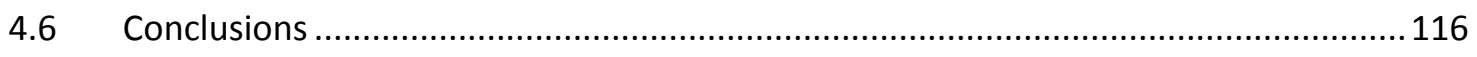

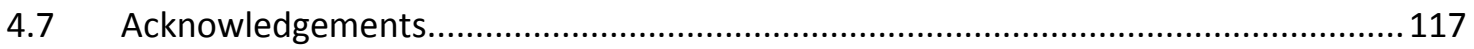

Chapter 5 Simultaneous Instantaneous Measurement of Soot Volume Fraction, Primary Particle

Diameter, and Aggregate Size in Turbulent Buoyant Diffusion Flames .............................. 118 


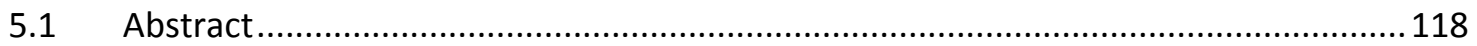

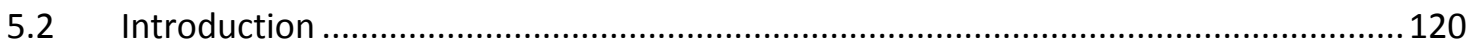

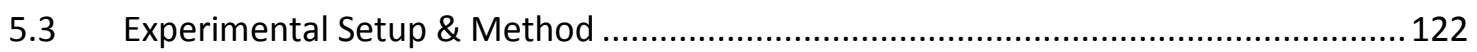

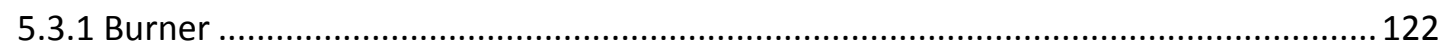

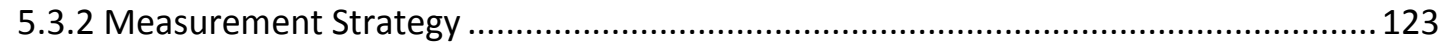

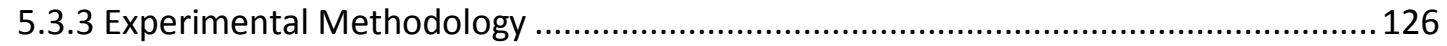

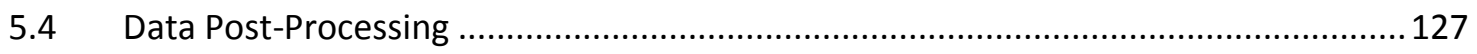

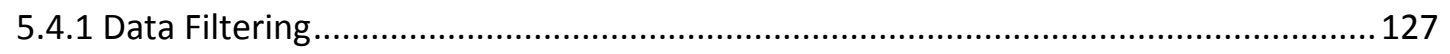

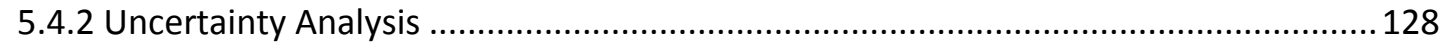

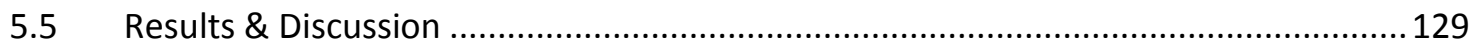

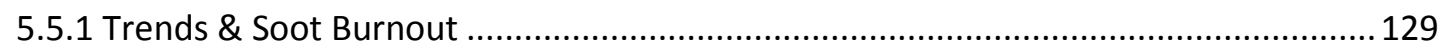

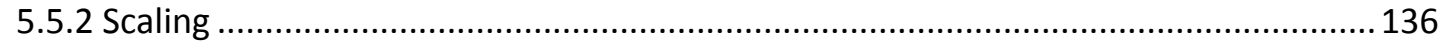

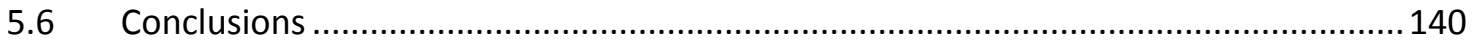

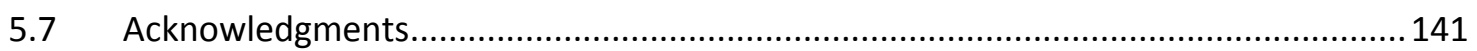

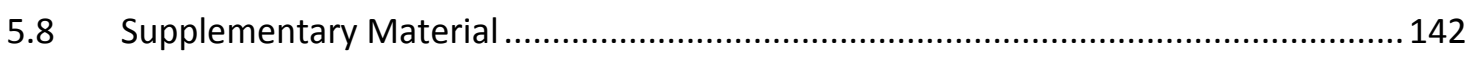

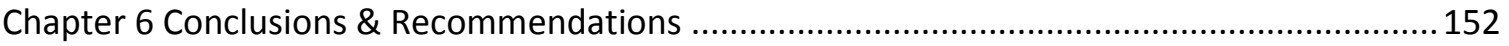

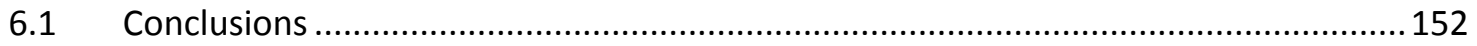

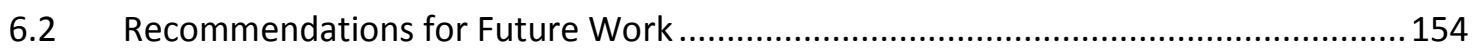

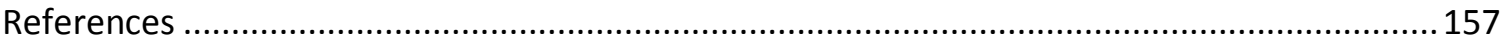

Appendix A: Additional Figures Describing the Transfer of the Scattering Calibration between

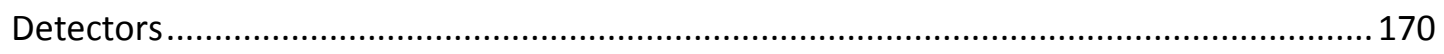

Appendix B: Supplemental Information and Figures Describing the Experimental Apparatus...173

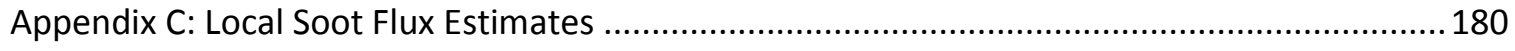




\section{List of Tables}

Table 1.1 - Summary of Literature examining the LII technique 8

Table 1.2 - Summary of literature examining the ELS technique for soot characterization 14

Table 1.3 - Summary of literature reporting turbulent and flickering flame soot measurements.

Table 2.1 - Summary of distributions used as inputs for the Monte Carlo simulation.

Table 2.2 - Sensitivity of soot volume fraction (ppm per standard deviation of variable in question). The high soot data is at $r / R=-0.39, y / R=6.35$, the low soot data $r / R=0$, $y / R=6.35$.

Table 3.1 - Comparison of Rayleigh and diffuse surface calibration techniques and associated magnitudes and uncertainties in instantaneous scattering coefficient measurements using PMT and photodiode detectors.

Table 3.2 - Comparison of potential uncertainty limits in measured scattering coefficients and dissymmetry ratios for optics configured to handle dynamic ranges of 5, 10, and 25 in transient signals from unsteady/turbulent flames.

Table 4.1 - Input parameters used in the Monte Carlo uncertainty propagation analysis.

Table 4.2 - Properties of the distributions resulting from Monte Carlo uncertainty propagation. Mean values are followed by upper and lower bounds of the $2 \sigma(95 \%)$ confidence intervals expressed both in absolute terms and as a percentage of the mean.

Table 5.1 - Flow conditions and flame parameters 


\section{List of Figures}

Figure 2.1 - The required equivalent sheet thickness remains relatively uniform during the intensifier gate......

Figure 2.2 - Schematic of the experimental apparatus.

Figure 2.3 - The a) equivalent temperature and soot volume fraction as measured instantaneously via b) 2D-AC-LII, c) by average of 2D-AC-LII measurements, and d) by 2D-LOSA (Trottier et al., 2007). The fuel tube radius, $R=5.45 \mathrm{~mm}$.

Figure 2.4 - Accounting for variations in soot temperature compensates for decreased laser fluence at the right hand soot peak.

Figure 2.5 - The non-zero gate width bias error for the current measurement system as a function of cooling rate, heated soot temperature and ICCD gate width. 50

Figure 2.6 - Histograms of soot volume fraction in a strongly-sooting region. .53

Figure 2.7 - Histograms of soot volume fraction in a weakly-sooting region. 54

Figure 2.8 - An instantaneous 2D-planar measurement of the soot volume fraction (in parts per million, ppm) (a), as well as the upper and lower bounds of the $95 \%$ confidence intervals for the total uncertainty $[(b)$ and $(c)]$ and the comparative uncertainty $[(d)$ and $(e)] \ldots . . .55$

Figure 2.9 - The relative uncertainty as a function of pixel bin size for square bins. 56

Figure 2.10 - Example scatter plots from the Monte-Carlo analysis showing the influence of the measured signal $\left(I_{2}\right)$ in determining the a) total uncertainty, and b) comparative uncertainty in measured soot volume fraction. Plotted lines are linear least-squares fit to indicate the strength of the correlation.

Figure 3.1 - Experimental setup for detection of ELS during Rayleigh and diffuse surface calibration. The diffuse scattering calibration is transferred from the backward scattering optics to the forward scattering optics via an integrating sphere (not shown).

Figure 4.1 - Laser beam shaping and detector arrangement. 99

Figure 4.2 - Signal treatment flow chart. Laser excitation (a), induces both elastic light scattering and soot incandescence signals (b), which vary both spectrally and temporally. ELS signals were collected at forward and backward angles (c), focused onto a pair of photodiodes (d), and amplified using a $5 x$ fast preamplifier (e). LII signals were collected at a backward angle (c), spectrally filtered (f), attenuated using neutral density (ND) filters, and focused unto a pair of photomultiplier tubes (h). All four signals were then gated in time (i), before being digitized (j) and stored in a computer (k). 100

Figure 4.3 - Profiles of laser fluence measured across the width of the laser sheet taken at three vertical locations within the measurement volume. The three locations are designated by a vertical coordinate, $z$, relative to the centre of the measurement volume. The mean fluence is approximately $0.9 \mathrm{~mJ} / \mathrm{mm} 2$. 101 
Figure 4.4 - (a) Scatter plot comparing instantaneous measurements of soot volume fraction and primary particle size obtained via combined LII/ELS in the present work with $95 \%$ confidence intervals of total uncertainty for a single instantaneous measurement (dotted lines), uncertainty with fixed soot properties (thin solid lines), and uncertainty considering instrument noise only (thick solid lines). Also shown are soot volume fraction results from Snelling et al. (2005) plotted versus primary particle diameter results presented in Tian et al. (2004) and calculated from the results in Snelling et al. (2011). b) Scatter plot comparing instantaneous measurements of soot aggregate radius of gyration and primary particle size with $95 \%$ confidence intervals of total uncertainty on a single instantaneous measurement (dotted lines), uncertainty with fixed soot properties (thin solid lines), and uncertainty considering instrument noise only (thick solid lines). Radius of gyration calculated from TEM measurements in Snelling et al. (2011) and calculated from scattering data from Snelling et al. (2011) and Link et al. (2011) are shown for comparison at the primary particle diameter results of both Snelling et al. (2011) and Tian et al. (2004). All measurements taken on the burner centreline at a height above the burner exit of $42 \mathrm{~mm}$ ( $65 \%$ along the visible flame length).

Figure 5.1 - Axial profiles of mean a) $f_{v}$, b) $f_{v}^{s}$, c) $R_{g m 1}$ and d) $d_{p}$ along the flame centreline for the $25.4 \mathrm{~mm}$ nozzle conditions.

Figure 5.2 - (a) mean centreline $u$ profiles and (b) mean centreline $f_{v}$. Results for the nine cases not in the legend fall within the grey shaded region.

Figure 5.3 - Mean residence time and flame length for all conditions.......................................133

Figure 5.4 - PDFs of $f_{v}^{s}$ for various flame conditions. .136

Figure 5.5 - Nozzle-diameter normalized flame height (solid symbols) and height of peak $f_{v}$ (hollow symbols) vary with Richardson ratio. 137

Figure $5.6-R_{g m 1}$ as a function of $\tau$, where a) $\tau=0$ at $x / L_{f}=0$ and b) $\tau$ has been shifted for each condition to maximize correlation. c) Calculated time shifts as a function of exit velocity. 


\section{Nomenclature}

Latin

Symbol

$2 \mathrm{C}$

2D-

LOSA

A

AC Auto-Compensating, referring to the variant of the laser-induced incandescence diagnostic that employs optical pyrometry combined with calibration to spectral radiance standard to determine soot volume fraction

ADU Analog-to-Digital units $A_{L} \quad$ surface area of camera lens

$A_{p}$

$c$

CCD Charge-Coupled Device

$C_{R}$

$C_{s}$

$D$

$D_{e}$

$D_{f}$

$D_{\text {filt }}$

$d_{p}$

E

$E\left(m_{\lambda}\right)$

ELS area of a single CCD pixel

Chapter 2: speed of light

Chapter 3: molar concentration of calibration gas

calibration constant of ELS system based on Rayleigh system

curve-fit parameters used to describe the aggregate structure factor dark count of an ICCD

diameter of the burner exit nozzle fractal dimension change in transmissivity between calibration and experimental measurement diameter of a single (primary) soot particle

energy collected by optical detection system the wavelength-dependent soot index of refraction absorption function Elastic Light Scattering, referring to the scattering of electromagnetic waves by soot particles without a shift of the wavelength of the light
First Use Eq. $\mathrm{Pg}$. 32

$\left[\mathrm{m}^{2}\right]$

$\begin{array}{lll}{\left[\mathrm{m}^{2}\right]} & (2.2) & 52 \\ {\left[\mathrm{~m}^{2}\right]} & (2.2) & 34 \\ {\left[\mathrm{~m} \cdot \mathrm{s}^{-1}\right]} & (2.1) & 33 \\ {\left[\mathrm{~mol} \mathrm{~m} \mathrm{~m}^{3}\right]} & (3.2) & 67\end{array}$

$[\mathrm{V} \cdot \mathrm{m}]$

91

[ADU]

(2.2) 33

[m]

(4.3) 15

(3.4) 67

[m]

(4.3) 8

$[\mathrm{J}]$

66

(2.1) 8

4 
Latin

First Use

\begin{tabular}{|c|c|c|c|c|}
\hline Symbol & Description & Units & Eq. & Pg. \\
\hline$F\left(m_{\lambda}\right)$ & $\begin{array}{l}\text { the wavelength-dependent soot index of } \\
\text { refraction scattering function }\end{array}$ & & $(4.9)$ & 96 \\
\hline$f / \#$ & f number of an optical detection system & & & 38 \\
\hline$F_{L}$ & peak laser sheet fluence & {$\left[\mathrm{J} \cdot \mathrm{m}^{-2}\right]$} & & 46 \\
\hline$f_{n}$ & $\begin{array}{l}\text { ratio of the first two moments of the } \\
\text { distribution of aggregate sizes }\end{array}$ & & $(4.9)$ & 96 \\
\hline$f_{v}$ & soot volume fraction & [ppm] & $(2.2)$ & 5 \\
\hline$g$ & acceleration due to gravity & {$\left[\mathrm{m} \cdot \mathrm{s}^{-2}\right]$} & & 127 \\
\hline$h$ & Planck constant & {$[\mathrm{J} \cdot \mathrm{s}]$} & $(2.1)$ & 33 \\
\hline$I$ & signal measured by a CCD & [ADU] & $(2.2)$ & 33 \\
\hline ICCD & Intensified Charge-Coupled Device & & & 33 \\
\hline$I_{\text {lamp }}$ & signal measured during calibration & [ADU] & $(2.3)$ & 34 \\
\hline$k$ & Boltzmann constant & {$\left[\mathrm{J} \cdot \mathrm{K}^{-1}\right]$} & $(2.1)$ & 33 \\
\hline$K_{a b s}$ & absorption coefficient & {$\left[\mathrm{m}^{-1}\right]$} & $(4.9)$ & 96 \\
\hline$k_{f}$ & $\begin{array}{l}\text { fractal prefactor, using } d_{p} \text { as characteristic } \\
\text { length }\end{array}$ & & $(4.3)$ & 90 \\
\hline$K_{v v}$ & $\begin{array}{l}\text { scattering coefficient for vertically- } \\
\text { polarized incident and scattered light }\end{array}$ & {$\left[\mathrm{m}^{-1}\right]$} & $(3.4)$ & 67 \\
\hline$L_{f}$ & flame length & {$[\mathrm{m}]$} & & 126 \\
\hline LII & Laser-Induced Incandescence & & & 1 \\
\hline LSF & lab-scale flare & & & 122 \\
\hline$M$ & magnification of the detection system & & $(2.2)$ & 34 \\
\hline$\dot{m}$ & mass flow rate & {$\left[\mathrm{kg} \cdot \mathrm{s}^{-1}\right]$} & & 127 \\
\hline$N$ & number of primary particles per aggregate & & $(4.3)$ & 15 \\
\hline $\bar{N}$ & $\begin{array}{l}\text { arithmetic mean number of primary } \\
\text { particles per aggregate in a sample of } \\
\text { aggregates }\end{array}$ & & $(4.8)$ & 92 \\
\hline$N_{A}$ & Avogadro's number & & $(3.2)$ & 67 \\
\hline$N_{m}$ & $\begin{array}{l}\text { geometric mean number of primary } \\
\text { particles per aggregate in a sample of } \\
\text { aggregates }\end{array}$ & & $(4.7)$ & 91 \\
\hline$N_{S}$ & $\begin{array}{l}\text { number of measurements where soot was } \\
\text { present }\end{array}$ & & & 128 \\
\hline$N_{T}$ & total number of measurements made & & & 128 \\
\hline PAH & Polycyclic Aromatic Hydrocarbons & & & 9 \\
\hline PDF & Probability Density Function & & & 134 \\
\hline PMT & Photomultiplier Tube & & & 24 \\
\hline ppm & parts per million & & & 24 \\
\hline$q$ & scattering wave vector, $q=\sin (\theta / 2) \cdot 4 \pi / \lambda$ & {$\left[\mathrm{m}^{-1}\right]$} & & 90 \\
\hline$R$ & radius of the fuel tube, $5.45 \mathrm{~mm}$ & {$[\mathrm{~m}]$} & & 40 \\
\hline$r$ & distance from the burner centreline & {$[\mathrm{m}]$} & & 40 \\
\hline$r^{2}$ & coefficient of determination & & & 138 \\
\hline$R D G-F A$ & $\begin{array}{l}\text { Rayleigh-Debye-Gans fractal aggregate } \\
\text { theory }\end{array}$ & & & 87 \\
\hline
\end{tabular}


Latin

First Use

\begin{tabular}{|c|c|c|c|c|}
\hline Symbol & Description & Units & Eq. & Pg. \\
\hline $\operatorname{Re}$ & Reynolds number & & & 18 \\
\hline$R_{g}$ & radius of gyration & {$[\mathrm{m}]$} & $(4.3)$ & 14 \\
\hline$R_{g m 1}$ & $\begin{array}{l}\text { effective radius of gyration based on the } \\
\text { mean number of primary particles per } \\
\text { aggregate in a sample of aggregates }\end{array}$ & {$[\mathrm{m}]$} & $(4.8)$ & 92 \\
\hline$R_{i}$ & Chapter 3: laser irradiance & {$\left[\mathrm{J} \cdot \mathrm{m}^{-2}\right]$} & $(3.2)$ & 67 \\
\hline & Chapter 5: Richardson ratio & & & 127 \\
\hline$R_{S}$ & spectral radiance & {$\left[\mathrm{W} \cdot \mathrm{sr}^{-1} \cdot \mathrm{m}^{-3}\right]$} & $(2.3)$ & 34 \\
\hline$r_{s}$ & total reflectivity of diffuse surface & & $(3.6)$ & 69 \\
\hline$R_{v v}$ & dissymmetry ratio & & $(4.7)$ & 91 \\
\hline$S$ & structure factor & & $(4.4)$ & 90 \\
\hline$\overline{S\left(q \cdot R_{g}\right)}$ & effective polydisperse structure factor & & $(4.6)$ & 91 \\
\hline $\mathrm{sccm}$ & Standard Cubic Centimetres per Minute & & & 39 \\
\hline slpm & Standard Litres Per Minute & & & 39 \\
\hline SVF & soot volume fraction & {$[\mathrm{ppm}]$} & & 28 \\
\hline$T_{0}$ & $\begin{array}{l}\text { soot temperature at beginning of ICCD } \\
\text { gate }\end{array}$ & {$[\mathrm{K}]$} & & 49 \\
\hline$T_{e}$ & equivalent soot particle temperature & {$[\mathrm{K}]$} & & 35 \\
\hline TEM & $\begin{array}{l}\text { Transmission Electron Microscopy, } \\
\text { referring to the use of a transmission } \\
\text { electron microscope to examine the } \\
\text { morphological properties of soot }\end{array}$ & {$[-]$} & & 8 \\
\hline$T_{g}$ & gas phase temperature before LII heating & {$[\mathrm{K}]$} & & 88 \\
\hline$T_{p}$ & soot particle temperature & {$[\mathrm{K}]$} & $(2.1)$ & 33 \\
\hline$u$ & $\begin{array}{l}\text { Chapter 2: distance between the } \\
\text { measurement volume and the camera lens }\end{array}$ & {$[\mathrm{m}]$} & $(2.2)$ & 34 \\
\hline & Chapter 5: mean local velocity & {$\left[\mathrm{m} \cdot \mathrm{s}^{-1}\right]$} & & 125 \\
\hline$u_{e}$ & cold flow exit velocity & {$\left[\mathrm{m} \cdot \mathrm{s}^{-1}\right]$} & & 126 \\
\hline$V_{\text {meas }}$ & signal measured by PMTs & {$[\mathrm{V}]$} & $(4.1)$ & 87 \\
\hline$V_{m r}$ & volume of measurement region & {$\left[\mathrm{m}^{3}\right]$} & $(3.2)$ & 67 \\
\hline$w_{b}$ & laser sheet thickness & {$[\mathrm{m}]$} & $(2.2)$ & 33 \\
\hline$w_{e}$ & equivalent laser sheet thickness & {$[\mathrm{m}]$} & & 35 \\
\hline$x$ & height above the LSF nozzle & {$[\mathrm{m}]$} & & 126 \\
\hline$y$ & height above the fuel tube exit & {$[\mathrm{m}]$} & & 40 \\
\hline
\end{tabular}


Greek

First Use

Symbo

Description

Units

$\alpha \quad$ Chapters $2 \& 4$ : thermal accommodation $\quad[-]$ coefficient

Chapter 3: angle between the incident laser light $\quad$ [rd] 70

and the diffuse surface normal

Chapter 5: constant used to relate Lagrangian

$[-]$

125

and Eulerian time scales

$\alpha_{i} \quad$ gain of the $i^{\text {th }}$ image intensifier

$[-] \quad(2.2) \quad 34$

$\beta_{\mathrm{i}} \quad$ gain of the CCD

$[-]$

(2.2) 34

$\beta \quad$ Chapter 3: angle between the diffuse surface

normal and the direction of detection

Chapter 5: ratio between Lagrangian and

[rd]

(3.6) 69

Eulerian time scales

$\Delta \varphi \quad$ measured voltage at PMT output

$[-]$

125

$\eta$

Chapter 2: wavelength-independent calibration

coefficient of the detection system

Chapter 3: optical calibration constant

Chapter 4: wavelength-independent calibration coefficient of the detection system

$\Theta \quad$ wavelength-dependent responsivity of the $i^{\text {th }}$

ICCD

$\theta \quad$ angle between the incident laser sheet and the

axis of detection

$\lambda \quad$ wavelength of light

$\rho$ depolarization ratio of the diffuse surface

$\sigma_{g}$

standard deviation of the number of primary

particles per aggregate in a sample of aggregates

$\sigma_{s} \quad$ scattering cross-section

Chapter 2-3: transmissivity of an optical element

Chapter 4: parameter for self-preserving distribution

[V]

(3.1) 66

$\left[\mathrm{ADU} \cdot \mathrm{m}^{3} \cdot \mathrm{A}^{-1}\right]$

(2.3) 34

$\left[\mathrm{V} \cdot \mathrm{J}^{-1}\right]$

(3.1) 66

$\left[\mathrm{V} \cdot \mathrm{m}^{3} \cdot \mathrm{A}^{-1}\right]$

(4.1) 87

$[-]$

(2.2) 33

[rd]

(4.6) 90

$[\mathrm{nm}]$

(2.1) 33

[-]

(3.6) 69

$[-]$

(4.5) 91

$\left[\mathrm{m}^{2}\right]$

(3.2) 67

$[-]$

(2.2) 33

$[-]$

94

Chapter 5: residence time

[s]

132

ratio of soot index of refraction absorption

function at the detection wavelengths

$\phi_{p} \quad$ theoretical emission per unit volume of soot

$\Omega \quad$ Chapter 2: wavelength-dependent-only part of

ICCD throughput, $\Omega(\lambda)=\tau(\lambda) \Theta(\lambda)$

Chapter 5: intermittency index, $N_{S} / N_{T}$

$[-]$

46

$\left[\mathrm{W} \cdot \mathrm{m}^{-3}\right]$

(2.1) 33

$[-]$

(2.2) 33

[-]

128

$\Omega_{\text {det }} \quad$ solid angle of detection

[sr]

(3.2) 67 
First Use

\begin{tabular}{|c|c|c|c|}
\hline Subscripts & Description & Eq. & Pg. \\
\hline 1 or 2 & indicating a particular measurement channel & $(4.1)$ & 87 \\
\hline cal & referring to the measurements taken during calibration & $(3.3)$ & 67 \\
\hline$D$ & $\begin{array}{l}\text { indicating association with a calibration performed via } \\
\text { diffuse surface scattering }\end{array}$ & $(3.5)$ & 69 \\
\hline $\exp$ & $\begin{array}{l}\text { referring to measurements taken during experimental } \\
\text { measurement }\end{array}$ & $(3.4)$ & 68 \\
\hline$i$ & referring to the $\mathrm{i}^{\text {th }}$ detection channel & $(2.2)$ & 33 \\
\hline lamp & $\begin{array}{l}\text { referring to a calibration signal originating from a tungsten } \\
\text { lamp and integrating sphere }\end{array}$ & $(2.3)$ & 34 \\
\hline$R$ & $\begin{array}{l}\text { indicating association with a calibration performed via } \\
\text { Rayleigh scattering }\end{array}$ & $(3.3)$ & 67 \\
\hline$S$ & $\begin{array}{l}\text { indicating association with the elastic light scattering } \\
\text { diagnostic }\end{array}$ & $(4.9)$ & 96 \\
\hline$v v$ & $\begin{array}{l}\text { indicating that both the incident and detected light was } \\
\text { vertically-polarized }\end{array}$ & $(4.7)$ & 92 \\
\hline$\lambda$ & indicating that a term is dependent on wavelength & & \\
\hline & & \multicolumn{2}{|c|}{ First Use } \\
\hline Superscripts & Description & Eq. & Pg. \\
\hline$S$ & $\begin{array}{l}\text { referring to measurements where negligibly-sooting events } \\
\text { have been removed from the dataset }\end{array}$ & & 128 \\
\hline
\end{tabular}




\section{Preface}

This integrated thesis is composed of four articles that have been published or submitted to scholarly journals:

Crosland, BM, MR Johnson, and KA Thomson (2011) Analysis of uncertainties in instantaneous soot volume fraction measurements using two-dimensional, auto-compensating, laser-induced incandescence (2D-AC-LII), Applied Physics B 102(1):173-183. doi: 10.1007/s00340-010-4130-7.

Crosland, BM, MR Johnson, and KA Thomson (2013) Diffuse surface calibration method to improve accuracy and dynamic range of aerosol elastic light scattering measurements, Applied Physics B, 110(3):315320. doi: 10.1007/s00340-013-5357-x.

Crosland, BM, KA Thomson and MR Johnson (2013) Instantaneous in-flame measurement of soot volume fraction, primary particle diameter and aggregate radius of gyration via auto-compensating laser-induced incandescence and two-angle elastic light scattering, Applied Physics B, 112(3):381-393. doi: 10.1007/so0340-013-5539-6.

Crosland, BM, KA Thomson, MR Johnson (2013) Simultaneous instantaneous measurement of soot volume fraction, primary particle diameter, and aggregate size in turbulent buoyant diffusion flames, submitted to the Proceedings of the Combustion Institute, December 4, 2013. Manuscript ID: PROCI-D-13-00156.

The second article is what Applied Physics B refers to as a "Rapid Communication." According to their instructions for authors, "important new results may be considered as a rapid communication. They are handled by the editorial office in a special procedure that ensures rapid reviewing." The standard peer review process is followed in all other respects. All four articles are included in their entirety; the only substantial changes to the manuscripts are to the numbering of equations, figures, tables, and references to ensure consistency 
throughout the thesis as well as minor edits resulting from the examiner's comments during the defence.

Since they were prepared and accepted for publication with a co-author at the National Research Council of Canada, the copyright of the first three works have been attributed to Her Majesty the Queen in Right of Canada. Permissions to reproduce these works with minor edits are included in supporting documents. Copyright for the fourth article is held by the authors since it has not yet been published.

The first three articles are primarily concerned with diagnostic development. They provide detailed accounts of the experimental procedures followed to obtain results, and are considered sufficient to allow readers to test the validity of research outcomes. For this reason the thesis does not contain a separate "Methods Chapter" as described in $\S 12.4 \mathrm{~B}$ of the 2013-2014 Carleton University Graduate Calendar.

The preferred method of citing work from this thesis is to directly reference the published articles when possible, citing this thesis only when an appropriate citation in the included articles cannot be found. 


\section{Student Statement Regarding Student Involvement}

I, Brian Crosland, was fully involved and responsible for setting up equipment, obtaining data, analyzing results and writing the first drafts of the material presented in the accompanying thesis.

Brian M Crosland

\section{Supervisor Statement Regarding Student Involvement}

The student, Brian Crosland, was fully involved and responsible for setting up equipment, obtaining data, analyzing results and writing the first drafts of the material presented in the accompanying thesis.

Matthew R Johnson 


\section{Chapter 1}

\section{Introduction}

\section{$1.1 \quad$ Background \& Literature Review}

Airborne carbon nanoparticles, including soot generated by combustion processes, are detrimental to human health (US EPA 2010) and are important agents in global climate forcing (IPCC 2007). Atmospheric black carbon aerosol including combustion-generated soot is the second-most important climate forcing human emission, with a total climate forcing of $1.1 \mathrm{~W} \cdot \mathrm{m}^{-2}$ and $90 \%$ uncertainty bounds of 0.17 to $+2.1 \mathrm{~W} \cdot \mathrm{m}^{-2}$ (Bond et al., 2013). Soot is loosely defined as a black carbonaceous material produced by combustion, usually consisting of single or chains of spherical nanoparticles. There is a critical lack of understanding of soot production and emission processes. In addition, uncertainty in the properties of combustion-generated soot is a significant source of climate modeling uncertainty.

Targeted literature reviews are contained in each article presented in this thesis. The review presented here will discuss three broad topics: the laserinduced incandescence (LII) diagnostic, elastic light scattering (ELS) diagnostics, and measurements of soot in turbulent non-premixed flames. A broad overview of each subject will be followed by a table summarizing the relevant literature and a discussion of how the current work fits into the body of work. 


\subsubsection{Laser-Induced Incandescence}

LII is an optical combustion diagnostic that can be used to determine the volume fraction of soot. If the gas phase temperature surrounding the soot is known, a time-resolved LII signal can be used to determine the size of soot primary particles. A summary of important contributions to the LII literature is provided in Table 1.1.

Development of LII began following its description by Eckbreth (1977) as interference in Raman scattering measurements. Experimental, numerical and theoretical work followed, leading to the development of prompt, time-resolved and multiple-delay measurement systems capable of measuring soot volume fraction, $f_{v}$, and primary particle size in 0,1 and 2 dimensions.

The LII diagnostic relies on increased radiative emission at higher temperatures to allow distinction of the heated soot in the measurement volume from unheated soot elsewhere in the detector line of sight. Thus, the LII signal is inherently dependent on the heated soot temperature. The first and most common technique to overcome this temperature dependence is to heat all of the soot in the measurement volume to its sublimation temperature of approximately $4000 \mathrm{~K}$. This is referred to as 'plateau' regime LII. Once the soot is heated to a constant temperature, the soot volume fraction is assumed to be directly and linearly related to the LII signal intensity. The second, more recent technique is to detect LII signals at two distinct wavelengths so that the heated soot temperature can be determined via pyrometry. The known soot temperature can then be used with the incandescence signal intensity to determine the soot 
volume fraction. This is referred to as 'auto-compensating' LII or AC-LII, and is generally considered to be less intrusive because the soot does not need to be heated to the point of sublimation.

The LII signal is unsteady in time, and decreases over the course of a few microseconds as the soot cools down to the temperature of the surrounding gas. Determination of soot volume fraction requires only a single measurement in time, usually immediately following the laser pulse when the signal is strongest. This is referred to as 'prompt' LII. Determination of the primary particle size via LII requires knowledge of the rate of cooling, and thus multiple measurements in time are required, through either time-resolved measurement of LII signal decay or multiple prompt measurements with a variable delay between excitation and detection.

As shown in Table 1.1, the most recent developments to the LII theory are focused on effects that contribute to diagnostic uncertainty, such as aggregate structure, primary particle size polydispersity, laser beam steering, and particle overlap. While these sources are numerous and important, prior to the present work there was not a single publication examining their cumulative effect on total soot volume fraction uncertainty as determined via LII. Table 1.1 also shows that the AC-LII technique was first introduced in 2005, and development of 2D-ACLII had been limited to a single article published in 2007 (De Iuliis et al., 2007). De Iuliis et al. acquired time-averaged measurements in a steady flame using a single detector filtered first at one wavelength then at another. While an important step in the development of a 2D-LII diagnostic, the experimental setup 
was not capable of instantaneous measurements, and could not provide direct information of the feasibility of instantaneous measurements of soot volume fraction. These limitations were overcome with the novel real-time measurement apparatus presented in the first article in this thesis, which featured a comprehensive uncertainty analysis of the instantaneous 2D-AC-LII method. 
Table 1.1 - Summary of Literature examining the LII technique

\begin{tabular}{|c|c|c|c|c|c|c|}
\hline Reference & $\begin{array}{l}\text { Temperature } \\
\text { Corr. Method }\end{array}$ & $\begin{array}{l}\text { Temporal } \\
\text { Nature }\end{array}$ & $\begin{array}{l}\text { Spatial } \\
\text { Type }\end{array}$ & Flame Type & Type & Goals and Conclusions \\
\hline Hadef et al., 2013 & Plateau & $\begin{array}{l}\text { Multiple } \\
\text { delays }\end{array}$ & $2 \mathrm{D}$ & $\begin{array}{l}\text { Laminar non- } \\
\text { premixed }\end{array}$ & Experimental & $\begin{array}{l}\text { Demonstrate feasibility of 2D particle sizing via gated } \\
\text { imaging. } \\
\text { Reasonable results everywhere, underestimation at } \\
\text { location where transmission electron microscopy (TEM) } \\
\text { data are available. }\end{array}$ \\
\hline $\begin{array}{l}\text { Johnsson et al., } \\
2013\end{array}$ & $\mathrm{~N} / \mathrm{A}$ & $\begin{array}{l}\text { Time } \\
\text { resolved }\end{array}$ & $\mathrm{N} / \mathrm{A}$ & $\mathrm{N} / \mathrm{A}$ & Theoretical & $\begin{array}{l}>\text { Influence of aggregate structure and particle bridging on } \\
\text { primary particle diameter }\left(d_{p}\right) \text { determination via LII. } \\
\text { Primary particle size is overestimated by } 9 \% \text { if particles } \\
\text { with } 25 \% \text { overlap are assumed to be in point contact. }\end{array}$ \\
\hline $\begin{array}{l}\text { Liu \& Smallwood, } \\
2013\end{array}$ & $A C$ & $\begin{array}{l}\text { Time } \\
\text { resolved }\end{array}$ & $\mathrm{N} / \mathrm{A}$ & $\mathrm{N} / \mathrm{A}$ & $\begin{array}{l}\text { Theoretical / } \\
\text { Numerical }\end{array}$ & $\begin{array}{l}\text { The effect of primary particle size polydispersity on LII } \\
\text { signal. } \\
\text { LII signal is strictly proportional to } f_{v} \text { with monodisperse } \\
\text { particle sizes, or when particles of different diameter are } \\
\text { heated to the same temperature. } \\
>\text { The LII signal is biased toward both hotter and larger } \\
\text { particles. }\end{array}$ \\
\hline Olofsson et al., 2013 & $A C$ & $\begin{array}{l}\text { Time } \\
\text { resolved }\end{array}$ & OD & $\begin{array}{l}\text { Laminar } \\
\text { premixed }\end{array}$ & Experimental & $\begin{array}{l}\text { Investigation of sublimation during LII heating. } \\
\text { Young soot requires higher fluence to reach sublimation. } \\
\text { Sublimation begins at } 3500-3700 \mathrm{~K} \text { as determined via } \\
\text { AC-LII with constant soot index of refraction absorption } \\
\text { function, } E(m) \text {. }\end{array}$ \\
\hline $\begin{array}{l}\text { Charwath et al., } \\
2011\end{array}$ & $\mathrm{AC}$ & $\begin{array}{l}\text { Time } \\
\text { resolved }\end{array}$ & $N / A$ & $N / A$ & Numerical & $\begin{array}{l}\text { High-pressure effects on time resolved AC-LII. } \\
\text { Time-resolved AC-LII particle sizing is shown to be } \\
\text { applicable up to a few bars using a nanosecond laser } \\
\text { pulse. } \\
\text { Use of a picosecond laser pulse extends applicability to } \\
\text { higher pressures. }\end{array}$ \\
\hline $\begin{array}{l}\text { Crosland et al., } \\
2011\end{array}$ & $A C$ & Prompt & $2 \mathrm{D}$ & $\begin{array}{l}\text { Laminar non- } \\
\text { premixed }\end{array}$ & Experimental & $\begin{array}{l}\text { Demonstration of 2D-AC-LII and comprehensive } \\
\text { uncertainty analysis. } \\
\text { The total uncertainty in } f_{v} \text { is on the order of } 70 \% \text { and is } \\
\text { dominated by } E(m) \text {, while the precision uncertainty } \\
\text { varies with signal strength and is dominated by photon } \\
\text { shot noise. }\end{array}$ \\
\hline
\end{tabular}




\begin{tabular}{|c|c|c|c|c|c|c|}
\hline Reference & $\begin{array}{l}\text { Temperature } \\
\text { Corr. Method }\end{array}$ & $\begin{array}{l}\text { Temporal } \\
\text { Nature }\end{array}$ & $\begin{array}{l}\text { Spatial } \\
\text { Type }\end{array}$ & Flame Type & Type & Goals and Conclusions \\
\hline De luliis et al., 2011 & $\mathrm{AC}$ & Prompt & OD & $\begin{array}{l}\text { Cold soot } \\
\text { from i) } \\
\text { quenched } \\
\text { non-premixed } \\
\text { \& ii)laminar } \\
\text { premixed } \\
\text { flames }\end{array}$ & Experimental & $\begin{array}{l}\text { Influence of the cumulative effects of multiple laser } \\
\text { pulses on laser-induced incandescence signals from } \\
\text { soot. } \\
>\text { Laser heating induces permanent graphitization of soot } \\
\text { particles. } \\
>\text { The effect is cumulative with each pulse. } \\
>\text { Graphitization effects } E(m) \text {. } \\
\text { The fluence at which graphitization occurs differs } \\
\text { between the two flame types studied. }\end{array}$ \\
\hline Köhler et al., 2011 & Plateau & Prompt & $2 \mathrm{D}$ & $\begin{array}{l}\text { Turbulent } \\
\text { non-premixed }\end{array}$ & Experimental & $\begin{array}{l}\text { Demonstration of simultaneous high-speed LII and } \\
\text { velocity measurement. } \\
>\text { High-quality LII images were obtained at } 3 \mathrm{kHz} \text { with } 6 \mathrm{~mm} \\
\text { laser sheet height. } \\
>\text { Soot particles were likely heated multiple times. } \\
>\text { LII images do not indicate significant changes due to } \\
\text { multiple laser pulse heating. }\end{array}$ \\
\hline Bladh et al., 2009 & $A C$ & $\begin{array}{l}\text { Time } \\
\text { resolved }\end{array}$ & OD & $\begin{array}{l}\text { Laminar } \\
\text { premixed }\end{array}$ & Experimental & $\begin{array}{l}>\text { Influence of laser fluence profile on determination of } d_{p} \\
\text { via time-resolved LII. } \\
>\text { Non-uniform profiles cause } 5-15 \% \text { underestimation of } d_{p}\end{array}$ \\
\hline Lemaire et al., 2009 & Plateau & Prompt & $2 \mathrm{D}$ & $\begin{array}{l}\text { Turbulent } \\
\text { non-premixed }\end{array}$ & Experimental & $\begin{array}{l}\text { Effects of fuel-type on species adsorbed on soot } \\
\text { particles. } \\
\text { Petrogenic polycyclic aromatic hydrocarbons (PAHs) } \\
\text { affect soot composition while other soot characteristics } \\
\text { remain unmodified. }\end{array}$ \\
\hline Liu et al., 2009 & $\mathrm{~N} / \mathrm{A}$ & $\mathrm{N} / \mathrm{A}$ & N/A & N/A & Theoretical & $\begin{array}{l}\text { Sensitivity and relative error analyses of soot } \\
\text { temperature and } f_{v} \text { determined by AC-LII. } \\
\text { Detection wavelengths for AC-LII should be as far apart } \\
\text { as possible to minimize uncertainty. }\end{array}$ \\
\hline Migliorini et al., 2009 & Plateau & Prompt & OD & $\begin{array}{l}\text { Laminar } \\
\text { premixed }\end{array}$ & Experimental & $\begin{array}{l}\text { Investigation on the influence of soot size on prompt LII } \\
\text { signals in flames. } \\
\text { Prompt LII signals can be used to determine } f_{v} \text { without } \\
\text { correction for size effects. }\end{array}$ \\
\hline Snelling et al., 2009 & $\mathrm{AC}$ & $\begin{array}{l}\text { Time } \\
\text { resolved }\end{array}$ & OD & $\begin{array}{l}\text { Laminar non- } \\
\text { premixed }\end{array}$ & Experimental & $\begin{array}{l}\text { Comparison of LII derived soot temperature } \\
\text { measurements with LII model predictions. } \\
\text { Below sublimation temperatures, soot heating is well- } \\
\text { predicted with a soot refractive index absorption function } \\
E\left(m_{532 \mathrm{~nm}}\right)=0.4 \text {. }\end{array}$ \\
\hline
\end{tabular}




\begin{tabular}{|c|c|c|c|c|c|c|}
\hline Reference & $\begin{array}{l}\text { Temperature } \\
\text { Corr. Method }\end{array}$ & $\begin{array}{l}\text { Temporal } \\
\text { Nature } \\
\end{array}$ & $\begin{array}{l}\text { Spatial } \\
\text { Type }\end{array}$ & Flame Type & Type & Goals and Conclusions \\
\hline Zerbs et al., 2009 & Plateau & Prompt & 2D & $\begin{array}{l}\text { Turbulent } \\
\text { non- } \\
\text { premixed, } \\
\text { laminar } \\
\text { premixed }\end{array}$ & Experimental & $\begin{array}{l}\text { The influence of beam-steering on LII measurements. } \\
\text { Local laser fluence is affected by beam steering. The } \\
\text { effect is increased at elevated pressure. }\end{array}$ \\
\hline Bladh et al., 2008 & Plateau & $\begin{array}{l}\text { Time } \\
\text { resolved }\end{array}$ & OD & N/A & Theoretical & $\begin{array}{l}\text { Dependence of LII signal on soot volume fraction for } \\
\text { variations in particle size. } \\
\text { Short prompt temporal gates should be used to minimize } \\
\text { the effects of } d_{p} \text { on } f_{v} \text {. }\end{array}$ \\
\hline $\begin{array}{l}\text { Desgroux et al., } \\
2008\end{array}$ & Plateau & $\begin{array}{l}\text { Time } \\
\text { resolved }\end{array}$ & OD & $\begin{array}{l}\text { Laminar } \\
\text { premixed }\end{array}$ & Experimental & $\begin{array}{l}\text { Effect of decreased pressure on soot formation. } \\
\text { Lil signal increase with fluence occurs more quickly at } \\
\text { greater heights above the burner. }\end{array}$ \\
\hline Bouvier et al., 2007 & Plateau & $\begin{array}{l}\text { Prompt / } \\
\text { delayed }\end{array}$ & 2D & $\begin{array}{l}\text { Laminar } \\
\text { premixed \& } \\
\text { nonpremixed }\end{array}$ & Experimental & $\begin{array}{l}\text { Demonstration of combined } f_{v} / \mathrm{PAH} / \text { adsorbed species } \\
\text { diagnostic. } \\
\text { Calibration via cavity ring-down spectroscopy allows } \\
\text { detection of very low } f_{v} \text {. }\end{array}$ \\
\hline Daun et al., 2007 & $\mathrm{~N} / \mathrm{A}$ & $\begin{array}{l}\text { Time } \\
\text { resolved }\end{array}$ & N/A & N/A & Theoretical & $\begin{array}{l}\text { Determining } d_{p} \text { distributions using time-resolved LII. } \\
\text { The problem is ill-posed, and determining } d_{p} \\
\text { distributions this way is very sensitive to model } \\
\text { parameter uncertainty and measurement noise. }\end{array}$ \\
\hline De luliis et al., 2007 & $A C$ & Prompt & 2D & $\begin{array}{l}\text { Laminar non- } \\
\text { premixed }\end{array}$ & Experimental & $\begin{array}{l}\text { Demonstration of 2D AC-LII to determine } f_{v} \\
\text { Successful demonstration in agreement with literature. }\end{array}$ \\
\hline $\begin{array}{l}\text { Michelsen, Liu et al., } \\
2007\end{array}$ & N/A & $\mathrm{N} / \mathrm{A}$ & $\mathrm{N} / \mathrm{A}$ & $\mathrm{N} / \mathrm{A}$ & Review & $\begin{array}{l}\text { Review of LII numerical models. } \\
\text { There is a wide spread in predicted LII signals across } \\
\text { different models, mostly attributed to a few important } \\
\text { parameters such as } E(m) \text {. }\end{array}$ \\
\hline $\begin{array}{l}\text { Michelsen, Tivanski } \\
\text { et al., } 2007\end{array}$ & Plateau & $\mathrm{N} / \mathrm{A}$ & Global & N/A & Experimental & $\begin{array}{l}\text { Particle formation resulting from LII heating } \\
\text { New particles are formed at fluences above } 1.2 \mathrm{~mJ} / \mathrm{mm}^{2} \\
\text { @ } 532 \mathrm{~nm} \text { and } 2.2 \mathrm{~mJ} / \mathrm{mm}^{2} @ 1064 \mathrm{~nm} \text {. }\end{array}$ \\
\hline $\begin{array}{l}\text { Boiarciuc et al., } \\
2006\end{array}$ & AC/Plateau & $\begin{array}{l}\text { Time } \\
\text { resolved } \\
\text { and } \\
\text { prompt }\end{array}$ & 0D/2D & $\begin{array}{l}\text { Laminar non- } \\
\text { premixed, } \\
\text { diesel engine }\end{array}$ & Experimental & $\begin{array}{l}>\text { Demonstrate measurement of } f_{v} \text { and } d_{p} \text { via simultaneous } \\
\text { time-resolved AC-LII and 2D-LII. } \\
>\text { Successful. Good agreement with literature. }\end{array}$ \\
\hline Kock et al., 2006 & $A C$ & $\begin{array}{l}\text { Time } \\
\text { resolved }\end{array}$ & OD & Diesel engine & Experimental & $\begin{array}{l}\text { Demonstration of time resolved AC-LII to measure } d_{p} \text { in } \\
\text { the cylinder of a Diesel engine. } \\
\text { Successful demonstration, in agreement with TEM } \\
\text { measurements at exhaust. }\end{array}$ \\
\hline
\end{tabular}




\begin{tabular}{|c|c|c|c|c|c|c|}
\hline Reference & $\begin{array}{l}\text { Temperature } \\
\text { Corr. Method }\end{array}$ & $\begin{array}{l}\text { Temporal } \\
\text { Nature }\end{array}$ & $\begin{array}{l}\text { Spatial } \\
\text { Type }\end{array}$ & Flame Type & Type & Goals and Conclusions \\
\hline Pastor et al., 2006 & Plateau & Prompt & $2 \mathrm{D}$ & $\begin{array}{l}\text { Laminar non- } \\
\text { premixed }\end{array}$ & Experimental & $\begin{array}{l}\text { Comparison of LII calibration methods suitable for } \\
\text { axisymmetric flames. } \\
\text { The single-point extinction measurement method } \\
\text { performs poorly. }\end{array}$ \\
\hline Schulz et al., 2006 & N/A & $\mathrm{N} / \mathrm{A}$ & N/A & N/A & Review & $\begin{array}{l}\text { A review of work presented at a workshop focused on } \\
\text { fundamental aspects of soot measurements via LII. }\end{array}$ \\
\hline De luliis et al., 2005 & $A C$ & Prompt & OD & $\begin{array}{l}\text { Laminar } \\
\text { premixed }\end{array}$ & Experimental & $\begin{array}{l}>\text { Demonstration of AC-LII. } \\
>\text { Successful demonstration of AC-LII and fluence effects. }\end{array}$ \\
\hline Snelling et al., 2005 & $A C$ & $\begin{array}{l}\text { Time } \\
\text { resolved }\end{array}$ & OD & $\begin{array}{l}\text { Laminar non- } \\
\text { premixed }\end{array}$ & Experimental & $\begin{array}{l}\text { Demonstration of AC-LII. } \\
\text { Successful demonstration of AC-LII applied at low- } \\
\text { fluence (non-sublimation) temperatures. }\end{array}$ \\
\hline $\begin{array}{l}\text { Schoemaecker- } \\
\text { Moreau et al., } 2004\end{array}$ & Plateau & Prompt & $1 \mathrm{D}$ & $\begin{array}{l}\text { Laminar non- } \\
\text { premixed }\end{array}$ & Experimental & $\begin{array}{l}\text { Measurement of LII and PAH via LII excitation at two } \\
\text { wavelengths. } \\
\text { Successful demonstration of two-colour LII. Good } \\
\text { agreement between LII and cavity ring-down } \\
\text { spectroscopy. }\end{array}$ \\
\hline $\begin{array}{l}\text { Axelsson et al., } \\
2001\end{array}$ & Plateau & $\begin{array}{l}\text { Multiple } \\
\text { delays }\end{array}$ & 2D & $\begin{array}{l}\text { Laminar } \\
\text { premixed }\end{array}$ & Experimental & $\begin{array}{l}>\text { Measure } d_{p} \text { and } f_{v} \text { via LII with real-time extinction } \\
\text { calibration. } \\
>\text { Successful demonstration of LII calibration via real-time } \\
2 D \text { extinction measurement. }\end{array}$ \\
\hline $\begin{array}{l}\text { Axelsson et al., } \\
2000\end{array}$ & Plateau & $\begin{array}{l}\text { Time } \\
\text { resolved }\end{array}$ & OD & $\begin{array}{l}\text { Laminar } \\
\text { premixed }\end{array}$ & Experimental & $\begin{array}{l}>\text { Measure } d_{p} \text { based on LII measurements } \\
\text { in flame, possible due to aggregation effects. }\end{array}$ \\
\hline Bryce et al., 2000 & Plateau & Prompt & 2D & $\begin{array}{l}\text { Laminar non- } \\
\text { premixed }\end{array}$ & Experimental & $\begin{array}{l}\text { Overview of LII measurement technique for soot and } \\
\text { sources of error } \\
\text { High-energy excitation and prompt, short-wavelength } \\
\text { detection is recommended. }\end{array}$ \\
\hline Vander Wal, 1998 & Plateau & Prompt & $2 \mathrm{D}$ & $\begin{array}{l}\text { Laminar non- } \\
\text { premixed }\end{array}$ & Experimental & $\begin{array}{l}>\text { Calibration of LII via cavity ring-down. } \\
>\text { Demonstrated LII measurement at ppb levels. }\end{array}$ \\
\hline Ni et al., 1995 & Plateau & Prompt & $2 \mathrm{D}$ & $\begin{array}{l}\text { Laminar non- } \\
\text { premixed }\end{array}$ & Experimental & $\begin{array}{l}\text { Demonstration of single-point calibrated, 2D LII in } \\
\text { laminar and turbulent flames. } \\
\text { Successful demonstration of } 2 \text { D LII, good agreement } \\
\text { with laser scattering / extinction measurement. }\end{array}$ \\
\hline Will et al., 1995 & $\mathrm{~N} / \mathrm{A}$ & $\begin{array}{l}\text { Multiple } \\
\text { delays }\end{array}$ & $2 \mathrm{D}$ & $\begin{array}{l}\text { Laminar non- } \\
\text { premixed }\end{array}$ & Experimental & $\begin{array}{l}>\text { Measurement of } d_{p} \text { via } 2 \mathrm{D} \text {-LII with multiple gate delay } \\
\text { times. } \\
>\text { Successful demonstration of } 2 \mathrm{D} \text { particle sizing. }\end{array}$ \\
\hline $\begin{array}{l}\text { Vander Wal \& } \\
\text { Weiland, } 1994\end{array}$ & Plateau & $\begin{array}{l}\text { Time } \\
\text { resolved }\end{array}$ & $1 \mathrm{D}, 2 \mathrm{D}$ & $\begin{array}{l}\text { Premixed \& } \\
\text { nonpremixed }\end{array}$ & Exp. / Theor. & $\begin{array}{l}\text { Experimental and theoretical overview and } \\
\text { characterization of } f_{v} \text { measurement via LII. }\end{array}$ \\
\hline
\end{tabular}




\begin{tabular}{lllllll}
\hline Reference & $\begin{array}{l}\text { Temperature } \\
\text { Corr. Method }\end{array}$ & $\begin{array}{l}\text { Temporal } \\
\text { Nature }\end{array}$ & $\begin{array}{l}\text { Spatial } \\
\text { Type }\end{array}$ & Flame Type & Type & Goals and Conclusions \\
\hline Melton, 1984 & Plateau & $\begin{array}{l}\text { Time } \\
\text { resolved }\end{array}$ & N/A & N/A & Theoretical & $\begin{array}{l}>\text { Numerical investigation into the possibility of measuring } \\
f_{v} \text { via LII. }\end{array}$ \\
Eckbreth, 1977 & N/A & N/A & N/A & N/A & Theoretical & $\begin{array}{l}>\text { Presentation of LII as interference when performing } \\
\text { Raman scattering measurements. }\end{array}$ \\
\hline
\end{tabular}




\subsubsection{Elastic Light Scattering}

ELS has been used to characterize soot for more than three decades (e.g. Sorensen, 2001; Jones, 2006 and references therein). While soot primary particles are small enough to be treated using Rayleigh theory, the fractal nature of soot aggregates necessitates a more complex treatment of aggregate scattering. ELS from soot aggregates is best described by Rayleigh-Debye-Gans Fractal Aggregate Theory (Julien \& Botet, 1987; Martin \& Hurd, 1987; Dobbins \& Megaridis, 1991), which describes light absorption and scattering from small aggregated particles. Measurements of ELS at two or more angles is commonly used to infer information about aggregate size (Iyer et al., 2007; Köylü \& Faeth, 1994; Xing et al., 1999), and requires assumptions about the shape and width of the distribution of aggregate sizes, as well as morphological properties. Important contributions to the development of ELS measurements of soot are listed in Table 1.2. Two-angle scattering measurements have been used to determine aggregate size since the 1980s, with either an assumption of monodispersity or an assumed distribution shape. Recent attempts to solve for distribution shape by making additional measurements (Burr et al., 2011; Snelling et al., 2011; Link et al., 2011) have proven problematic due to the illposed nature of the problem. The use of combined scattering and absorption measurements to determine primary particle size was introduced by Sorensen (1992a), though this and all subsequent implementations had been based on time-averaged measurements until Oltmann et al. (2012) and the current work (Crosland, Thomson \& Johnson, 2013). 


\section{Table 1.2 - Summary of literature examining the ELS technique for soot characterization}

\begin{tabular}{|c|c|c|c|c|}
\hline Reference & $\begin{array}{l}\text { Reported } \\
\text { quantities }\end{array}$ & Type & Medium & Goals and Conclusions \\
\hline $\begin{array}{l}\text { Crosland, Thomson } \\
\text { \& Johnson, } 2013\end{array}$ & $\begin{array}{l}\text { Primary particle size, } \\
\text { aggregate size, } \\
\text { volume fraction }\end{array}$ & Experimental & $\begin{array}{l}\text { Laminar non- } \\
\text { premixed soot }\end{array}$ & $\begin{array}{l}\text { Description of combined diagnostic to allow instantaneous } \\
\text { simultaneous measurement of } d_{p} \text {, radius of gyration }\left(R_{g}\right) \text { and } f_{v} \text { of } \\
\text { in-flame soot } \\
\text { While absolute uncertainties are high due to uncertainty in soot } \\
\text { properties, uncertainties with fixed soot properties are } 20 \%, 8 \% \\
\text { and } 6 \% \text { for } f_{v}, d_{p} \text { and } R_{g} \text {. }\end{array}$ \\
\hline $\begin{array}{l}\text { Crosland, Johnson \& } \\
\text { Thomson, } 2013\end{array}$ & Scattering coefficient & Experimental & $\begin{array}{l}\text { Laminar non- } \\
\text { premixed soot }\end{array}$ & $\begin{array}{l}\text { Description of novel method of calibrating scattering coefficient to } \\
\text { an absolute scale. } \\
\text { New method has reduced uncertainty and allows use of wider } \\
\text { range of detectors. }\end{array}$ \\
\hline Oltmann et al., 2012 & Aggregate size & Experimental & $\begin{array}{l}\text { Turbulent non- } \\
\text { premixed flame } \\
\text { soot }\end{array}$ & $\begin{array}{l}\text { Single-shot measurement of soot aggregate sizes by wide-angle } \\
\text { light scattering. } \\
\text { Successful measurement of single-shot aggregate size, good } \\
\text { agreement with TEM. }\end{array}$ \\
\hline De luliis et al., 2011 & $\begin{array}{l}\text { Primary particle size, } \\
\text { aggregate size, } \\
\text { volume fraction }\end{array}$ & Experimental & $\begin{array}{l}\text { Laminar } \\
\text { premixed flame } \\
\text { soot }\end{array}$ & $\begin{array}{l}>\text { Measurement of } d_{p} \text { and } R_{g} \text { via LII and three-angle scattering. } \\
\text { Good agreement with mature soot, poor agreement low in the } \\
\text { flame where TEM shows liquid-like soot structures. }\end{array}$ \\
\hline Link et al., 2011 & Scattering coefficient & Experimental & $\begin{array}{l}\text { Laminar non- } \\
\text { premixed flame } \\
\text { soot }\end{array}$ & $\begin{array}{l}\text { Determination of polydisperse aggregate distribution information } \\
\text { via multi-angle scattering. } \\
\text { Multi-angle measurements at a single laser wavelength are not } \\
\text { capable of providing a unique distribution of aggregate sizes. }\end{array}$ \\
\hline Snelling et al., 2011 & $\begin{array}{l}\text { Primary particle size, } \\
\text { aggregate size, } \\
\text { volume fraction }\end{array}$ & Experimental & $\begin{array}{l}\text { Laminar non- } \\
\text { premixed flame } \\
\text { soot }\end{array}$ & $\begin{array}{l}\text { Measurement of soot morphology by integrated LII and elastic light } \\
\text { scattering. } \\
>\text { LII + } 1 \text { angle ELS shown to be effective for aggregate sizing. }\end{array}$ \\
\hline Oltmann et al., 2010 & $\begin{array}{l}\text { Scattering } \\
\text { coefficient, } \\
\text { aggregate size }\end{array}$ & Experimental & $\begin{array}{l}\text { Laminar } \\
\text { premixed flame } \\
\text { soot }\end{array}$ & $\begin{array}{l}\text { Measurement of soot aggregate sizes by wide-angle light } \\
\text { scattering. } \\
\text { Successful demonstration of technique. Overestimation compared } \\
\text { to TEM is attributed to strong aggregation. }\end{array}$ \\
\hline Reimann et al., 2009 & $\begin{array}{l}\text { Primary particle size, } \\
\text { aggregate size, } \\
\text { volume fraction }\end{array}$ & Experimental & $\begin{array}{l}\text { Laminar } \\
\text { premixed flame } \\
\text { soot }\end{array}$ & $\begin{array}{l}\text { 2D aggregate sizing via combined LII and ELS. } \\
\text { Successful demonstration of technique, good agreement with } \\
\text { TEM. }\end{array}$ \\
\hline lyer et al., 2007 & $\begin{array}{l}\text { Total scattering } \\
\text { coefficient }\end{array}$ & Experimental & $\begin{array}{l}\text { Laminar non- } \\
\text { premixed flame } \\
\text { soot }\end{array}$ & $\begin{array}{l}\text { Determination of total soot scattering coefficient and primary } \\
\text { particle size via extinction and three-angle scattering. } \\
\text { Good agreement of } d_{p} \text { with TEM. Good agreement of aggregate } \\
\text { size with TEM in growth region, poor agreement in the inception } \\
\text { region. }\end{array}$ \\
\hline
\end{tabular}




\begin{tabular}{|c|c|c|c|c|}
\hline Reference & $\begin{array}{l}\text { Reported } \\
\text { quantities }\end{array}$ & Type & Medium & Goals and Conclusions \\
\hline Jones, 2006 & & Review & & $\begin{array}{l}\text { A review of light scattering techniques used in combustion } \\
\text { measurement. }\end{array}$ \\
\hline Teng \& Köylü, 2006 & $\begin{array}{l}\text { Primary particle size, } \\
\text { aggregate size }\end{array}$ & Numerical & $\begin{array}{l}\text { Simulated soot } \\
\text { aggregates }\end{array}$ & $\begin{array}{l}\text { Development of two-angle scattering aggregate sizing method and } \\
\text { determination of optimal measurement angles. } \\
\text { Measurement angles should be as far apart as possible without } \\
\text { compromising spatial resolution. } 30^{\circ} \text { and } 150^{\circ} \text { are suggested. }\end{array}$ \\
\hline $\begin{array}{l}\text { Yang \& Köylü, 2005a } \\
\& 2005 b\end{array}$ & $\begin{array}{l}\text { Primary particle size, } \\
\text { aggregate size, } \\
\text { volume fraction }\end{array}$ & Experimental & $\begin{array}{l}\text { Turbulent non- } \\
\text { premixed soot }\end{array}$ & $\begin{array}{l}\quad \text { Time-averaged measurement of } f_{v}, d_{p} \text { and } R_{g} \text { via combined LII and } \\
\text { two-angle ELS measurement. } \\
>\text { Successful demonstration of apparatus in turbulent acetylene and } \\
\text { ethylene flames. }\end{array}$ \\
\hline Sorensen, 2001 & N/A & Review & N/A & $>$ A review of light scattering by fractal aggregates. \\
\hline De luliis et al., 1998 & Primary particle size & $\begin{array}{l}\text { Theoretical, } \\
\text { experimental }\end{array}$ & $\begin{array}{l}\text { Laminar non- } \\
\text { premixed flame } \\
\text { soot }\end{array}$ & $\begin{array}{l}\text { Determination of } d_{p} \& R_{g} \text { by two-angle scattering-extinction. } \\
\text { Successful demonstration of technique, good agreement with } \\
\text { literature. }\end{array}$ \\
\hline $\begin{array}{l}\text { Sorensen et al., } \\
1992 a\end{array}$ & $\begin{array}{l}\text { Primary particle size, } \\
\text { aggregate size, } \\
\text { fractal dimension }\end{array}$ & $\begin{array}{l}\text { Theoretical, } \\
\text { experimental }\end{array}$ & $\begin{array}{l}\text { Laminar } \\
\text { premixed flame } \\
\text { soot }\end{array}$ & $\begin{array}{l}\text { Description of new method to determine } d_{p} \text {, number of particles per } \\
\text { aggregate }(N) \text { and fractal dimension }\left(D_{f}\right) \text { based on scattering and } \\
\text { extinction measurements. } \\
\text { Successful determination of } d_{p}, N \text { and } D_{f} \text {, though } d_{p} \text { and } N \text { have } \\
\text { large uncertainty. }\end{array}$ \\
\hline $\begin{array}{l}\text { Sorensen et al., } \\
\text { 1992b }\end{array}$ & $\begin{array}{l}\text { Aggregate structure } \\
\text { factor }\end{array}$ & $\begin{array}{l}\text { Theoretical, } \\
\text { experimental }\end{array}$ & $\begin{array}{l}\text { Laminar } \\
\text { premixed flame } \\
\text { soot }\end{array}$ & $\begin{array}{l}\text { Comparison of different structure factors used to describe } \\
\text { scattering from fractal aggregates. } \\
\text { The effects of polydispersity must be included in structure factor } \\
\text { model. } \\
\text { The structure factor with a Gaussian cut-off, and it is expected that } \\
\text { other structure factors using an similarly sharp cut-off would } \\
\text { perform equally well. }\end{array}$ \\
\hline $\begin{array}{l}\text { Dobbins \& } \\
\text { Megaridis, } 1991\end{array}$ & $\begin{array}{l}\text { Scattering \& } \\
\text { absorption cross- } \\
\text { sections }\end{array}$ & $\begin{array}{l}\text { Numerical, } \\
\text { theoretical }\end{array}$ & $\begin{array}{l}\text { Simulated soot } \\
\text { aggregates }\end{array}$ & $\begin{array}{l}\text { Formulation of absorption and scattering theory for polydisperse } \\
\text { aggregates. }\end{array}$ \\
\hline Lin et al., 1990 & $\begin{array}{l}\text { Aggregate structure } \\
\text { factor, } D_{f}\end{array}$ & $\begin{array}{l}\text { Experimental, } \\
\text { Theoretical }\end{array}$ & $\begin{array}{l}\text { Gold, silica, } \\
\text { polystyrene latex }\end{array}$ & $\begin{array}{l}\text { A study of diffusion-limited colloid aggregation using light } \\
\text { scattering. } \\
\text { Measurement of fractal dimension and structure factor is found to } \\
\text { be in good agreement with simulations. }\end{array}$ \\
\hline
\end{tabular}




\begin{tabular}{|c|c|c|c|c|}
\hline Reference & $\begin{array}{l}\text { Reported } \\
\text { quantities }\end{array}$ & Type & Medium & Goals and Conclusions \\
\hline Hurd \& Flower, 1988 & $\begin{array}{l}\text { Aggregate structure } \\
\text { factor }\end{array}$ & $\begin{array}{l}\text { Theoretical, } \\
\text { experimental }\end{array}$ & $\begin{array}{l}\text { Laminar } \\
\text { premixed flame } \\
\text { soot }\end{array}$ & $\begin{array}{l}>\text { Development of aggregate scattering theory and comparison to } \\
\text { measurements. } \\
>\text { Flame-generated fumed silica aggregates have a fractal dimension } \\
\text { of } 1.5, \\
>\text { Description of a modified structure factor based on Fisher \& } \\
\text { Burford. }\end{array}$ \\
\hline $\begin{array}{l}\text { Mountain \& } \\
\text { Mulholland, } 1988\end{array}$ & $\begin{array}{l}\text { Aggregate structure } \\
\text { factor }\end{array}$ & $\begin{array}{l}\text { Theoretical, } \\
\text { simulation }\end{array}$ & $\begin{array}{l}\text { Simulated soot } \\
\text { aggregates }\end{array}$ & $\begin{array}{l}\text { Numerical simulation of aggregate growth and scattering } \\
\text { behaviour. } \\
\text { Simulation shows light-scattering can be used to infer } f_{v}, d_{p}, R_{g} \text { and } \\
D_{f} \text {. }\end{array}$ \\
\hline Martin \& Hurd, 1987 & $\mathrm{~N} / \mathrm{A}$ & Theoretical & $\begin{array}{l}\text { Idealized soot } \\
\text { aggregates }\end{array}$ & $\begin{array}{l}\text { Introduction of fractal geometry of aggregates and application to } \\
\text { scattering behaviour. }\end{array}$ \\
\hline $\begin{array}{l}\text { Berry \& Percival, } \\
1986\end{array}$ & $\begin{array}{l}\text { Aggregate structure } \\
\text { factor }\end{array}$ & Theoretical & N/A & $\begin{array}{l}\text { Discussion of soot as fractal aggregates. } \\
\text { Multiple scattering is negligible if fractal dimension is less than } 2 .\end{array}$ \\
\hline
\end{tabular}




\subsubsection{Turbulent Non-Premixed Flames}

Modeling and predicting soot formation in flames is possibly the most challenging problem in the field of combustion given the complex chemistry, aerosol dynamics, short time scales, and large spatial gradients involved. This complexity is further exacerbated considering most practical combustion applications involve turbulent flames. Research on soot formation within turbulent sooting flames is hindered by the difficulty in making quantitative measurements. Large thermal and concentration gradients, optical attenuation, background interference, and beam steering all complicate measurements resulting in a dearth of experimental data for theory development or simulation validation.

Recent numerical simulations of turbulent sooting flames are able to reproduce experimental soot volume fraction trends (El-Asrag \& Menon, 2009; Mueller et al., 2013; Blacha et al., 2011), but the absolute value of the soot volume fraction is difficult to predict with great accuracy; agreement is often considered 'good' if the absolute value of predicted soot volume fraction agrees with experiments to within an order of magnitude. Improved prediction of sooting turbulent flames requires comprehensive experimental data, which in turn requires well-characterized diagnostics.

Most studies providing spatially-resolved soot measurements in turbulent non-premixed flames have focused on momentum-dominated flames (e.g. Köhler et al., 2011; Hu et al., 2003; Santos \& Costa, 2005; Lee et al., 2009; Kent \& Bastin, 1984; B. Yang \& Köylü, 2005b; Sivathanu \& Faeth, 1990; Brookes \& Moss, 
1999; Qamar et al., 2009; Qamar et al., 2005; B. Yang \& Köylü, 2005a) with nozzle exit Reynolds numbers ( $R e$ ) ranging from 4,000 to 83,000. To the authors' knowledge, only two studies have reported spatially-resolved measurements of $f_{v}$ within buoyant non-premixed turbulent flames (Coppalle \& Joyeux, 1994; Xin \& Gore, 2005). Xin \& Gore (2005) performed twodimensional measurements in turbulent buoyant methane and ethylene flames with $R e$ of $\sim 140$. Coppalle \& Joyeux (1994) reported simultaneous local temperature and $f_{v}$ measurements in buoyancy- and momentum-dominated flames with $R e$ of 550, 5700 and 11800 . The limited literature for buoyancydominated turbulent non-premixed flames impedes analysis of practical systems involving such flames.

Gas flares used in the petroleum industry are a critical example of the importance of buoyancy-dominated flames to climate forcing and health. Satellite data suggest global flared volumes exceed 135 billion $\mathrm{m}^{3}$ annually (Elvidge et al., 2009), making gas flaring a potentially significant source of global soot emissions. Accurate estimation of soot emissions from gas flares to meet reporting regulations and support informed policy decisions is difficult due to the limited literature for buoyancy-dominated turbulent non-premixed flames, and the challenge of in-situ field measurements (McEwen \& Johnson, 2012; Johnson et al., 2010; Johnson et al., 2011; Johnson et al., 2013). A summary of the recent literature reporting soot measurements in both momentum- and buoyancydominated turbulent non-premixed flames is presented in Table 1.3. 
Table 1.3 - Summary of literature reporting turbulent and flickering flame soot measurements.

\begin{tabular}{|c|c|c|c|c|c|c|}
\hline Reference & $\begin{array}{l}\text { Measured } \\
\text { quantities }\end{array}$ & $\begin{array}{l}\text { Spatial } \\
\text { Nature }\end{array}$ & Fuel & Flame Type & Type & Goals and Conclusions \\
\hline $\begin{array}{l}\text { McEwen \& } \\
\text { Johnson, } \\
2012\end{array}$ & Soot yield & Global & $\begin{array}{l}\text { Solution } \\
\text { gas }\end{array}$ & $\begin{array}{l}\text { Turbulent } \\
\text { buoyant non- } \\
\text { premixed }\end{array}$ & Experimental & $\begin{array}{l}>\text { Determination of black carbon emission factors in } \\
\text { buoyancy-driven turbulent non-premixed flames. } \\
>\text { Soot yield behaves differently for large burners }(>1.5 " \\
\text { diameter) compared to smaller burners. } \\
>\text { Suggest a new soot yield factor that is approximately } 1 / 5 \\
\text { the currently accepted value. }\end{array}$ \\
\hline $\begin{array}{l}\text { Johnson } \\
\text { et al., } 2011\end{array}$ & Soot mass flow rate & Global & $\begin{array}{l}\text { Solution } \\
\text { gas }\end{array}$ & $\begin{array}{l}\text { Turbulent } \\
\text { buoyant non- } \\
\text { premixed }\end{array}$ & Experimental & $\begin{array}{l}\text { Field demonstration of novel method to measure mass } \\
\text { emission rate of soot from solution gas flares. } \\
\text { Successful demonstration of field measurements. } \\
\text { Uncertainty is estimated at } 33 \%\end{array}$ \\
\hline $\begin{array}{l}\text { Köhler et al., } \\
2011\end{array}$ & $\begin{array}{l}\text { Temperature, velocity, } \\
\text { soot volume fraction, } \\
\mathrm{OH}^{*}\end{array}$ & $\mathrm{OD} / 2 \mathrm{D}$ & $\mathrm{C} 2 \mathrm{H} 4$ & $\begin{array}{l}\text { Turbulent jet } \\
\text { non-premixed }\end{array}$ & Experimental & $\begin{array}{l}\text { Publication of detailed measurements suitable for } \\
\text { subsequent numerical simulation of a turbulent sooting } \\
\text { flame for evaluation of soot models. } \\
\text { Detailed and accurate measurements of soot properties } \\
\text { and temperature are presented. }\end{array}$ \\
\hline $\begin{array}{l}\text { Johnson } \\
\text { et al., } 2010\end{array}$ & Soot mass flow rate & Global & $\begin{array}{l}\text { Solution } \\
\text { gas }\end{array}$ & $\begin{array}{l}\text { Turbulent } \\
\text { buoyant non- } \\
\text { premixed }\end{array}$ & Experimental & $\begin{array}{l}\text { Theoretical presentation and lab-scale demonstration of } \\
\text { novel method to measure mass emission rate of soot } \\
\text { from solution gas flares. } \\
\text { Results suggest field measurements with uncertainties } \\
\text { of about } 32 \% \text { are possible. }\end{array}$ \\
\hline $\begin{array}{l}\text { Saqr et al., } \\
2010\end{array}$ & $\begin{array}{l}\text { Temperature, NO } \\
\text { concentration, rate of } \\
\text { soot generation }\end{array}$ & $2 \mathrm{D}$ & $\mathrm{CH} 4$ & $\begin{array}{l}\text { Turbulent jet } \\
\text { non-premixed }\end{array}$ & Numerical & $\begin{array}{l}\text { Effect of free stream turbulence on NOx and soot } \\
\text { formation. } \\
\text { Results reveal that increased turbulence intensity in the } \\
\text { oxidizer reduces pollutant formation rate. }\end{array}$ \\
\hline $\begin{array}{l}\text { El-Asrag \& } \\
\text { Menon, } 2009\end{array}$ & $\begin{array}{l}\text { Temperature, soot } \\
\text { volume fraction, } \\
\text { primary particle size, } \\
\text { and more. }\end{array}$ & $2 \mathrm{D}$ & $\mathrm{C} 2 \mathrm{H} 4$ & $\begin{array}{l}\text { Turbulent jet } \\
\text { non-premixed }\end{array}$ & Numerical & $\begin{array}{l}\text { Demonstration of a new subgrid model for soot } \\
\text { formation in a turbulent flame simulation. } \\
\text { Order of magnitude of } f_{v} \text {, as well as peak } f_{v} \text { location and } \\
d_{p} \text { distribution are well reproduced. } \\
\text { Diffusion effects are important in the soot formation } \\
\text { region, while thermophoretic effects are important in the } \\
\text { oxidation region. }\end{array}$ \\
\hline
\end{tabular}




\begin{tabular}{|c|c|c|c|c|c|c|}
\hline Reference & $\begin{array}{l}\text { Measured } \\
\text { quantities }\end{array}$ & $\begin{array}{l}\text { Spatial } \\
\text { Nature }\end{array}$ & Fuel & Flame Type & Type & Goals and Conclusions \\
\hline $\begin{array}{l}\text { Lee et al., } \\
2009\end{array}$ & $\begin{array}{l}\text { Soot volume fraction, } \\
\text { OH \& PAH } \\
\text { concentrations }\end{array}$ & $2 \mathrm{D}$ & $\mathrm{C} 2 \mathrm{H} 4$ & $\begin{array}{l}\text { Turbulent jet } \\
\text { non-premixed }\end{array}$ & Experimental & $\begin{array}{l}\text { Examination of soot formation via measurements of } f_{v}, \\
\mathrm{OH} \text {, and PAH concentrations. } \\
\text { Three soot growth regions are identified: a rapid soot } \\
\text { growth region, a mixing region, and an oxidation region. }\end{array}$ \\
\hline $\begin{array}{l}\text { Lemaire } \\
\text { et al., } 2009\end{array}$ & $\begin{array}{l}\text { Soot volume fraction } \\
\text { and relative (not } \\
\text { calibrated) PAH. }\end{array}$ & $2 \mathrm{D}$ & $\begin{array}{l}\text { Diesel / } \\
\text { diesel } \\
\text { surrogate }\end{array}$ & $\begin{array}{l}\text { Turbulent jet } \\
\text { non-premixed }\end{array}$ & Experimental & $\begin{array}{l}\text { Comparison of soot formation using diesel and diesel } \\
\text { surrogates. } \\
\text { A previously-studied diesel surrogate was found to form } \\
40 \% \text { more soot than diesel. } \\
\text { A second diesel surrogate with a threshold soot index } \\
\text { similar to diesel shows spatially-resolved soot and PAH } \\
\text { profiles identical to those of diesel. }\end{array}$ \\
\hline $\begin{array}{l}\text { Narayanan \& } \\
\text { Trouvé, } 2009\end{array}$ & $\begin{array}{l}\text { Radiant fraction, } \\
\text { temperature, soot } \\
\text { mass fraction and } \\
\text { more. }\end{array}$ & $2 \mathrm{D}$ & $\mathrm{C} 2 \mathrm{H} 4$ & $\begin{array}{l}\text { Turbulent non- } \\
\text { premixed }\end{array}$ & Numerical & $\begin{array}{l}\text { Study flame weakening, flame extinction, and soot } \\
\text { leakage in turbulent non-premixed flames via numerical } \\
\text { modeling of soot formation. } \\
\text { Flame weakening events are similar to radiation } \\
\text { extinction seen in microgravity laminar flames. } \\
\text { Turbulent flames seem to be more susceptible to } \\
\text { radiation extinction than similar laminar flames. }\end{array}$ \\
\hline $\begin{array}{l}\text { Qamar et al., } \\
2009\end{array}$ & Soot volume fraction & $2 \mathrm{D}$ & $\begin{array}{l}\text { Simulated } \\
\text { Natural } \\
\text { Gas }\end{array}$ & $\begin{array}{l}\text { Turbulent jet } \\
\text { non-premixed }\end{array}$ & Experimental & $\begin{array}{l}\text { Study of sooting behaviour of turbulent flames via 2D } \\
\text { LIl. } \\
\text { Soot intermittency typically exceeded } 97 \% \text {. } \\
\text { Results are consistent with the idea that soot is in } \\
\text { strained flame sheets which are transported and } \\
\text { distorted by the flow. } \\
>\text { Soot burnout appears to occur via increased } \\
\text { intermittency rather than partial oxidation of all flame } \\
\text { structures. }\end{array}$ \\
\hline $\begin{array}{l}\text { Qamar et al., } \\
2005\end{array}$ & Soot volume fraction & 2D & $\mathrm{C} 3 \mathrm{H} 8$ & $\begin{array}{l}\text { Turbulent jet } \\
\text { non-premixed }\end{array}$ & Experimental & $\begin{array}{l}\text { The effect of global mixing on } f_{v} \text {. } \\
\text { An increase in global mixing rate causes a decrease in } \\
\text { both total volume of soot in the flame and the } \\
\text { instantaneous soot volume in flame sheets. } \\
\text { Soot burnout appears to occur via increased } \\
\text { intermittency rather than partial oxidation of all flame } \\
\text { structures. }\end{array}$ \\
\hline $\begin{array}{l}\text { Xin \& Gore, } \\
2005\end{array}$ & Soot volume fraction & $2 \mathrm{D}$ & $\begin{array}{l}\mathrm{CH} 4, \\
\mathrm{C} 2 \mathrm{H} 4\end{array}$ & $\begin{array}{l}\text { Turbulent } \\
\text { buoyant non- } \\
\text { premixed }\end{array}$ & Experimental & $\begin{array}{l}\text { Measurements of } f_{v} \text { in vertical and horizontal planes. } \\
\text { Instantaneous } f_{v} \text { distributions are significantly different } \\
\text { from their ensemble averages. }\end{array}$ \\
\hline
\end{tabular}




\begin{tabular}{|c|c|c|c|c|c|c|}
\hline Reference & $\begin{array}{l}\text { Measured } \\
\text { quantities }\end{array}$ & $\begin{array}{l}\text { Spatial } \\
\text { Nature }\end{array}$ & Fuel & Flame Type & Type & Goals and Conclusions \\
\hline $\begin{array}{l}\text { Yang and } \\
\text { Köylü, 2005a }\end{array}$ & $\begin{array}{l}\text { Soot volume fraction, } \\
\text { primary particle size, } \\
\text { aggregate size }\end{array}$ & OD & $\mathrm{C} 2 \mathrm{H} 4$ & $\begin{array}{l}\text { Turbulent jet } \\
\text { non-premixed }\end{array}$ & Experimental & $\begin{array}{l}>\text { Time-averaged measurements of } f_{v}, d_{p} \text { and } R_{g} \text { using } \\
\text { local extinction and ELS to allow assessment of } \\
\text { numerical models. } \\
>\text { Both } f_{v} \text { and } d_{p} \text { reach their peak at the same axial } \\
\text { location. } \\
>R_{g} \text { increases continuously along the flame centerline. }\end{array}$ \\
\hline $\begin{array}{l}\text { Yang and } \\
\text { Köylü, 2005b }\end{array}$ & $\begin{array}{l}\text { Soot volume fraction, } \\
\text { primary particle size, } \\
\text { aggregate size }\end{array}$ & OD & $\mathrm{C} 2 \mathrm{H} 2$ & $\begin{array}{l}\text { Turbulent jet } \\
\text { non-premixed }\end{array}$ & Experimental & $\begin{array}{l}\text { Demonstration and theory development of combined } \\
\text { measurement apparatus that measures } f_{v}, d_{p} \text { and } R_{g} \text { via } \\
\text { local extinction and ELS. } \\
\text { Temperature, } f_{v} \text { and } d_{p} \text { all reach their peak at } \\
\text { approximately the same axial location. }\end{array}$ \\
\hline $\begin{array}{l}\text { Hu et al., } \\
2003\end{array}$ & $\begin{array}{l}\text { Size, morphology, } \\
\text { volume fraction }\end{array}$ & $\begin{array}{l}\text { Sampling, } \\
\text { Line of } \\
\text { sight }\end{array}$ & $\mathrm{C} 2 \mathrm{H} 4$ & $\begin{array}{l}\text { Turbulent jet } \\
\text { non-premixed }\end{array}$ & Experimental & $\begin{array}{l}\text { Measurements of soot in a turbulent flame via extinction } \\
\text { and TEM analysis. } \\
\text { Identification of distinct regions of soot nucleation, } \\
\text { surface growth, agglomeration and oxidation. }\end{array}$ \\
\hline $\begin{array}{l}\text { Roditcheva \& } \\
\text { Bai, } 2001\end{array}$ & $\begin{array}{l}\text { Mixture fraction, } \\
\text { temperature, soot } \\
\text { volume fraction, and } \\
\text { more. }\end{array}$ & $2 \mathrm{D}$ & $\mathrm{CH} 4$ & $\begin{array}{l}\text { Turbulent non- } \\
\text { premixed }\end{array}$ & Numerical & $\begin{array}{l}\text { Numerical examination of pressure effects on soot } \\
\text { formation. } \\
\text { Increased pressure leads to an increased rate of soot } \\
\text { surface growth which in turn leads to increased } f_{v} \text {. }\end{array}$ \\
\hline $\begin{array}{l}\text { Decroix \& } \\
\text { Roberts, } 2000\end{array}$ & Soot volume fraction & $2 \mathrm{D}$ & $\mathrm{C} 3 \mathrm{H} 8$ & $\begin{array}{l}\text { Oscillating } \\
\text { non-premixed }\end{array}$ & Experimental & $\begin{array}{l}\text { Measurements of } f_{v} \text { in an oscillating propane-air } \\
\text { counterflow flame via LII. } \\
\text { Soot formation becomes insensitive to fluctuations in } \\
\text { strain rate if the initial strain rate is high. } \\
>\text { Soot formation is strongly reduced by strain rate } \\
\text { fluctuations if the initial strain rate is low. }\end{array}$ \\
\hline $\begin{array}{l}\text { Brookes \& } \\
\text { Moss, } 1999\end{array}$ & $\begin{array}{l}\text { Mean mixture fraction, } \\
\text { temperature, soot } \\
\text { volume fraction. Mean } \\
\text { and instantaneous } \\
\text { radiant intensity. }\end{array}$ & OD & $\mathrm{CH} 4$ & $\begin{array}{l}\text { Turbulent jet } \\
\text { non-premixed }\end{array}$ & Experimental & $\begin{array}{l}\text { Comparison of thermal radiation and soot production } \\
\text { between atmospheric and elevated pressure turbulent } \\
\text { flames. } \\
\text { Data important to coupled numerical modeling of soot } \\
\text { formation and radiation heat transfer are reported. } \\
>\text { Increasing the pressure by a factor of three produces an } \\
\text { order of magnitude increase in soot volume fraction. }\end{array}$ \\
\hline
\end{tabular}




\begin{tabular}{|c|c|c|c|c|c|c|}
\hline Reference & $\begin{array}{l}\text { Measured } \\
\text { quantities }\end{array}$ & $\begin{array}{l}\text { Spatial } \\
\text { Nature }\end{array}$ & Fuel & Flame Type & Type & Goals and Conclusions \\
\hline $\begin{array}{l}\text { Shaddix \& } \\
\text { Smyth, } 1996\end{array}$ & Soot volume fraction & $2 \mathrm{D}$ & $\begin{array}{l}\mathrm{CH} 4 \\
\mathrm{C} 3 \mathrm{H} 8 \\
\mathrm{C} 2 \mathrm{H} 4\end{array}$ & $\begin{array}{l}\text { Steady and } \\
\text { flickering non- } \\
\text { premixed }\end{array}$ & Experimental & $\begin{array}{l}\text { Comparison of soot volume fraction and scattering } \\
\text { between steady and flickering flames. } \\
\text { Peak soot scattering and volume fraction in flickering } \\
\mathrm{CH} 4 \text { flames are greatly enhanced compared to steady } \\
\text { flames. } \\
>\text { Peak soot scattering and volume fraction in flickering } \\
\mathrm{C} 2 \mathrm{H} 4 \text { and } \mathrm{C} 3 \mathrm{H} 8 \text { flames are only moderately enhanced } \\
\text { compared to steady flames. }\end{array}$ \\
\hline $\begin{array}{l}\text { Coppalle \& } \\
\text { Joyeux, } 1994\end{array}$ & $\begin{array}{l}\text { Temperature and soot } \\
\text { volume fraction }\end{array}$ & $\mathrm{OD}$ & $\mathrm{C} 2 \mathrm{H} 4$ & $\begin{array}{l}\text { Buoyancy \& } \\
\text { momentum } \\
\text { driven, } \\
\text { turbulent jet } \\
\text { non-premixed }\end{array}$ & Experimental & $\begin{array}{l}\text { Determination of correlation between temperature and } \\
f_{v} \text {. } \\
>\text { Soot production is influenced by turbulent mixing. } \\
>\text { Low in the flame, buoyant flames have higher soot } \\
\text { production than momentum-driven flames. } \\
>\text { Correlation between temperature and } f_{v} \text { is low on the } \\
\text { axis of all flames. }\end{array}$ \\
\hline $\begin{array}{l}\text { Shaddix } \\
\text { et al., } 1994\end{array}$ & Soot volume fraction & $2 \mathrm{D}$ & $\mathrm{CH} 4$ & $\begin{array}{l}\text { Flickering non- } \\
\text { premixed }\end{array}$ & Experimental & $\begin{array}{l}\text { Measurement of } f_{v} \text { in flickering flame for validation of } \\
\text { soot models in unsteady flames. } \\
\text { Soot production is four times greater at forcing condition } \\
\text { for which flame clipping occurs as compared to a steady } \\
\text { flame. }\end{array}$ \\
\hline $\begin{array}{l}\text { Sivathanu \& } \\
\text { Faeth, } 1990\end{array}$ & $\begin{array}{l}\text { Soot volume fraction } \\
\text { and temperature }\end{array}$ & $\mathrm{OD}$ & $\begin{array}{l}\mathrm{C} 2 \mathrm{H} 2 \\
\mathrm{C} 3 \mathrm{H} 6 \\
\mathrm{C} 2 \mathrm{H} 4 \\
\mathrm{C} 3 \mathrm{H} 8\end{array}$ & $\begin{array}{l}\text { Turbulent } \\
\text { buoyant non- } \\
\text { premixed }\end{array}$ & Experimental & $\begin{array}{l}\text { Examination of sooting behaviour and fuel effects within } \\
\text { pool-like flames. } \\
\text { Temperature and } f_{v} \text { are highly correlated in the fuel-rich } \\
\text { region of pool-like fires. The correlations depend on fuel } \\
\text { type but are independent of other operating conditions. }\end{array}$ \\
\hline $\begin{array}{l}\text { Kent \& Bastin, } \\
1984\end{array}$ & $\begin{array}{l}\text { Soot volume fraction \& } \\
\text { temperature }\end{array}$ & $\begin{array}{l}\text { Line of } \\
\text { sight }\end{array}$ & $\mathrm{C} 2 \mathrm{H} 2$ & $\begin{array}{l}\text { Turbulent jet } \\
\text { non-premixed }\end{array}$ & Experimental & $\begin{array}{l}>\text { Parametric effects on } f_{V} \text { and temperature. } \\
f_{V} \text { profiles scale with a global time constant. } \\
\text { Soot formation and oxidation rates are limited by mixing } \\
\text { at low flow rates and by soot kinetics at high flow rates. }\end{array}$ \\
\hline
\end{tabular}




\subsection{Thesis Motivation \& Objectives}

The work presented in this thesis was motivated by the dearth of experimental data on soot morphologies and volumes fractions within turbulent flames. Due to the difficulties in obtaining these data, the first major focus of this thesis was the development, testing, and uncertainty analysis of the 2D-AC-LII and LII/ELS measurement systems. The second major focus of this thesis was the measurement of soot data in a laboratory flame of practical interest for a range of conditions spanning a gap in the current literature between purely momentumand buoyancy-dominated flames.

The objectives of this thesis were: 1) to design, characterize, and implement diagnostics capable of making quantitative measurements of soot volume fraction and morphology in turbulent sooting flames, and 2) to make well-characterized measurements in turbulent buoyant non-premixed sooting flames to improve fundamental understanding of the factors affecting soot production and oxidation in turbulent buoyant flames representative of solution gas flares.

\subsection{Overview of Thesis}

The thesis follows the research chronologically. Initially, a two-dimensional LII diagnostic was developed and characterized to allow visualization of soot structures and spatial correlations and to better characterize the AC-LII technique via a thorough uncertainty analysis. This early work culminated in the publication of the first journal article included here: an analysis of the uncertainties in instantaneous 2D measurements of soot volume fraction in a 
non-premixed laminar ethylene flame. The uncertainty was found to be dominated by inexact knowledge of the soot index of refraction absorption function, $E\left(m_{\lambda}\right)$, resulting in total uncertainties on the order of $+90 \% /-65 \%$ in moderately sooting $(\approx 5 \mathrm{ppm})$ regions of the flame. A comparative error, calculated assuming fixed soot properties, and useful in examining trends within a given flame, was determined to be on the order of $\pm 20 \%$ in moderately sooting regions of the flame. Based on the large precision uncertainty and the slow repetition rate of the intensified $\mathrm{CCDs}$ used for data acquisition, 2D measurements were abandoned in favour of point measurements.

The second article is a rapid communication describing a novel method of detector calibration for ELS measurements. The traditional method of calibration uses Rayleigh scattering from gas molecules. Because the scattering coefficients of these molecules are very small compared to those of soot aggregates, the calibration generally requires a very sensitive detector such as a photomultiplier tube (PMT). However, the high sensitivity and low dynamic range of PMTs means that subsequent in-flame experimental measurements require the use of neutral density filters with a transmissivity on the order of 10-4 to avoid detector saturation, resulting in weaker measurement signals with increased photon shot noise. The new, diffuse surface scattering calibration method presented in Chapter 3 produces approximately $10^{6}$ more photons during calibration, allowing the use of less-sensitive detectors with larger dynamic ranges. As detailed in the paper, the new method was verified to produce the same calibration coefficient as the traditional Rayleigh scattering method within 
experimental uncertainties. Moreover, a comprehensive uncertainty analysis showed that: i) PMTs calibrated via the diffuse surface scattering method have reduced calibration uncertainty ( $\pm 6 \%$ versus $+12 /-10 \%$ for Rayleigh scattering), and ii) the usage of photodiode detectors instead of PMTs reduced the uncertainty of measured scattering coefficients ( $\pm 8 \%$ versus $+14 /-13 \%$ for PMTs, both calibrated via the diffuse surface scattering calibration method) in a laminar non-premixed ethylene flame.

The third article describes the development of a point-measurement (oD) apparatus capable of making simultaneous, instantaneous measurements of soot volume fraction, aggregate size, and primary particle diameter. The apparatus is described in detail along with the theoretical basis for interpreting measurements. Demonstration measurements are performed in a non-premixed laminar ethylene flame, and used in a detailed, Monte Carlo analysis of experimental uncertainties. Results are also compared with available measurements in the literature obtained using different techniques.

In the combined LII/ELS approach, a single Nd:YAG laser operating at a wavelength of $1064 \mathrm{~nm}$ is used for excitation of both LII and ELS. While the use of $1064 \mathrm{~nm}$ wavelength excitation produces less scattering than $532 \mathrm{~nm}$ excitation, the longer wavelength is preferable for LII excitation to avoid inducing fluorescence. As noted in the first article in this thesis, the total uncertainty in soot volume fraction remains dominated by the soot index of refraction absorption function, $E\left(m_{\lambda}\right)$, and is thus quite high at $+69 \% /-45 \%$ in a moderately sooting region of the flame $(\approx 4 \mathrm{ppm})$. The primary particle diameter uncertainty 
is dominated by soot morphological properties (i.e. the fractal prefactor and the fractal dimension), producing an uncertainty of $+50 \% /-33 \%$ in a moderately sooting region. Uncertainty in the effective aggregate radius of gyration is dominated by the lack of knowledge of the shape of the distribution of aggregate sizes, producing a total uncertainty of $+22 \% /-19 \%$. If the uncertainty in the soot properties is neglected as can be relevant to making comparative measurements among flames where properties can be expected to be quasi-constant, all of the measurement uncertainties are approximately halved. All of the measured quantities agree with results from the literature within experimental uncertainty.

The final article builds on the advances and results of the previous articles, and specifically draws on the uncertainty analysis framework from the first article, the high-dynamic range ELS calibration method from the second article, and the theory and uncertainty analysis for the combined diagnostic described in the third article. The sum of these works allows measurement and analysis of soot volume fraction, aggregate radius of gyration, and primary particle diameter in non-premixed buoyant turbulent flames representative of solution gas flares common to the upstream oil and gas industry. Many of the 15 conditions studied were found to be similar when scaled by flame length in the axial direction. Differences were seen in the largest flames, where the literature predicts the laminar-to-turbulent transition should proceed by shear rather than buoyancy effects, and the smallest flames, whose larger soot volume fractions low in the flame were attributed to their comparatively long laminar region which resulted in higher temperatures low in the flame. Measurements of velocity along the 
flame centerlines using laser Doppler velocimetry also allowed scaling by mean residence time. After correcting for temporal offsets resulting from differences in the flow low in the flame, aggregate radius of gyration is shown to correlate strongly with residence time $\left(r^{2}=0.94\right)$. Using the same correction, soot volume fraction correlates well only within flames issued from the larger diameter nozzles (50.8 and $76.2 \mathrm{~mm})$.

Based on histograms of soot volume fraction, calculations of intermittency, and the observation of constant primary particle diameter near the flame tip, mean soot volume fraction is found to decrease high in the flame due to complete, rather than partial, oxidation of individual soot bearing structures. Furthermore, the invariant shape of the soot volume fraction histograms conditioned on the presence of soot indicate that oxidation does not occur preferentially in structures with lower soot volume fraction.

The final article demonstrates the achievement of the goals of this thesis: a well-characterized diagnostic tool is used to provide quantitative soot measurements in a flame of great practical importance to climate forcing and health, providing new insight into the mechanisms of soot growth and destruction, where measured data are supported by a comprehensive uncertainty analysis. 


\section{Chapter 2}

\section{Analysis of Uncertainties in Two-Dimensional, Auto-Compensating Laser-Induced Incandescence Measurements}

This chapter has been peer-reviewed and was published in Applied Physics B on July 20, 2010. It should be cited as:

Crosland, BM, MR Johnson, and KA Thomson (2011) Analysis of uncertainties in instantaneous soot volume fraction measurements using two-dimensional, auto-compensating, laser-induced incandescence (2D-AC-LII), Applied Physics B 102(1):173-183. doi: 10.1007/s00340-010-4130-7.

This paper was co-authored by the thesis author, Brian Crosland, and his Ph.D. supervisors Prof. Matthew Johnson and Dr. Kevin Thomson. Mr. Crosland setup, tested, and characterized the measurement equipment; performed the measurements, uncertainty analysis, and initial data analysis; and wrote a first draft of the manuscript. The theory development, final data analysis, and editing and revision of the manuscript were conducted jointly.

\section{$2.1 \quad$ Abstract}

Laser-induced incandescence (LII) is an optical measurement technique capable of measuring soot volume fraction over a wide range of conditions. However, development of two-dimensional auto-compensating LII (2D-AC-LII) in the literature has been limited and until now, instantaneous measurements have not been demonstrated. In this paper, we successfully demonstrate instantaneous 2D-AC-LII soot volume fraction (SVF) measurements in an ethylene-air coannular diffusion flame. Results were then used to support a detailed uncertainty 
analysis based on a Monte Carlo simulation. Agreement between both the instantaneous and average SVF measurements with published data from attenuation measurements under identical conditions was found to be good. Uncertainties are discussed both in terms of an overall accuracy of the SVF measurement, which is strongly dominated by uncertainty in the optical properties of soot, and the comparative uncertainties with optical properties fixed. The uncertainty in an instantaneous 2D determination of SVF for a comparative measurement is dominated by photon shot noise, and in regions of high soot volume fraction it is below $25 \%$ ( $95 \%$ confidence interval). Shot noise uncertainty could be further reduced with additional pixel averaging at the expense of spatial resolution. This diagnostic shows significant promise for quantitative planar soot concentration measurements within turbulent flames. 


\subsection{Introduction}

As a component of particulate matter, soot is a regulated pollutant that is closely linked with significant adverse health effects on humans (US EPA 2010) and climate forcing (IPCC 2007). Accurate quantification of soot is vitally important both in the fundamental understanding of its formation mechanisms and in the quantification of emissions from flames and practical combustion devices.

Laser-induced incandescence (LII) measurement is an emergent optical combustion diagnostic which can be used to determine the volume fraction and primary particle size distribution of soot (Melton, 1984; Schulz et al., 2006; Michelsen, Liu, et al., 2007; Will et al., 1995; Schraml et al., 2000; Daun et al., 2007; Kock et al., 2006). In this technique, a laser pulse is used to heat soot aerosols to or close to their vaporization temperature. The incandescence signature from the soot is intense and short-lived, as the particles rapidly cool to the ambient temperature principally through conductive cooling and in some cases sublimation. The emission intensity is proportional to the concentration of the soot, but it is also highly dependent on the soot temperature. This temperature dependence can be used to advantage when the decay of the incandescence is measured as a function of time and used to predict the active surface area or effective primary particle size of the soot aggregates (Will et al., 1995; Schraml et al., 2000; Daun et al., 2007; Kock et al., 2006). Conversely, the temperature dependence presents a challenge when trying to infer the particle concentration from the emission intensity, especially if the initial temperature of the soot before heating is unknown. 
Two distinct strategies exist to overcome the temperature dependence of the measured emission. The first, often referred to as high-fluence or 'plateauregime' LII (Schulz et al., 2006; Ni et al., 1995; Axelsson et al., 2000; Bryce et al., 2000), involves imparting sufficient energy to the particles to ensure they reach a sublimation temperature of 4000 to $4500 \mathrm{~K}$ independent of their initial temperature, thus ensuring a spatially-uniform soot temperature distribution. Under this condition, a near-proportionality of emission intensity and concentration is assumed to exist when comparing soot from different locations in a flame or indeed different sources (Bladh et al., 2008; Migliorini et al., 2009). Plateau-regime LII requires calibration by comparing LII emission measurements to results from another calibrated technique (e.g. extinction measurements as in Zerbs et al. (2009); Axelsson et al. (2001); Pastor et al. (2006); Fuentes et al. (2007), or cavity ring-down spectroscopy as in Vander Wal (1998); Bouvier et al. (2007); Desgroux et al. (2008); Lemaire et al. (2009)). These secondary techniques are either applied simultaneously or are used to quantify soot volume fraction in a reference flame that is subsequently used to calibrate the LII measurement.

The second strategy involves measurement of the temperature of the heated soot in real-time by two-color emission pyrometry (Kock et al., 2006; Snelling et al., 2005; De Iuliis et al., 2005; Bladh et al., 2009). Since the temperature of the soot is explicitly calculated based on measurements, it is not necessary to reach sublimation temperatures, and thus the diagnostic is less intrusive and less sensitive to in-flame laser attenuation (Snelling et al., 2005). 
Measurement of incandescence intensity shortly after the laser pulse is used to determine soot concentration while the temperature decay is used to determine soot morphology. The method is referred to interchangeably as autocompensating or two-color LII (2C-LII). We use auto-compensating LII (AC-LII) here to avoid confusion with another LII variant by Schoemaecker-Moreau et al. (2004) also named 2C-LII, which involves two laser wavelengths. AC-LII offers the significant advantage that calibration does not require comparison to other soot concentration diagnostics or to flames of known concentration. The method is also better suited for morphology measurement, since high fluence LII has been demonstrated to significantly alter the interrogated soot (Michelsen, Tivanski, et al., 2007).

Although development and application of AC-LII is progressing rapidly (e.g. Bladh et al., 2009; Snelling et al., 2009; De Iuliis et al., 2007), including the use of single point AC-LII to calibrate simultaneous 2D-LII measurements (Boiarciuc et al., 2006), two-dimensional auto-compensating LII (2D-AC-LII) has received little attention to date (De Iuliis et al., 2007) and has yet to be demonstrated as an instantaneous measurement technique. Specifically, there remain significant challenges for the design and demonstration of an optical system which provides an optimal laser excitation and sufficient sensitivity throughout the measurement field-of-view to permit single shot data acquisition. In this paper we present a 2D-AC-LII apparatus and quantitatively evaluate its potential for instantaneous planar measurements of soot concentration. The system is demonstrated on a laminar co-annular ethylene/air non-premixed 
flame to permit direct, critical comparison of results with data from other sources. Detailed uncertainty limits are also analyzed and discussed. This proposed approach shows significant promise for quantitative planar soot concentration measurements within turbulent flames.

\subsection{Theory}

The underlying principle of AC-LII is two-color pyrometry. Soot temperature is first determined by the ratio of emission intensity at two wavelengths and soot concentration is determined from comparison of the absolute emission intensity at either measurement wavelength and the theoretical emission intensity per unit volume of soot at the measurement temperature.

The theoretical emission per unit volume of soot at temperature $T_{p}$ and at wavelength $\lambda$ is (Snelling et al., 2005):

$$
\phi_{p}\left(\lambda, T_{p}\right)=\frac{48 \pi^{2} c^{2} h}{\lambda^{6}}\left[\exp \left(\frac{h c}{k \lambda T_{p}}\right)-1\right]^{-1} E\left(m_{\lambda}\right)
$$

where $c$ is the speed of light, $h$ is Planck's constant, $k$ is the Boltzmann constant and $E\left(m_{\lambda}\right)$ is the wavelength-dependent soot absorption function. Recognizing that practical detectors measure an integration of signal over a finite spectral range, $I_{i}$, the signal measured by the intensified charge-coupled device (ICCD) on channel $i$ is then:

$$
I_{i}=f_{v}\left(M_{i}^{2} A_{p} w_{b}\right)\left(A_{L} / u_{i}^{2}\right) \alpha_{i} \beta_{i} \int_{\lambda} \phi_{p}\left(\lambda, T_{p}\right) \Omega_{i}(\lambda) d \lambda+D_{i}
$$

where $f_{v}$ is the volume fraction of soot, $w_{b}$ is the laser sheet thickness, $D_{i}$ is the ICCD dark count and $\Omega_{i}(\lambda)=\tau_{i}(\lambda) \Theta_{i}(\lambda)$, for which $\tau_{i}(\lambda)$ is the product of the optical 
transmissivities of the lens and filters and $\Theta_{i}(\lambda)$ is the photocathode responsivity, both of which can be determined from manufacturers' specifications. It should be noted that even for the present case of soot measurements within an ethylene diffusion flame, the contribution of flame luminosity was determined to be negligible compared to the LII signal. This leaves only wavelength-independent terms relating to the detector package, including magnification of the collection optics, $M$; area of a CCD pixel, $A_{p}$; area of the camera lens, $A_{L}$; distance between the lens and the laser sheet, $u$; intensifier gain, $\alpha_{i}$; and CCD gain, $\beta_{i}$, which are hereafter grouped into a single term, $\eta_{i}$. The coefficient $\eta_{i}$ can be determined from a calibration of the optical system using a radiant standard placed coincident with the measurement location according to:

$$
I_{\text {lamp }, i}=\eta_{i} 4 \pi \int_{\lambda} R_{S}(\lambda) \Omega_{i}(\lambda) d \lambda+D_{\text {lamp }, i}
$$

where $R_{s}(\lambda)$ is the spectral radiance of the calibrated source, and $I_{\text {lamp }, i}$ is the measured signal during calibration and $D_{\text {lamp }, i}$ is the dark count measured with the intensifier off but the lamp on. This latter term is especially important in correcting for leakage through the photocathode during calibration, since the lamp provides a continuous signal and the $\mathrm{CCD}$ readout time is long compared to the intensifier gate width. This calibration is performed for each pixel on the CCD to generate a spatially-variant pixel sensitivity map, $\eta_{i, x, y}$.

The ratio of LII signals from the two wavelength ranges corresponding to the two measurement channels provides an expression: 


$$
\frac{I_{1}}{I_{2}}=\eta_{1} \int_{\lambda} \phi_{p}\left(\lambda, T_{p}\right) \cdot \Omega_{1}(\lambda) d \lambda / \eta_{2} \int_{\lambda} \phi_{p}\left(\lambda, T_{p}\right) \cdot \Omega_{2}(\lambda) d \lambda
$$

where $f_{v}$ and $w_{b}$ cancel in the ratio and temperature is the only unknown. However, determination of $T_{p}$ is computationally intensive. Snelling et al. (2005, 2009) propose an 'equivalent filter' method that allows Equation (2.4) to be reformulated into an explicit expression from which $T_{p}$ is easily determined. To avoid this approximation while maintaining a fast data processing algorithm, we instead pre-compute the RHS of Equation (2.4) for a range of $T_{p}$ and develop a look-up table of $T_{p}=f n\left(I_{1} / I_{2}\right)$. Once $T_{p}$ has been determined, $f_{v}$ can be solved by Equation (2.2), using the measured LII signal from either measurement channel.

To account for the Gaussian intensity profile of the laser sheet used in this study, where soot will not be uniformly heated to a single peak temperature, an equivalent temperature and sheet thickness method (Snelling et al., 2005) can be used. In this case, the soot temperature calculated using Equation (2.4) will only be an equivalent temperature $\left(T_{e}\right)$, and thus requires a corresponding equivalent laser thickness $\left(w_{e}\right)$, which by definition is the thickness that will yield a correct soot volume fraction when used with the equivalent temperature in Equation (2.2) (Snelling et al., 2005). The impacts of this approach on measurement uncertainty are considered in the overall uncertainty analysis discussed later.

An appropriate equivalent laser thickness for the current laser sheet profile and peak fluence $\left(1.3 \mathrm{~mJ} / \mathrm{mm}^{2}, \lambda=1064 \mathrm{~nm}\right)$ was determined via numerical simulation of the LII process using the method described in Snelling et al. (2005). Sublimation was not considered in the simulation because of the low 
fluences involved. Example simulation results for three primary particle diameters and three peak laser fluences are shown in Figure 2.1.

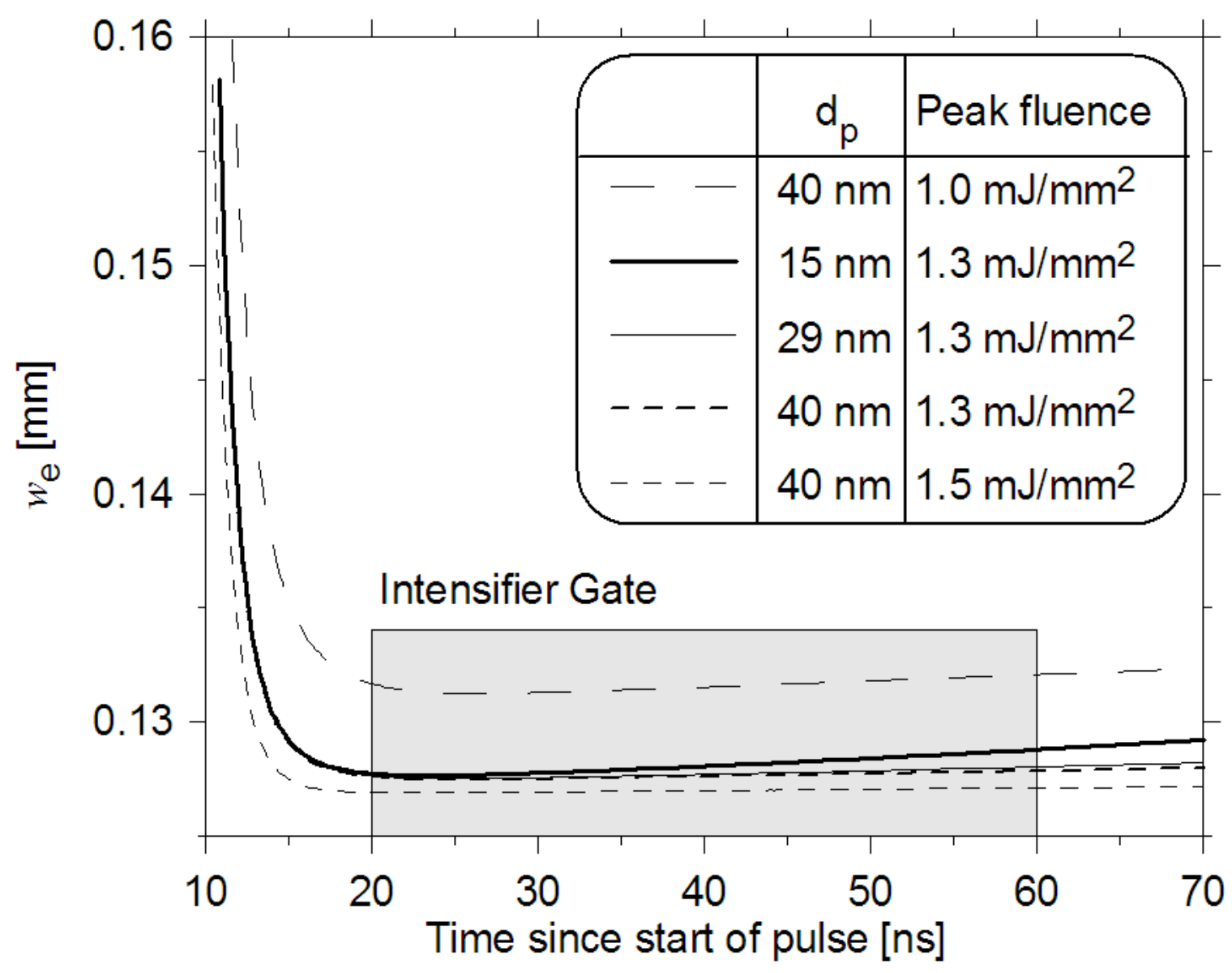

Figure 2.1 - The required equivalent sheet thickness remains relatively uniform during the intensifier gate.

After strong variation immediately following the laser pulse, the equivalent width remains quite stable over the ICCD gate period from 20 to $60 \mathrm{~ns}$. This is helpful both in reducing sensitivity to timing between the laser and the ICCD and in keeping the formulation of the soot volume fraction equations independent of time. Furthermore, variation in $w_{e}$ with primary particle diameter is negligible and modest with peak laser fluence. 
Beam steering is an important issue to consider when applying optical diagnostics in flames. Distortion of the excitation laser due to refractive index gradients has been shown to be a problem in high pressure test rigs but was found to be less significant at atmospheric pressure (Zerbs et al., 2009). In the present case, the laser is passed through the centreline of an axisymmetric flame and thus normal to the temperature and refractive index gradients and therefore negligible distortion of the laser beam is anticipated. Beam steering can also influence the emitted incandescent signal in the form of image blurring where the largest steering occurs in regions of low temperature and high temperature gradient, or outside of the soot region of the present flame. Within the sooting zone, beam steering is expected to be quite small other than near the burner exit (Thomson et al., 2008).

\subsection{Equipment}

A schematic of the experimental apparatus is shown in Figure 2.2. The output of a pulsed Nd:YAG laser (Litron Lasers Ltd., LPY-642T-10) operating at $1064 \mathrm{~nm}$ and a pulse width of about 10 ns was focused into a sheet using a Powell lens (Laser Line Generator, StockerYale Canada). The laser fluence was adjusted using a half-wave plate and thin-film polarizer. The sheet had a near-uniform profile over its $4 \mathrm{~cm}$ height and a Gaussian profile through the waist with a fullwidth, half-maximum thickness of $130 \mu \mathrm{m}$. The peak fluence of the sheet was approximately $1.3 \mathrm{~mJ} / \mathrm{mm}^{2}$, determined using a beam profile camera (Coherent Inc., LaserCam-HR) and a power meter (Scientech Inc.). 


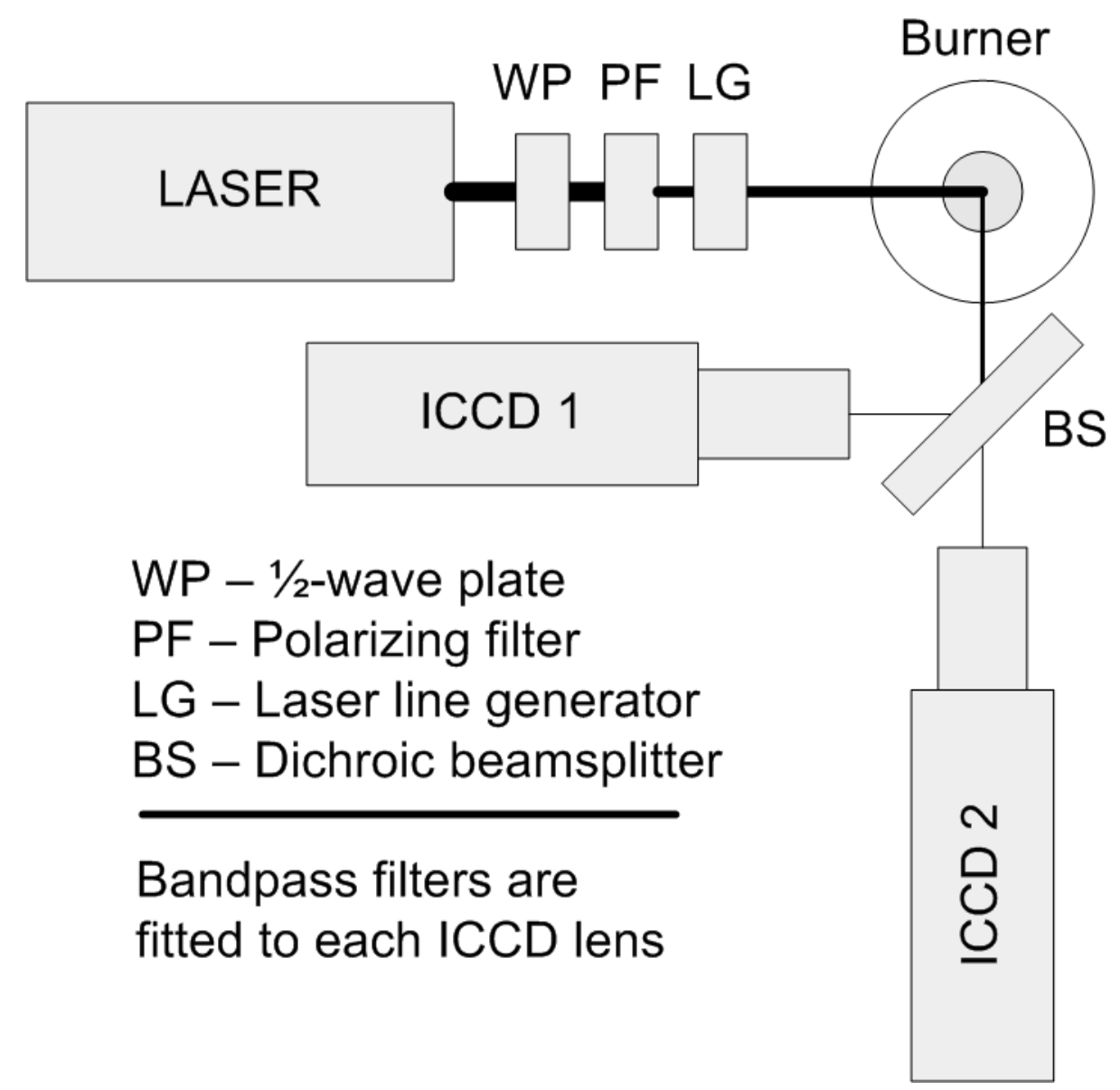

Figure 2.2 - Schematic of the experimental apparatus.

A pair of 16-bit PI-MAX ICCD cameras (Princeton Instruments) were fitted with $180 \mathrm{~mm}, f / \# 3.5$ macro camera lenses (Sigma Corporation). The ICCDs differed only in their wavelength optimizations. The ICCDs were fitted with bandpass filters (Semrock Inc.) with centre wavelengths of $442 \mathrm{~nm}$ and $684 \mathrm{~nm}$ and bandwidths of $46 \mathrm{~nm}$ and $24 \mathrm{~nm}$, respectively. A dichroic beamsplitter (BMV Optical Technologies) was used to split the LII emission normal to the laser sheet from a height of $22 \mathrm{~mm}$ to $39 \mathrm{~mm}$ above the burner exit onto the two ICCDs. The magnification was 0.9, with one pixel representing $22.2 \times 22.2 \mu \mathrm{m}$; however, images were binned horizontally and vertically by 5 pixels in order to improve signal to noise. The spectral transmissivity of the 
filters and beamsplitter and the quantum efficiency of the intensifiers were provided by the manufacturers.

A NIST-traceable 4" integrating sphere and tungsten filament lamp (SphereOptics LLC) calibrated as a unit to provide a source of radiant intensity, uniform to $1 \%$ over the exit port of the sphere, was used to determine $\eta_{i, x, y}$ for both ICCDs. The spectral radiance of the sphere was monitored using a spectrometer calibrated by SphereOptics for use with the sphere. During calibration, multiple images were averaged to reduce the photon shot noise uncertainty to $2.5 \%$ of the mean signal. The integrating sphere was also used to determine the ICCD gain using photon transfer theory (Janesick 2001). This allowed the photon shot noise in a given instantaneous measurement to be approximated and allowed verification that photon shot noise was the dominant source of noise over all of the selected operating range. An average image of the exit port of the sphere was acquired with the intensifier disabled to be subtracted as $D_{\text {lamp }, i}$. All acquired images were spatially calibrated and correlated (registered) between the ICCDs by acquiring images of a rectangular grid of $0.75 \mathrm{~mm}$ diameter circles, spaced $1.10 \mathrm{~mm}$ apart, and applying a commercial spatial calibration and pixel registration algorithm DaVis (LaVision GmbH).

Measurements were performed on a Gülder burner ethylene/air flame described in Snelling et al. (1999) for the standard operating conditions of $194 \mathrm{sccm}$ ethylene $\left(1 \mathrm{~atm}, 21^{\circ} \mathrm{C}\right)$ and $284 \mathrm{slpm}$ co-flow air. This is a stable and repeatable flame for which detailed measured soot volume fraction data were available (Trottier et al., 2007). 


\subsection{Results}

Figure 2.3 summarizes the key measurement results. In Figure 2.3a, $T_{e}$ determined from the ratio of a single shot image pair is shown. Figure $2.3 \mathrm{~b}$ is the corresponding instantaneous $f_{v}$, while Figure 2.3c is the 100-image averaged soot volume fraction. Two-dimensional line-of-sight attenuation (2D-LOSA) measurements of soot volume fraction (Trottier et al., 2007), are included in Figure $2.3 \mathrm{~d}$ for comparison. As will be discussed in the uncertainty analysis below, the results obtained via $2 \mathrm{D}$-AC-LII are expected to underestimate the soot volume fraction by as much as $5 \%$ due to soot cooling during measurement.
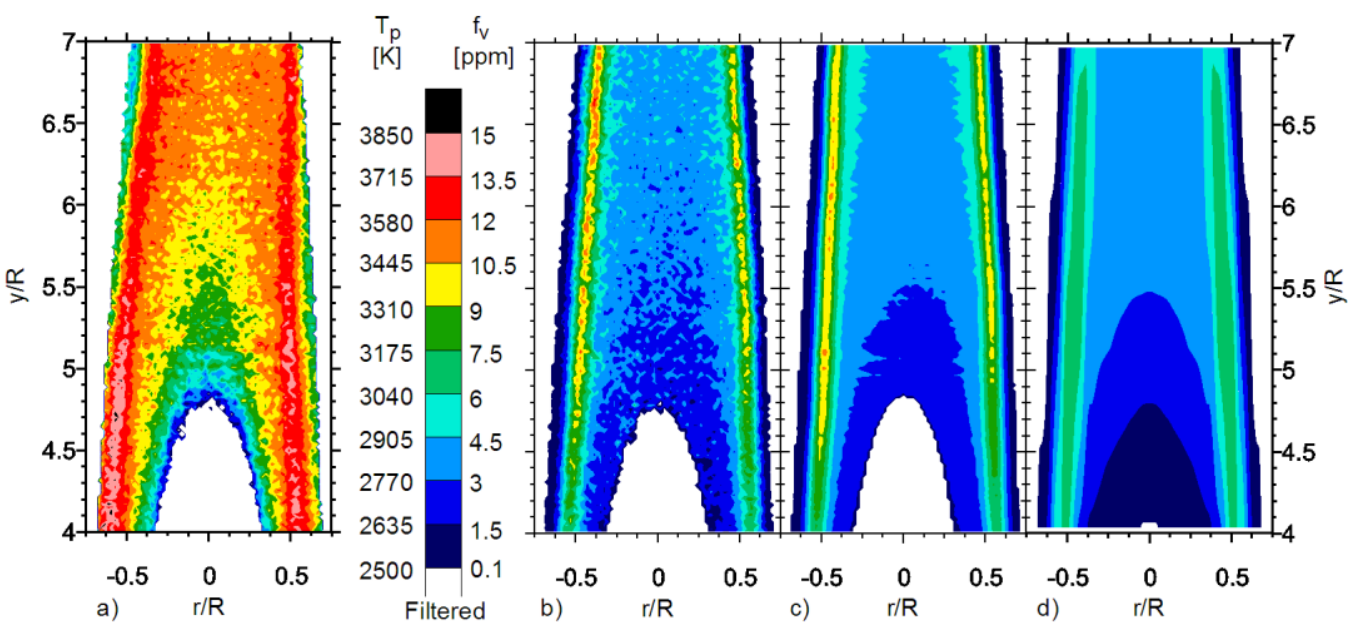

Figure 2.3 - The a) equivalent temperature and soot volume fraction as measured instantaneously via b) 2D-AC-LII, c) by average of 2D-AC-LII measurements, and d) by 2D-LOSA (Trottier et al., 2007). The fuel tube radius, $R=5.45 \mathrm{~mm}$.

The equivalent temperatures shown in Figure 2.3a range from $2700 \mathrm{~K}$ between $y / R=5$ to $y / R=7$, and $r / R= \pm 0.4$ to a maximum of approximately $3900 \mathrm{~K}$ at isolated points near $r / R=-0.55$ and $y / R \approx 4.7$. The temperatures in Figure 2.3a are all below the LII plateau regime which nominally begins at 
temperatures of approximately 4000-4500 K (Migliorini et al., 2009; Snelling et al., 2009; Michelsen et al., 2003).

Comparing the left and right peaks of equivalent temperature from $y / R=4.5$ to $y / R=6.5$, the right peak is, on average, $90 \mathrm{~K}$ lower than the left due to laser sheet attenuation from soot. The effect of laser attenuation on the LII signal can be seen in Figure 2.4, where the LII signal peaks are not equal. The soot volume fraction, however, is near-symmetric due to the incorporation of a spatially-varying temperature term in its calculation. This result highlights the importance of correcting for spatial variation of temperature in 2D-LII and reveals a potential advantage of the present approach over single point or reference flame calibrations, for which laser attenuation must be overcome by operating well above the sublimation threshold. 


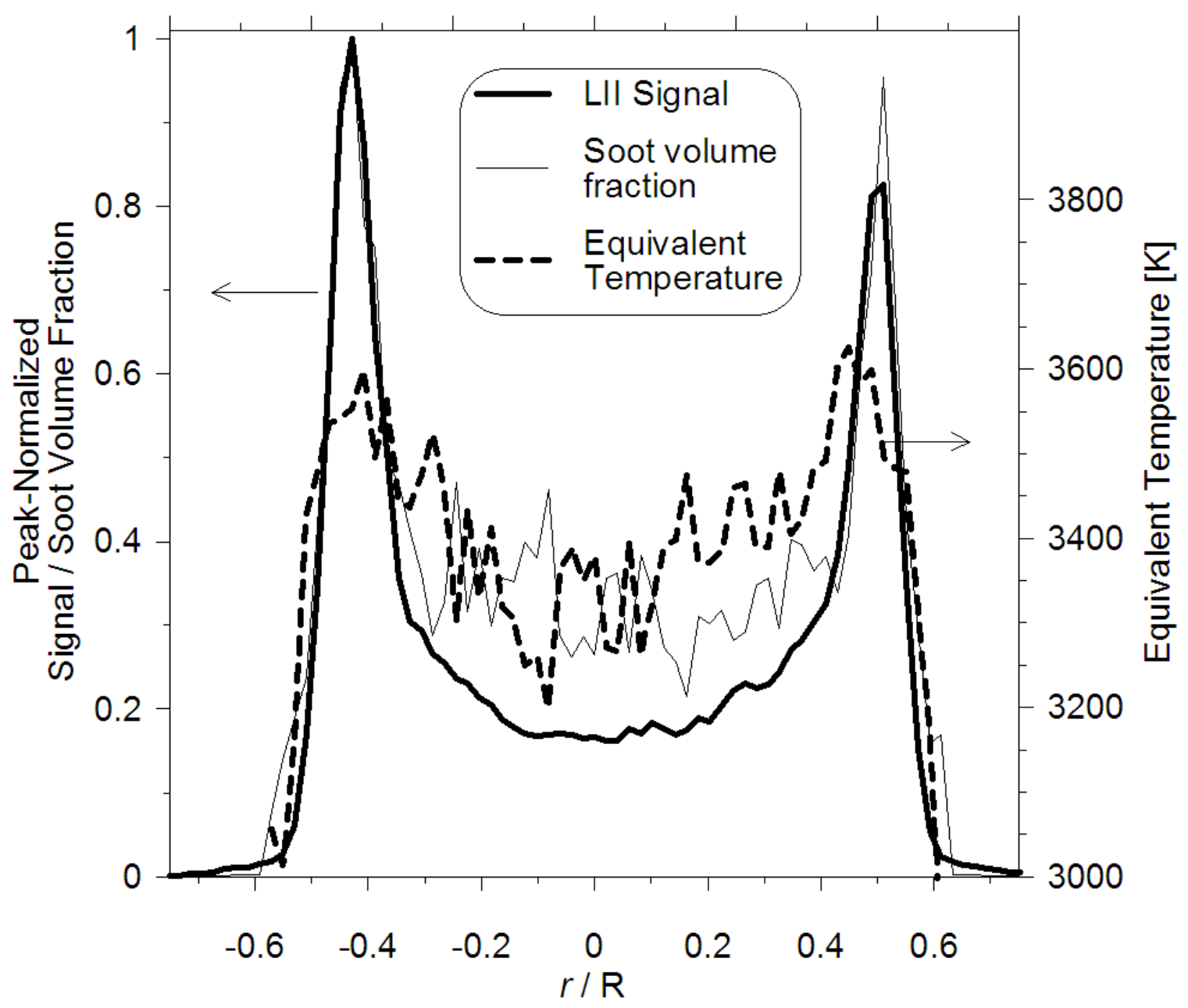

Figure 2.4 - Accounting for variations in soot temperature compensates for decreased laser fluence at the right hand soot peak.

\subsection{Discussion and Analysis of Uncertainty}

The propagation of uncertainty from elemental sources of error through to the soot volume fraction calculation was performed via Monte-Carlo simulation. Repeated calculations of soot volume fraction were made at each point in the measurement volume using values randomly selected from appropriate probability distributions accounting for the individual uncertainties of each term in Equation (2.2). This yields a sample of soot volume fractions whose normalized histogram approximately represents the probability density function 
of the soot volume fraction at that point. The sample was considered converged when the half-width of the $99 \%$ confidence interval of the mean soot volume fraction was found to be less than $1 \%$ of the sample mean soot volume fraction. Unbiased estimates of the confidence intervals used to determine convergence are obtained using the method of Law \& Carson (1979).

\subsubsection{Calibration Uncertainties}

The first source of uncertainty arises during the calibration of the ICCDs. Calibration was accomplished using a tungsten filament lamp irradiating a 4" diameter integrating sphere. The uncertainty of the NIST standard and the transfer uncertainty (from the NIST standard to the spectrometer) were provided by the manufacturer of the spectrometer. Multiple spectra were obtained and averaged, and the variation between measurements was added to the NIST standard and the transfer uncertainties as the root of the sum of the squares. For the purposes of the uncertainty analysis the spectral radiance was assumed not to vary as a function of wavelength within the relatively narrow range of each bandpass filter.

Simultaneous with the acquisition of spectra using the spectrometer, multiple images of the sphere output were obtained with each ICCD using the same experimental parameters $(f / \#$, intensifier gate width, ICCD placement and frame rate) that were used later during LII measurements. Photons emitted by the lamp travelled through the integrating sphere, passed through the beamsplitter, filter, and camera lens, struck the image intensifier, and induced an intensified signal on the CCD. The beamsplitter, filter, camera lens and 
intensifier photocathode are all wavelength-dependent devices. Though the nominal values of the wavelength-dependent transmissivities, $\Omega_{i}(\lambda)$, were known, their uncertainties were not. However, by calibrating the cameras and performing the data gathering with an identical optical arrangement any uncertainties that are independent of wavelength cancel (Snelling et al., 2005). Furthermore, any uncertainties that vary linearly with wavelength cancel to a first-order approximation, if the lamp and soot emission signals also vary linearly with wavelength over the relatively narrow width of each filter. The robustness of this approach was verified by an analytical simulation which revealed that a rather extreme wavelength dependent variation of $20 \%$ in the system transmissivity over the filter bandwidth produced a change of less than $1 \%$ in the calibration. Thus, uncertainties in the component transmissivities of the collection optics were considered negligible. It is noted that this result also explains why the "equivalent filter" approximation (Snelling et al., 2005) works well.

The uncertainty in the ICCD calibration signal, $I_{\text {lamp }}$, is dominated by inherent randomness of the emitted photons. Because the gate width of the intensifier is short, the random nature of photon emission has a non-negligible effect on the final image, known as photon shot noise. Since it is known that photon shot noise follows a Poisson distribution, it is possible to determine the approximate camera gain in counts/e using a sensitivity-corrected flat-field image, which in turn can be used to approximate the photon shot noise in a measured signal (Janesick 2001). 
Photon shot noise was verified to be the dominant source of uncertainty in the range of signals used for calibration. Since the dark count $\left(D_{\text {lamp }}\right)$ was small relative to the calibration signal, any uncertainty in the subtracted dark count was negligible relative to the uncertainty in the calibration signal itself. The total uncertainty in the calibration constant, $\eta_{i, x, y}$, was thus reduced to the contributions of the uncertainty in the spectrometer and the photon shot noise inherent in the lamp signal. Since the calibration signal was made up of the photon count amplified by a gain, a Poisson distribution should be used to represent it. However, the mean signal was large enough relative to its standard deviation that a normal distribution could be used with negligible risk of randomly selecting a negative calibration signal. For this reason, and to simplify coding, normal distributions were thus used for all shot-noise dominated uncertainty.

\subsubsection{Uncertainties During Data Collection}

The uncertainty in the equivalent sheet thickness calculation arises from the assumptions inherent in the numerical model which relate to imperfect knowledge of the laser profile, laser fluence, and soot optical properties. It is difficult to assess the accuracy of the numerical model alone, since this would require determination of the accuracy of the LII model which is beyond the scope of this work, and is indeed an open question in the literature. However, it is possible to estimate the overall uncertainty associated with using the equivalent sheet thickness approximation by considering a wide range of potential values for the relevant experimental parameters and soot properties used in the model to determine a range of possible equivalent sheet widths. Given that the 
uncertainties in optical properties dominate the overall uncertainties as noted below, such an approach will also encompass the range of sheet widths that would result from the inaccuracies of the model itself.

Parametric simulations of the LII process were performed to facilitate statistical sampling during Monte-Carlo simulations necessary to calculate overall uncertainties. The range of possible values of the soot absorption function $\left(E(m)_{\lambda}\right)$ and the ratio between the $E(m)$ values at the two detection wavelengths were chosen to slightly exceed the nominal ranges derived from data reported in the literature (Schnaiter et al., 2003; Coderre, 2009; Krishnan et al., 2000; Köylü \& Faeth, 1996), to permit sampling from a Gaussian distribution profile. For each value of $E(m)_{1}$ ranging from 0.27 to 0.41 in increments of 0.02 , four values of $E(m)_{2}$ were tested based on a range of potential wavelength dependencies of $E(m)_{\lambda}$ prescribed as the ratio $\varphi=E(m)_{1} / E(m)_{2}$ which had assigned values of $0.8,0.9,1.0$ and 1.1. Additionally, for each pair of $E(m)_{l}$ and $\varphi$ tested, a probability distribution of equivalent sheet width thickness was determined based on a range of peak laser fluences $\left(F_{L}=1.0-1.6 \mathrm{~mJ} / \mathrm{mm}^{2}\right)$, primary particle diameters $\left(d_{p}=15 \mathrm{~nm}-40 \mathrm{~nm}\right)$ and thermal accommodation coefficients $(\alpha=0.20-0.50)$. During the Monte-Carlo simulation, this library of probability distributions was used to select an appropriate random equivalent sheet width based on randomly selected $E(m)_{l}$ and $\varphi$. The same $E(m)_{l}$ and $\varphi$ pair was also used in the subsequent determination of the soot equivalent temperature and the soot volume fraction. As noted by Liu et al. (2009), although the uncertainties in the values of $E(m)$ at the two detection wavelengths each contribute to the overall 
uncertainty in the measured soot volume fraction, the relative contributions to the overall uncertainty can vary. Similarly, depending on how the uncertainties in $E(m)$ may vary with wavelength, a slightly different estimate of the overall uncertainty in soot volume fraction can be derived depending on which of the two detector signals is used in the final calculation of $f_{v}$, following the calculation of temperature. However, the calculated $f_{v}$ and the true uncertainty of $f_{v}$ (which is not determinable) are not affected by the choice of image used to determine $f_{v}$ and so there is no advantage in choosing one signal wavelength over the other.

Photon shot noise remained the dominant source of uncertainty in LII emission measurements over the range of measured intensities. As was true during calibration, the uncertainty in the dark count was negligible compared to the uncertainty in the measured signal from photon shot noise. Thus the uncertainty in the measured signal, $I_{i}-B_{i}$, was based on the magnitude of the measured signal alone, converted into photons via the measured system gain. Once again, uncertainties related to the collection optics cancelled out between calibration and data measurement.

The effects of photon shot noise during LII measurements contributed not only to the uncertainty of the soot volume fraction directly via the $I$ term in Equation (2.2), but also formed a significant component of the uncertainty in the determination of the equivalent temperature $\left(T_{e}\right)$. To decrease this uncertainty in an instantaneous measurement more photons must strike the photocathode of the intensifier or adjacent pixels must be binned during post-processing. More photons can be collected by making any of a number of changes to the 
experimental setup, including using a faster lens arrangement (lower $f$-number), increasing the intensifier gate width (thus increasing the bias error due to particle cooling during measurement), or using a thicker laser sheet (thus sacrificing spatial resolution in this direction). Binning adjacent pixels during postprocessing decreases the spatial resolution in the plane of the image but also increases signal to noise by the square root of the number of binned pixels. In the current measurements the spatial resolution perpendicular to the plane of the image (represented by the laser sheet thickness) was greater than the spatial resolution represented by a single pixel width, making binning the preferable first choice for reducing photon shot noise uncertainty. As mentioned previously, all LII data presented here resulted from a binning of 5x5 pixels during analysis.

The non-linearity of an individual pixel's response to incident photons is considered negligible in the range used for the current measurement (less than $20 \%$ of the CCD full-well capacity). If this were not the case, a simultaneous correction for $\mathrm{CCD}$ pixel response non-uniformity and non-linear CCD response such as that proposed by Williams \& Shaddix (2007) could be employed. The non-uniform pixel response among pixels in the CCD array was corrected using a sensitivity map created during calibration with the tungsten filament lamp and integrating sphere.

The formulation of Equation (2.1) implicitly assumes that the soot particle temperature does not change significantly during measurement. The shortest gate width possible with the ICCDs used is about $5 \mathrm{~ns}$, which is not negligible relative to typical measured soot cooling rates in the range of 1-10 K/ns (Snelling 
et al., 2009). Thus the assumption of a constant temperature introduces a nonnegligible bias error into the soot volume fraction calculation. The amount of bias introduced will depend on the soot cooling rate, the ICCD gate width and the soot temperature. Because the cooling rate will differ temporally and spatially, as well as from one flame to another, it would be a challenge to correct for the cooling rate without performing complementary time-resolved measurements. The bias introduced by a range of cooling rates using the present apparatus was approximated by simulating an LII signal created by a given volume of soot cooling at a constant rate and calculating soot volume fraction based solely on the time-integral of this signal. Results for a range of cooling rates beginning at two initial temperatures $\left(T_{0}\right)$ and using three gate widths are presented in Figure 2.5.

The current research used a gate width of $40 \mathrm{~ns}$ as a compromise between a stronger signal (decreasing photon shot noise) and an increased gate width bias error. Because the cooling rate is not precisely known for most flames it is difficult to account for it in the uncertainty analysis. However, the bias error for the current results should be less than about 5\% (Figure 2.5, hollow square, highest cooling rate) which is not a significant factor in the overall uncertainty as will be shown below. 


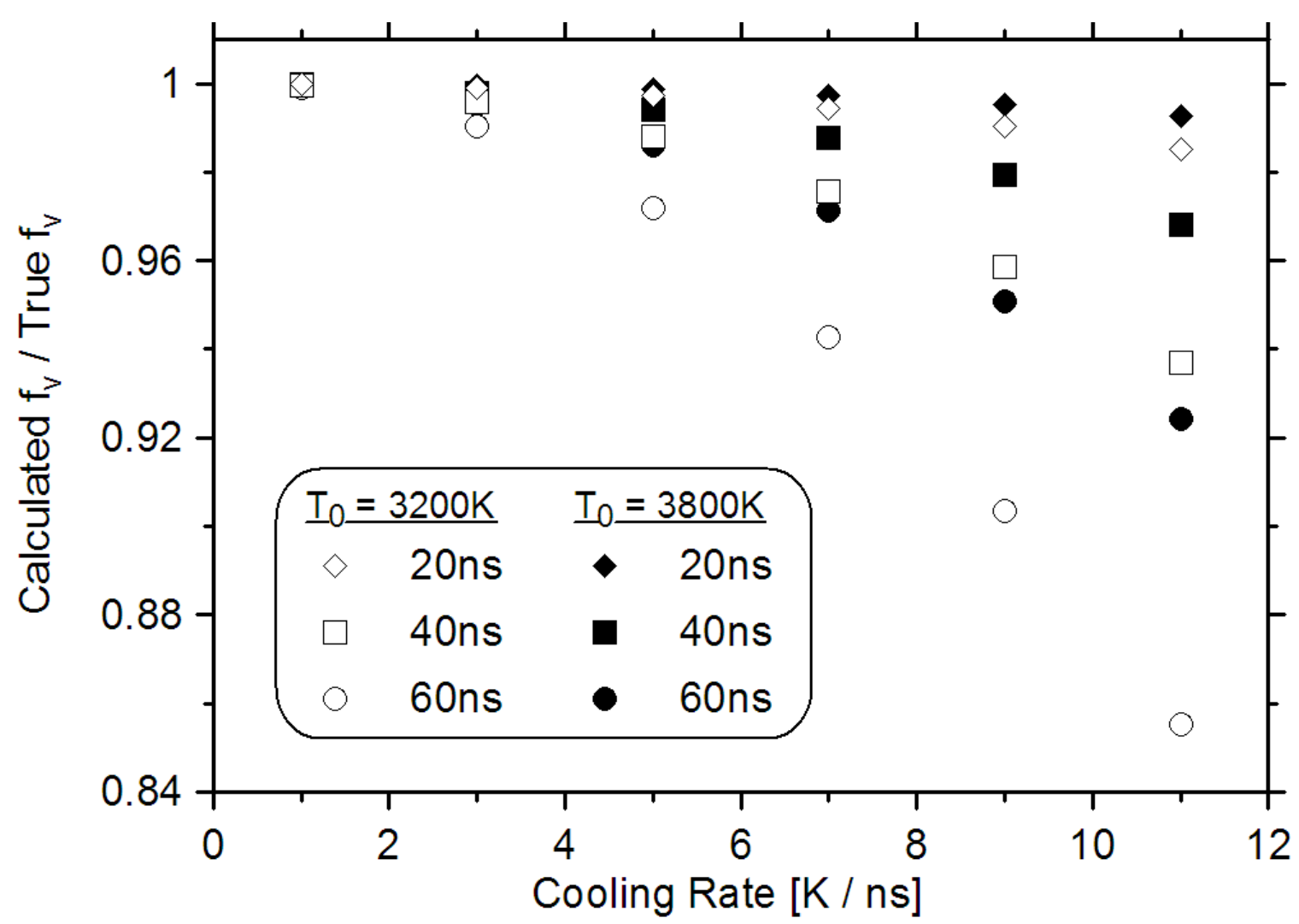

Figure 2.5 - The non-zero gate width bias error for the current measurement system as a function of cooling rate, heated soot temperature and ICCD gate width.

Another bias error is introduced via the absorption of the soot incandescence signal by soot located between the measurement volume and the detector, an effect known as signal trapping. Though corrections for signal trapping exist based on Bouguer's law, they all require knowledge of the soot concentration between the measurement volume and the detector. Since this information would not be available for instantaneous measurements of an unsteady flame, it is treated as an unknown bias uncertainty. Since lower wavelengths are preferentially absorbed, the heated soot temperature inferred via pyrometry will be underestimated, often resulting in the overestimation of soot volume fraction (Liu et al., 2008; Daun et al., 2008; Migliorini et al., 2006). Recent work by Liu et al. (2008) indicates that the underestimation of the 
temperature combined with the decreased signal intensity causes overestimation of soot volume fraction by $17 \%$ or less for the flame studied here. As with the underestimation due to the non-zero gate width bias error, this is a limit on the maximum expected error and is not considered to be significant to the overall uncertainty.

\subsubsection{Uncertainties of Instantaneous and Mean $f_{v}$ Measurements Using 2D-AC-LII}

A summary of the probability distributions used in the random sampling of variables for the Monte-Carlo analysis is provided in Table 2.1. The final measurement uncertainty at each location in the flame was determined via analysis of the soot volume fraction histograms produced by the Monte-Carlo simulation. To distinguish between the total measurement uncertainty (i.e. including uncertainties in soot properties common to all similar optical techniques) and the uncertainty specific to the diagnostic (i.e. the uncertainty that would be apparent in comparative measurements using the same diagnostic), Monte-Carlo simulations were performed under two distinct sets of conditions. During the first Monte-Carlo simulation all the terms in (2.2) were allowed to vary, producing histograms of soot volume fraction that incorporate the total measurement uncertainty. During the second Monte-Carlo simulation only those terms that vary from one single instantaneous measurement to the next were allowed to change. Thus terms which are imprecisely known from the literature such as the thermal accommodation coefficient and the soot absorption function were fixed at nominal values. This produces histograms incorporating only the error terms which are present when comparing one instantaneous 
measurement to another, referred to here as the comparative error. Example normalized histograms of measured soot volume fraction, taking into account the total error and the comparative error, are shown in Figure 2.6 and Figure 2.7 for a strongly- and weakly-sooting region of the flame respectively.

Table 2.1 - Summary of distributions used as inputs for the Monte Carlo simulation.

\begin{tabular}{|c|c|c|c|c|}
\hline Variable & Distribution & \multicolumn{2}{|l|}{ Parameters } & Units \\
\hline \multicolumn{5}{|c|}{ Variables used in (2.1) and (2.2) } \\
\hline$R_{\mathrm{s}}\left(\lambda_{1}\right)$ & Normal & $\mu=182$ & $\sigma=2.7$ & $\mathrm{~W} /\left(\mathrm{cm}^{2}-\mathrm{nm}\right)$ \\
\hline$R_{S}\left(\lambda_{2}\right)$ & Normal & $\mu=974$ & $\sigma=8.3$ & $\mathrm{~W} /\left(\mathrm{cm}^{2}-\mathrm{nm}\right)$ \\
\hline$\Omega(\lambda)$ & $\begin{array}{l}1^{\text {st }} \text { order } \\
\text { negligible }\end{array}$ & -- & --- & --- \\
\hline$I_{\text {lamp, } 1}$ & Normal & $\mu=1061$ & $\sigma=2.8$ & ADU \\
\hline$I_{\text {lamp, } 2}$ & Normal & $\mu=1233$ & $\sigma=4.5$ & ADU \\
\hline$D_{\text {lamp }, 1}$ & Negligible & --- & --- & --- \\
\hline$D_{\text {lamp, } 2}$ & Negligible & --- & --- & |--- \\
\hline$I_{1}$ & Normal & Measured & $f$ (gain) & ADU \\
\hline$I_{2}$ & Normal & Measured & $f$ (gain) & ADU \\
\hline$B_{1}$ & Negligible & --- & --- & --- \\
\hline$B_{2}$ & Negligible & --- & --- & --- \\
\hline$E(m)_{1}$ & Normal & $\mu=0.32$ & $\sigma=0.023$ & --- \\
\hline$\varphi$ & Normal & $\mu=0.99$ & $\sigma=0.056$ & --- \\
\hline$\omega_{e}$ & Custom & \multicolumn{2}{|c|}{$\begin{array}{l}E(m)_{1}, E(m)_{2}, \alpha, \\
d_{p}, \mathrm{~F}_{\mathrm{L}}\end{array}$} & $\mathrm{mm}$ \\
\hline \multicolumn{5}{|c|}{ Variables specific to the equivalent sheet width calculation } \\
\hline$F_{L}$ & Uniform & Min 1.0 & Max 1.6 & $\mathrm{~mJ} / \mathrm{mm}^{2}$ \\
\hline$d_{p}$ & Uniform & $\mu=15$ & $\sigma=40$ & $\mathrm{~nm}$ \\
\hline$\alpha$ & Uniform & $\mu=0.20$ & $\sigma=0.50$ & --- \\
\hline
\end{tabular}




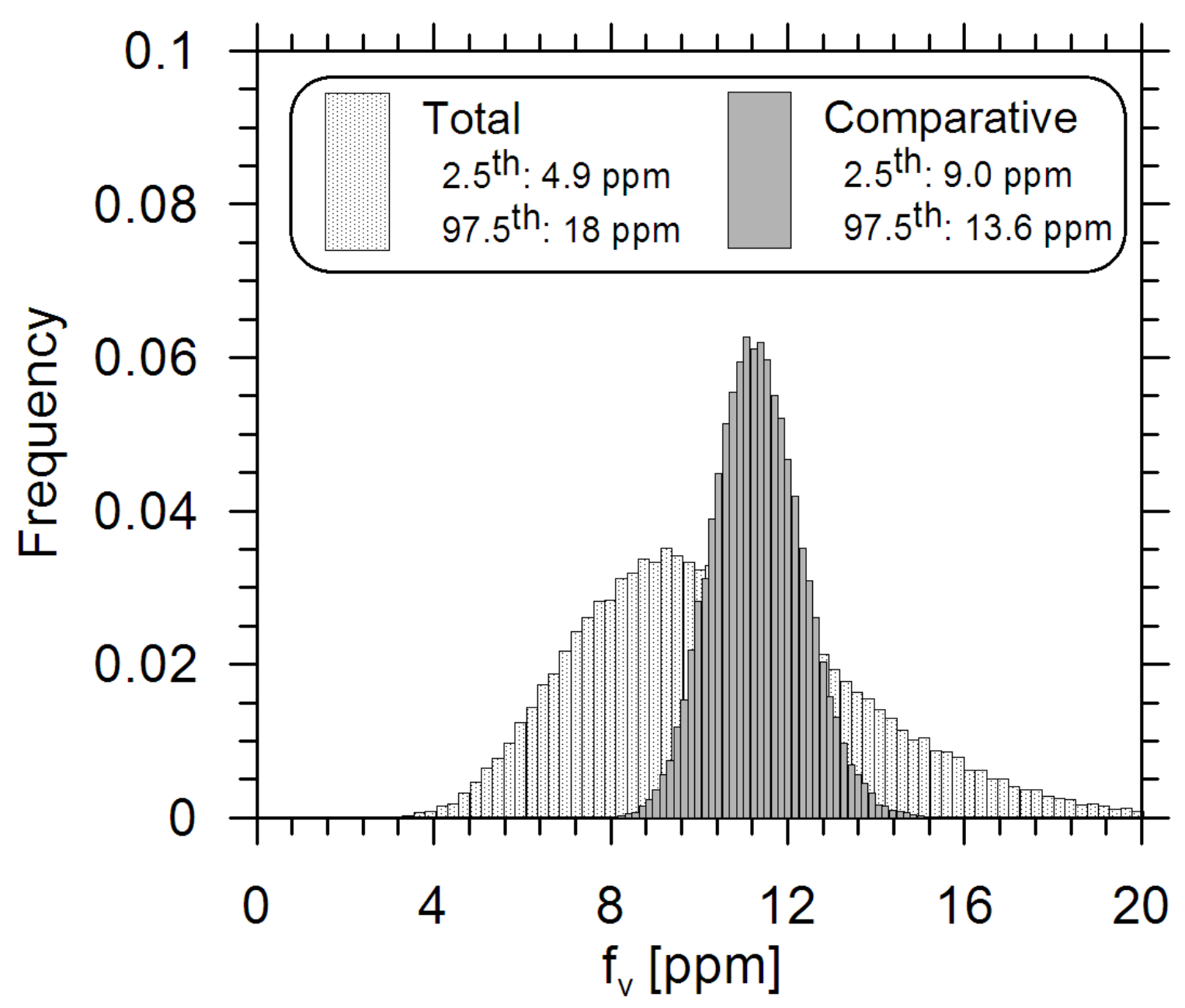

Figure 2.6 - Histograms of soot volume fraction in a strongly-sooting region.

As expected, the uncertainty distributions are narrower when comparing two measurements with the 2D-AC-LII diagnostic than when considering the absolute magnitudes of the soot volume fraction. Also evident in Figure 2.6 and Figure 2.7 is the slight asymmetry of the uncertainty distributions themselves. The lower and upper limits of a 95\% confidence interval are the 2.5 and 97.5 percentile of the calculated soot volume fractions distribution. Because the distribution is asymmetric, these limits are not equidistant from the mean soot volume fraction. For this reason the half-width relative to the mean (relative uncertainty) must be calculated separately for both the upper and lower limits of 
the confidence interval as is done in Figure 2.8, which shows data for an instantaneous 2D planar measurement of the soot volume fraction within an ethylene-air co-flow diffusion flame.

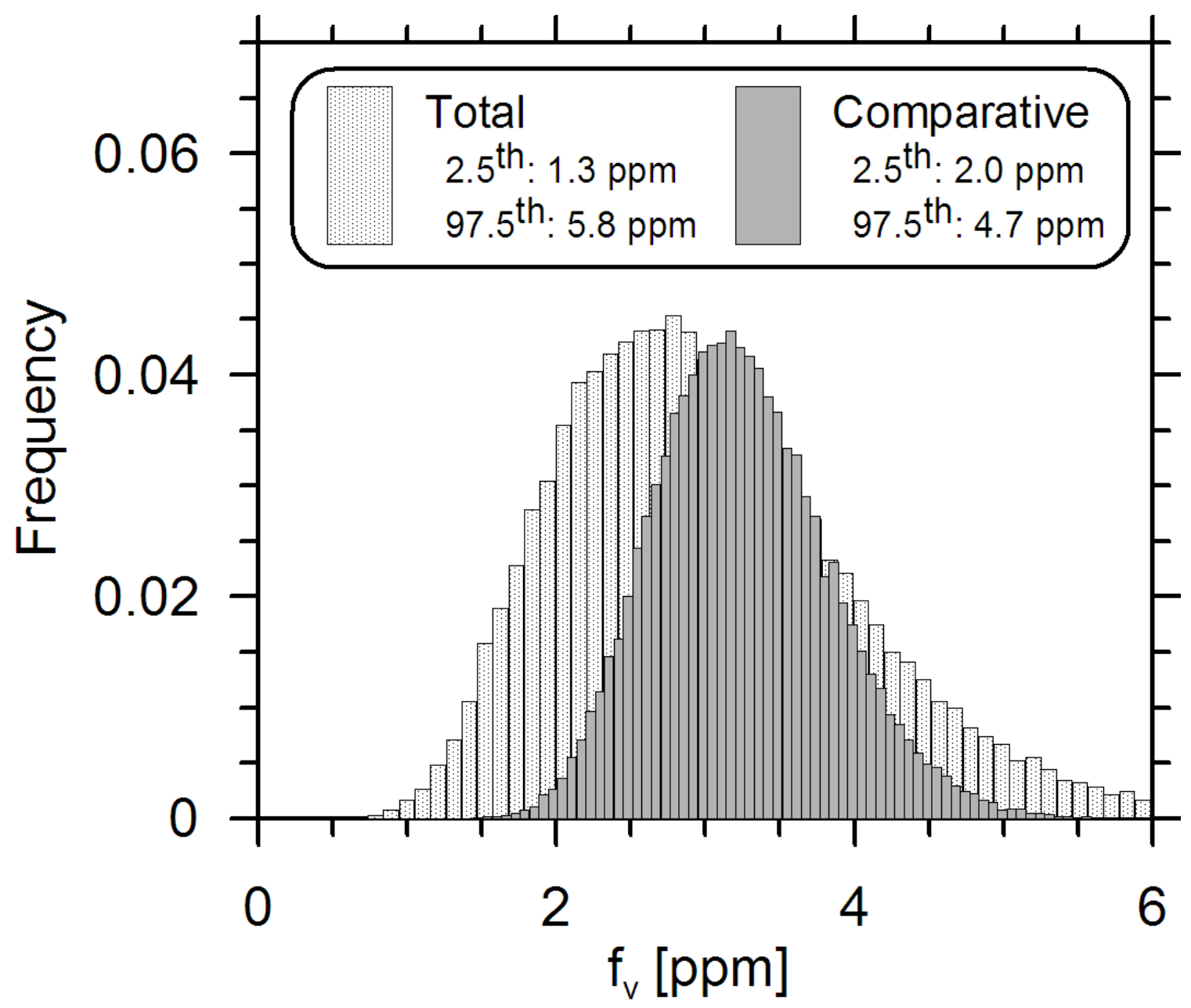

Figure 2.7 - Histograms of soot volume fraction in a weakly-sooting region.

The total uncertainty is significantly greater than the comparative uncertainty through much of the flame. The uncertainty for a comparative measurement (Figure 2.8d,e) falls to a minimum where the measured signal is at its maximum, indicating that it is dominated by signal-to-noise associated with photon shot-noise. By contrast, the uncertainty for an absolute measurement (Figure 2.8b,c) varies less spatially, does not show a clear minimum at the region 
of maximum soot volume fraction, and has a larger contour of minimum uncertainty. This indicates that the dominant uncertainty in an absolute measurement of the soot volume fraction is a state variable (e.g. optical properties of soot, laser sheet width or the equipment optical arrangement).
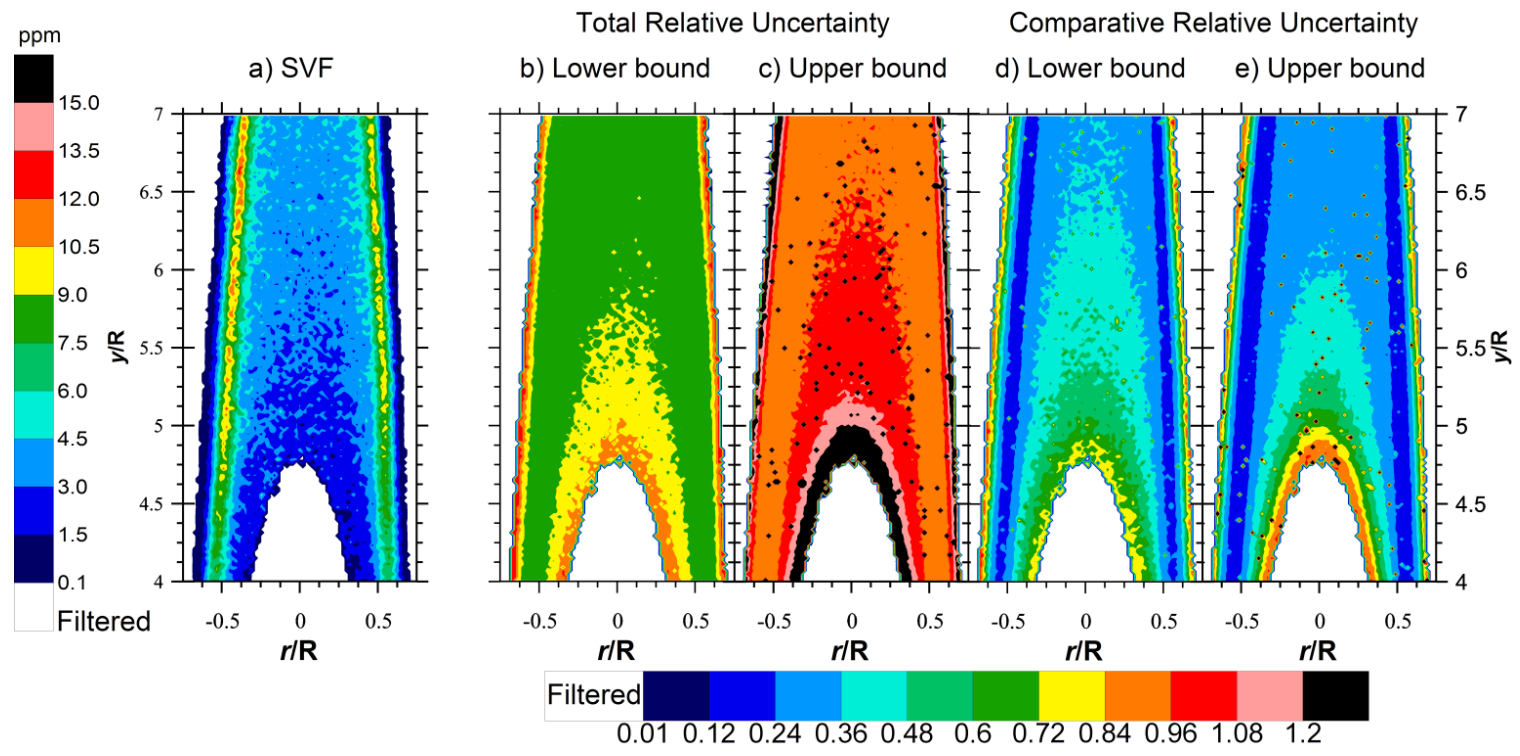

Figure 2.8 - An instantaneous 2D-planar measurement of the soot volume fraction (in parts per million, $\mathbf{p p m}$ ) (a), as well as the upper and lower bounds of the $95 \%$ confidence intervals for the total uncertainty $[(b)$ and $(c)]$ and the comparative uncertainty $[(d)$ and $(e)]$.

Although Figure 2.9 shows that the shot noise uncertainty can be reduced with increased pixel binning, the effect is much stronger for a comparative than an absolute measurement, further confirming the importance of a state variable in determining the overall uncertainty. The uncertainty in a comparative measurement drops roughly as $\mathrm{N}^{-1 / 2}$, where $\mathrm{N}$ is the number of pixels binned. Binning pixels into regions larger than $5 \times 5$ has no apparent benefit in reducing the overall uncertainty. 


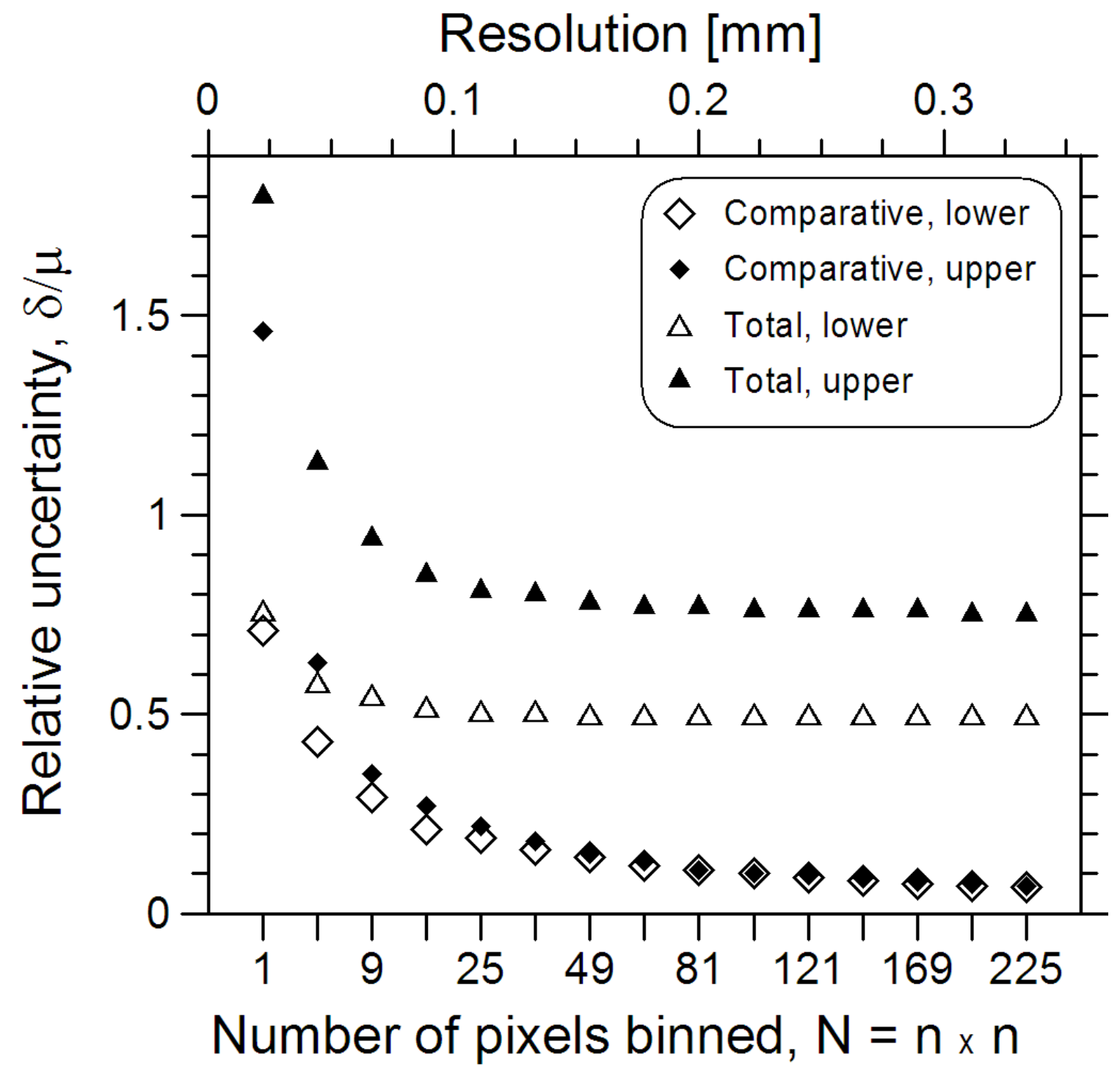

Figure 2.9 - The relative uncertainty as a function of pixel bin size for square bins.

The sensitivity of the soot volume fraction to each of the variables in Equation (2.2) can be shown as a scatter plot comparing the computed soot volume fractions and a variable of choice. This was done for all of the variables included in the Monte-Carlo analysis to assess the relative influence of each in determining the comparative and total uncertainties. An example plot relating the computed soot volume fraction to the intensity of the LII signal measured by channel $2\left(I_{2}\right)$ for a sample location in the flame $(r / R=-0.39, y / R=6.35)$ is 
shown in Figure 2.10. In this case, a weak correlation is observed between the total uncertainty in SVF and the uncertainty in $I_{2}$, while strong correlation is observed for the comparative uncertainty. This indicates the influence of the uncertainty in $I_{2}$ in each of the measures.

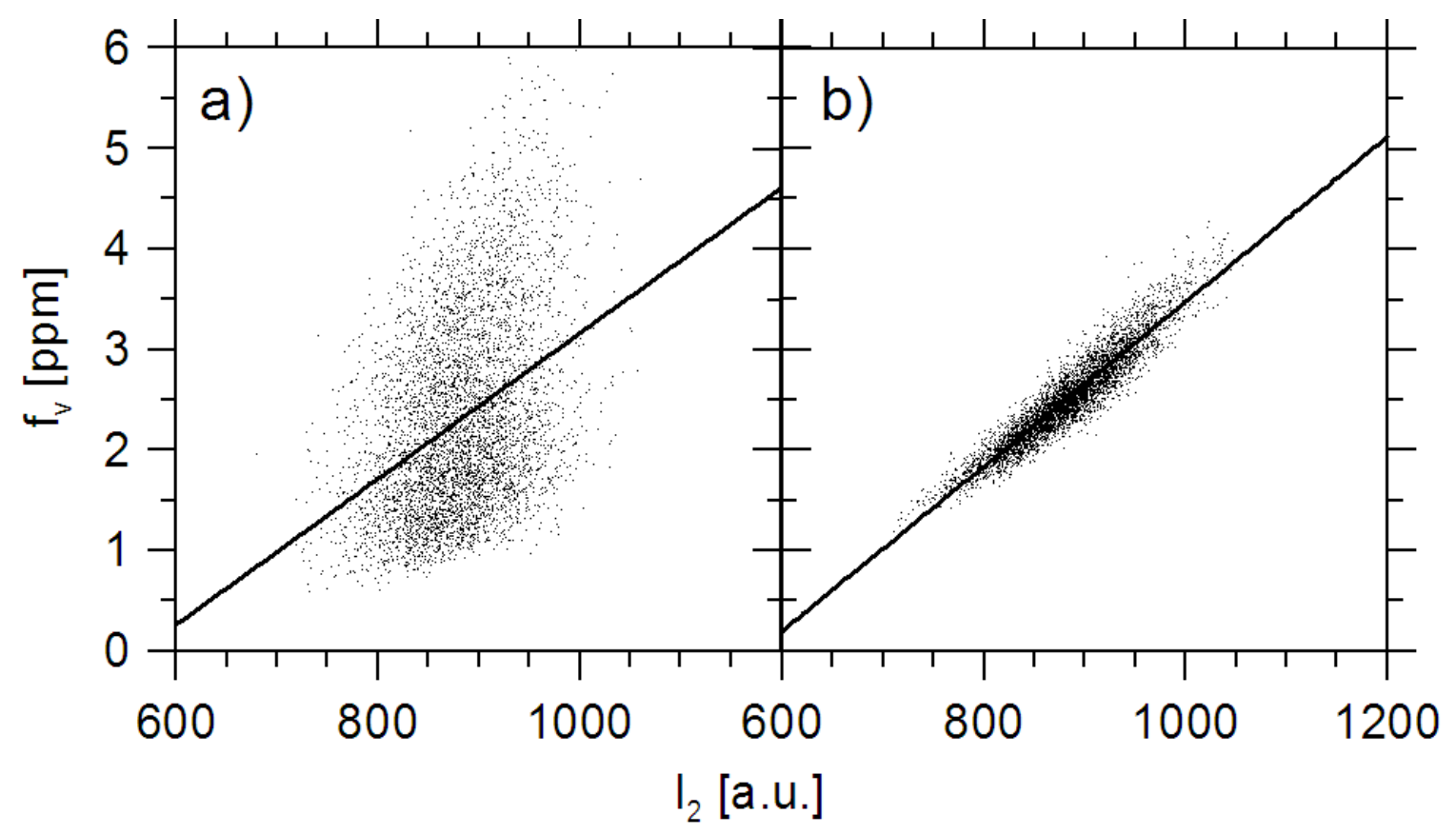

Figure 2.10 - Example scatter plots from the Monte-Carlo analysis showing the influence of the measured signal $\left(I_{2}\right)$ in determining the a) total uncertainty, and b) comparative uncertainty in measured soot volume fraction. Plotted lines are linear least-squares fit to indicate the strength of the correlation.

To permit comparison among the different input variables, the slope of each linear least-squares fit line was multiplied by the standard deviation of the variable in question. For example, if $I_{1}$ were to increase by one standard deviation, the resultant soot volume fraction would decrease by $0.25 \mathrm{ppm}$. If $I_{2}$ were to increase by one standard deviation, the resultant soot volume fraction would increase by $0.7 \mathrm{ppm}$. Table 2.2 shows these sensitivities for two sample locations in the flame. Intermediary results such as $w_{e}$ and $T_{p}$ are included at the 
bottom of the table. Variables that were considered negligible (see Table 2.1 for a summary) were not included in Table 2.2.

Table 2.2 - Sensitivity of soot volume fraction ( $\mathrm{ppm}$ per standard deviation of variable in question). The high soot data is at $r / R=-0.39, y / R=6.35$, the low soot data $r / R=0, y / R=6.35$.

\begin{tabular}{|l|l|l|l|l|}
\hline Variable & Total & \multicolumn{2}{l|}{ Comparative } \\
\hline & High soot & Low soot & High soot & Low soot \\
\hline$f_{v}$ & $10.2 \mathrm{ppm}$ & $2.9 \mathrm{ppm}$ & $10.2 \mathrm{ppm}$ & $2.9 \mathrm{ppm}$ \\
\hline \multicolumn{5}{|l|}{ Monte-Carlo input variables } \\
\hline$R s(\lambda 1)$ & -0.30 & -0.09 & --- & --- \\
\hline$R_{S}\left(\lambda_{2}\right)$ & 0.26 & 0.08 & --- & --- \\
\hline$I_{\text {lamp, } 1}$ & 0.02 & $\sim 0$ & --- & --- \\
\hline$I_{\text {lamp, } 2}$ & -0.04 & $\sim 0$ & --- & --- \\
\hline$I_{1}$ & -0.10 & -0.06 & -0.11 & -0.06 \\
\hline$I_{2}$ & 0.29 & 0.17 & 0.32 & 0.18 \\
\hline$E(m)_{1}$ & -0.47 & -0.14 & --- & --- \\
\hline$\varphi=\frac{E(m)_{1}}{E(m)_{2}}$ & 2.54 & 0.733 & --- & --- \\
\hline Intermediate results derived using the above input variables \\
\hline$w_{e}$ & -2.37 & -0.67 & --- & --- \\
\hline$T_{p}$ & -2.52 & -0.73 & -0.30 & -0.19 \\
\hline$\eta_{1}$ & 0.30 & 0.09 & --- & --- \\
\hline$\eta_{2}$ & -0.27 & -0.08 & --- & --- \\
\hline
\end{tabular}

Results of the sensitivity analysis demonstrate that the total uncertainty is dominated by the uncertainty in the soot absorption function. This uncertainty strongly influences the intermediary calculations of equivalent width and equivalent soot temperature, which ultimately influence the measured soot volume fraction. Decreasing the photon shot noise via increased pixel binning would have little effect on the total uncertainty, both in strongly- and weaklysooting regions since the $I_{1}$ and $I_{2}$ sensitivities are negligible compared to the $\varphi$ sensitivity. The comparative uncertainty results indicate that increased signal on measurement channel 2, perhaps via a change in the filter bandwidth, would 
decrease the comparative uncertainty in both strongly- and weakly-sooting regions.

The large total uncertainty and the strong dependence of soot volume fraction on soot optical properties are consistent with observations made previously in the literature for single point LII measurements. In Snelling et al. (2002), soot volume fraction results were plotted for a range of possible $E(m)$ slopes and it was found that soot volume fraction varied from $-30 \%$ to $65 \%$ as the slope of $E(m)$ was varied over a realistic range. De Iuliis et al. (2005) noted the influence of $E(m)_{\lambda}$ in their data interpretation and inconsistencies between optimal choice for $E(m)_{\lambda}$ in LII and extinction measurements and suggested the need for a follow up investigation. Liu et al. (2009) presented a formalized analysis of the sensitivity of soot temperature and concentration from autocompensating LII and noted a strong dependence of soot volume fraction on $E(m)_{1}$ and $E(m)_{2}$. We can therefore only reiterate that accurate determination of the variation of the soot absorption function with wavelength is critical to the accuracy of auto-compensating LII. However, the comparative uncertainty analysis, which is the important uncertainty in experiments designed to measure and observe responses to controlled variation of input parameters, suggests the current implementation of 2D-AC-LII could be a valuable tool for understanding instantaneous soot formation in turbulent or time-varying flames. Furthermore, in situations amenable to ensemble averaging such as synchronized instantaneous realizations of in-cylinder reactions or of an acoustically forced flame, the comparative uncertainties could be further reduced via repeated 
measurements. In light of the significant challenges common to all optical diagnostics for measuring soot, the 2D-AC-LII technique is a significant development in the search for quantitative approaches to measuring instantaneous soot volume fractions in more than one dimension.

\subsection{Conclusions}

Instantaneous, 2D measurements of soot volume fraction have been successfully demonstrated in a co-annular ethylene diffusion flame. Measured results were used to perform a Monte Carlo simulation which permitted a comprehensive determination of the total and comparative uncertainty in 2D-AC-LII measurements. The spectral variation of the soot refractive index absorption function, $E(m)_{\lambda}$, dominates the total measurement uncertainty because of its relatively high uncertainty and strong influence on the measured soot volume fraction. The comparative uncertainty, which fixes values of key optical properties and is the relevant uncertainty to consider when comparing between measurements, is strongly dependent on the photon shot noise present in the measured signal at the upper measurement wavelength. The calculation method has been shown to correct for laser sheet attenuation to within experimental uncertainty. With careful attention to experimental parameters and experimental uncertainty, instantaneous auto-compensating measurements of two-dimensional soot volume fraction are capable of providing valuable information about the soot formation process within turbulent flames. 


\subsection{Acknowledgements}

This project was supported as part of a collaborative research program between Helmholtz-DLR / NRC-ICPET and in partnership with Carleton University. The authors would like to thank everyone involved in the collaboration and especially Fengshan Liu, Dave Snelling, Greg Smallwood, and Klaus-Peter Geigle. 


\section{Chapter 3}

\section{Diffuse Surface Calibration of Elastic Light Scattering Detectors}

This chapter has been peer-reviewed and was published in Applied Physics B on February 27, 2013. It should be cited as:

Crosland, BM, MR Johnson, and KA Thomson (2013) Diffuse surface calibration method to improve accuracy and dynamic range of aerosol elastic light scattering measurements, Applied Physics B, 110(3):315320. doi: 10.1007/s00340-013-5357-x.

This paper was co-authored by the thesis author, Brian Crosland, and his Ph.D. supervisors Prof. Matthew Johnson and Dr. Kevin Thomson. Mr. Crosland setup, tested, and characterized the measurement equipment; performed the measurements, uncertainty analysis, and initial data analysis; and wrote a first draft of the manuscript. The theory development, final data analysis, and editing and revision of the manuscript were conducted jointly.

\subsection{Abstract}

A new method to calibrate detectors for elastic light scattering (ELS) measurement based on diffuse scattering from a Lambertian surface is presented. The method produces a calibration signal that is approximately seven orders of magnitude larger than a propane gas Rayleigh scattering calibration. The method also allows for calibration of detectors such as photodiodes, which are not sensitive enough to detect Rayleigh scattering for calibration, which possess characteristics desirable for the measurement of soot ELS. Since the method is only suitable for backward scattering calibrations, transfer of calibration data 
from a backward- to a forward-oriented detector is accomplished with a secondary laser and integrating sphere. In demonstration experiments, calibration constants for photomultiplier tube (PMT) detectors obtained using both Rayleigh scattering and diffuse surface scattering agreed within experimental uncertainties as did measurements of in-flame scattering coefficients obtained with PMTs and photodiodes. However, achievable uncertainties with the diffuse-surface calibration approach were significantly reduced. More importantly, by enabling the use of photodiode detectors in elastic light scattering measurements, the new method facilitates operation at higher photon fluxes, resulting in improved signal to noise ratios, reduced influence of photon shot noise, and the ability to achieve higher dynamic range in transient measurements. 


\subsection{Introduction: Calibration of Scattering Measurements}

Elastic light scattering has been used to characterize soot for more than three decades (e.g., Sorensen, 2001; Jones, 2006 and references therein). Absolute detector calibration for elastic light scattering typically involves measuring the scattered signal from a population of scattering particles or molecules with a known scattering cross-section (Sutton \& Driscoll 2004). This nearly universally leads to calibration methods using pure gases such as nitrogen (Sorensen et al., 1992a; Yang \& Köylü, 2005b) or hydrocarbons (Sorensen et al., 1992a; Yang \& Köylü, 2005b; Santoro \& Semerjian, 1983; Snelling et al., 2011), where background signal correction is obtained from corresponding measurements using helium (whose scattering cross-section is negligible). Since gas molecules scatter in the Rayleigh regime, their use for calibration has the distinct advantages that the scattering signal is independent of scattering angle and the scattering cross-sections of pure gases are reasonably well-known. However, the very small scattering cross-section of gas molecules has the significant disadvantage of necessitating the use of very sensitive detectors during calibration, usually photomultiplier tubes (PMTs). Because the ultimate measurement target of aerosolized soot particles has an effective scattering crosssection that is orders of magnitude greater than the gases used during calibration, significant filtering (often $10^{-4}$ or darker) is required during actual measurements to prevent detector saturation. Thus, despite the availability of photons, the system must be purposely operated in a much lower photon range where issues of low-signal to noise ratios and/or shot noise can be significant. 
The use of Rayleigh scattering from gases for absolute detector calibration introduces four sources of uncertainty: i) non-negligible background interferences due to ambient scattering during gas calibration, ii) bias error due to possible change in detector gain and/or the use of filters to attenuate signals during subsequent measurements post-calibration, iii) photon shot-noise associated with the small number of photons that will be scattered by a calibration gas in a typical combustion-related elastic light scattering apparatus and iv) the uncertainty in the scattering cross-section of the calibration gas. By contrast, a calibration method that produced a quantity of photons equal to or moderately exceeding that seen during post-calibration measurements could allow PMTs to be replaced by less sensitive detectors capable of collecting more photons before saturation, alleviating the need for optical filtering and reducing photon shot noise during both calibration and measurements. Eliminating the need for PMTs for signal detection would also allow detection at longer wavelengths beyond typical PMT operating ranges within the UV and visible spectra. This latter benefit could be particularly advantageous if scattering measurements were to be combined with another diagnostic such as laserinduced incandescence for which excitation at longer wavelengths is preferred to avoid inducing fluorescence signals.

This paper introduces an absolute calibration method for elastic light scattering measurements that is based on the known scattering properties of a Lambertian (diffuse) surface. The new method specifically avoids issues associated with Rayleigh scattering-based calibration using gases, and enables 
calibration of less-sensitive detectors that are better suited to soot scattering both in terms of the sources of error noted above and the potential for detection at longer wavelengths. Experimental data are presented which quantitatively compare uncertainties and sensitivities using Rayleigh- and diffuse-scattering calibrations with PMT detectors, and using diode-based detectors enabled by the diffuse-scattering calibration approach. While the new method is restricted to backward scattering angles greater than about $120^{\circ}$, it is possible to transfer a backward scattering calibration to forward-scattering detectors using a secondary light source attached to an integrating sphere as described below. The reduction of photon shot noise is particularly important for instantaneous measurements of scattering, such as measurements of scattering by soot aggregates in unsteady or turbulent flames where single-shot measurements are desired (Crosland, Thomson, et al., 2013).

\subsection{Calibration Theory and Experimental Methodology}

\subsubsection{Rayleigh Scattering Calibration}

The measured voltage at the PMT output $(\Delta \varphi)$ can be expressed as the product of the calibration constant of the optical system including the PMT multiplied by the light collected by the optical system:

$$
\Delta \varphi=\eta E
$$

where $\eta$ is the optical calibration constant $[\mathrm{V} / \mathrm{J}]$ and $E[\mathrm{~J}]$ is the energy collected by the optics. During a calibration using Rayleigh scattering from a gas, the energy seen by the optics can be expressed as: 


$$
E=R_{i} \frac{\sigma_{s} N_{A} c}{4 \pi} \Omega_{\operatorname{det}}(z) V_{m r}
$$

where $R_{i}\left[\mathrm{~J} / \mathrm{m}^{2}\right]$ is the laser irradiance incident on the scattering gas particles located in the measurement region; $\sigma_{s}\left[\mathrm{~m}^{2}\right]$ is the known scattering cross-section of the scattering gas (Sutton \& Driscoll 2004); $N_{A}\left[\mathrm{~mol}^{-1}\right]$ is Avogadro's number; $c$ $\left[\mathrm{mol} / \mathrm{m}^{3}\right]$ is the molar concentration of the scattering gas; $\Omega_{\text {det }}[\mathrm{sr}]$ is the solid angle of detection (which can be assumed to be independent of the scattering gas particle location if the measurement region is small compared to the distance between the measurement region and the detector); and $V_{m r}\left[\mathrm{~m}^{3}\right]$ is the volume of the measurement region. Equation (3.2) can be rearranged to define an experimental calibration constant $\left(C_{R}\right.$ in the case of calibration via Rayleigh scattering of a known gas), by grouping properties that do not change between calibration and experimental measurement $\left(\eta, R_{i}, \Omega_{d e t}, V_{m r}\right)$ as a function of the signal measured during calibration $\left(\Delta \varphi_{c a l}\right)$, Avogadro's number, and gas properties $\left(N_{A}, \sigma_{s}, c\right)$ :

$$
\eta R_{i} \Omega_{d e t} V_{m r}=C_{R}=\frac{\Delta \varphi_{\mathrm{cal}}}{\frac{\sigma_{S} N_{A} c}{4 \pi}}
$$

During subsequent experiments using the calibrated detector, the measured scattering coefficient, $K_{v v}\left(\theta_{\text {exp }}\right)$, is determined via Equation (3.4) which includes an additional correction for any change in the total transmissivity due to neutral density filters $\left(D_{\text {filt }}\right)$ that are added or removed between calibration and experimental measurement: 


$$
K_{v v}\left(\theta_{\text {exp }}\right)=\frac{\Delta \varphi_{\text {exp }}}{D_{\text {filt }} C_{R}}
$$

where $\Delta \varphi_{\text {exp }}$ is the voltage measured in the flame due to soot scattering. Note that $D_{\text {filt }}$ can be less than or greater than 1 depending on whether filters were added (as with Rayleigh scattering calibration) or removed (as with diffuse surface calibration) for experimental measurement. The total uncertainty in the scattering coefficient is thus a combination of the uncertainties in the measured signal, the calibration constant $\left(C_{R}\right)$, and the transmissivity of the changed filters.

\subsubsection{Diffuse Surface Scattering Calibration}

For absolute detector calibration using a diffuse surface, the reference sample of known scatterers (gas molecules) is replaced with a Lambertian surface. When calibrating using gas molecules, the attenuation of the laser beam due to scattering and absorption as the laser propagates through the measurement volume is generally negligible due to the small cross-sections of gas molecules, allowing the entire measurement region to be calibrated with every laser pulse. By contrast, when calibrating using a diffuse scattering surface, there is no transmission through the surface (i.e. the combined reflectance and absorption of the surface is unity), so that it is only possible to calibrate a single plane of the measurement volume at a time. Calibration of the measurement volume is thus accomplished by traversing the diffuse scattering surface along the laser axis $(z-$ axis) through the measurement volume to collect data from an array of scatter planes. The calibration of the entire measurement volume can then be represented using the integral of the measured signal: 


$$
\int_{z} \Delta \varphi_{c a l}(z) d z=\eta_{D} \int_{z} E_{D} d z
$$

where the energy collected by the optics during the diffuse-surface scattering calibration at a single plane is $E_{D} ; \eta_{D}$ is the optical calibration constant $[\mathrm{V} / \mathrm{J}]$. The subscript $D$ is used to distinguish the collected energy and calibration constant obtained via diffuse surface scattering from those obtained via Rayleigh scattering. If the diffuse surface is treated as a Lambertian scatterer, then the scattered energy can be described as:

$$
E_{D}=R_{i} r_{S} \frac{(1-\rho) \cos [\beta(z)]}{\pi} \Omega_{d e t}(z) A(z)
$$

where $R_{i}$ is the irradiance of the incident laser beam; $r_{s}[-]$ is the total reflectivity of the diffuse surface; $\beta(z)$ [rad] is the angle between the diffuse surface normal and the direction of detection; $A(z)$ is the irradiated area on the diffuse surface that is visible to the detection optics; and $\rho[-]$ is the depolarization ratio of the diffuse material, here defined as the ratio of depolarized scattered light to total scattered light. Both $\beta$ and $\Omega_{\text {det }}$ can be assumed to be independent of $z$ when the length of the measurement volume (in the $z$-direction) is small compared to the distance between the measurement volume and the detector. The diffuse surface used in the current work is a $51 \mathrm{~mm}$ diameter by $6.4 \mathrm{~mm}$ thick piece of Spectralon Reflectance Material (SphereOptics Hoffman LLC, Contocook, NH), which has a total reflectance of 0.99 at $532 \mathrm{~nm}$. The depolarization ratio is a function of the scattering material, scattering angle, and the laser wavelength, and was found to be 0.48 by comparing signals measured with a polarizing filter first in the vertical 
and then the horizontal position. Combining Equation (3.5) and Equation (3.6) again allows an experimental calibration constant to be defined ( $C_{D}$ in this case) that collects invariant terms between calibration and experiment $\left(\eta_{D}, R_{i}, \Omega_{d e t}, V_{m r}\right)$ and expresses them as a function of the signal measured during calibration and known properties of the surface $\left(r_{s}, \beta, \rho\right)$ :

$$
\eta_{D} R_{i} \Omega_{d e t} V_{m r}=C_{D}=\frac{\int \Delta \varphi_{\text {meas }}(z) d z}{r_{s} \frac{(1-\rho) \cos \beta}{\pi}}
$$

Combining Equation (3.7) with Equation (3.4) similarly enables subsequent experiments to measure the scattering coefficient, $K_{v v}\left(\theta_{\text {exp }}\right)$, while accounting for any neutral density filters $\left(D_{\text {filt }}\right)$ that are added or removed between calibration and experimental measurement.

For an ideal Lambertian scatterer the relation between the scattered signal and angle $\beta$ follows a cosine relationship that is independent of the angle between the incident laser light and the surface normal $(\alpha)$. Tests where both $\beta$ and $\alpha$ were varied simultaneously (through rotation of the diffuse surface about the x-axis) verified a cosine relationship with a maximum at $\beta=0^{\circ}$. Due to the cosine relationship, alignment of the diffuse surface such that $\beta=0 \pm 6^{\circ}$ ensured a bias error of less than $1 \%$.

While an ideal Lambertian surface exhibits scattering that is independent of the angle between the surface normal and the incident light, real surfaces have a weak dependence on the incident light angle that can become stronger as the incident light angle becomes large. For this reason it is impractical to calibrate 
small $\theta$ (forward) angle scattering detectors using the diffuse surface method. Instead, the diffuse surface calibration constant obtained for the backward scattering detector can be transferred to the forward scattering detector. For the validation experiments presented below, this was accomplished using a $100 \mathrm{~mm}$ diameter integrating sphere (SMS-500, SphereOptics Hoffman LLC, Contocook, NH) illuminated by a small CW Nd:YAG laser (Crystalaser GCL532-075-L). The sphere output port was mounted along the axis of detection (i.e. axis of the output port coincident with the axis of detection), first facing the backward scattering detector and subsequently facing the forward scattering detector, with the CW laser entering the sphere from the same relative location in each case. Additional figures describing the optical configuration used for the calibration transfer are included in Appendix A. The difference in detector output for the constant integrating sphere input signal provided a means to transfer the calibration constant from the backward scatter detector to the forward scatter detector. The power output of the CW laser was sufficiently weak that no neutral density filtering was required when transferring the calibration from the backward- to the forward-scattering detector.

\subsubsection{Methodology for Validation Experiments}

The experimental setups for both Rayleigh and diffuse surface scattering calibrations are shown in Figure 3.1. A pulsed Nd:YAG laser beam, frequencydoubled to $532 \mathrm{~nm}$, was formed into a small sheet and directed into the measurement volume where it was used for scattering calibration and subsequent in-flame measurements. The laser sheet was $8 \mathrm{~mm}$ tall by $0.45 \mathrm{~mm}$ thick and has a mean fluence of $0.8 \mathrm{~mJ} / \mathrm{mm}^{2}$. The scattered laser light is picked up by 
detection optics mounted at a forward angle of $-30^{\circ}$ and a backward angle of $144^{\circ}$ and carried via fiber to a nearby filtering and detector apparatus. In-flame measurements were made on the centreline of a laminar non-premixed flame at $42 \mathrm{~mm}$ above the burner exit. As described in Crosland et al. (2011), a $10.9 \mathrm{~mm}$ inner diameter central fuel tube flow is surrounded by a co-annular air nozzle of $100 \mathrm{~mm}$ inner diameter. The burner was operated in "Gülder flame" conditions with ethylene as a fuel flowing at $0.24 \mathrm{~g} / \mathrm{min}$ and air co-flowing at $367 \mathrm{~g} / \mathrm{min}$, producing a stable laminar flame with a visible height of approximately $65 \mathrm{~mm}$.

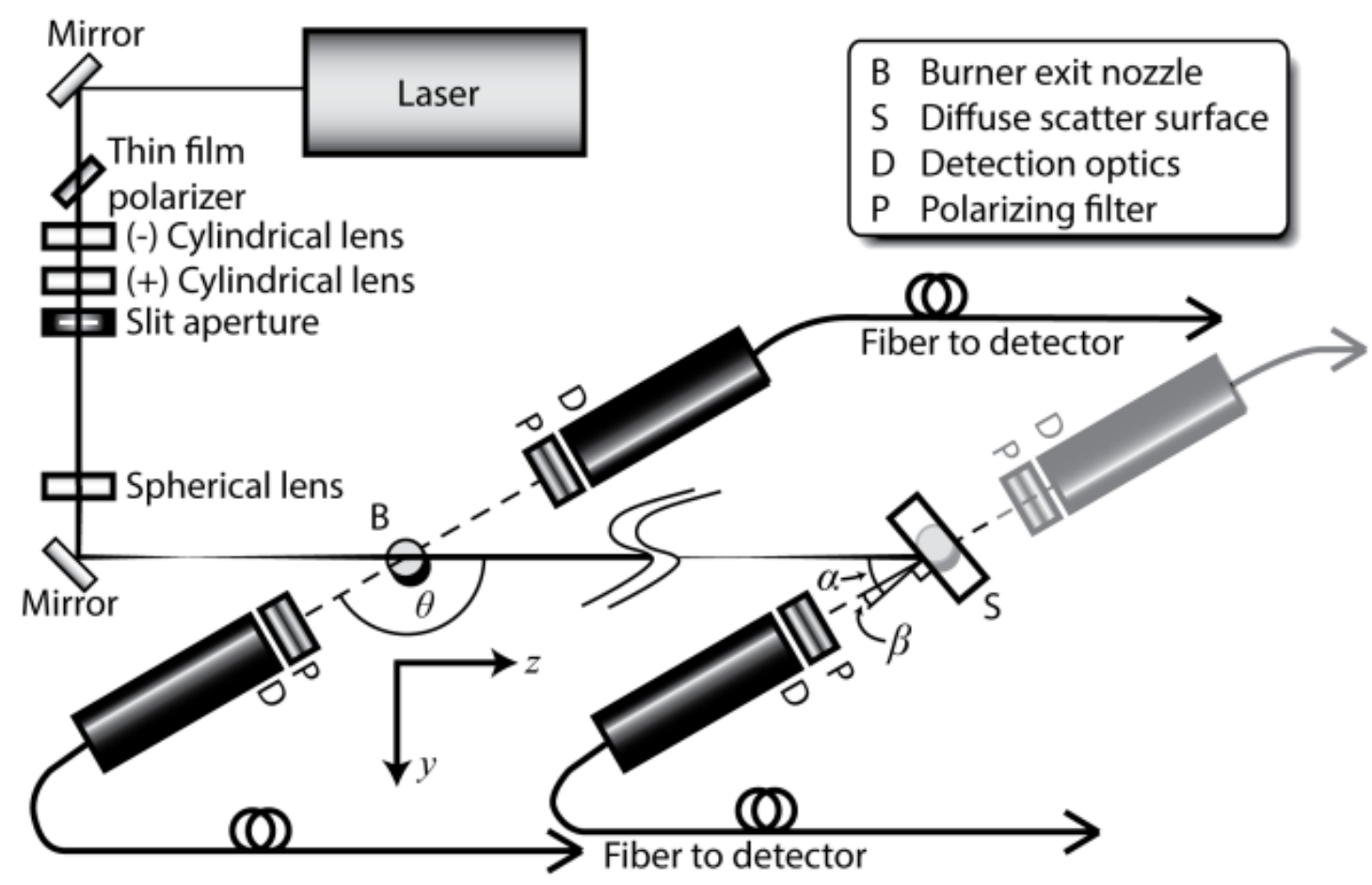

Figure 3.1 - Experimental setup for detection of ELS during Rayleigh and diffuse surface calibration. The diffuse scattering calibration is transferred from the backward scattering optics to the forward scattering optics via an integrating sphere (not shown). 


\subsection{Results}

Table 3.1 presents an overview of the experimental results used to validate the diffuse surface scattering calibration method and quantitatively compare uncertainties with different calibration technique / detector combinations. The experimental uncertainties were calculated based on the elemental sources of error present within the measurement apparatus and propagated using MonteCarlo simulation. To experimentally verify the diffuse surface scattering calibration methodology, a direct comparison was first made between diffusesurface and Rayleigh scattering calibrations of a PMT capturing backscattered light. The effective calibration constants $\left(C^{*} D_{\text {filt }}\right)$, which take into account the different neutral density filters used in the two approaches, agree within experimental uncertainty. However, both the effective $\left(C^{*} D_{\text {filt }}\right)$ and raw $(C)$ calibration constants determined for the PMTs using the diffuse scattering method have much lower uncertainties than the corresponding values determined via Rayleigh calibration, which are higher mostly due to the uncertainty in the scattering cross-section of propane taken from Sutton \& Driscoll (2004), who report a $2 \sigma$ uncertainty of $9 \%$. 
Table 3.1 - Comparison of Rayleigh and diffuse surface calibration techniques and associated magnitudes and uncertainties in instantaneous scattering coefficient measurements using PMT and photodiode detectors.

\begin{tabular}{|c|c|c|c|}
\hline Detector & H5783 PMT & H5783 PMT & $\begin{array}{l}\text { DET-36A } \\
\text { photodiode }\end{array}$ \\
\hline Calibration Method & Rayleigh & Diffuse & Diffuse \\
\hline \multicolumn{4}{|l|}{ Backward Scattering } \\
\hline $\begin{array}{l}\text { Calibration Constant }(2 \sigma) \\
C[\mathrm{~V} \cdot \mathrm{m} / \mathrm{sr}]\end{array}$ & \begin{tabular}{|l|}
$2.1 \times 10^{5}$ \\
$(+10 /-8.5 \%)$ \\
\end{tabular} & $\begin{array}{l}0.18 \\
(+3.2 /-3.0 \%)\end{array}$ & $\begin{array}{l}0.11 \\
(+3.2 /-3.1 \%)\end{array}$ \\
\hline $\begin{array}{l}\text { Effective Calibration Constant } \\
(2 \sigma) \\
C^{*} D_{\text {filt }}^{\dagger}[\mathrm{V} \cdot \mathrm{m} / \mathrm{sr}]\end{array}$ & $\begin{array}{l}18 \\
(+12 /-10 \%)\end{array}$ & $\begin{array}{l}16 \\
(5.9 /-5.7 \%)\end{array}$ & $\begin{array}{l}24 \\
(+5.6 /-5.3 \%)\end{array}$ \\
\hline $\begin{array}{l}\text { Scattering Coefficient } \\
K_{v v}\left(144^{\circ}\right)[1 / \mathrm{m}]\end{array}$ & $\begin{array}{l}0.19 \\
(+17 /-16 \%)\end{array}$ & $\begin{array}{l}0.22 \\
(+14 /-13 \%)\end{array}$ & $\begin{array}{l}0.20 \\
(+8.2 /-7.8 \%)\end{array}$ \\
\hline \multicolumn{4}{|l|}{ Forward Scattering } \\
\hline $\begin{array}{l}\text { Calibration Constant }(2 \sigma) \\
C[\mathrm{~V} \cdot \mathrm{m} / \mathrm{sr}]\end{array}$ & $\begin{array}{l}3.8 \times 10^{5} \\
(+10 /-8.5 \%)\end{array}$ & $\begin{array}{l}0.026 \\
(+4.3 /-4.2 \%)\end{array}$ & $\begin{array}{l}0.035 \\
(+3.5 /-3.4 \%)\end{array}$ \\
\hline $\begin{array}{l}\text { Effective Calibration Constant } \\
(2 \sigma) \\
C^{*} D_{f i l}^{\dagger}[\mathrm{V} \cdot \mathrm{m} / \mathrm{sr}]\end{array}$ & $\begin{array}{l}3.8 \\
(+11 /-9.6 \%)\end{array}$ & $\begin{array}{l}3.4 \\
(+6.2 /-5.9 \%)\end{array}$ & $\begin{array}{l}7.8 \\
(+5.0 /-4.7 \%)\end{array}$ \\
\hline $\begin{array}{l}\text { Scattering Coefficient }{ }^{\ddagger}(2 \sigma) \\
K_{v v}\left(30^{\circ}\right)[1 / \mathrm{m}]\end{array}$ & $\begin{array}{l}0.77 \\
(+18 /-17 \%)\end{array}$ & $\begin{array}{l}0.87 \\
(+16 /-15 \%)\end{array}$ & $\begin{array}{l}0.80 \\
(+6.9 /-6.8 \%)\end{array}$ \\
\hline \multicolumn{4}{|l|}{ Forward vs. Backward } \\
\hline $\begin{array}{l}\text { Dissymmetry ratio }(2 \sigma) \\
\frac{K_{\mathrm{Vv}}\left(30^{\circ}\right)}{\mathrm{K}_{\mathrm{Vv}}\left(144^{\circ}\right)}[1 / \mathrm{m}]\end{array}$ & $\begin{array}{l}4.1 \\
(+21 /-18 \%)\end{array}$ & $\begin{array}{l}4.0 \\
(+20 /-17 \%)\end{array}$ & $\begin{array}{l}4.0 \\
(+6.6 /-6.2 \%)\end{array}$ \\
\hline
\end{tabular}

${ }^{\dagger} D_{\text {filt }}$ is the change is transmissivity due to neutral density filters that are added or removed between calibration and experiment and can be $>$ or $<1$.

* Evaluated on the centreline of co-annular, laminar non-premixed flame (Gülder flame) at $42 \mathrm{~mm}$ above the burner.

Table 3.1 also shows a comparison of the calibration for the forward scattering PMT detector obtained via the two methodologies, where the diffusesurface approach incurs additional uncertainty due to the need to transfer the back scattering calibration to the forward scattering detector via the integrating sphere method described previously. The calibration transfer procedure was performed 10 times and was found to have a $2 \sigma$ uncertainty of $1.5 \%$. As shown in Table 3.1, the effect of this added uncertainty is nearly negligible (forward 
scattering detector calibration uncertainty of $+6.2 /-5.9$ vs. $+5 \cdot 9 /-5 \cdot 7 \%$ for the backward scattering detector), and the diffuse-surface approach still results in a reduced calibration uncertainty relative to the Rayleigh calibration technique $(+6.2 /-5.9 \%$ vs. $+12 /-10 \%$ respectively $)$.

Using the diffuse-surface calibration methodology, comparable calibration uncertainties are realized for the PMT and photodiode detectors, where the latter show slightly reduced uncertainties attributable to the lower amount of filtering required. However, comparison of measured in-flame scattering coefficient data reveals the first significant advantage of the diffuse-surface calibration / photodiode combination.

As apparent in Table 3.1, the measured scattering coefficients obtained using all three calibration method / detector combinations agree within experimental uncertainties. For the PMT detectors, the reduction in measurement uncertainty using the diffuse-surface calibrated PMT is less pronounced due to the influence of three additional error sources present in single-shot measurements: flame stability $(2 \sigma<2 \%)$, shot-to-shot fluctuations in the laser output $(2 \sigma \approx 4 \%)$ and instrument noise $(2 \sigma \approx 12 \%)$. However, the uncertainties in measured scattering coefficient are reduced by more than half when using diffuse-surface-calibrated photodiode detectors vs. Rayleighcalibrated PMTs. This is directly attributable to the reduced influence of shot noise in the photodiodes which are able to operate at higher signal to noise levels with a reduced amount of neutral density filtering. 
The final row of Table 3.1 shows the measured ratio of scattering coefficients at two angles, termed the dissymmetry ratio, which is often used to measure soot aggregate size information (Sorensen et al., 1992a; Yang \& Köylü, 2005b; De Iuliis et al., 1998). Fluctuations in the flame or laser cancel out in a dissymmetry ratio measurement since they linearly influence the measurement on both detectors. In addition, for the diffuse surface calibration methodology, the uncertainty in the target reflectivity cancels so that only the transfer calibration using the integrating sphere affects the measurement. Similarly, for the Rayleigh scattering calibration methodology, the uncertainty on the reference gas constant cancels. Thus, measurements of dissymmetry ratio tend to be dominated by shot noise. For the measurements in the co-flow diffusion flame shown in Table 3.1, the results show good agreement among the three detector/calibration method combinations that is well within experimental uncertainties. There is a slight improvement in the measurement uncertainty when using PMT detectors calibrated using the diffuse surface method instead of the Rayleigh scattering approach. However, because shot noise more directly impacts the PMTs (which even when calibrated using the diffuse-surface methodology must still use significant neutral density filtering to allow the PMT gain to remain high enough to maintain linear response), there is a factor of 3 reduction in uncertainty when using diffuse-surface calibrated photodiode detectors

The current measurements were taken using a steady flame with neutral density filters optimized to produce a maximum signal to noise ratio. However, 
this level of optimization is not generally possible in unsteady flames where it is necessary to make measurements over a large dynamic range to capture transient events. Instead, neutral density filters must be adjusted to attenuate stronger transient signals to avoid detector saturation at the expense of reducing mean signal to noise levels. Table 3.2 shows calculated uncertainties in measured scattering coefficient and dissymmetry ratio considering three measurement scenarios in which the dynamic range of signal fluctuations associated with flame transients is 5,10 or 25 . Higher dynamic range requires stronger neutral density filters such that the effect of shot noise at the correspondingly reduced mean signal levels becomes more pronounced. For the results shown in Table 3.2, the increase in shot noise was quantitatively estimated by analyzing noise characteristics at varying PMT and photodiode signal levels measured during calibration as the diffuse plate was traversed through the measurement volume. The results reveal another significant advantage of the ability to use calibrated photodiodes instead of PMTs. While the uncertainty in scattering coefficients and dissymmetry ratios measured using PMTs goes up a factor of two to three as shot noise becomes more significant and are unacceptably high at dynamic range of 25, uncertainties in the photodiode-based measurements are much lower and increase much more modestly due to the $7 \times 10^{3}$ higher photon flux measured by the photodiodes. Consequently, the photodiodes enable measurements with improved accuracy at higher dynamic range than is possible with PMTs. 
Table 3.2 - Comparison of potential uncertainty limits in measured scattering coefficients and dissymmetry ratios for optics configured to handle dynamic ranges of 5, 10, and 25 in transient signals from unsteady/turbulent flames.

\begin{tabular}{|c|c|c|c|}
\hline Detector & H5783 PMT & H5783 PMT & $\begin{array}{l}\text { DET-36A } \\
\text { photodiode }\end{array}$ \\
\hline Calibration Method & Rayleigh & Diffuse & Diffuse \\
\hline \multicolumn{4}{|l|}{ Dynamic Range of 5} \\
\hline $\begin{array}{l}\text { Scattering coefficient }(2 \sigma) \\
\mathrm{K}_{\mathrm{vv}}\left(144^{\circ}\right)[1 / \mathrm{m}]\end{array}$ & $\begin{array}{l}0.19 \\
(+29 /-27 \%)\end{array}$ & $\begin{array}{l}0.22 \\
(+27 /-26 \%)\end{array}$ & $\begin{array}{l}0.20 \\
( \pm 10 \%)\end{array}$ \\
\hline $\begin{array}{l}\text { Dissymmetry ratio }(2 \sigma) \\
\frac{\mathrm{K}_{\mathrm{vV}}\left(30^{\circ}\right)}{\mathrm{K}_{\mathrm{vv}}\left(144^{\circ}\right)}[1 / \mathrm{m}]\end{array}$ & $\begin{array}{l}4.1 \\
(+47 /-36 \%)\end{array}$ & $\begin{array}{l}4.1 \\
(+46 /-36 \%)\end{array}$ & $\begin{array}{l}4.0 \\
( \pm 10 \%)\end{array}$ \\
\hline \multicolumn{4}{|l|}{ Dynamic Range of 10} \\
\hline $\begin{array}{l}\text { Scattering coefficient }(2 \sigma) \\
\mathrm{K}_{\mathrm{Vv}}\left(144^{\circ}\right)[1 / \mathrm{m}]\end{array}$ & $\begin{array}{l}0.19 \\
(+39 /-37 \%) \\
\end{array}$ & $\begin{array}{l}0.22 \\
(+36 \% /-37 \%) \\
\end{array}$ & $\begin{array}{l}0.20 \\
( \pm 13 \%) \\
\end{array}$ \\
\hline $\begin{array}{l}\text { Dissymmetry ratio }(2 \sigma) \\
\frac{\mathrm{K}_{\mathrm{Vv}}\left(30^{\circ}\right)}{\mathrm{K}_{\mathrm{Vv}}\left(144^{\circ}\right)}[1 / \mathrm{m}] \\
\end{array}$ & $\begin{array}{l}4.2 \\
(+70 /-49 \%)\end{array}$ & $\begin{array}{l}4.2 \\
(+70 \% /-49 \%)\end{array}$ & $\begin{array}{l}4.0 \\
(+16 /-14 \%)\end{array}$ \\
\hline \multicolumn{4}{|l|}{ Dynamic Range of 25} \\
\hline $\begin{array}{l}\text { Scattering coefficient }(2 \sigma) \\
\mathrm{K}_{\mathrm{vv}}\left(144^{\circ}\right)[1 / \mathrm{m}]\end{array}$ & $\begin{array}{l}0.19 \\
(+59 /-57 \%) \\
\end{array}$ & $\begin{array}{l}0.22 \\
(+58 \% /-57 \%)\end{array}$ & $\begin{array}{l}0.20 \\
( \pm 24 \%) \\
\end{array}$ \\
\hline $\begin{array}{l}\text { Dissymmetry ratio }(2 \sigma) \\
\frac{\mathrm{K}_{\mathrm{Vv}}\left(30^{\circ}\right)}{\mathrm{K}_{\mathrm{Vv}}\left(144^{\circ}\right)}[1 / \mathrm{m}]\end{array}$ & $\begin{array}{l}4.5 \\
(+135 /-73 \%) \\
\end{array}$ & $\begin{array}{l}4.5 \\
(+135 \% /-73 \%)\end{array}$ & $\begin{array}{l}4.0 \\
(+36 /-27 \%)\end{array}$ \\
\hline
\end{tabular}

\subsection{Conclusions}

Experiments have shown that the diffuse surface calibration method for absolute calibration of elastic light scattering detectors produces equivalent calibration constants as traditional Rayleigh calibration using a reference gas, but with lower uncertainty. This was further demonstrated through in-flame measurements of scattering coefficients using Rayleigh- and diffuse-surface-calibrated PMT detectors, as well as diffuse-surface-calibrated photodiode detectors. More significantly, by enabling calibration of photodiode detectors for use in elastic light scattering measurements, the new method permits scattering measurements with lower amounts of neutral density filtering, which facilitates operation at higher photon fluxes. As a direct consequence, diffuse-surface-calibration of 
photodiode detectors offers improved signal to noise ratios, reduced influence of photon shot noise, and the ability to achieve higher dynamic range in transient measurements before being limited by shot noise. 


\section{Chapter 4}

\section{Simultaneous Measurement of Soot Volume Fraction, Aggregate Size and Primary Particle Diameter}

This chapter has been peer-reviewed and was published in Applied Physics B on May 31, 2013. It should be cited as:

Crosland, BM, KA Thomson and MR Johnson (2013) Instantaneous in-flame measurement of soot volume fraction, primary particle diameter and aggregate radius of gyration via auto-compensating laser-induced incandescence and two-angle elastic light scattering, Applied Physics B, 112(3):381-393. doi: 10.1007/so0340-013-5539-6.

This paper was co-authored by the thesis author, Brian Crosland, and his Ph.D. supervisors Prof. Matthew Johnson and Dr. Kevin Thomson. Mr. Crosland setup, tested, and characterized the measurement equipment; performed the measurements, uncertainty analysis, and initial data analysis; and wrote a first draft of the manuscript. The theory development, final data analysis, and editing and revision of the manuscript were conducted jointly.

\subsection{Abstract}

A new combination of soot diagnostics employing two-angle elastic light scattering (ELS) and laser-induced incandescence (LII) is described that is capable of producing non-intrusive, instantaneous and simultaneous, in-situ measurements of soot volume fraction, primary particle size, and aggregate radius of gyration within flames. Controlled tests of the new apparatus on a wellcharacterized laminar flame show good agreement with existing measurements in the literature. From a detailed and comprehensive Monte Carlo uncertainty 
analysis of the results, it was found that the uncertainty in all three measured parameters is dominated by knowledge of soot properties and aggregation behavior. The soot volume fraction uncertainty is dominated by uncertainty in the soot refractive index light absorption function; the primary particle diameter uncertainty is dominated by uncertainty in the fractal prefactor; while the uncertainty in the aggregate radius of gyration is dominated by the uncertainty in the width of the distribution of aggregate sizes. 


\subsection{Introduction}

Soot emissions are a known health hazard (US EPA, 2010; Pope III et al., 2002) and recently have been shown to be an important forcing factor for global climate change (IPCC, 2007; Ramanathan \& Carmichael, 2008; Jacobson, 2010). Soot is generally composed of mass-fractal aggregates of spherical carbonaceous particles which are generated as a consequence of incomplete combustion of hydrocarbons. The distribution of the diameter of the primary particles comprising the aggregates are relatively narrow and have been described as monodisperse, (Megaridis \& Dobbins 1990) normal (Köylü \& Faeth 1992), or lognormal (Köylü \& Faeth 1992). Conversely, the distribution of aggregate sizes, in terms of the number of primary particles per aggregate, $N$, or the radius of gyration of the aggregates, $R_{g}$, is generally quite wide and is commonly described as log-normal (Köylü \& Faeth, 1992; Snelling et al., 2011) or sometimes as selfpreserving (Megaridis \& Dobbins, 1990; Snelling et al., 2011; Sorensen, 2001).

Modeling and predicting soot formation in flames is possibly the most challenging problem in the field of combustion given the complex chemistry, aerosol dynamics, short time scales, and large spatial gradients involved. This complexity is further exacerbated considering most practical combustion applications involve turbulent flames. Research on soot formation within turbulent sooting flames is hindered by the difficulty in making quantitative measurements. Large thermal and concentration gradients, optical attenuation, background interference, and beam steering all complicate measurements 
resulting in a dearth of experimental data for theory development or simulation validation.

A thorough description of soot emissions requires measurement of soot volume fraction, primary particle size, and aggregate size and morphological properties. Laser-induced incandescence (LII) (Eckbreth, 1977; Melton, 1984; Vander Wal \& Weiland, 1994; Bryce et al., 2000) and line-of-sight attenuation (LOSA) (Greenberg \& Ku, 1997; Snelling et al., 1999; Arana et al., 2004; Thomson et al., 2008) are commonly used to measure soot volume fraction in steady flames. While spatially-resolved measurements of soot volume fraction with LOSA require symmetry to deconvolve the line-of-sight measurements, LII is intrinsically spatially-resolved and thus offers the possibility of time-resolved point measurements in unsteady flames. When LII is collected at two wavelengths with detectors calibrated to an absolute light intensity scale (known as auto-compensating or AC-LII) (Snelling et al., 2005; Schulz et al., 2006), it becomes possible to determine soot volume fraction without reliance on in situ or ex situ calibration with attenuation measurements (Schulz et al., 2006). With sufficient temporal resolution of the LII signal and a soot cooling model, it is also possible to infer a soot primary particle size (Schulz et al., 2006; Will et al., 1995; Mewes \& Seitzman, 1997; Axelsson et al., 2000; Axelsson et al., 2001; Boiarciuc et al., 2006; Kock et al., 2006). Unfortunately, an important parameter in the soot cooling model is the local gas temperature, making primary particle diameter determination via time-resolved LII extremely difficult in unsteady flames where instantaneous temperature measurements can be prohibitive. 
Soot primary particle size can also be measured via elastic light scattering (ELS) (Sorensen et al., 1992a; De Iuliis et al., 1998; Teng \& Köylü, 2006). Both Sorensen et al. (1992a) and De Iuliis et al. (1998) show that primary particle diameter can be determined via ELS if the soot absorption coefficient and aggregate radius of gyration are known along with the soot optical refractive index functions and the fractal parameters describing the soot aggregates. The soot absorption coefficient, which is also used to determine soot volume fraction, is commonly determined via extinction measurements with the assumption made that absorption by soot dominates over scattering (Sorensen et al., 1992a; De Iuliis et al., 1998; Teng \& Köylü, 2006; Link et al., 2011). Teng and Köylü (2006) showed computationally that a single backward scattering measurement can be used to measure primary particle diameter provided the scattering behavior is in the power-law regime where the ratio of scattering to absorption coefficients is only weakly dependent on aggregate size. The limitation to the power-law regime restricts measurement to large aggregates (e.g. a soot mean aggregate radius of gyration above $85 \mathrm{~nm}$ for detection at $150^{\circ}$ and $1064 \mathrm{~nm}$ ) while many flames have smaller aggregates, especially early in the aggregation process low in the flame.

Alternatively, if the effective soot aggregate radius of gyration is known or can be measured, it is possible to account for the weak dependence of primary particle diameter on radius of gyration in the primary particle measurement (De Iuliis et al., 1998). Various attempts have been made to use scattering measurements at additional angles to discern more information about the 
aggregate size distribution (Link et al., 2011; Oltmann et al., 2010; De Iuliis et al., 2011). However, deconvolution of multi-angle scattering measurements to determine the aggregate size distribution is very challenging due to the ill-posed nature of the problem (Link et al., 2011; Burr et al., 2011) and thus a distribution shape (such as log-normal) and width, as well as morphological properties are commonly assumed (Iyer et al., 2007; Köylü \& Faeth, 1994; Xing et al., 1999).

A limitation of extinction plus scattering measurements is that spatially resolved absorption coefficients must be determined via deconvolution (Dasch 1992), and thus this approach is best suited to steady, axisymmetric flames (Sorensen et al., 1992a; De Iuliis et al., 1998; De Iuliis et al., 2011; Iyer et al., 2007). Yang and Köylü (2005b) measured localized light extinction in an unsteady flame using both deconvolved LOSA measurements and local LOSA measurements for which a $6.4 \mathrm{~mm}$ OD pipe traversed through the flame was used to shield the laser beam from extinction outside of an exposed $2.3 \mathrm{~mm}$ sample length. In both instances, measurements were time averaged and scattering and extinction coefficients were measured asynchronously. Although the localized extinction method permits spatially resolved measurements, the intrusiveness of the probe combined with the inability to determine local extinction data concurrently with the ELS measurements means the method remains ill-suited for unsteady flames.

The use of LII in place of extinction measurements offers the possibility of simultaneous measurement of soot absorption and scattering characteristics for the instantaneous determination of soot concentration and aggregate 
morphological properties. The principle has been demonstrated by several authors (e.g. Snelling et al., 2011; Reimann et al., 2009); however, LII and ELS measurements have not been obtained concurrently and averaged data have typically been analyzed.

The objectives of this paper are to present and critically analyze an approach for achieving simultaneous, instantaneous point measurements of soot volume fraction, primary particle diameter, and aggregate radius of gyration via the combination of AC-LII and two-angle ELS. Measurements are performed in a steady laminar diffusion flame for the purpose of apparatus validation and quantitative assessment of measurement uncertainties with the specific goal of enabling future measurements in unsteady flames.

\subsection{Theory}

\subsubsection{Measurement of Soot Volume Fraction, $\boldsymbol{f}_{v}$}

The LII method described in Snelling et al. (2005), including the equivalent filter approximation and numerical determination of the equivalent laser sheet width, was used to calculate soot volume fraction $\left(f_{v}\right)$. Briefly, a detector calibrated to an absolute intensity scale can be used to measure the power radiated by the volume of heated particulate. Employing Rayleigh-Debye-Gans Fractal Aggregate Theory (RDG-FA) (Julien \& Botet, 1987; Martin \& Hurd, 1987; Dobbins \& Megaridis 1991) which describes light absorption and scattering from small aggregated particles, the volume fraction of soot in the measurement volume is calculated via: 


$$
f_{v}=\frac{V_{\text {meas }, 1}}{\eta_{1} \frac{12 \pi c^{2} h}{\lambda_{1}^{6}} E\left(m_{\lambda_{1}}\right) w_{e}\left[\exp \left(\frac{h c}{k \lambda_{1} T_{p e}}\right)-1\right]^{-1}}
$$

where $\lambda$ is the equivalent centre wavelength (Snelling et al., 2005) of the detection system; $E\left(m_{\lambda}\right)$ is the soot refractive index light absorption function evaluated at $\lambda ; V_{\text {meas }}$ is the experimentally-measured voltage; $\eta$ is the calibration constant obtained using a calibrated tungsten lamp and integrating sphere (Snelling et al., 2005); $c$ is the speed of light; $h$ is the Planck constant; $w_{e}$ is the equivalent laser sheet thickness which is described in more detail below; $k$ is the Boltzmann constant; and $T_{p e}$ is the equivalent heated particle (soot) temperature. The subscript 1 refers to the first measurement channel, which in the present experiments is designed for detection at $447 \mathrm{~nm} . E\left(m_{\lambda}\right)$ is taken to have a mean value of 0.348 at $\lambda_{1}$ (Dobbins et al., 1994; Snelling et al., 2004; Yon et al., 2011; Coderre et al., 2011; Köylü \& Faeth, 1996; Krishnan et al., 2000; Schnaiter et al., 2003; Bond \& Bergstrom, 2006) and varies linearly with wavelength such that $E\left(m_{\lambda_{1}}\right) / E\left(m_{\lambda_{2}}\right)=1.15$, where $\lambda_{2}=800 \mathrm{~nm}$ (Coderre et al., 2011; Snelling et al., 2004; Dobbins et al., 1994; Yon et al., 2011). The values of $E\left(m_{\lambda}\right)$ and all other parameters introduced are allowed to fluctuate during the Monte-Carlo uncertainty propagation procedure discussed in section 4.5.1. A key assumption of RDG-FA theory is that the absorption cross-section of a soot aggregate is equal to the sum of the absorption cross-sections of its individual primary particles and that primary particles absorb light in proportion to their volume (Julien \& Botet, 1987; Martin \& Hurd, 1987). 
The calculation of $f_{v}$ via Equation (4.1) requires knowledge of the heated soot particle temperature which is determined explicitly via pyrometry using LII detected at two distinct wavelengths and Wien's approximation $\left(\exp \left(h c / k \lambda T_{p e}\right) \gg\right.$ 1):

$$
T_{p e}=-h c \frac{\left(\lambda_{2}-\lambda_{1}\right)}{\ln \left(\frac{V_{\text {meas }, 1}}{V_{\text {meas }, 2}} \frac{\eta_{2}}{\eta_{1}} \frac{\lambda_{1}^{6}}{\lambda_{2}^{6}} \frac{E\left(m_{\lambda_{1}}\right)}{E\left(m_{\lambda_{2}}\right)}\right) k \lambda_{1} \lambda_{2}}
$$

where the subscript 2 refers to the second measurement channel. The temperature determined in this way is referred to as an equivalent temperature since it is representative of the non-uniform temperature distribution within the laser-heated zone. The calculation of the equivalent sheet width accounts for this non-uniform heating.

The equivalent laser sheet thickness, $w_{e}$, was determined via numerical calculations based on a model of the LII process (Snelling, 1997; Smallwood et al., 2001; Snelling et al., 2000) as described in Snelling et al. (2005), with sublimation of soot assumed to be negligible at the temperatures encountered $\left(T_{p e} \leq 3500 \mathrm{~K}\right)$. Calculations were performed for a time-averaged laser profile at the centre of the measurement volume and a range of soot absorption functions $\left(0.21<E\left(m_{\lambda_{1}}\right)<0.41\right.$ and $\left.0.8<E\left(m_{\lambda_{1}}\right) / E\left(m_{\lambda_{2}}\right)<1.2\right)$, thermal accommodation coefficients $(0.2<\alpha<0.5)$, initial gas temperatures $\left(1500 \mathrm{~K}<T_{g}<2100 \mathrm{~K}\right)$, and primary particle diameters $\left(15 \mathrm{~nm}<d_{p}<60 \mathrm{~nm}\right)$. The resulting distribution of equivalent sheet thicknesses had a mean of $w_{e}=0.50 \mathrm{~mm}$ and exhibited a lognormal like shape with $95 \%$ of the distribution falling between 0.42 and 
$0.58 \mathrm{~mm}$. Calculations were also performed using time-averaged laser profiles taken at five other locations in the measurement volume and these confirmed that the equivalent sheet width is spatially independent within the measurement volume. As stated in Crosland et al. (2011), a complete assessment of the accuracy of the equivalent laser sheet thickness calculation is difficult, since this would require determination of the accuracy of the LII model, a task that is beyond the scope of the current work and one which remains an open question in the literature.

Equations (4.1) and (4.2) use equivalent centre wavelengths to represent the detection system for the two measurement wavelength bands, whereas the bandpass filters used in the experiments have spectral widths of 60 and $64 \mathrm{~nm}$ for $\lambda_{1}$ and $\lambda_{2}$, respectively. The equivalent width approximation is estimated to introduce $1 \%$ error in the determination of a typical in-flame heated soot temperature (Snelling et al., 2005). To account for this potential bias, an error term with a mean of 1 and a standard deviation of $0.5 \%$ (i.e. half of the maximum potential systematic error) is multiplied by $T_{p e}$ in the uncertainty analysis. This approach to quantifying the uncertainty of heuristic (Type B) estimates is based on NASA Measurement Uncertainty Analysis Principles and Methods (National Aeronautics and Space Administration 2010). Similar error terms will be used for the modeling errors discussed in subsequent sections.

Absorption of the LII signal by in-flame soot has the dual effect of altering the perceived heated soot temperature and the signal intensity. The error arising from these competing effects will vary on a case-by-case basis. Working with the 
same flame at the same measurement location, Liu et al. (2008) report an estimated effect on $f_{v}$ of $5 \%$. To account for this potential bias error, a corresponding error term with a standard deviation of $2.5 \%$ is included in the uncertainty analysis for $f_{v}$.

\subsubsection{Determination of Soot Mean Aggregate Radius of Gyration}

Using the mass fractal aggregate theory combined with an additional forward scattering measurement it is possible to determine a mean soot aggregate radius of gyration representative of the polydisperse distribution of aggregate sizes. In mass fractal aggregate theory, the number of primary spheres in an aggregate is described according to the mass fractal relation (Julien \& Botet, 1987; Dobbins \& Megaridis, 1991):

$$
N=k_{f}\left(\frac{2 R_{g}}{d_{p}}\right)^{D_{f}}
$$

where $N$ is the number of primary spheres in an aggregate, $k_{f}$ is the fractal prefactor, $D_{f}$ is the fractal dimension, and $R_{g}$ is the soot aggregate radius of gyration. Mean values of 1.7 are used for both $k_{f}$ and $D_{f}$ (Köylü et al., 1995; Sorensen, 2001). When dealing with polydisperse aggregate populations, the only term dependent on the angle of a scattering measurement is the structure factor (Dobbins \& Megaridis 1991), $S$, which is typically expressed as a function of the product of the scattering wave vector $(q=\sin (\theta / 2) \cdot 4 \pi / \lambda)$ and the radius of gyration $\left(R_{g}\right)$. Many different forms of the structure factor have been suggested, and a thorough summary is provided in Sorensen (2001). We employ the 
structure factor proposed by Lin et al. (1990), which is similar to the Gaussian cutoff structure factor but less computationally expensive:

$$
S\left(q \cdot R_{g}\right)=\left(1+\sum_{s=1}^{4} C_{s}\left(q \cdot R_{g}\right)^{2 s}\right)^{-D_{f} / 8}
$$

where $C_{1}=8 /\left(3 D_{f}\right), C_{2}=2.50, C_{3}=-1.52$, and $C_{4}=1.02$. Polydispersity of aggregate size is accounted for in the current work by modeling the number of primary particles per aggregate with the log-normal probability density function,

$$
p\left(N, N_{m}, \sigma\right)=\frac{\exp \left(-\frac{1}{2}\left(\frac{\ln N / N_{m}}{\ln \sigma_{g}}\right)^{2}\right)}{\sqrt{2 \pi} N \ln \left(\sigma_{g}\right)}
$$

where $N_{m}$ and $\sigma_{g}$ are the parameters describing the size and shape of the lognormal distribution, and by defining an effective polydisperse structure factor:

$$
\overline{S\left(q \cdot R_{g}\right)}=\frac{\int_{0}^{\infty} N^{2} S\left(q(\theta) \cdot R_{g}\right) p\left(N, N_{m}, \sigma_{g}\right) d N}{\int_{0}^{\infty} N^{2} p\left(N, N_{m}, \sigma_{g}\right) d N}
$$

Note that the radius of gyration used to calculate the structure factor depends on $N$ as well as primary particle diameter, fractal dimension, and fractal prefactor via the mass fractal relation presented in Equation (4.3). Given two measurement angles of the form $\theta$ and $180^{\circ}-\theta$, the dissymmetry ratio $\left(R_{v v}\right)$ can be defined as the ratio of the effective structure factor at the first angle to the effective structure factor at the second angle (Snelling et al., 2011):

$$
R_{v v}=\frac{\int_{0}^{\infty} N^{2} S\left(q\left(\theta_{1}\right) \cdot R_{g}\right) p\left(N, N_{m}, \sigma\right) d N}{\int_{0}^{\infty} N^{2} S\left(q\left(\theta_{2}\right) \cdot R_{g}\right) p\left(N, N_{m}, \sigma\right) d N}
$$


where the subscript $v v$ indicates that both the incident and measured scattered light are vertically polarized.

One common measure of effective radius of gyration is based on the mean number of primary particles per aggregate for the population of aggregates (De Iuliis et al., 1998):

$$
R_{g m 1}=\frac{d_{p}}{2}\left(\frac{\bar{N}}{k_{f}}\right)^{1 / D_{f}}
$$

where $\bar{N}$ is the mean value of the distribution of $N$, equal to $\left(\mathrm{N}_{m} \exp \left(\frac{\ln (\sigma)^{2}}{2}\right)\right)$ for the log-normal distribution described in Equation (4.5). The subscript $m 1$ refers to the dependence of the expression on the first moment (also the arithmetic mean), of the distribution of $N$.

If the fractal dimension and prefactor as well as the approximate width of the log-normal distribution are known a priori, it becomes possible to solve Equation (4.7) for an assumed primary particle diameter and create a lookup table for $N_{m}$ based on dissymmetry ratio. When $R_{v v}$ is then determined via experimental measurement, $N_{m}$ can be found via the lookup table and used to determine $R_{g m l}$ via Equation (4.8). It is interesting to note that the assumed value of the primary particle diameter has no effect on the determined $R_{g m l}$, since the value of $N_{m}$ determined via Equation (4.7) has an inverse dependence on $d_{p}{ }^{D_{f}}$, canceling the dependence of $R_{g m l}$ on $d_{p}$ in Equation (4.8).

It is important to note that $R_{g m l}$ approaches a vertical asymptote for large dissymmetry ratios. For the current experimental setup $\left(\lambda_{s}=1064 \mathrm{~nm}, \theta_{l}=30^{\circ}\right)$ 
measurement of $R_{g m l}$ values above $300 \mathrm{~nm}$ at a dissymmetry ratio of about 6.9 becomes much more uncertain. The current setup allows measurement of a larger range of particle diameters at the cost of slightly reduced system sensitivity compared to, for example, a system with $\lambda_{s}=532 \mathrm{~nm}, \theta_{1}=30^{\circ}$ that allows measurement up to approximately $200 \mathrm{~nm}$ at a dissymmetry ratio of about 8.2.

As mentioned above, many forms of the structure factor have been proposed and so a comparison of the relation between dissymmetry ratio and $R_{g m l}$ determined using the definition of structure factor presented above based on Lin et al. (1990) and six others described by Sorensen (2001) was performed. The comparison was made using a constant primary particle diameter, fractal dimension, fractal prefactor and log-normal shape parameter $\left(d_{p}=30 \mathrm{~nm}, D_{f}=\right.$ $1.7, k_{f}=1.7$, and $\left.\sigma_{\mathrm{g}}=2.1\right)$. The value of $R_{g m l}$ predicted by the Gaussian cut-off (Sorensen et al., 1992b; Hurd \& Flower, 1988; Dobbins \& Megaridis, 1991) structure factors differ by less than $6 \%$ from the values predicted via the Lin $e t$ al. (1990) structure factor for $25 \mathrm{~nm}<R_{g m l}<300 \mathrm{~nm}$. The Mountain \& Mulholland (1988) structure factor underestimates (relative to the Lin et al. (1990) model) by $6 \%$ at $R_{g m l}=25 \mathrm{~nm}$ and by $25 \%$ at $R_{g m l}=300 \mathrm{~nm}$. The Fisher \& Burford (1965) and exponential cutoff (Berry \& Percival 1986) structure factors both greatly overestimate $R_{g m l}$ compared to the Lin et al. (1990) structure factor, surpassing $70 \%$ overestimation near $R_{g m l}=300 \mathrm{~nm}$. These differences are expected based on the observation of Sorensen (2001) that the exponential cutoff (Berry \& Percival 1986) and Fisher \& Burford (1965) structure factors perform well for monodisperse aggregates, but are quite poor at representing polydisperse 
populations of aggregates. Sorensen (2001) concludes that the structure factors with sharp cutoffs (such as the Gaussian cutoff (Sorensen et al., 1992b)) perform best at reproducing experimental results (i.e. for polydisperse aggregate sizes). Thus, when considering cutoff functions with Gaussian-like behavior it is reasonable to conclude that an uncertainty in $R_{g m l}$ of less than $6 \%$ can be expected due to the choice of structure factor, and a corresponding error term with a standard deviation of $3 \%$ of the calculated $R_{g m l}$ has been included in the uncertainty analysis.

A similar analysis was completed employing a self-preserving distribution of aggregate sizes with $\tau=-0.3$ (Snelling et al., 2011) in place of the log-normal distribution. The percent differences associated with the choice of structure factor are not significantly affected by the change in distribution type, i.e. $R_{g m I}$ determined using the Gaussian cut-off structure factor (Sorensen et al., 1992b) still underestimates $R_{g m l}$ by $6 \%$ when compared to the similar result calculated using the Lin et al. (1990) structure factor. For a given structure factor, however, the change in distribution type has an effect on the determination of $R_{g m l}$. For dissymmetry ratios where the log-normal distribution returns $R_{g m l}=70 \mathrm{~nm}$, the self-preserving distribution returns a 2-4\% larger value for $R_{g m l}$ depending on the chosen structure factor. For dissymmetry ratios where the log-normal distribution returns $R_{g m l}=300 \mathrm{~nm}$, the self-preserving distribution returns a 4$7 \%$ smaller value for $R_{g m l}$ depending on the chosen structure factor. Since the current work produces values of $R_{g m l}$ near $70 \mathrm{~nm}$, an error term with a standard deviation of $2 \%$ is included with $R_{g m l}$ during uncertainty analysis. 
As discussed in Sorensen (2001), intra-aggregate scattering is expected to enhance scattering uniformly in all directions by approximately $10 \%$. Since this proportional enhancement is expected to be independent of angle, it is assumed to have a negligible effect on the calculated dissymmetry ratio and hence on the determination of $R_{g m l}$. Inter-aggregate multiple scattering is also assumed to be negligible since the soot volume fraction is much less than 0.006 (Modest 2003). Another potential source of modeling error for both $R_{g m l}$ and $d_{p}$ is in the assumption that the primary particles are in point-contact. As reported in Oh \& Sorensen (1997), the effect of particle overlap is generally to increase both $D_{f}$ and $k_{f}$ Examining the range of overlaps from point-contact to $50 \%$ overlap (i.e. primary particle radius equal to the distance between sphere centres), Oh \& Sorensen (1997) report an increase of $D_{f}$ from 1.8 to 2.0 and an increase of $k_{f}$ from 1.3 to 3.o. The effects of particle overlap are neglected in the current work since the range of $D_{f}$ and $k_{f}$ employed in the uncertainty analysis are sufficiently large to account for the range of particle overlap likely to be seen in the mature soot being considered.

\subsubsection{Determination of Primary Particle Diameter}

As noted above, it is possible to determine the soot primary particle diameter from a measurement of scattering coefficient, absorption coefficient, and the effective soot aggregate radius of gyration (De Iuliis et al., 1998) via

$$
d_{p}=\left(\frac{\lambda_{s}{ }^{3}}{\pi^{3}} \frac{4 \pi E\left(m_{\lambda_{s}}\right) K_{v v}\left(\theta_{2}\right)}{F\left(m_{\lambda_{s}}\right) f_{n} \overline{S\left(q \cdot R_{g}\right)} K_{a b s, \lambda_{s}}} \frac{1}{k_{f}\left(2 R_{g m 1}\right)^{D_{f}}}\right)^{\frac{1}{3-D_{f}}}
$$


where $d_{p}$ is the primary particle diameter; $\lambda_{s}$ is the wavelength of the laser used to produce the scattering signal; $K_{v v}$ is the scattering coefficient for verticallypolarized incident and scattered light which is equal to the measured scattering signal voltage divided by an appropriate calibration constant determined using the method described in Crosland, Johnson, et al. (2013); $\theta_{2}$ is the backward scattering angle measured relative to the incident laser direction; and $E\left(m_{\lambda_{S}}\right)$ and $F\left(m_{\lambda_{s}}\right)$ are functions of the refractive index of soot. $F\left(m_{\lambda_{s}}\right)$ is taken to be 0.31 at $\lambda_{s}=1064 \mathrm{~nm}$ based on Yon et al. (2011) and $E\left(m_{\lambda_{s}}\right)$ will be seen to cancel based on Equation (4.11). The variable $f_{n}$ represents the ratio of the first two moments of the distribution of aggregate sizes (De Iuliis et al., 1998):

$$
f_{n}=\frac{\int_{0}^{\infty} N^{2} p(N) d N}{\left(\int_{0}^{\infty} N p(N) d N\right)^{2}}
$$

The $K_{a b s, \lambda_{s}}$ term in Equation (4.9) is the absorption coefficient of soot at the scattering wavelength, and is derived using the soot volume fraction measurement (discussed previously) as

$$
K_{a b s, \lambda_{s}}=\frac{6 \pi E\left(m_{\lambda_{s}}\right) f_{v}}{\lambda_{s}}
$$

where $f_{v}$ is the soot volume fraction measured via LII. When Equation (4.11) is used in Equation (4.9) the soot index of refraction function $E(m)_{\lambda_{s}}$ cancels out.

Determination of primary particle diameter via Equation (4.9) assumes that the primary particle diameter distribution is monodisperse. Tian et al. 
(2004) found soot primary particle diameters in the current flame to be well approximated by a normal distribution with a mean of $28.3 \mathrm{~nm}$ and a standard deviation of $6.5 \mathrm{~nm}$. While ELS is known to scale with primary particle diameter to the $6^{\text {th }}$ power, aggregation effects will decrease this dependency to a power of approximately $6-D_{f}$ according to the aggregation model used in the current work. As well, this dependency assumes a constant number of primary particles, while in reality a comparison must be made with a constant volume of soot. Once the scattering signals are normalized to a constant volume of soot, it is estimated that for the current flame conditions and assumed soot parameters, the use of a monodisperse distribution of primary particle diameters will overestimate the primary particle diameter by approximately 20\%. As discussed in Snelling et al. (2011), it is not appropriate to apply a correction for $d_{p}$ polydispersity since the ratio $E(m) / F(m)$ was derived from measurements and theory which ignored the polydispersity of primary particle diameter. It is further stated in Snelling et al. (2011) that if a log-normal primary particle diameter distribution with a geometric mean of $28.9 \mathrm{~nm}$ and a width of 1.26 is assumed to have been present in all the measurements used to derive $F(m)$, then $F(m)$ is expected to decrease. This would counteract to some degree the overestimation resulting from the monodisperse assumption. To account for uncertainty in $d_{p}$ resulting from the assumption of monodispersity, an error term with a standard deviation of $10 \%$ is included in the uncertainty analysis for $d_{p}$.

As discussed in Sorensen (2001), intra-aggregate multiple scattering for soot particles is expected to enhance the scattering signal by approximately $10 \%$ 
at all angles compared with single scattering as assumed in the current work. To account for uncertainty due to the negligence of intra-aggregate multiple scattering effects, an error term with a standard deviation of $5 \%$ is included in the uncertainty analysis for $d_{p}$.

Absorption of the scattering signals by in-flame soot causes an underestimation of $K_{v v}$. A simple radial traverse of the flame verified that the scattering coefficient is relatively uniform between the flame centreline and edge, validating the assumption that inter-aggregate multiple scattering is negligible $\left(K_{v v} \approx 0.04 \mathrm{~m}^{-1}\right)$ compared to absorption $\left(K_{a b s} \approx 17 \mathrm{~m}^{-1}\right)$. Using the radial soot volume fraction profile from Snelling et al. (2005), the absorption of scattering signals is estimated to cause underestimation of $K_{v v}$ by approximately $6.6 \%$. To account for this bias error, a corresponding error term with a standard deviation of $3.3 \%$ is included in the uncertainty analysis for $K_{v v}$.

\subsection{Experimental Setup}

\subsubsection{General Arrangement}

To support future measurements on an unsteady turbulent flame greater than $1 \mathrm{~m}$ tall, the measurement apparatus was designed so that a platform supporting the laser head, beam shaping optics, and signal collection optics could be traversed in three axes about a fixed location burner. The general layout of the experimental excitation and collection system is shown in Figure 4.1. The $1064 \mathrm{~nm}$ beam from the Nd:YAG laser is formed into a small sheet and directed into the flame where it induces incandescence and scattering. These signals are 
picked up by detection optics mounted at a forward angle of $30^{\circ}$ and a backward angle of $150^{\circ}$ and carried via fiber to a nearby filtering and detector apparatus.

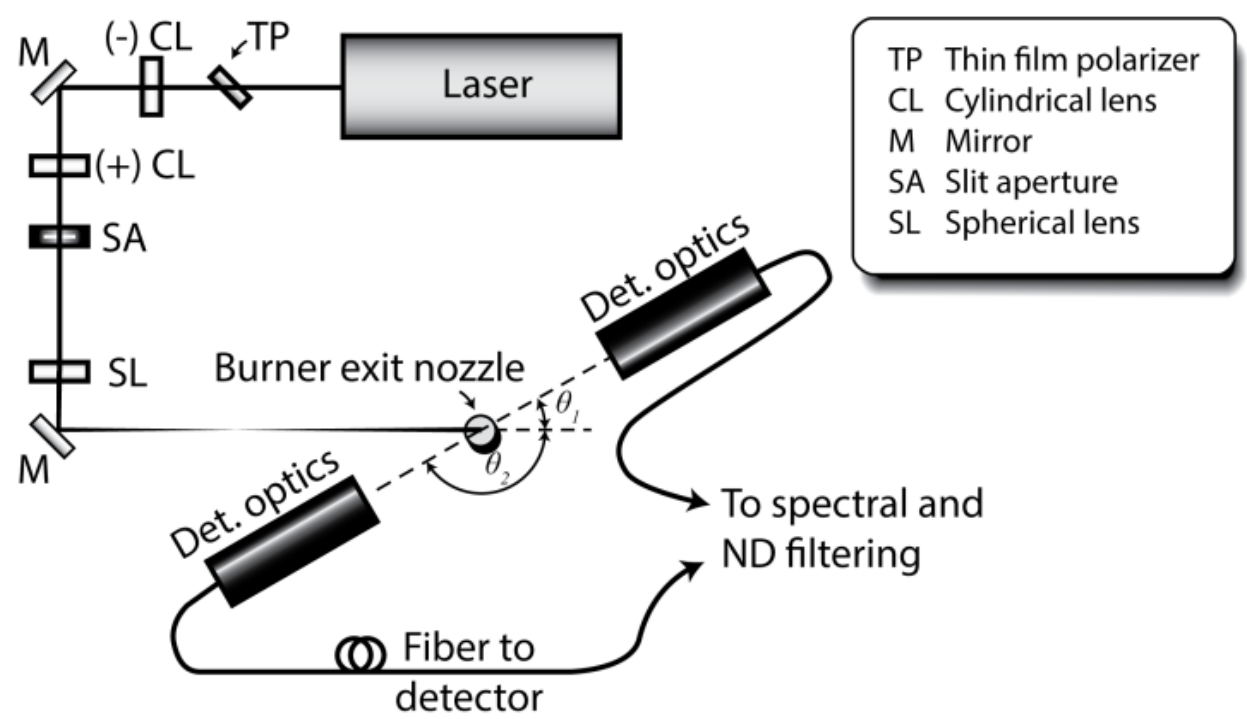

Figure 4.1 - Laser beam shaping and detector arrangement.

Figure 4.2 shows a schematic of the signal handling during measurements. Laser excitation (a), induces both elastic light scattering and soot incandescence signals (b), which vary both spectrally and temporally. ELS signals were collected at forward and backward angles (c), focused onto a pair of photodiodes (d), and amplified using a $5 \mathrm{x}$ fast preamplifier (e). LII signals were collected at a backward angle (c), spectrally filtered (f), attenuated using neutral density (ND) filters (g), and focused onto a pair of photomultiplier tubes (h). All four signals were then gated in time (i), before being digitized (j) and stored in a computer $(\mathrm{k})$. 


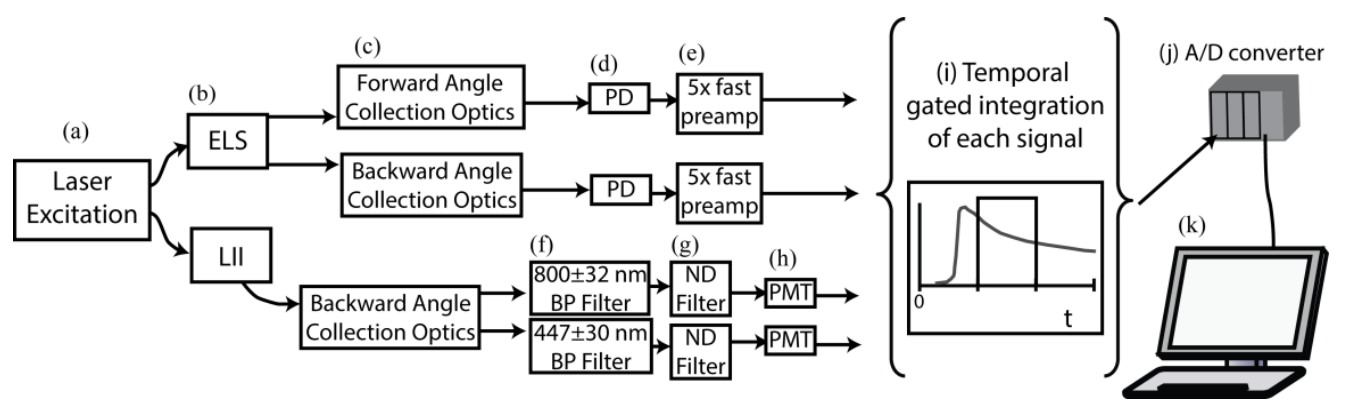

Figure 4.2 - Signal treatment flow chart. Laser excitation (a), induces both elastic light scattering and soot incandescence signals (b), which vary both spectrally and temporally. ELS signals were collected at forward and backward angles (c), focused onto a pair of photodiodes (d), and amplified using a 5x fast preamplifier (e). LII signals were collected at a backward angle (c), spectrally filtered (f), attenuated using neutral density (ND) filters, and focused unto a pair of photomultiplier tubes (h). All four signals were then gated in time (i), before being digitized (j) and stored in a computer $(\mathbf{k})$.

\subsubsection{Laser excitation}

A pulsed Nd:YAG laser (New Wave Research, SOLO 120) operating at $15 \mathrm{~Hz}$ and $1064 \mathrm{~nm}$ was used to produce a scattering signal and to induce incandescence of the soot particles. A schematic of the beam shaping layout is included in Figure 4.1. The beam was first passed through a thin film polarizer (CVI Melles-Griot, TFP-1064) to ensure only vertically-polarized light remained. The beam was subsequently expanded into a sheet using a pair of cylindrical lenses (focal length, $f=-100$ and $200 \mathrm{~mm}$ ) and passed through a $7.5 \mathrm{~mm} \times 0.5 \mathrm{~mm}$ slit to produce a thin sheet with a mean fluence of $0.9 \mathrm{~mJ} / \mathrm{mm}^{2}$. While only point measurements were made, the usage of a small sheet was necessary to ensure a constant sheet thickness throughout the measurement volume. The slit was then imaged into the measurement volume using a $100 \mathrm{~mm}$-diameter, $f=400 \mathrm{~mm}$ spherical lens. Laser beam profiles were taken at three evenly spaced heights within the measurement volume, as shown in Figure 4.3. In spite of the non- 
uniformity across the beam profile, the equivalent laser sheet thickness does not vary significantly from one profile to the next.

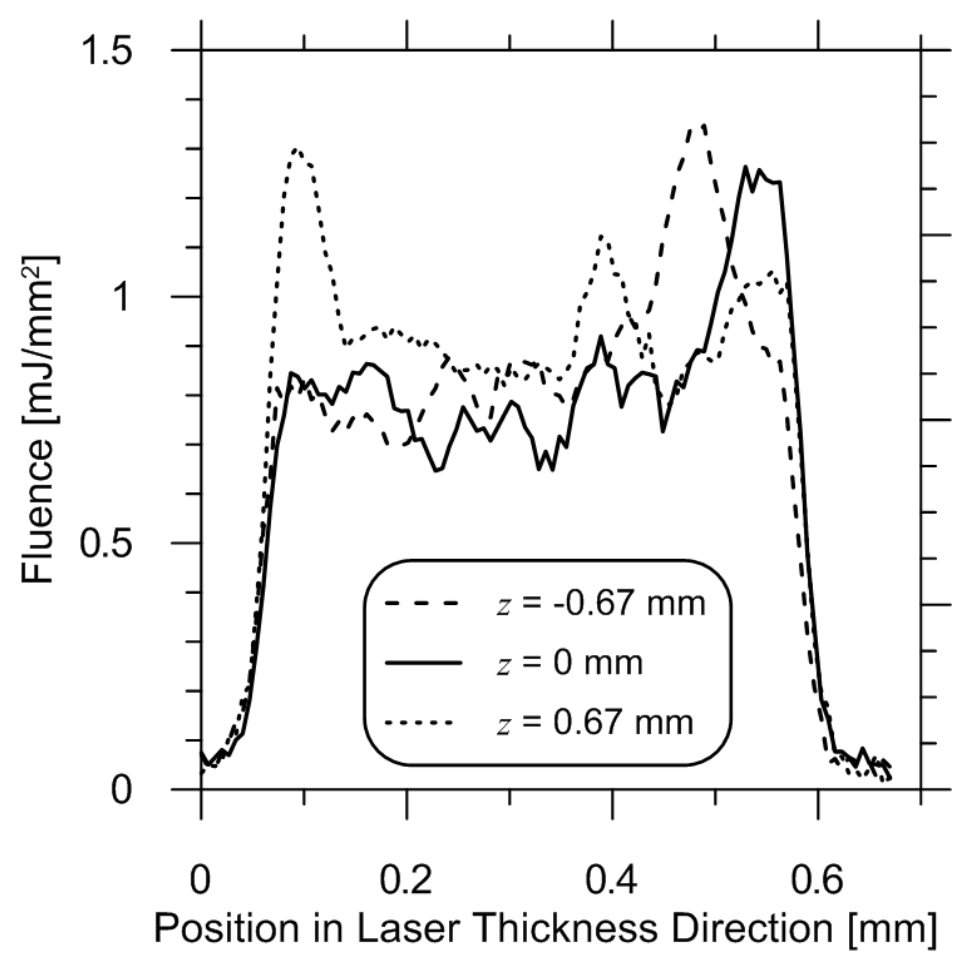

Figure 4.3 - Profiles of laser fluence measured across the width of the laser sheet taken at three vertical locations within the measurement volume. The three locations are designated by a vertical coordinate, $z$, relative to the centre of the measurement volume. The mean fluence is approximately $0.9 \mathrm{~mJ} / \mathrm{mm} 2$.

\subsubsection{Collection optics}

The forward- and backward-scattering collection optical assemblies were identical. A mirror was first used to reflect the scattering and LII signals into a vertically-mounted lens tube. The lens tube contained two $50 \mathrm{~mm}$ diameter achromatic lenses $(f=400 \mathrm{~mm}$ and $f=200 \mathrm{~mm})$ to collect and focus the emissions onto a $0.5 \mathrm{~mm}$ diameter aperture, behind which is a $1 \mathrm{~mm}$ diameter optical fiber (FG-1.o-UAT, ThorLabs) which carried the signals out of the burner enclosure. The aperture and achromatic lenses along with the laser sheet 
combine to create a measurement volume that is a $2 \mathrm{~mm}$ by $1 \mathrm{~mm}$ ellipse with a thickness of $0.5 \mathrm{~mm}$. Collection optics and tubes were placed at two locations on the measurement platform to allow collection of forward $\left(30^{\circ}\right)$ and backward $\left(150^{\circ}\right)$ elastic light scattering. LII signals were simultaneously collected through the backward scatter optics as further detailed below. Alignment of the collection optics with the laser sheet was aided by directing a $671 \mathrm{~nm}$ diode laser back through the fiber, providing a focused spot at the focal point of the collection optics.

A consideration for angular scatter measurements is that the intersection volume of the excitation laser and collection optical axis varies with collection angle, and thus soot properties determined from a combination of measurements made at different angles can be biased if the soot properties are not uniform across both measurement volumes (Oltmann et al., 2012). To avoid this problem, the forward and backward scattering collection optics were arranged along a common optical axis (detectors placed on opposite sides of the laser axis at $30^{\circ}$ and $150^{\circ}$ ), such that their measurement volumes were coincident. By collecting the LII signal along this same optical axis, the identical sample volume was observed for both LII and scattering measurements.

\subsubsection{Signal Treatment}

After exiting the $1 \mathrm{~mm}$ diameter optical fiber, the light collected by the lens tube at $150^{\circ}$ passed through a collimating lens before being split by a high pass dichroic mirror (Semrock model LP12-514RU) that reflected light at wavelengths below $514 \mathrm{~nm}$ toward the first LII detection package and transmitted higher- 
wavelength light. The higher wavelength light was then transmitted through a short pass dichroic mirror (DMSP805, ThorLabs) mounted at a $15^{\circ}$ angle of incidence into the second LII detection package. While the short pass dichroic mirror has a specified cutoff of $805 \mathrm{~nm}$ when used at $45^{\circ}$, the cutoff is shifted upward to $877 \mathrm{~nm}$ when used at $15^{\circ}$. Each LII detection package contained a bandpass filter $(447 \pm 30 \mathrm{~nm}$, Semrock model FFo2-447/60-25 and $800 \pm 32 \mathrm{~nm}$, Coherent 42-7435 T-CXK 811-A, respectively), a calibrated neutral density filter ( $13.4 \%$ and $15.8 \%$, respectively) to avoid detector saturation, and a $f=50 \mathrm{~mm}$ lens to focus the light onto the surface of a PMT (Hamamatsu H5783o3 or $\mathrm{H}_{5783-20}$ for low and high wavelength signals, respectively). The PMTs were operated at a gain setting of $550 \mathrm{~V}$. The outputs of the PMTs were then integrated in time using gated integrators (Stanford Research Systems SR250) with a $50 \Omega$ termination. The $10 \mathrm{~ns}$ duration gates were initiated $30 \mathrm{~ns}$ after the onset of the PMT response as a compromise between maximizing LII signal strength and minimizing the uncertainty in the equivalent laser sheet thickness (Snelling et al., 2005). Laser-induced fluorescence of polycyclic aromatic hydrocarbons (PAHs) was not a factor in gate timing since $1064 \mathrm{~nm}$ excitation was employed (Schulz et al., 2006). The integrated output was then digitized using two channels of a four-channel simultaneous 16-bit analog-to-digital converter (National Instruments, NI 9205). The detection system was calibrated to an absolute radiance scale using a NIST-traceable filament lamp and integrating sphere system (SphereOptics Hoffman LLC, SMS-500) as described in Snelling et al. (2005). 


\subsubsection{Scattering}

The backward scattered light was extracted using the reflection from the short pass dichroic mirror described above. The forward scattered light exited the $1 \mathrm{~mm}$ diameter optical fiber into a $25 \mathrm{~mm}$ diameter lens tube where it was collimated using a $f=50 \mathrm{~mm}$ lens. Each scattering signal was then focused onto the surface a photodiode (ThorLabs DET-36A with $50 \Omega$ termination) using an additional $f=50 \mathrm{~mm}$ lens. The detector outputs were integrated in time using gated integrators (Stanford Research Systems SR250, gate width of $30 \mathrm{ns)}$ whose outputs were then sampled by the analog-to-digital converter. The scattering calibration was performed via the diffuse surface scattering method as described in Crosland, Johnson, et al. (2013), for which a $51 \mathrm{~mm}$ diameter by $6.5 \mathrm{~mm}$ thick piece of Spectralon Reflectance Material (SphereOptics Hoffman LLC, Contocook, NH) was traversed through the measurement volume in the laser propagation direction in increments of $0.2 \mathrm{~mm}$. While traditional calibrations for scattering measurements make use of a gas of known scattering cross-section, this method instead uses a diffuse surface with known scattering properties, producing a much stronger calibration signal and allowing calibration of different detectors (e.g. photodiodes) that are sensitive to longer wavelengths, but are otherwise incapable of detecting the traditional gas-scattering calibration signal. Since the block reflects or absorbs all of the light incident on its surface, calibration of the measurement volume requires a series of measurements where the diffuse scattering block is moved through the volume between measurements. The resulting signal was fit using local polynomial regression and integrated numerically. Though largely negligible, secondary light scattering off of other 
surfaces within the flame enclosure was accounted for by traversing the diffuse surface far away from the measurement volume (in this case, four times the fullwidth half-maximum of the spatially-resolved calibration signal) to perform a background measurement.

As discussed in Crosland, Johnson, et al. (2013), the diffuse surface scattering calibration method is only applicable to backward scattering measurements. Unlike the method described in Crosland, Johnson, et al. (2013), the current apparatus does not use a secondary CW laser to transfer the diffuse scattering calibration obtained using the backward scattering detection optics to the forward scattering detection optics. Instead, the same pulsed laser used for LII and ELS excitation is used to illuminate an integrating sphere $(150 \mathrm{~mm}$ diameter sphere with a $40 \mathrm{~mm}$ output port) similar to the one described earlier for LII calibration. By measuring the output signal from the laser-illuminated integrating sphere from first the forward scattering, and then the backward scattering detection optics, it was possible to obtain a relative calibration between the two detection systems. Additional figures describing the optical configuration used for the calibration transfer are included in Appendix A.

\subsubsection{Burner}

Verification and validation experiments to assess the accuracy and repeatability of the combined LII/ELS approach were performed in an ethylene laminar coflow diffusion flame previously described in Snelling et al. (2011) at a height of $42 \mathrm{~mm}$ above the fuel tube exit plane on the centreline. Briefly, the burner consists of an inner fuel tube (10.9 mm inner diameter) surrounded by an outer 
coflow of air ( $88 \mathrm{~mm}$ inner diameter). Ethylene was flowed through the inner tube at a rate of 0.24 grams per minute while air was flowed through the outer tube at a rate of 367 grams per minute. The visible flame height was approximately $65 \mathrm{~mm}$.

\subsection{Results \& Discussion}

On two separate days, the entire system was calibrated and used to take seven sets of measurements, resulting in 14 data sets containing 512 measurements per set. Using mean or mid-point values for all calculation parameters, mean values of $f_{v}, d_{p}$ and $R_{g m l}$ were calculated for each data set. On the first day, the mean values (and pooled population standard deviations) of $f_{v}, d_{p}$ and $R_{g m l}$ were 3.75 (o.18) ppm, $36.6(0.66) \mathrm{nm}$ and $70.2(1.9) \mathrm{nm}$ respectively. On the second day the corresponding results were $f_{v}=3.56(0.19) \mathrm{ppm}, d_{p}=35.9(0.75) \mathrm{nm}$ and $R_{g m 1}$ $=68.6(2.0) \mathrm{nm}$. As will be seen, these differences are quite small compared to the overall uncertainties.

Results of soot volume fraction, primary particle diameter and aggregate radius of gyration measurements are shown in Figure 4.4. Instantaneous measurements from Day 1, Set 1, are reported along with upper and lower confidence intervals which intersect at the mean of all 14 datasets. The uncertainty analysis is discussed further in the next section. Also plotted for comparison are the daily mean values and previously reported data obtained via TEM measurements (Tian et al., 2004), LII measurements (Snelling et al., 2005), and multi-angle scattering measurements (Snelling et al., 2011), all made at the 
same location within an equivalent flame at identical conditions and corrected to correspond to the soot properties used in the current work.

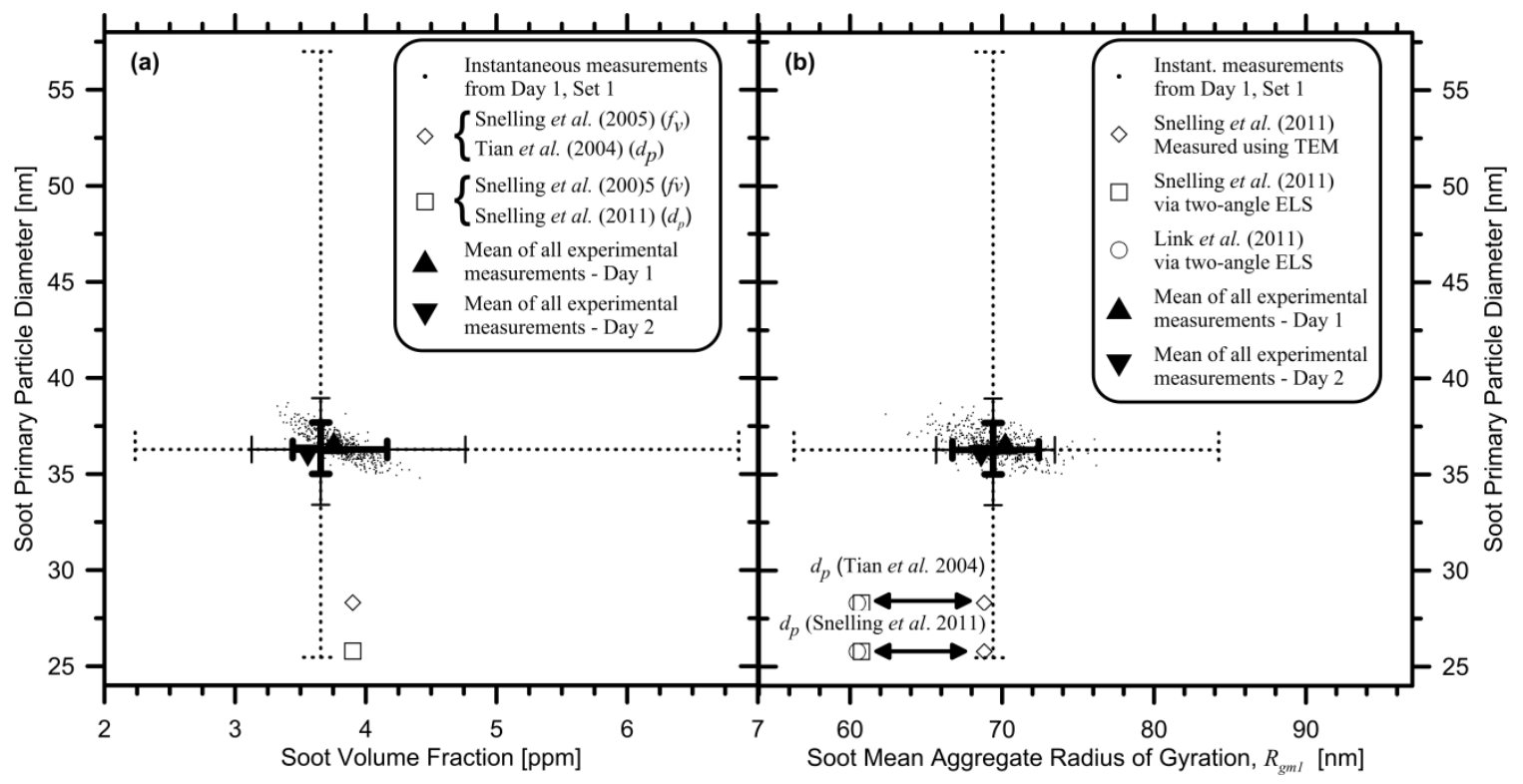

Figure 4.4 - (a) Scatter plot comparing instantaneous measurements of soot volume fraction and primary particle size obtained via combined LII/ELS in the present work with $\mathbf{9 5 \%}$ confidence intervals of total uncertainty for a single instantaneous measurement (dotted lines), uncertainty with fixed soot properties (thin solid lines), and uncertainty considering instrument noise only (thick solid lines). Also shown are soot volume fraction results from Snelling et al. (2005) plotted versus primary particle diameter results presented in Tian et al. (2004) and calculated from the results in Snelling et al. (2011). b) Scatter plot comparing instantaneous measurements of soot aggregate radius of gyration and primary particle size with $\mathbf{9 5 \%}$ confidence intervals of total uncertainty on a single instantaneous measurement (dotted lines), uncertainty with fixed soot properties (thin solid lines), and uncertainty considering instrument noise only (thick solid lines). Radius of gyration calculated from TEM measurements in Snelling et al. (2011) and calculated from scattering data from Snelling et al. (2011) and Link et al. (2011) are shown for comparison at the primary particle diameter results of both Snelling et al. (2011) and Tian et al. (2004). All measurements taken on the burner centreline at a height above the burner exit of $42 \mathrm{~mm}$ ( $65 \%$ along the visible flame length).

The dependence of primary particle diameter on both soot volume fraction and on radius of gyration can be seen in the instantaneous measurements in Figure 4.4a, which underscores the importance of accurate soot volume fraction 
and radius of gyration measurements when calculating primary particle diameter by this methodology. The mean daily soot volume fraction measurements of 3.75 and 3.56 are $4 \%$ and $9 \%$ lower than the previous LII measurement (Snelling et al., 2005) while the mean daily primary particle diameters of 36.6 and $35.9 \mathrm{~nm}$ are $27 \%$ to $29 \%$ larger than TEM measurements (Tian et al., 2004). The present $R_{g m l}$ data were compared to previous aggregate size measurements by first recalculating previous data to use soot morphological and optical properties consistent with the present work. Snelling et al. (2011) reported the geometric mean number of particles in the aggregate size distribution determined via TEM. This was converted to an $R_{g m l}$ value of $68.8 \mathrm{~nm}$ via Equation (4.8) using $d_{p}=28.3$ $\mathrm{nm}$ (Tian et al., 2004), $\sigma_{g}=2.1$ (De Iuliis et al., 1998), and fractal parameters of $k_{f}$ $=1.7$ (Sorensen 2001) and $D_{f}=1.7$ (Köylü et al., 1995). Snelling et al. (2011) and Link et al. (2011) report scattering coefficients at multiple angles. Using their measurements at either $35^{\circ}$ and $145^{\circ}$ (Snelling et al., 2011) or $30^{\circ}$ and $150^{\circ}$ (Link et al., 2011), $R_{g m l}$ was calculated via Equations (4.7) and (4.8) and found to be 60.8 and $60.5 \mathrm{~nm}$, respectively, with $k_{f}=1.7$ (Sorensen 2001), $D_{f}=1.7$ (Köylü et al., 1995) and $\sigma_{\mathrm{g}}=2.1$ (De Iuliis et al., 1998). The daily mean results in the current work of 70.2 and $68.6 \mathrm{~nm}$ are $20 \%$ to $23 \%$ above the scattering measurements of both Snelling et al. (2011) and Link et al. (2011), and 6\% and 9\% above the TEM-based $R_{g m l}$ value calculated using results from Snelling et al. (2011). 


\subsubsection{Measurement Uncertainty}

The strongly non-linear nature of the soot volume fraction Equation (4.1) suggests that a first-order linear error propagation method such as in (ANSI/ASME 1985) will produce erroneous results. Instead, Monte Carlo simulation similar to Crosland et al. (2011) was used for the propagation of elemental errors through to the calculation of soot volume fraction, primary particle diameter, and radius of gyration.

Most sources of uncertainty were characterized based on published literature values or manufacturer's specifications as detailed in Table 4.1. The value of $E(m)$ at the lower LII wavelength was taken to be a normal distribution truncated at $\pm 3 \sigma$ and centred at the nominal value of 0.348 with a standard deviation of 0.045 (Dobbins et al., 1994; Köylü \& Faeth, 1996; Krishnan et al., 2000; Schnaiter et al., 2003; Snelling et al., 2004; Bond \& Bergstrom, 2006; Yon et al., 2011; Coderre et al., 2011). The value of $E(m)$ at the upper LII wavelength is determined by allowing $E(m)$ to vary linearly with wavelength such that the ratio $E\left(m_{\lambda_{1}}\right) / E\left(m_{\lambda_{2}}\right)$ follows a normal distribution truncated at $\pm 3 \sigma$ and centred at a nominal value of 1.15 with a standard deviation of 0.11 (Snelling et al., 2004; Coderre et al., 2011; Yon et al., 2011; Dobbins et al., 1994). The value of $F\left(m_{\lambda_{s}}\right)$ was taken to be a normal distribution truncated at $\pm 3 \sigma$ and centred at a nominal value of 0.31 with a standard deviation of 0.04 (Yon et al., 2011). The equivalent laser sheet width distribution was calculated as described in Crosland et al. (2011) (based on measured laser profiles) and used to create a custom distribution of sheet widths from which random variates were drawn. The 
resulting distribution of sheet widths was approximately log-normal in shape with a mean thickness of $0.50 \mathrm{~mm}$ and $95 \%$ of the values falling between $0.42 \mathrm{~mm}$ and $0.58 \mathrm{~mm}$. Table 4.1 provides a summary of the Monte Carlo simulation input parameters, their source, and the resulting 95\% confidence intervals on $f_{v}, d_{p}$ and $R_{g m l}$ when all other terms are fixed.

Uncertainty analysis results of the Monte Carlo simulation are presented in Table 4.2. The analysis assumed the most challenging case of instantaneous measurements (i.e. assuming only single measurements are used and there is no time-averaging of the measured signals). The first of the three results columns represents the total uncertainty in each measured quantity. The uncertainty in the soot volume fraction is dominated by uncertainty in the soot absorption function $E\left(m_{\lambda}\right)$. While the experimental measurement uncertainty was constant in the steady flame studied, it will be a function of the measured LII signal in the case of an unsteady flame, making proper detector characterization a necessity in evaluating the uncertainty of such measurements. Uncertainty in the primary particle diameter is dominated by uncertainty in the fractal prefactor, $k_{f}$, followed by the error associated with the assumption of monodispersity of $d_{p}$. The largest contributor to the aggregate radius of gyration uncertainty is in the width of the log-normal distribution of aggregate sizes, $\sigma_{g}$. 
Table 4.1 - Input parameters used in the Monte Carlo uncertainty propagation analysis.

\begin{tabular}{|c|c|c|c|}
\hline Input & $\begin{array}{l}\text { Parameters of } \\
\text { Distribution }\end{array}$ & Source & $\begin{array}{l}\text { Contribution to } \\
2 \sigma \text { of } f_{v}, d_{p}, R_{g m 1}\end{array}$ \\
\hline Normalized laser irradiance & $\begin{array}{l}\text { Normal; } \mu=1 ; \\
\sigma=0.02\end{array}$ & Manufacturer Spec. & $0 \%, \pm 1.4 \%, 0 \%$ \\
\hline $\begin{array}{l}\text { Soot refractive index light } \\
\text { absorption function at lower LII } \\
\text { wavelength [-] }\end{array}$ & $\begin{array}{l}\text { Normal: } \mu=0.348 \\
\sigma=0.045\end{array}$ & $\begin{array}{l}\text { (Dobbins et al., 1994; Snelling et al., 2004; Yon et al., } \\
\text { 2011; Coderre et al., 2011; Köylü \& Faeth, 1996; } \\
\text { Krishnan et al., 2000; Schnaiter et al., 2003; Bond \& } \\
\text { Bergstrom, 2006) }\end{array}$ & $\begin{array}{l}+30 /-21 \% \\
+8 /-9 \%, 0 \%\end{array}$ \\
\hline $\begin{array}{l}\text { Ratio of soot refractive index } \\
\text { light absorption function at } \\
\text { lower and upper LII } \\
\text { wavelengths [-] }\end{array}$ & $\begin{array}{l}\text { Normal: } \mu=1.15 \\
\sigma=0.11\end{array}$ & $\begin{array}{l}\text { (Dobbins et al., 1994; Snelling et al., 2004; Yon et al., } \\
\text { 2011; Coderre et al., 2011) }\end{array}$ & $\begin{array}{l}+46 /-38 \% \\
+16 /-13 \%, 0 \%\end{array}$ \\
\hline $\begin{array}{l}\text { Soot refractive index light } \\
\text { scattering function at scattering } \\
\text { wavelength [-] }\end{array}$ & $\begin{array}{l}\text { Normal } \mu=0.31 \\
\sigma=0.04\end{array}$ & (Yon et al., 2011) & $\begin{array}{l}0 \%,+9 /-7 \% \\
0 \%\end{array}$ \\
\hline $\begin{array}{l}\text { LII calibration constant at lower } \\
\text { wavelength, } \eta_{1}\end{array}$ & $\begin{array}{l}\text { Normal : } \\
\mu=1.81 \frac{\mathrm{mm}^{3}}{A} \\
\sigma=0.028 \frac{\mathrm{mm}^{3}}{A}\end{array}$ & Calculated via constituent elemental errors & $\pm 4 \%, \pm 1 \%, 0 \%$ \\
\hline $\begin{array}{l}\text { LII calibration constant at upper } \\
\text { wavelength, } \eta_{2}\end{array}$ & $\begin{array}{l}\text { Normal }: \mu=0.38 \frac{\mathrm{mm}^{3}}{\mathrm{~A}} \\
\sigma=0.0035 \frac{\mathrm{mm}^{3}}{\mathrm{~A}}\end{array}$ & Calculated via constituent elemental errors & $\pm 5 \%, \pm 2 \%, 0 \%$ \\
\hline $\begin{array}{l}\text { Equivalent laser sheet } \\
\text { thickness, } w_{e}\end{array}$ & $\begin{array}{l}\text { Custom, similar to } \\
\text { Log-normal: } \\
\mu \approx \ln (0.50 \mathrm{~mm}) \\
\sigma \approx \ln (1.1 \mathrm{~mm})\end{array}$ & Numerical simulations (Crosland et al., 2011) & $\begin{array}{l}+15 /-16 \% \\
+6 /-5 \%, 0 \%\end{array}$ \\
\hline Fractal dimension, $D_{f}$ & $\begin{array}{l}\text { Normal: } \mu=1.7 \\
\sigma=0.15\end{array}$ & (Köylü et al., 1995) & $\begin{array}{l}0 \%,+17 /-14 \%, \\
+2 /-1 \%\end{array}$ \\
\hline
\end{tabular}




\begin{tabular}{|c|c|c|c|c|}
\hline \multicolumn{2}{|l|}{ Input } & $\begin{array}{l}\text { Parameters of } \\
\text { Distribution }\end{array}$ & Source & $\begin{array}{l}\text { Contribution to } \\
2 \sigma \text { of } f_{v}, d_{p}, R_{g m 1}\end{array}$ \\
\hline \multicolumn{2}{|c|}{ Fractal prefactor, $k_{f}$} & $\begin{array}{l}\text { Normal: } \\
\mu=1.7 ; \sigma=0.5\end{array}$ & Based on values summarized in Sorensen (2001) & $\begin{array}{l}0 \%,+33 /-17 \% \\
<0.5 \%\end{array}$ \\
\hline \multicolumn{2}{|c|}{$\begin{array}{l}\text { Width of log-normal } \\
\text { distribution of aggregates, } \sigma_{\mathrm{g}}\end{array}$} & $\begin{array}{l}\text { Uniform: } \\
\text { Min }=1.7 ; \operatorname{Max}=2.5\end{array}$ & Link et al. (2011); Sorensen et al. (1995) & $\begin{array}{l}0 \%, \pm 3 \%,+18 /- \\
16 \%\end{array}$ \\
\hline \multicolumn{2}{|c|}{ Forward detection angle, $\theta_{1}$} & $\begin{array}{l}\text { Uniform: } \\
\text { Min }=-28^{\circ} ; \operatorname{Max}=- \\
32^{\circ}\end{array}$ & Measured & $\begin{array}{l}0 \%,<0.5 \% \\
<0.5 \%\end{array}$ \\
\hline \multicolumn{2}{|c|}{ Backward detection angle, $\theta_{2}$} & $\begin{array}{l}\text { Uniform: } \operatorname{Min}=148^{\circ} ; \\
\operatorname{Max}=152^{\circ}\end{array}$ & Measured & $\begin{array}{l}0 \%,<0.5 \% \\
\pm 1 \%\end{array}$ \\
\hline \multicolumn{2}{|c|}{$\begin{array}{l}\text { Forward scat. calibration } \\
\text { constant, } \eta_{3}\end{array}$} & $\begin{array}{l}\text { Normal: } \mu=28.3 \mathrm{Vm}^{-} \\
{ }^{\prime} ; \sigma=0.65 \mathrm{Vm}^{-1}\end{array}$ & Measured (Crosland, Johnson, et al., 2013) & $0 \%, \pm 1 \%, \pm 4 \%$ \\
\hline \multicolumn{2}{|c|}{$\begin{array}{l}\text { Backward scat. calibration } \\
\text { constant, } \eta_{4}\end{array}$} & $\begin{array}{l}\text { Normal: } \mu=78 \mathrm{Vm}^{-1} \\
\sigma=1.5 \mathrm{Vm}^{-1}\end{array}$ & Measured (Crosland, Johnson, et al., 2013) & $\begin{array}{l}0 \%,<0.5 \% \\
<0.5 \%\end{array}$ \\
\hline \multirow[t]{4}{*}{$\begin{array}{l}\text { Experimental } \\
\text { measurement }\end{array}$} & LII at $\lambda_{1}$ & $\begin{array}{l}\text { Normal: } \mu=5.6 \mathrm{~V} ; \\
\sigma=0.089 \mathrm{~V}\end{array}$ & Measured & $\pm 4 \%, \pm 1 \%, 0 \%$ \\
\hline & LII at $\lambda_{2}$ & $\begin{array}{l}\text { Normal: } \mu=2.5 \mathrm{~V} ; \\
\sigma=0.091 \mathrm{~V}\end{array}$ & Measured & $\begin{array}{l}+9 /-8 \%, \pm 3 \% \\
0 \%\end{array}$ \\
\hline & Forward scatter & $\begin{array}{l}\text { Normal: } \mu=2.2 \mathrm{~V} \\
\sigma=0.026 \mathrm{~V}\end{array}$ & Measured & $0 \%, \pm 1 \%, \pm 3 \%$ \\
\hline & \begin{tabular}{|l} 
Backward \\
scatter
\end{tabular} & $\begin{array}{l}\text { Normal: } \mu=3.3 \mathrm{~V} ; \\
\sigma=0.033 \mathrm{~V}\end{array}$ & Measured & $0 \%, \pm 1 \%, \pm 3 \%$ \\
\hline \multirow{3}{*}{\begin{tabular}{|l} 
Background \\
during \\
experimental \\
measurement
\end{tabular}} & LII at $\lambda_{1}$ & $\begin{array}{l}\text { Normal: } \mu=0.023 \mathrm{~V} \\
\sigma=0.011 \mathrm{~V}\end{array}$ & Measured & $\begin{array}{l}<0.5 \%,<0.5 \% \\
<0.5 \%\end{array}$ \\
\hline & LII at $\lambda_{2}$ & $\begin{array}{l}\text { Normal: } \mu=-0.0084 \\
V ; \sigma=0.017 \mathrm{~V}\end{array}$ & Measured & $\begin{array}{l}<0.5 \%,<0.5 \% \\
<0.5 \%\end{array}$ \\
\hline & Forward scatter & $\begin{array}{l}\text { Normal: } \mu=0.036 \mathrm{~V} \\
\sigma=0.015 \mathrm{~V}\end{array}$ & Measured & $\begin{array}{l}<0.5 \%,<0.5 \% \\
<0.5 \%\end{array}$ \\
\hline
\end{tabular}




\begin{tabular}{|c|c|c|c|c|}
\hline \multicolumn{2}{|l|}{ Input } & \multirow{2}{*}{$\begin{array}{l}\text { Parameters of } \\
\text { Distribution } \\
\text { Normal: } \mu=0.0012 \mathrm{~V} ; \\
\sigma=0.017 \mathrm{~V}\end{array}$} & \multirow{2}{*}{$\begin{array}{l}\text { Source } \\
\text { Measured }\end{array}$} & \multirow{2}{*}{$\begin{array}{l}\text { Contribution to } \\
2 \sigma \text { of } f_{v}, d_{p}, R_{g m 1} \\
<0.5 \%,<0.5 \%, \\
<0.5 \% \\
\end{array}$} \\
\hline & $\begin{array}{l}\text { Backward } \\
\text { scatter }\end{array}$ & & & \\
\hline \multicolumn{2}{|c|}{$\begin{array}{l}\text { Various calibrated neutral } \\
\text { density filters }\end{array}$} & $\begin{array}{l}\text { Normal: } \sigma=1 \% \text { of } \\
\text { nominal value }\end{array}$ & Based on spec. of calibration device & $\begin{array}{l} \pm 5 \%, \pm 2 \% \\
\pm 0 \%\end{array}$ \\
\hline \multirow[t]{7}{*}{$\begin{array}{l}\text { Modeling } \\
\text { errors }\end{array}$} & $\begin{array}{l}\text { Equivalent filter } \\
\text { approx. }\end{array}$ & $\begin{array}{l}\text { Normal: } \mu=1 \\
\sigma=0.005, \text { on } T_{p e}\end{array}$ & $\begin{array}{l}\text { Calculated for } \\
T_{p e}=3500 \mathrm{~K}\end{array}$ & $\begin{array}{l}+10 /-9 \%, \pm 3 \% \\
0 \%\end{array}$ \\
\hline & LII signal trapping & $\begin{array}{l}\text { Normal: } \mu=1 \\
\sigma=0.025, \text { on } f_{v}\end{array}$ & Liu et al. (2008) & $\pm 5 \%, \pm 2 \%, 0 \%$ \\
\hline & $\begin{array}{l}\text { Assumed } \\
\text { monodisperse } d_{p}\end{array}$ & $\begin{array}{l}\text { Normal: } \mu=1 ; \sigma=0.1 \text {, } \\
\text { on } d_{p}\end{array}$ & $\begin{array}{l}\text { Calculated } \\
\text { based on Tian et al. (2004) }\end{array}$ & $0, \pm 20 \%, 0 \%$ \\
\hline & $\begin{array}{l}\text { ELS signal } \\
\text { trapping }\end{array}$ & $\begin{array}{l}\text { Normal: } \mu=1 \\
\sigma=0.033, \text { on } K_{v v}\end{array}$ & $\begin{array}{l}\text { Calculated } \\
\text { from } f_{v} \text { Snelling et al. (2005) }\end{array}$ & $0, \pm 1.3 \%, 3.3 \%$ \\
\hline & $\begin{array}{l}\text { ELS intra- } \\
\text { aggregate } \\
\text { scattering }\end{array}$ & $\begin{array}{l}\text { Normal }: \mu=1 ; \\
\sigma=0.05, \text { on } K_{v v}\end{array}$ & Based on Sorensen (2001) & $0, \pm 1 \%, 0 \%$ \\
\hline & $\begin{array}{l}\text { Choice of } \\
\text { structure factor }\end{array}$ & $\begin{array}{l}\text { Normal: } \mu=1 \\
\sigma=0.03, \text { on } R_{g m 1}\end{array}$ & Calculated & $0,+4 /-3 \%, \pm 6 \%$ \\
\hline & $\begin{array}{l}\text { Choice of } R_{g} \\
\text { distribution }\end{array}$ & $\begin{array}{l}\text { Normal: } \mu=1 \\
\sigma=0.02, \text { on } R_{g m 1}\end{array}$ & Calculated & $0, \pm 2 \%, \pm 4 \%$ \\
\hline
\end{tabular}


The next column of Table 4.2 fixes values related to the characterization of soot $\left(E(m), F(m), D_{f}, k_{f}, \sigma_{g}\right)$ and excludes the various soot modeling errors grouped together at the bottom of Table 4.1 while allowing all remaining parameters to vary as outlined above. These results represent the relevant uncertainty when comparing one single measurement to another, since for any given flame location it is reasonable to assume that these soot properties are not changing significantly. The final column presents the uncertainty attributable only to measurement noise, and is instructive when considering possible improvements to the apparatus. For this latter case, the soot volume fraction uncertainty remains large due to the high photon shot noise associated with the use of PMTs used in detection of the LII signals. The soot primary particle diameter uncertainty is dominated by the uncertainty in the soot volume fraction, while the uncertainty in the radius of gyration is quite low since the process of ratioing two measurement signals cancels out any shot-to-shot variations in the laser energy or flame movement. 
Table 4.2 - Properties of the distributions resulting from Monte Carlo uncertainty propagation. Mean values are followed by upper and lower bounds of the $2 \sigma(95 \%)$ confidence intervals expressed both in absolute terms and as a percentage of the mean.

\begin{tabular}{|c|c|c|c|}
\hline & Total Uncertainty & Fixed Soot Properties & $\begin{array}{l}\text { Measurement Noise } \\
\text { Only }\end{array}$ \\
\hline & $4.0\left\{\begin{array}{l|l}6.8 \\
2.2\end{array}\right.$ & $3.9\left\{\begin{array}{c|c}4.7 \\
2.3 .1\end{array}\right.$ & $3.8\left\{\begin{array}{l|l}4.2 \\
3.4\end{array}\right.$ ppm $\left.\begin{array}{l}9.8 \% \\
9.1 \%\end{array}\right\}$ \\
\hline ary & $38\left\{\begin{array}{l|l}57 \\
25\end{array} \mathrm{~nm} \mid \begin{array}{l}50 \% \\
33 \%\end{array}\right\}$ & $36\left\{\begin{array}{l|l}39 \\
34\end{array} \mathrm{~nm} \mid \begin{array}{l}8.0 \% \\
7.0 \%\end{array}\right\}$ & 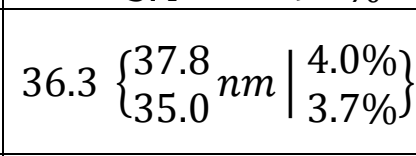 \\
\hline gregate & $69\left\{\begin{array}{l|l}85 \\
56\end{array} \mathrm{~nm} \mid \begin{array}{l}22 \% \\
19 \%\end{array}\right\}$ & 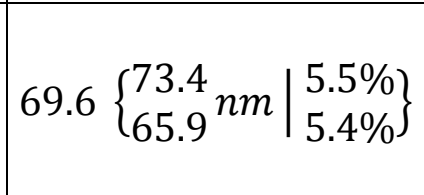 & 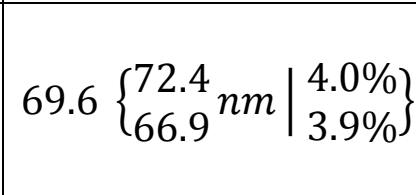 \\
\hline
\end{tabular}

Although the total uncertainties of $33-69 \%$ for instantaneous measurement of primary particle size and soot volume fraction shown in Table 4.2 are non-negligible, they are dominated by uncertainties in soot properties which are a common concern among all optical diagnostics for soot. For relative measurements in which soot properties can be assumed invariant among a given set of conditions, the achievable uncertainties of $<21 \%$ are quite encouraging. Moreover, the combined LII/ELS technique for the first time enables instantaneous, simultaneous measurement of soot volume fraction, primary particle diameter and radius of gyration within a turbulent sooting flame, and to the authors' knowledge there is currently no well-characterized alternative measurement apparatus that can produce equally detailed, non-intrusive, spatially-resolved, instantaneous data. 


\subsection{Conclusions}

Combined laser-induced incandescence and two-angle elastic light scattering was shown to be a viable method of calculating instantaneous soot volume fraction, primary particle diameter, and radius of gyration. A new experimental arrangement that places the two scattering angles on opposite sides of the incident laser beam was introduced in an effort to maximize measurement volume overlap. Measurements in a previously-studied flame show good agreement with published soot volume fraction, primary particle diameter, and aggregate radius of gyration results. While the total uncertainty of the $f_{v}(+69 \% /-$ 45\%) measurement is considerable, it is dominated by imperfect knowledge of soot optical properties which plagues all optically-based techniques for measuring soot aggregates and is thus not specific to the current apparatus. The total uncertainties of $d_{p}(+50 \% /-33 \%)$ and $R_{g m l}(+22 /-19 \%)$ measurements are also considerable and are dominated by imperfect knowledge of soot aggregation characteristics, which are difficult to determine via scattering and very timeconsuming and expensive to determine via TEM. Uncertainties for relative measurements, in which soot properties can be considered fixed among conditions, are much more modest at $+21 /-20 \%,+8.0 /-7.0 \%$, and $+5 \cdot 5 /-5.4 \%$ for $f_{v}, d_{p}$ and $R_{g m l}$, respectively. Because the LII signals were decreased by a factor of about 7 using neutral density filters to avoid detector saturation, with the present technique it should be possible to make measurements in more weakly-sooting flames by adjusting the filtering without increasing the levels of uncertainty reported here. It is important to note that some of the specific uncertainties discussed in the current work are dependent on the particular signal levels and 
experimental setup employed, and should not be directly extrapolated to other experimental cases without reproducing a similarly thorough uncertainty analysis. By offering the possibility of simultaneous, instantaneous, and spatially resolved measurements of soot volume fraction and morphology within turbulent flames, the new combined LII/ELS technique has potential for acquiring critical data not available to other techniques.

\subsection{Acknowledgements}

The authors acknowledge support in part from the PERD Particles and Related Emissions Program, Project C11.008, the PERD AFTER Program, Project C23.006, the PERD UPAIRI Program 1.1.4, and from the Natural Sciences and Engineering Research Council of Canada. 


\section{Chapter 5}

\section{Simultaneous Instantaneous Measurement of Soot Volume Fraction, Primary Particle Diameter, and Aggregate Size in Turbulent Buoyant Diffusion Flames}

This chapter is currently undergoing peer review for possible publication in the Proceedings of the Combustion Institute. It should be cited as:

Crosland, BM, KA Thomson, MR Johnson (2013) Simultaneous instantaneous measurement of soot volume fraction, primary particle diameter, and aggregate size in turbulent buoyant diffusion flames, submitted to the Proceedings of the Combustion Institute, December 4, 2013. Manuscript ID: PROCI-D-13-00156.

This paper was co-authored by the thesis author, Brian Crosland, and his Ph.D. supervisors Prof. Matthew Johnson and Dr. Kevin Thomson. Mr. Crosland setup, tested, and characterized the measurement equipment; performed the measurements, uncertainty analysis, and initial data analysis; and wrote a first draft of the manuscript. The theory development, final data analysis, and editing and revision of the manuscript were conducted jointly.

\section{$5.1 \quad$ Abstract}

Understanding the mechanisms of soot formation, growth, oxidation, and emission is important for diverse reasons including better combustor design, quantifying soot's contribution to climate change, and mitigating air quality concerns. Instantaneous soot measurement in turbulent flames is difficult, and has mostly been restricted to high-momentum jet flames and pool fires. The 
current work partially fills this gap by presenting simultaneous measurements of soot volume fraction $\left(f_{v}\right)$, effective aggregate radius of gyration $\left(R_{g m l}\right)$, and primary particle diameter $\left(d_{p}\right)$ in combination with separately-acquired measurements of mean gas velocity, within a range of turbulent buoyant nonpremixed jet flames burning a fuel mixture representative of associated gas flares in the upstream oil and gas industry. Fifteen cases comprising six possible nozzle exit velocities and four nozzle diameters were studied. Soot intermittency and histograms of $f_{v}$ and $d_{p}$ support the suggestion that reduced $f_{v}$ near the flame tip results from increased soot intermittency rather than reduced local $f_{v}$. Furthermore, the data indicate that oxidation of mature soot structures occurs rapidly and completely, and is insensitive to the local $f_{v}$. For most conditions studied, centerline $f_{v}$ shows self-similar behavior when scaled by measured flame height in the axial direction. The more buoyancy-dominated flames show a marked increase in peak $f_{v}$ that occurs lower in flame-length-normalized coordinates, while the more momentum-dominated flames show a decreased peak $f_{v}$ that occurs higher in flame-length-normalized coordinates. Low in the flame, soot is only present in an annular region where $f_{v}, d_{p}$, and $R_{g m l}$ all grow. Once soot is present on the centerline, $d_{p}$ growth slows and $d_{p}$ is relatively constant at all radial locations and all conditions higher in the flame. Aggregate size continues to grow steadily with increased flame height and correlates well with residence time when adjusted to account for differing flow fields close to the burner outlet. 


\subsection{Introduction}

Combustion-generated soot is a known health hazard (US EPA, 2010; Pope III et al., 2002), and black carbon, a principal constituent of soot, is a critical climate forcer (IPCC, 2007; Hansen et al., 2000; Ramanathan \& Carmichael, 2008). Recent studies implicate black carbon as the second-most important climateforcing agent after carbon dioxide (Bond et al., 2013; Jacobson, 2010; Ramanathan \& Carmichael, 2008). Gas flaring in the petroleum industry is a potentially significant source of global soot emissions given that satellite data indicate global flared volumes exceed 135 billion $\mathrm{m}^{3}$ annually (Elvidge et al., 2009). Accurate estimation of soot emissions to meet reporting regulations and support informed policy decisions is difficult due to the limited literature for buoyancy-dominated turbulent non-premixed flames, the questionable relevance of existing emission factor models (see McEwen \& Johnson 2012), and the challenges of in-situ field measurements (Johnson et al., 2011; Johnson et al., 2013). Although flares, like most practical combustion processes, involve turbulent flames, academic research of sooting flames has traditionally focused on laminar flames due to their relative simplicity. Both modeling and measurements of turbulent flames are complicated by their unsteady nature, short time scales, complex chemistry, large spatial gradients, and thermal radiation. Consequently, there are comparatively few works focusing on sooting in turbulent flames. Most previous studies reporting spatially-resolved measurements of soot in non-premixed turbulent flames have focused on momentum-dominated flames (e.g. Köhler et al., 2011; Hu et al., 2003; Santos \& Costa, 2005; Lee et al., 2009; Kent \& Bastin, 1984; B. Yang \& Köylü, 2005a; 
Sivathanu \& Faeth, 1990; Brookes \& Moss, 1999; Qamar et al., 2009; Qamar et al., 2005; B. Yang \& Köylu, 2005b) with nozzle exit Reynolds numbers (Re) ranging from 4,000 to 83,000 . Of these, most use heavier fuels than the methane-dominated compositions found in typical associated gas flares (Johnson \& Coderre, 2012). A notable exception is Qamar et al. (2009), who performed 2D laser-induced incandescence (LII) measurements in the Delft Flame III with simulated Dutch natural gas and postulated that the reduction in mean soot volume fraction $\left(f_{v}\right)$ near the flame tip occurs via reduction in the number of soot sheets, rather than reduction in $f_{v}$ within soot sheets. This was supported by instantaneous 2D measurements of $f_{v}$ by Köhler et al. (2011) in a turbulent nonpremixed ethylene jet flame.

To the authors' knowledge, only two studies have reported spatiallyresolved measurements of $f_{v}$ within buoyant non-premixed turbulent flames (Coppalle \& Joyeux, 1994; Xin \& Gore, 2005). Xin \& Gore (2005) performed two-dimensional $f_{v}$ measurements in turbulent buoyant methane and ethylene flames with $R e$ of $\sim 140$. Coppalle \& Joyeux (1994) reported simultaneous local temperature and $f_{v}$ measurements in buoyancy- and momentum-dominated ethylene flames with $R e$ of 550, 5700 and 11800.

Scaling of buoyant non-premixed flames is complicated by the dependence of flame length $\left(L_{f}\right)$ on fuel flow rate. Results from Coppalle \& Joyeux (1994) were presented on spatial coordinates normalized by the location of the peak $f_{v}$, producing some agreement low in the flame for the two momentum-dominated flames, but generally poor agreement with the buoyancy-dominated flame. Xin 
and Gore (2005) presented results with axial location normalized by nozzle diameter, $D_{e}$ (as is common practice for momentum-dominated flames where $L_{f}$ is typically only dependent on fuel properties and $D_{e}$ ), but were unable to directly compare quantitative results between their two fuel types due to optically-thick conditions in the ethylene flame.

The primary objectives of the current research are to i) use a novel diagnostic technique to explore soot trends in turbulent buoyant flames of practical interest, ii) investigate the mechanism of soot burnout high in the flame, and iii) evaluate methods of scaling mean $f_{v}$ and morphology trends in turbulent buoyant non-premixed flames.

\subsection{Experimental Setup \& Method}

\subsubsection{Burner}

A schematic of the turbulent non-premixed lab-scale flare (LSF) is provided in McEwen \& Johnson (2012). Mass flow controllers feed mixed, gaseous fuel through a diffusing chamber, settling chamber, cubic-contoured converging nozzle, and into an interchangeable burner tip. Burner tip diameters of 25.4, 38.1, 50.8, and $76.2 \mathrm{~mm}$ were used in the present experiments. Turbulence grids placed three to five diameters upstream of each burner exit were used to produce cold-flow turbulence intensities (confirmed by hotwire anemometer measurements) of $2-5 \%$ at the exit plane. The fuel mixture was selected to be representative of associated gas flare compositions (McEwen \& Johnson, 2012;

Johnson \& Coderre, 2012) and contained 85.3\% $\mathrm{CH}_{4}, 7.1 \% \mathrm{C}_{2} \mathrm{H}_{6}, 3.1 \% \mathrm{C}_{3} \mathrm{H}_{8}, 1.4 \%$ $\mathrm{C}_{4} \mathrm{H}_{10}, 1.9 \% \mathrm{CO}_{2}$ and $1.2 \% \mathrm{~N}_{2}$ by volume. 


\subsubsection{Measurement Strategy}

A novel combined laser induced incandescence (LII) and elastic light scattering (ELS) apparatus (Crosland, Thomson, et al., 2013) was used to make simultaneous, instantaneous measurements of $f_{v}$, primary particle diameter $\left(d_{p}\right)$ and aggregate radius of gyration $\left(R_{g m l}\right)$. Due to vertical space constraints, the burner was fixed in place and a platform supporting the laser head as well as the beam shaping and signal collection optics was positioned using a three-axis traverse. Light from a pulsed Nd:YAG laser operating at the fundamental wavelength of $1064 \mathrm{~nm}$ was formed into an $8 \mathrm{~mm} \times 0.5 \mathrm{~mm}$ cross-section sheet and used to induce incandescence and scattering signals from soot present in the flame. The scattering signal was detected at two diametrically opposed locations representing forward scattering $\left(30^{\circ}\right)$ and backward scattering $\left(150^{\circ}\right)$; incandescence signals were also collected from the backward scattering optics. The signals were filtered by wavelength (centered at 447 and $800 \mathrm{~nm}$ for LII, $1064 \mathrm{~nm}$ for ELS) and integrated over gate widths of $10 \mathrm{~ns}$ for LII and $30 \mathrm{~ns}$ for ELS. The current detection optics produced measurement volumes of $2 \mathrm{~mm} \mathrm{x}$ $4 \mathrm{~mm} \times 0.5 \mathrm{~mm}$. As a result of the highly intermittent nature of the flame, it was possible to characterize background signals (composed of the mean flame radiation and any secondary laser scattering) during regular data acquisition. The background was calculated by creating a histogram of measured signals and fitting a normal distribution in the vicinity of the most probable value. This information was subsequently used for background subtraction and uncertainty analysis. 
The two incandescence signals were used to determine the heated soot temperature via pyrometry. The signal at $447 \mathrm{~nm}$ was then used with the absolute detector calibration to determine $f_{v}$ (Snelling et al., 2005), which is then solely a function of physical constants, measured signals, detection wavelengths, light detection efficiency calibration constants, and the soot index of refraction absorption function, $E\left(m_{\lambda}\right)$. A full treatment of the LII calculation and associated uncertainty quantification for the current apparatus is given in Crosland, Thomson, et al. (2013). Because the soot is not heated to its sublimation temperature during LII measurement and the laser fluence is reasonably constant $(2 \sigma=4 \%)$, the heated soot temperature is indicative of the gas temperature in the flame plus a heating offset. While it would be impractical to infer absolute flame temperatures in this manner, results are useful for analysis of $f_{v}$ versus temperature trends.

The ratio of the two ELS measurements can be combined with RayleighDebye-Gans fractal aggregate theory (RDG-FA) (Martin \& Hurd, 1987; Julien \& Botet, 1987; Dobbins \& Megaridis 1991) to determine a representative mean aggregate radius of gyration of soot in the measurement volume noted as $R_{g m l}$. This measure of the central tendency of the distribution of aggregate sizes is based on the mean number of primary particles per aggregate. In the current work, calculation of $R_{g m l}$ requires assumptions for aggregate size distribution shape and width, aggregate structure factor, fractal dimension, and fractal prefactor, for which we have chosen log-normal, $\sigma_{g}=2.1$, the Gaussian cutoff structure factor of Lin et al. (1990), 1.7, and 1.7. Detailed justification for these 
selections, as well as quantification of their influence on the uncertainty of $R_{g m l}$, is provided in Crosland, Thomson, et al. (2013).

The backward scattering signal calibrated to an absolute scale (Crosland, Johnson, et al., 2013), combined with the absorption coefficient (measured using LII), and the mean aggregate size can be used with RDG theory to determine $d_{p}$ (De Iuliis et al., 1998). The diameter determined in this way depends on all of the soot properties used for determination of $f_{v}$ and $R_{g m}$, as well as the soot index of refraction scattering function, $F\left(m_{\lambda}\right)$, at the scattering wavelength.

In separate measurements, the flow was seeded with fumed silica particles for in-flame measurement of velocity via laser Doppler velocimetry (Dantec, F30). The mean velocity profiles were fitted using local polynomial regression and the reciprocal of the resulting fits were integrated in space to determine a characteristic residence time. The residence times measured this way are based on Eulerian time scales, and as such are expected to underestimate the residence time experienced by soot structures following a given pathline in a turbulent flow. The true residence times are expected to differ from the measured residence times by a time scaling factor of $\beta=\alpha / \sqrt{\overline{u^{\prime 2}}} / \bar{u}$ (Pasquill \& Smith 1983). The constant $\alpha$ is reported to have a value between 0.35 and 0.8 for atmospheric flows (Pasquill \& Smith 1983) or between 0.3 and 0.6 for low Reynolds number flows (Sato \& Yamamoto 1987). Since the turbulence intensity profiles are similar throughout the flame height for all conditions, it is expected that all the measured residence times share a similar $\beta$, with values of the order of 2 . These measurements used the same traverse system as the LII/ELS measurements, but 
the presence of the seed particles precluded simultaneous measurement of velocity and ELS.

\subsubsection{Experimental Methodology}

Experiments were conducted using mass flow rates that would produce mean cold flow exit velocities $\left(u_{e}\right)$ of $0.1,0.25,0.5,0.9,1.5$ and $2.2 \mathrm{~m} / \mathrm{s}$ at a pressure of $101.3 \mathrm{kPa}$ and a temperature of $\mathrm{o}^{\circ} \mathrm{C}$. All flow rates were not possible with all burner diameters since the flames produced were sometimes too large for the LSF enclosure. The test conditions are detailed in Table 5.1, and assigned unique labels for use in subsequent figures. Measurements at five radial locations were made at each of eight heights above the burner. The heights, $x$, were chosen relative to previously-measured visible flame heights, so that $x / L_{f}=0.08,0.16$, $0.22,0.35,0.5,0.7,0.9$, and 1.1. The shot-to-shot measurement variability of $f_{v}$, $R_{g m l}$ and $d_{p}$ were calculated in real-time and used to decide the number of measurement points needed at each location. 
Table 5.1 - Flow conditions and flame parameters

\begin{tabular}{|c|c|c|c|c|c|c|c|}
\hline Label & $\begin{array}{l}D_{e} \\
\mathrm{~mm}\end{array}$ & $\begin{array}{c}\dot{m} \\
\operatorname{SLPM}^{a}\end{array}$ & $\begin{array}{l}u_{e}^{a, b} \\
\mathrm{~m} / \mathrm{s}\end{array}$ & $\begin{array}{c}L_{f}, \mathrm{~m} \\
\text { (McEwen } \\
\text { 2010) }\end{array}$ & $R e^{a}$ & $\begin{array}{c}R i= \\
g D_{e} / u_{e}^{2}\end{array}$ & $\begin{array}{c}\text { Global Froude Number } \\
\frac{u_{e}}{\sqrt{g D_{e}}(s+1)^{3 / 2}} \\
\text { (Delichatsios 1993) }\end{array}$ \\
\hline $25-1$ & \multirow{6}{*}{25.8} & 3.0 & 0.1 & 396 & 210 & 25 & 0.0033 \\
\hline $25-2$ & & 7.6 & 0.25 & 509 & 500 & 4.0 & 0.0080 \\
\hline $25-3$ & & 15.2 & 0.5 & 682 & 1080 & 1.0 & 0.016 \\
\hline $25-4$ & & 27.4 & 0.9 & 845 & 1940 & 0.31 & 0.030 \\
\hline $25-5$ & & 45.6 & 1.5 & 1070 & 3240 & 0.11 & 0.048 \\
\hline $25-6$ & & 66.9 & 2.2 & 1220 & 4750 & 0.052 & 0.071 \\
\hline $38-1$ & \multirow{4}{*}{38.1} & 6.8 & 0.1 & 519 & 320 & 37 & 0.0028 \\
\hline $38-2$ & & 17.1 & 0.25 & 662 & 810 & 6.0 & 0.0067 \\
\hline $38-3$ & & 34.2 & 0.5 & 893 & 1620 & 1.5 & 0.013 \\
\hline $38-4$ & & 61.6 & 0.9 & 1127 & 2920 & 0.46 & 0.023 \\
\hline $51-1$ & \multirow{3}{*}{50.8} & 12.2 & 0.1 & 610 & 430 & 50 & 0.0025 \\
\hline $51-2$ & & 30.4 & 0.25 & 948 & 1080 & 8.0 & 0.0058 \\
\hline $51-3$ & & 60.8 & 0.5 & 1130 & 2160 & 2.0 & 0.012 \\
\hline $76-1$ & \multirow{2}{*}{76.2} & 27.4 & 0.1 & 774 & 650 & 74 & 0.0020 \\
\hline $76-2$ & & 68.4 & 0.25 & 997 & 1620 & 12 & 0.0048 \\
\hline
\end{tabular}

\subsection{Data Post-Processing}

\subsubsection{Data Filtering}

Due to the inherently intermittent nature of the flame and the non-linear nature of the equations used to calculate $f_{v}, R_{g m l}$ and $d_{p}$, it was necessary to filter measurements to avoid erroneous and non-physical results. Data with low signal-to-noise, in which one or more of the measured voltages were not more than five standard deviations above the measured background signal, were first removed. Calculations of $f_{v}, d_{p}$ and $R_{g m l}$ were performed on the remaining data. The results were then filtered based on physical criteria which involved removing data where: i) $R_{g m l}$ was greater than $300 \mathrm{~nm}$, and ii) $R_{g m l}$ was less than one third of $d_{p}$. The first case arises when the dissymmetry ratio is large since the relation between dissymmetry ratio and $R_{g m l}$ approaches a vertical asymptote. The second case is a geometrically impossible result, produced when weak signals and 
strong noise at low values of $R_{g m l}$ and $f_{v}$ combine to produce asymptotic growth in measured $d_{p}$.

When reporting $f_{v}$, it is interesting to look at both the case of mean $f_{v}$ conditional on the presence of detectable soot (filtered points are removed from the dataset) and of time-averaged $f_{v}$ (filtered points are replaced with $f_{v}=0$ ). These two quantities are related by an intermittency index, defined as $\Omega=N_{s} / N_{T}$, (Lee et al., 2009) where $N_{T}$ is the total number of measurements made and $N_{s}$ is the number of measurements where soot was present. Intermittency is then expressed as $1-\Omega$. The letter $s$ is used as a superscript with $f_{v}$ to indicate when only values where soot was present are included. Measurements of $d_{p}$ and $R_{g m I}$ do not have meaning when soot is not present, and thus the filtered data points were simply removed from the dataset.

\subsubsection{Uncertainty Analysis}

The uncertainty in $f_{v}, R_{g m l}$ and $d_{p}$ was determined via propagation of elemental errors through Monte-Carlo simulations as described in detail in Crosland, Thomson, et al. (2013), but with two important differences. First, the unsteady nature of the LSF meant that independent determination of the uncertainty of each instantaneous measurement was computationally quite expensive. Uncertainty calculations were instead performed on a range of possible measurement signals and used to build lookup tables for the 95\% confidence intervals based on measured voltages and detector gain settings, allowing the uncertainty of each measurement to be quickly determined. Secondly, the various sources of elemental error discussed in Crosland, Thomson, et al. (2013) 
were separated into bias errors and instrument precision errors and propagated independently to calculate bias and instrument precision uncertainties. Since bias uncertainty is dominated by soot properties which are relatively global in nature, examination of only the precision uncertainty allows for realistic comparison of the differences among spatial locations within flames and among flame conditions. The instrument precision uncertainty combines with flame fluctuations to produce scatter in the measured data. The influence of this scatter on the mean measurement is characterized by the standard error of the mean of the measured data (i.e. $\sigma / \sqrt{N_{T}}$ ) multiplied by a coverage factor of two to produce 95\% confidence intervals.

\subsection{Results \& Discussion}

\subsubsection{Trends \& Soot Burnout}

Mean values (indicated by brackets) of $f v, f_{v}^{s}, R_{g m l}$ and $d_{p}$ on the flame centreline for the six conditions using the $D_{e}=25.4 \mathrm{~mm}$ burner tip are shown versus $x / L_{f}$ in Figure 5.1 along with $95 \%$ confidence intervals based on the standard error of the mean. Supplementary Figures S5.1-S5.3 show similar data for the other three burner tips, while supplementary Figures $\mathrm{S}_{5} \cdot 4-\mathrm{S}_{5} .7$ show axial profiles of mean data taken at the radial location of maximum time-averaged $f_{v}$ for all four burner tips. Most of the bias errors are common to all measurements, so the range of bias errors is included as text to avoid obscuring trends. The increase in $f_{v}$ between $x / L_{f}=0.08$ and 0.22 occurs off of the centreline (Figures S5.4-S5.7) and is primarily the result of surface growth. Between $x / L_{f}=0.22$ and 0.5 (Figures 5.1 and $\left.\mathrm{S}_{5.1}-\mathrm{S} 5.3\right), d_{p}$ remains relatively constant while $f_{v}$ continues to increase. 
However since even small growth in $d_{p}$ would induce large changes in $f_{v}$ (proportional to $d_{p}^{3}$ ), both surface growth and nucleation could be relevant in this region. Between $x / L_{f}=0.5$ and $0.9, f_{v}$ decreases strongly at all radial locations while $f_{v}^{s}$ remains relatively flat in comparison, indicating that oxidation is primarily the result of increased intermittency. The time-averaged $f_{v}$ in Figure 5.1a shows that as $u_{e}$ is increased, the magnitude of peak $f_{v}$ decreases (in agreement with Coppalle \& Joyeux (1994) and Lee et al. (2009), who attribute the decrease to increased mixing), and the location of peak $f_{v}$ begins to shift higher in the flame. Although mean $f_{v}^{s}$ decreases slightly between $x / L_{f}=0.7$ and 0.9 for the majority of the flow conditions studied, $d_{p}$ continues to grow. One explanation for the slight decrease in $f_{v}^{s}$ is that soot structures are becoming smaller due to stretching or oxidation such that they are occasionally smaller than the measurement volume. 


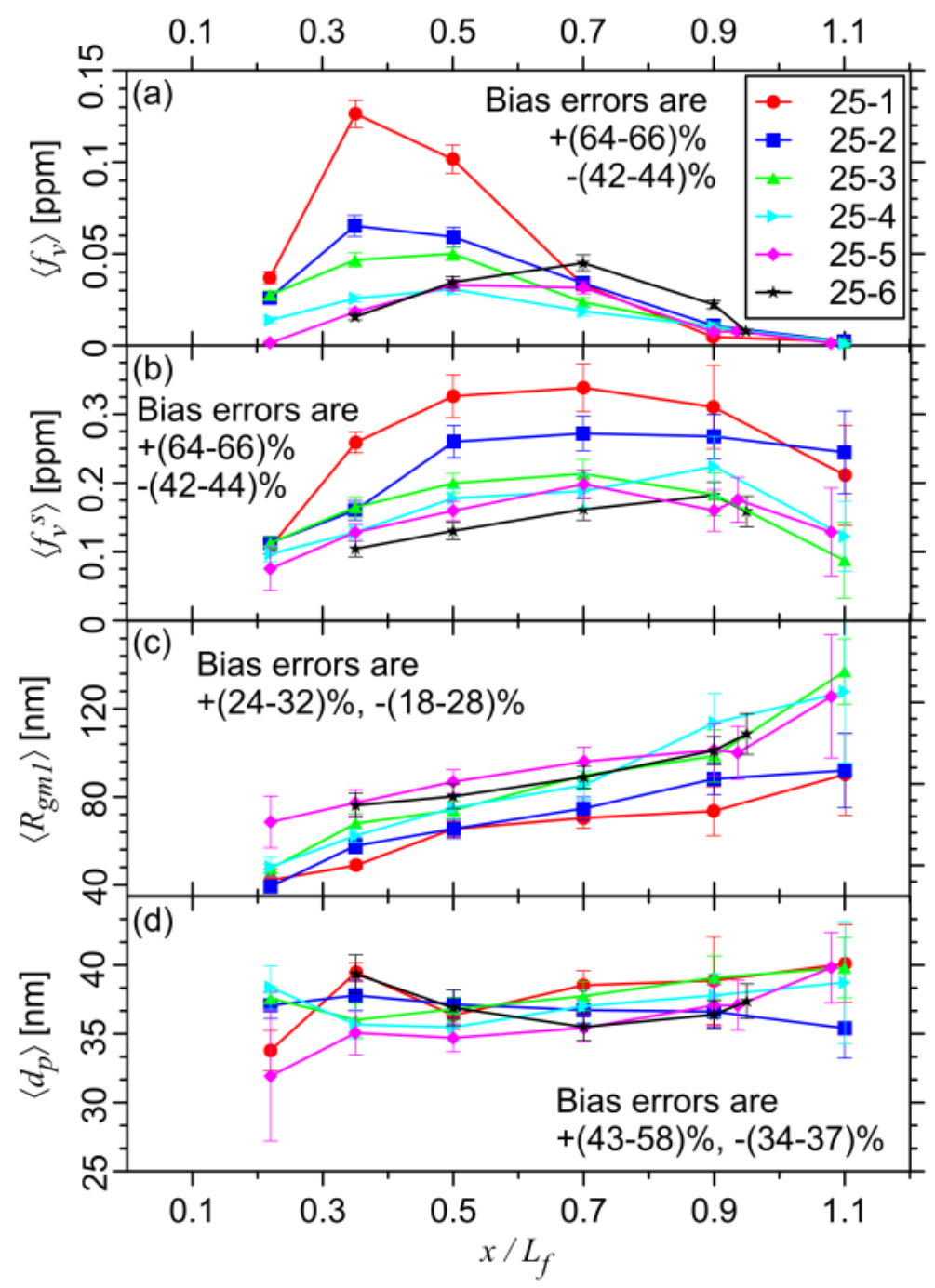

Figure 5.1 - Axial profiles of mean a) $f_{v}$, b) $f_{v}^{s}$, c) $R_{g m 1}$ and d) $d_{p}$ along the flame centreline for the $25.4 \mathrm{~mm}$ nozzle conditions.

For any given condition, $R_{g m l}$ (Figure 5.1c) increases with $x / L_{f}$. When soot is first detectable at the flame centreline near $x / L_{f}=0.22$, mean $d_{p}$ (Figure 5.1d) has reached a steady value and remains relatively constant throughout the flame height for all 15 conditions.

The mean centreline axial velocities and $f_{v}$ for all 15 conditions are represented in Figures 5.2a and 5.2b, with axial location normalized by $L_{f}$. Nine of the conditions $(25-2,25-3,38-2,38-3,51-1,51-2,51-3,76-1,76-2)$ closely 
overlap within the region indicated with grey bands, while the six nonoverlapping conditions are distinguished with individual lines. In the axial velocity plots, two conditions (25-6 and 38-4) stand out as having consistently higher velocities than the others, an indication they are somewhat affected by their initial momentum rather than just buoyancy effects. Momentum effects are also evident when comparing mean centreline residence time $(\tau)$ and $L_{f}$ as shown in Figure 5.3: $L_{f}$ varies directly with $\tau$ for both constant $u_{e}$ and constant $D_{e}$, but only when $u_{e}$ is small. For the largest values of $u_{e}$, momentum effects begin to dominate, causing a decrease in total residence time.

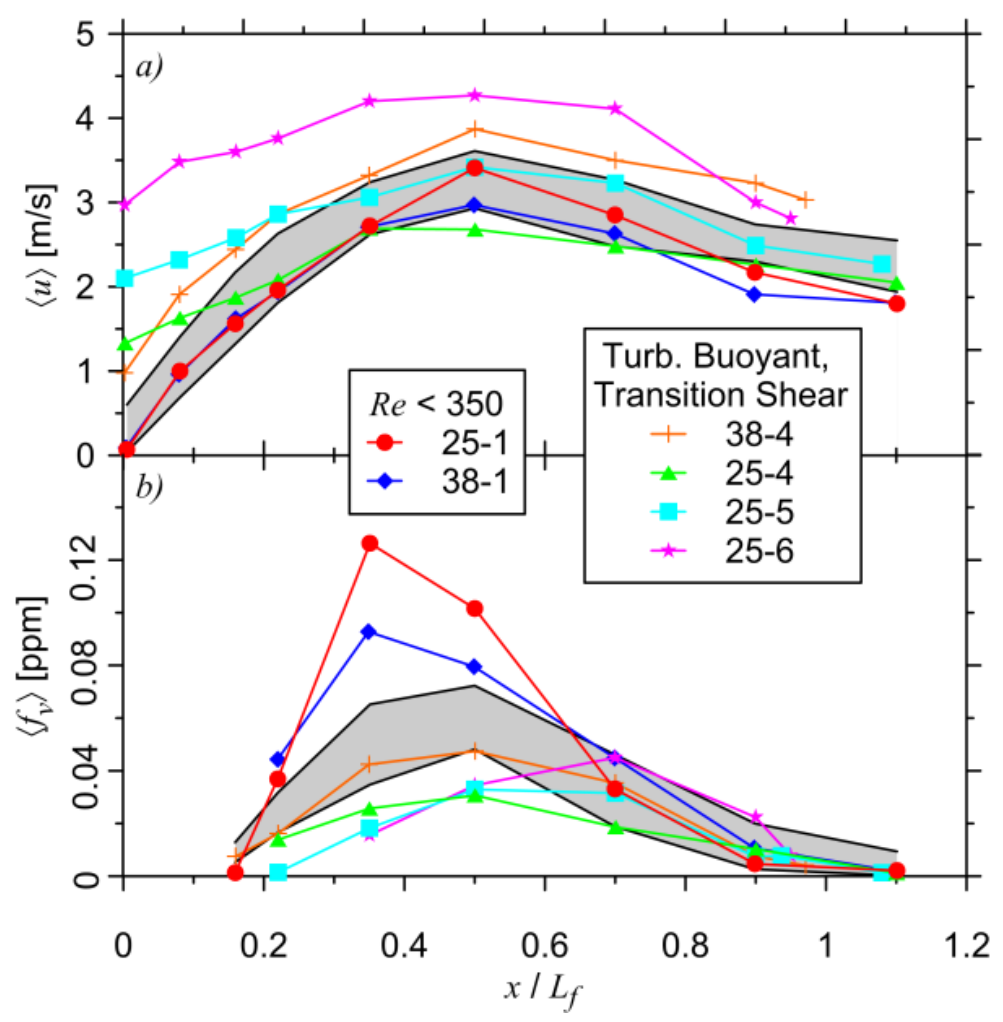

Figure 5.2 - (a) mean centreline $u$ profiles and (b) mean centreline $f_{v}$. Results for the nine cases not in the legend fall within the grey shaded region.

Delichatsios (1993) distinguishes two types of turbulent buoyant flames by the mechanism responsible for the transition from laminar-to-turbulent flow 
based on source Reynolds number and a global fire Froude number. The two conditions mentioned $(25-6,38-4)$ as well as $25-4$ and $25-5$ are expected to transition due to shear with the ambient air while the other eleven conditions are expected to transition due to buoyant mixing. The changeover between the two regimes is expected to be smooth, with increasing $u_{e}$ and decreasing $D_{e}$ favoring the shear-transition regime. As conditions fall further into the shear-transition regime, the peak $f_{v}$ moves higher in the flame. The $25-4,25-5$ and 25-6 cases also have mean heated soot temperatures that are consistently among the four coldest cases, indicating that the low $f_{v}$ in the lower half of these flames is likely the result of increased mixing, resulting in lower temperatures and thus slower soot formation.

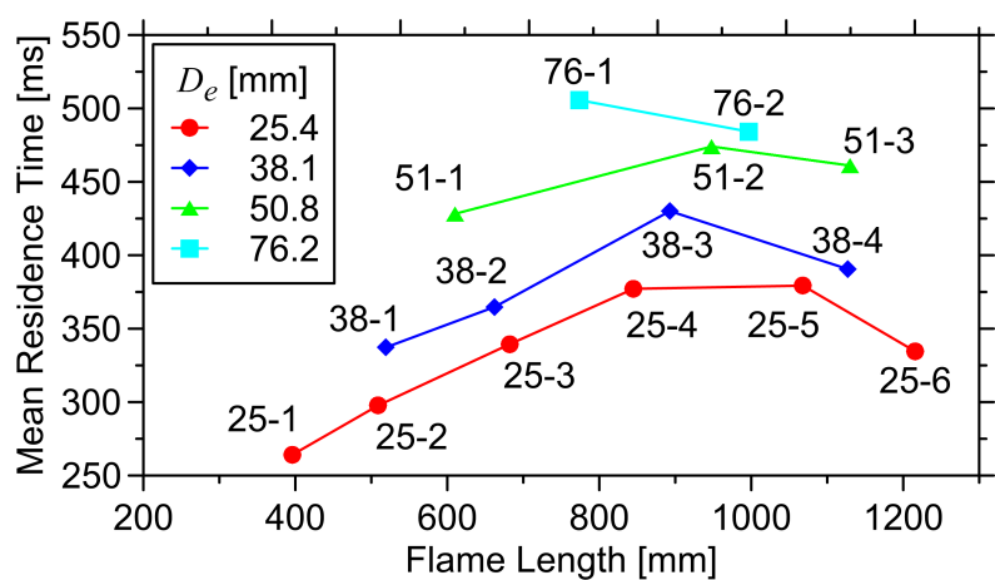

Figure 5.3 - Mean residence time and flame length for all conditions.

The other two conditions of note in Figure 5.2 are 25-1 and 38-1. While their velocity profiles remain mostly within the range of the grey band, their peak $f_{v}$ are significantly greater than all the other cases, and occur earlier than most of the other cases. These two conditions have the lowest Reynolds number of all 15 conditions, and would thus be the last flames to transition to turbulent flow. The 
laminar region would experience little mixing with the ambient air, producing higher flame temperatures and increased soot production. Analysis of flame emission videos confirms that the laminar region becomes shorter (relative to $L_{f}$ ) as the reactant mass flow rate increases.

Probability density functions (PDFs) of $f_{v}^{s}$ for four conditions at five heights above the burner are shown in Figure 5.4, while similar PDFs of $d_{p}$ are shown in Figure S5.8. At the two lowest heights, the PDF is shown at the radial location of peak $f_{v}$. Higher in the flame, where the radial profiles of mean $f_{v}^{s}$ are generally flat, the PDFs are shown at the centreline. As shown in Figure 5.4, as the diameter increases from (a) 25.4 to (b) $76.2 \mathrm{~mm}$ and $u_{e}$ increases from (a) 0.1 to (c) 0.5 to (d) $1.5 \mathrm{~m} / \mathrm{s}$, there is little noticeable change in the shape of the $f_{v}^{s}$ distributions except perhaps at $x / L_{f}=1.10$ where data are sparse. Low in the flame the intermittency decreases with increasing height as sooting structures continue to be created and are convected upward from lower in the flame. From mid-flame to flame tip, the intermittency grows steadily as soot is oxidized. If oxidation were proceeding via partial oxidation of all soot, then the PDF would become taller while shifting to smaller values of $f_{v}$, while the PDF of $d_{p}$ would shift toward smaller values of $d_{p}$. The comparative consistency of the PDFs of $f_{v}^{s}$ and $d_{p}$ at and above $x / L_{f}=0.50$ leads to two important observations. First, the suggestion of Qamar et al. (2009) that decreasing $f_{v}$ near the flame tip of momentum-dominated flames is due to increasing intermittency, rather than decreasing $f_{v}$ within soot-bearing flow structures, appears true for the buoyancydominated flames studied here. Secondly, oxidation of soot-bearing structures 
appears to be equally likely in all structures regardless of $f_{v}^{s}$ and $d_{p}$, such that entire structures appear to be either rapidly and completely oxidized, or not oxidized at all. This implies that the characteristic time of oxidation must be short relative to the characteristic time within the measurement volume, which is estimated to be on the order of $1 \mathrm{~ms}$. This contrasts with the suggestion in Lee $e t$ al. (2009) based on planar LII images in momentum-dominated flames that only high- $f_{v}$ structures survive to be emitted, which would imply that oxidation occurs preferentially in low- $f_{v}$ structures. 


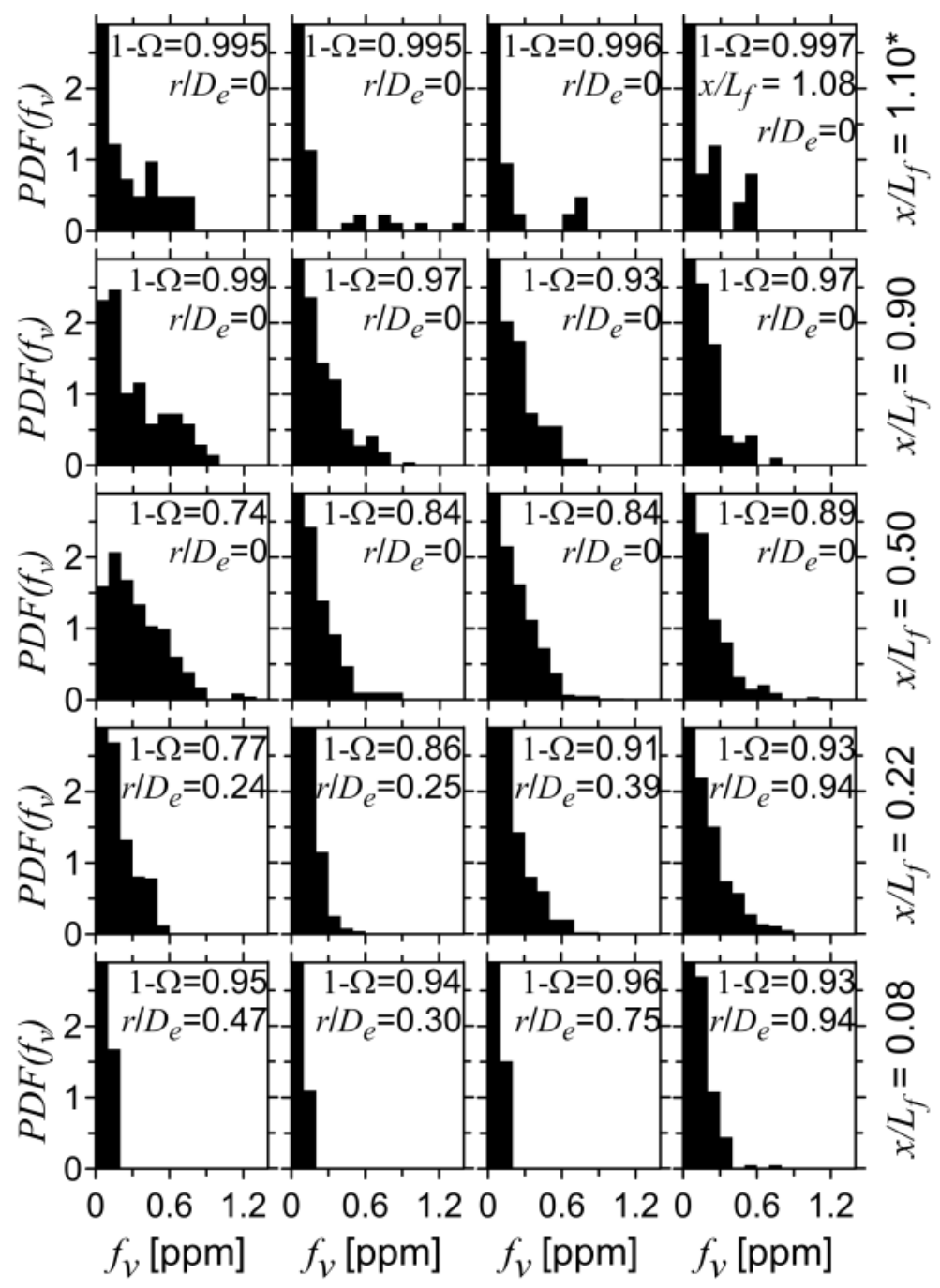
a) $25-1$
b) $76-1$
c) $25-3$
d) $25-5$

Figure 5.4 - PDFs of $f_{v}^{s}$ for various flame conditions.

\subsubsection{Scaling}

Most previous works presenting soot measurements in jet flames scale the axial dimension with $D_{e}$ (Hu et al., 2003; Qamar et al., 2009; Kent \& Bastin, 1984; B. Yang \& Köylü, 2005a; B. Yang \& Köylü, 2005b; Lee et al., 2009), but since $L_{f}$ of buoyancy-dominated flames varies with $u_{e}$, spatially-resolved soot measurements are not expected to scale with $D_{e}$-normalized axial location. Nevertheless, scaling $L_{f}$ and axial location of peak $f_{v}$ by $D_{e}$ is useful for comparison to a wide range of 
results from literature. Figure 5.5 shows $L_{f}$ and the axial location of peak $f_{v}$, both normalized by $D_{e}$, versus Richardson ratio along with similar results from literature. In the current results, there is a distinct downward trend with increasing Richardson ratio for both $L_{f}$ and peak $f_{v}$ location. Figure 5.5 also shows that the current work fills a gap in the literature, between the momentumdominated flames shown in the upper-left of the figure and the buoyancydominated flames in the lower-right. The location of peak $f_{v}$ is between 0.37 and $0.5 L_{f}$ for all cases shown except the 25-6 condition in the current work $\left(0.7 L_{f}\right)$ and the momentum-dominated natural gas flame described in Qamar et al. (2009) $\left(0.77 L_{f}\right)$

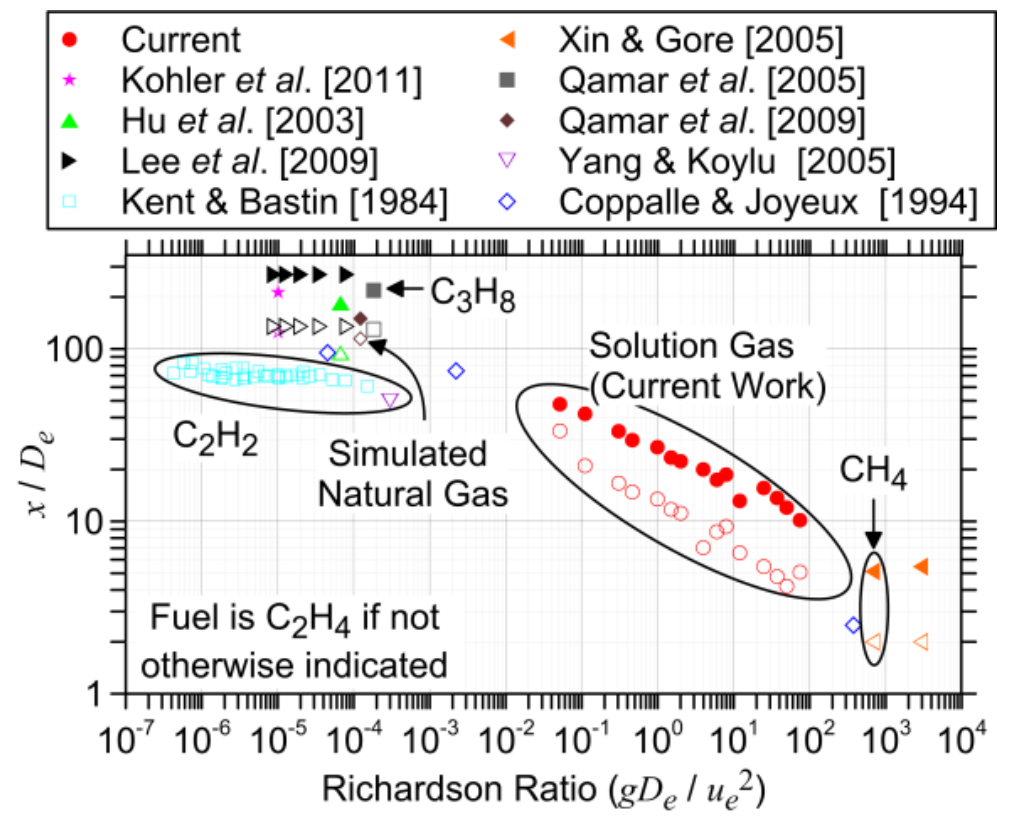

Figure 5.5 - Nozzle-diameter normalized flame height (solid symbols) and height of peak $f_{v}$ (hollow symbols) vary with Richardson ratio.

Figure 5.6a shows $R_{g m l}$ plotted versus $\tau$ for all conditions. The centreline rate of aggregation for all 15 conditions is between 2 and $6 \mathrm{~nm} / \mathrm{ms}$ with a mean of $3.9 \mathrm{~nm} / \mathrm{ms}$, but different conditions seem to be shifted in time by amounts 
dependent on both $u_{e}$ and $D_{e}$. Santoro et al. (1987) reported analogous delays in laminar non-premixed ethylene flames, attributing them to differences early in the flow due to varied temperature fields. They corrected these delays by decreasing each residence time by the time required for the gas phase temperature to reach $1300 \mathrm{~K}$, producing very good overlap in profiles of $f_{v}$, particle diameter $\left(D_{63}=\left(\sum_{i=1}^{N} n_{i} D_{i}^{6} / \sum_{i=1}^{N} n_{i} D_{i}^{3}\right)^{1 / 3}\right)$, and particle number density. The threshold temperature value of $1300 \mathrm{~K}$ was chosen because it was the lowest temperature at which soot was detected. Gas phase temperature measurements are not available in the current work, and the coarse spatial resolution in the axial direction makes it difficult to precisely determine the location of soot inception. However, if it is assumed that all the data points of $R_{g m l}$ as shown in Figure 5.6a should overlap, it is possible to calculate the residence time delays that will maximize the correlation between the adjusted residence time and $R_{g m l}$. This optimization was performed using a nonlinear solver employing the generalized reduced gradient method and produced corrected data with a correlation coefficient of $r^{2}=0.94$, shown in Figure 5.6b. As shown in Figure 5.6c, the delay times were found to be functions of both $D_{e}$ and $u_{e}$, with smaller $D_{e}$ and larger $u_{e}$ shortening the delay time, as would be expected for a delay caused by differing velocity fields low in the flow before buoyancy effects dominate. Two prescriptive methods of determining the delay time (based on (i) the coarsely-approximated height of first detected soot and (ii) the height of onset of turbulence estimated via analysis of flame emission videos) produced similar trends among delay time, $D_{e}$ and $u_{e}$ with correlations of $r^{2} \approx 0.9$. 


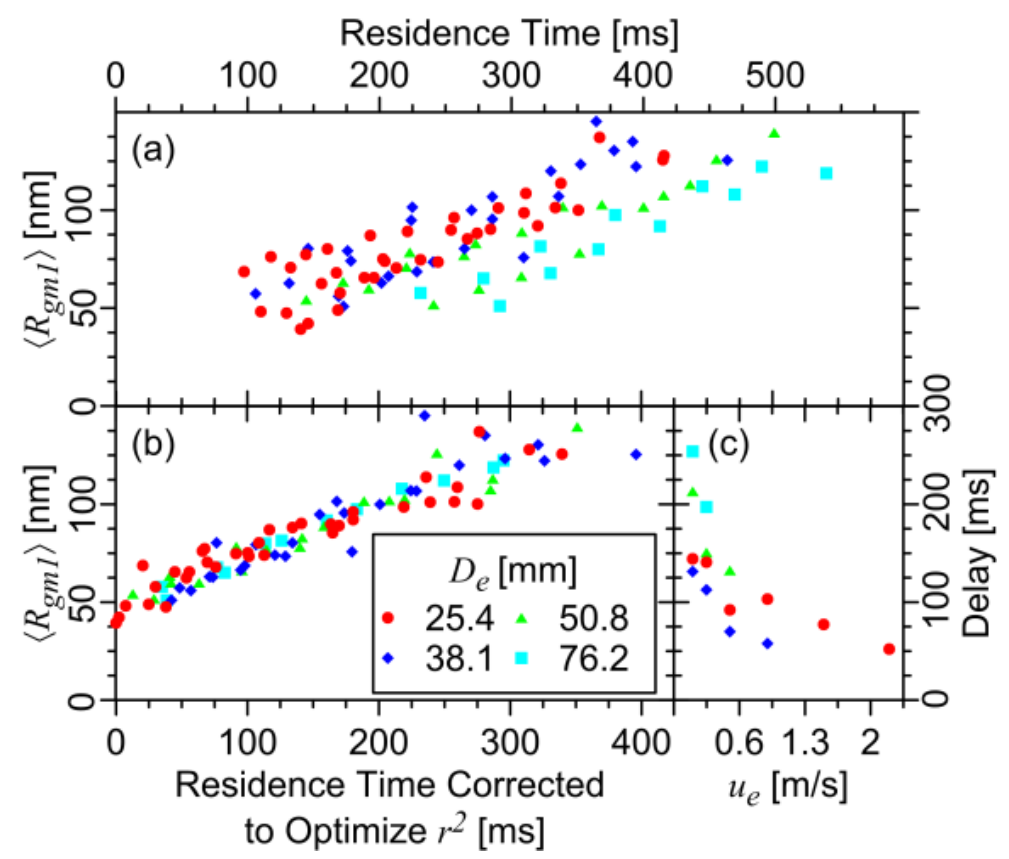

Figure 5.6 - $R_{g m 1}$ as a function of $\tau$, where a) $\tau=0$ at $x / L_{f}=0$ and b) $\tau$ has been shifted for each condition to maximize correlation. c) Calculated time shifts as a function of exit velocity.

The delays calculated using the $R_{g m l}$ results were also used when examining the temporal evolution of the other measured quantities. Supplementary Figures $\mathrm{S}_{5} \cdot 9-\mathrm{S} 5.12(\mathrm{e})$ show similar plots for $f_{v}, f_{v}^{s}, R_{g m 1}$, and $d_{p}$ including additional plots segregated by burner diameter (a-d). The left- and right-hand side of the supplementary figures show unshifted and shifted residence time scales using the delays based on $R_{g m l}$ correlation. The residence time correlations involving $f_{v}$ are quite good for the cases with large $D_{e}$ (50.8 and 76.2 mm, shown in S5.8-S5.11(f)), and as observed by Santoro et al. (1987) for laminar flames, correlation is good everywhere except in the oxidation region near the flame tip. The correlations involving $d_{p}$ and $R_{g m l}$ are strong for all flame conditions (S5.8-S5.11(e)). 


\subsection{Conclusions}

This work represents the first demonstration of simultaneous, instantaneous LII and two-angle ELS used to provide distributions of $f_{v}, d_{p}$ and $R_{g m l}$ in a turbulent buoyant diffusion flame. To the authors' knowledge, the various flames studied cover a range of Richardson ratios where sooting characteristics have not been previously examined. After initial growth low in the flame, $d_{p}$ was relatively stable, ranging from $31-43 \mathrm{~nm}$ along the centreline. $R_{g m 1}$ grew at approximately $3.9 \mathrm{~nm} / \mathrm{ms}$ throughout most of the flame height and reached maximum values of $90-145 \mathrm{~nm}$ for all 15 flame conditions. The $R_{g m 1}$ curves for all conditions correlated well $\left(r^{2}=0.94\right)$ with residence time after applying a correction to account for the differing velocities in the pre-sootinception zone.

Measurements of intermittency, $f_{v}^{s}$, and $d_{p}$ near the flame tip confirm the suggestions of Qamar et al. (2009) and Köhler et al. (2011) that the decrease in mean $f_{v}$ in the burnout region is due to an increase in soot intermittency rather than a decrease in $f_{v}^{s}$ within sooting structures. Furthermore, the invariant shapes of the $f_{v}^{s}$ and $d_{p}$ histograms in the burnout region indicate that oxidation is independent of $f_{v}$ within these structures.

All measured parameters were shown to have self-similar behaviour when axial location was normalized by $L_{f}$, with two restrictions: 1 ) the two cases that are closest to becoming laminar flames exhibit significantly higher $f_{v}$ and lower intermittency than the remaining flames, and 2) the cases where the laminar-to- 
turbulent transition occurs due to shear exhibit lower $f_{v}$ on centreline and reach peak $f_{v}$ later in the flame.

\subsection{Acknowledgments}

We gratefully acknowledge support of Natural Resources Canada (Program of Energy Research and Development, UPAIRI Project 1.1.4 and AFTER Project C23.006). 


\subsection{Supplementary Material}

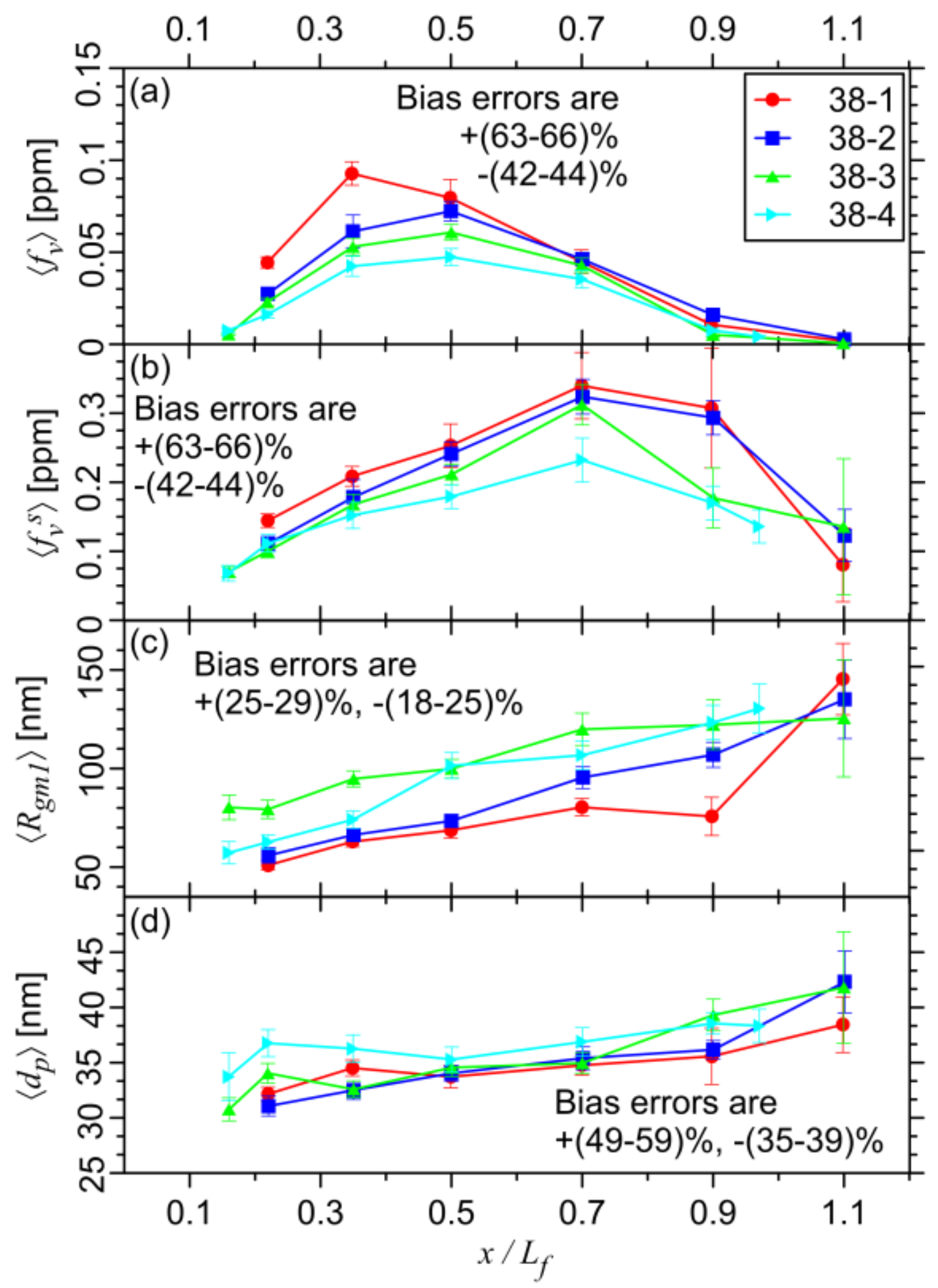

Figure S5.1: Axial profiles of mean a) $f_{v}$, b) $f_{v}^{s}$, c) $R_{g m 1}$ and d) $d_{p}$ along the flame centerline for the $38.1 \mathrm{~mm}$ nozzle conditions. 


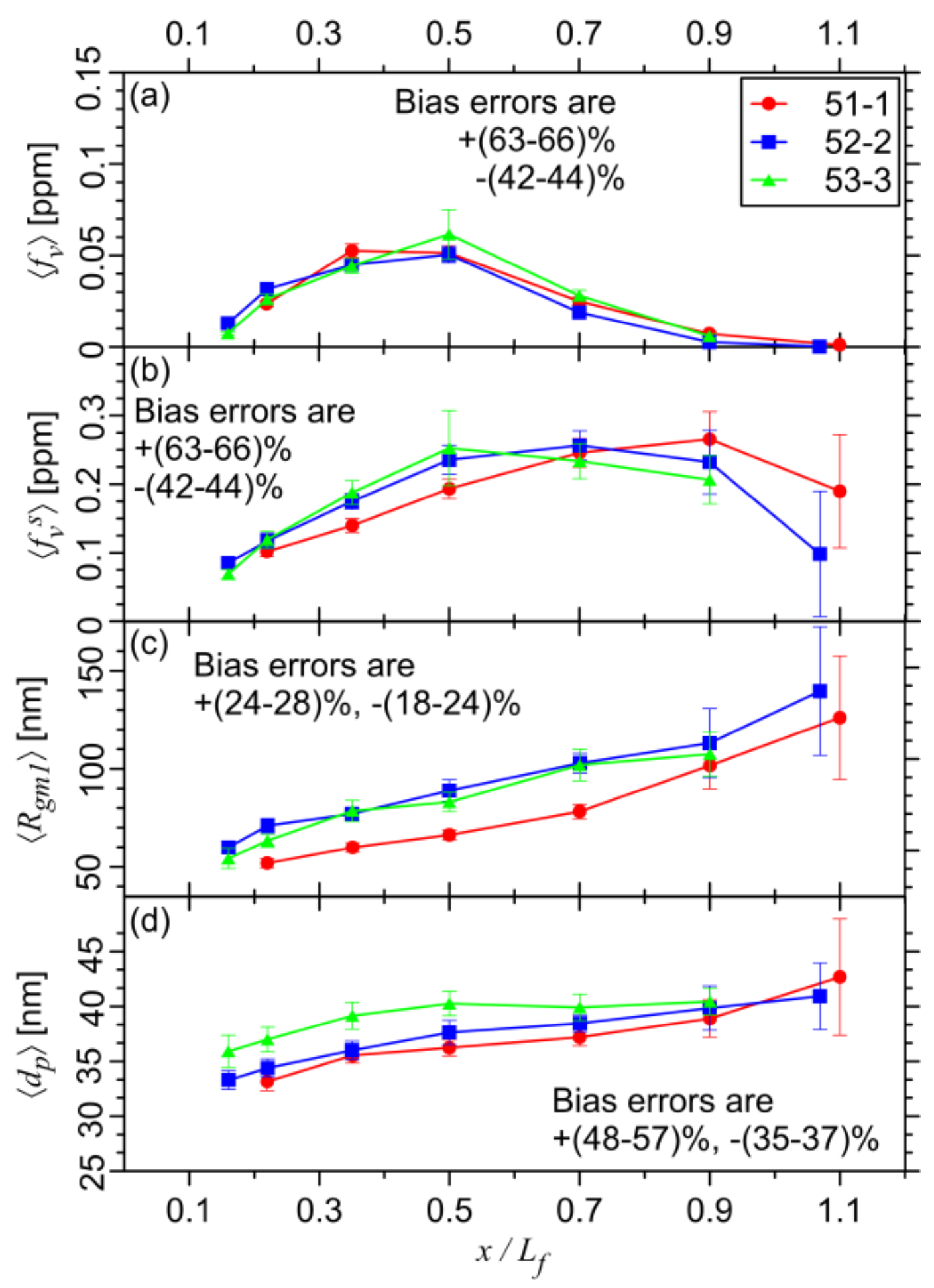

Figure S5.2: Axial profiles of mean a) $f_{v}$, b) $f_{v}^{s}$, c) $R_{g m 1}$ and d) $d_{p}$ along the flame centerline for the $\mathbf{5 0 . 8} \mathrm{mm}$ nozzle conditions. 


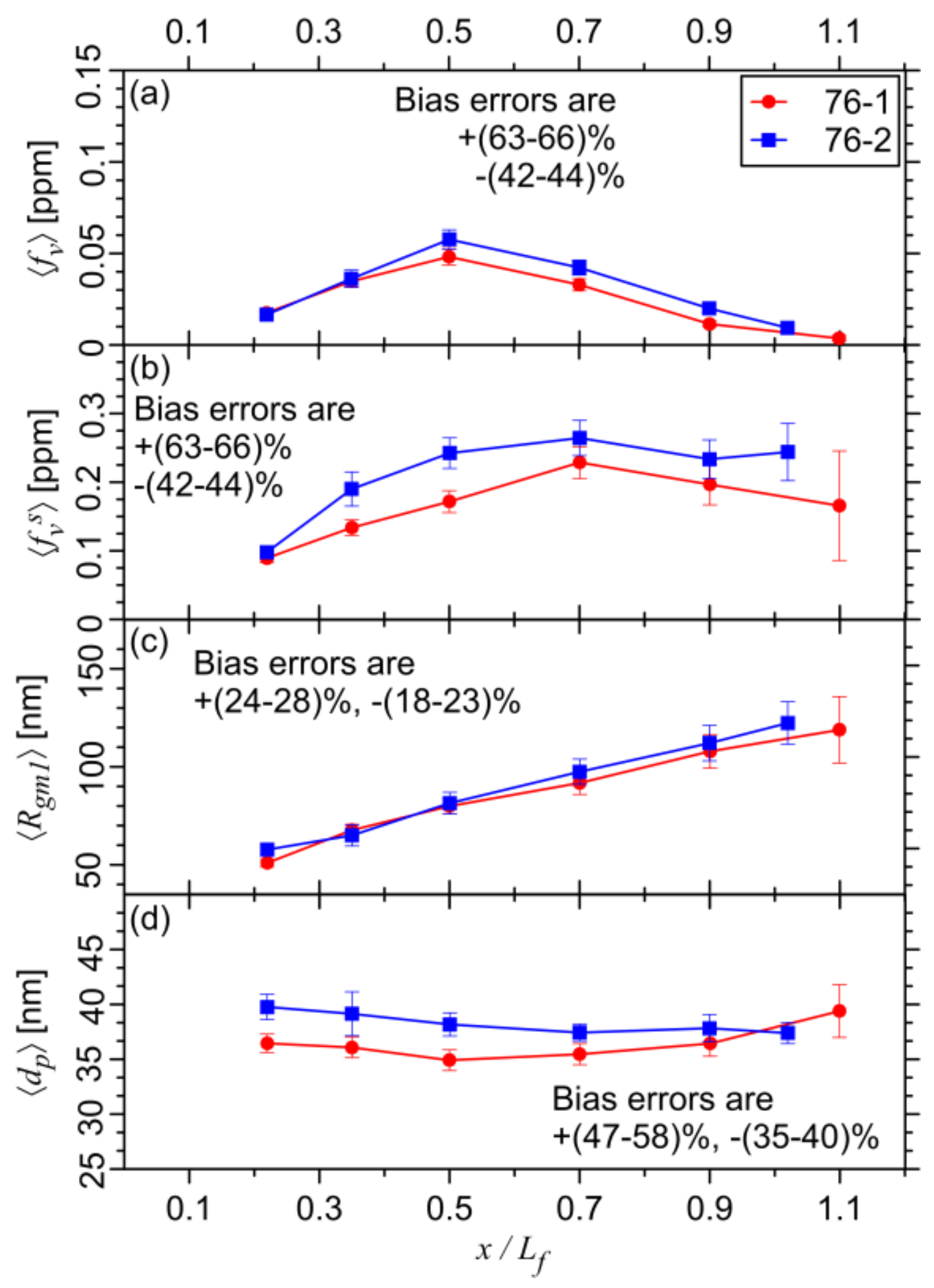

Figure S5.3: Axial profiles of mean a) $f_{v}$, b) $f_{v}^{s}$, c) $R_{g m 1}$ and d) $d_{p}$ along the flame centerline for the $76.2 \mathrm{~mm}$ nozzle conditions. 


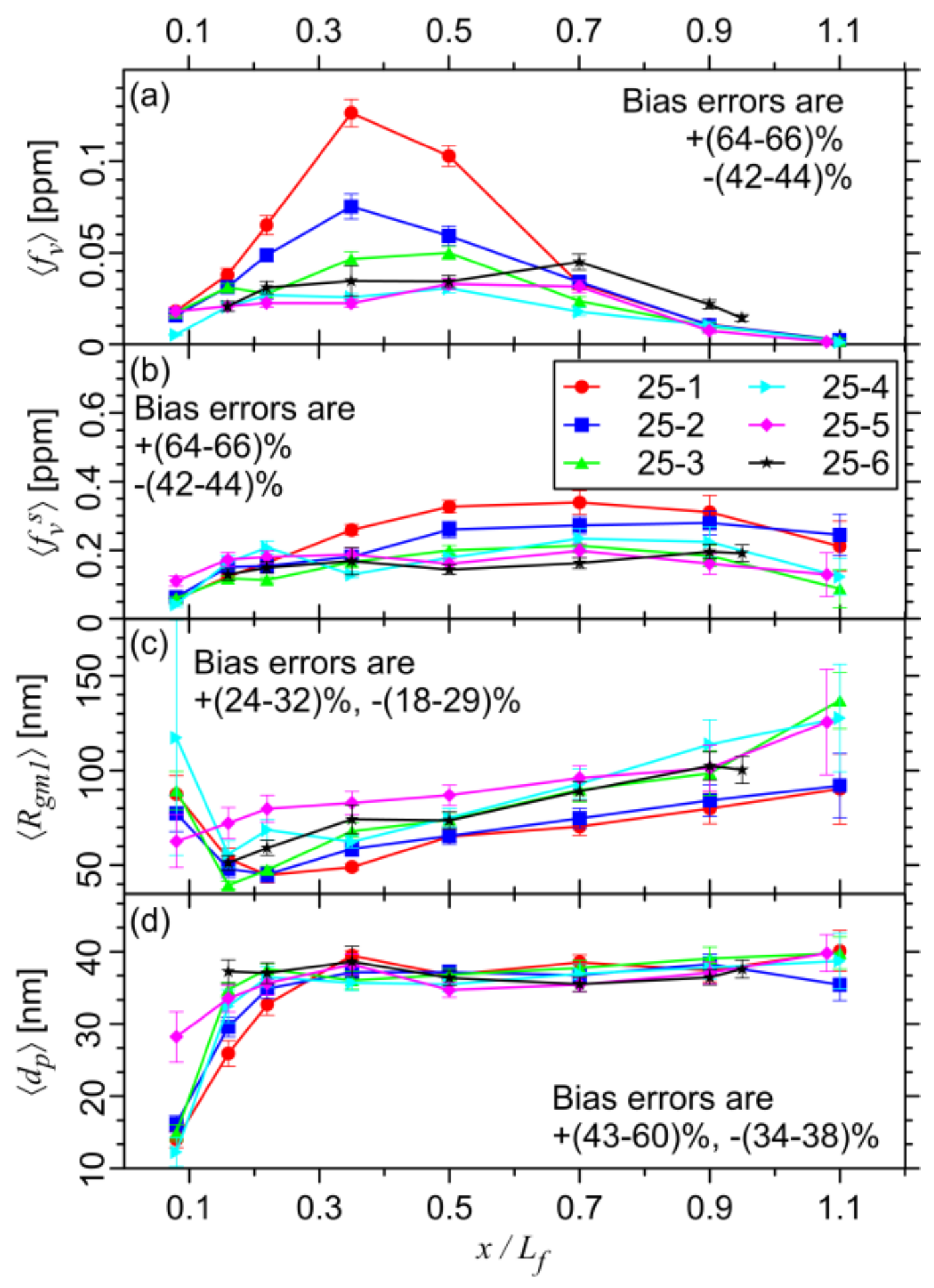

Figure S5.4: Axial profiles of mean a) $f_{v}$, b) $f_{v}^{s}$, c) $R_{g m 1}$ and d) $d_{p}$ at the radial location of maximum $f_{v}$ for the $25.4 \mathrm{~mm}$ nozzle conditions. 


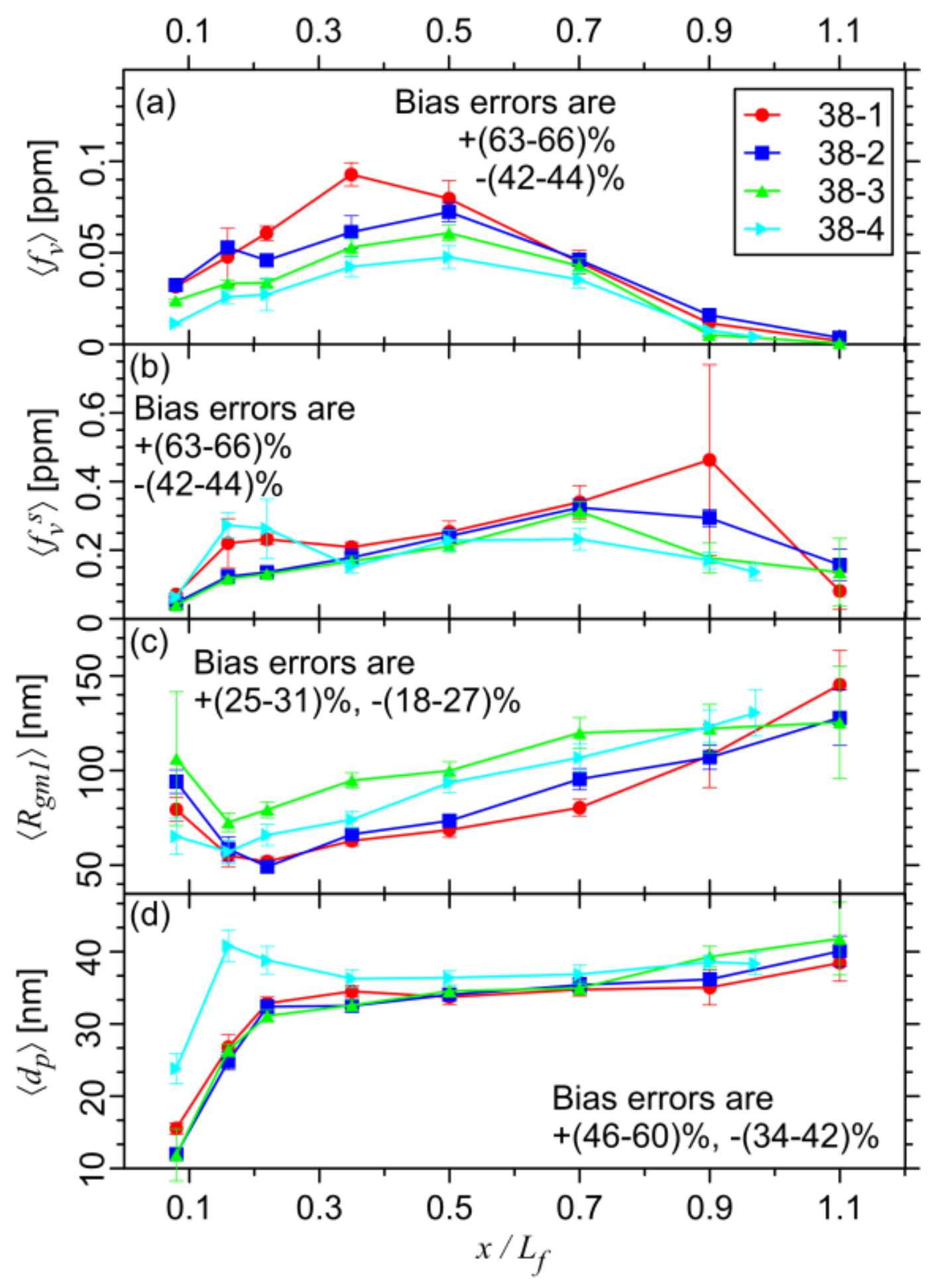

Figure S5.5: Axial profiles of mean a) $f_{v}$, b) $f_{v}^{s}$, c) $R_{g m 1}$ and d) $d_{p}$ at the radial location of maximum $f_{v}$ for the $38.1 \mathrm{~mm}$ nozzle conditions. 


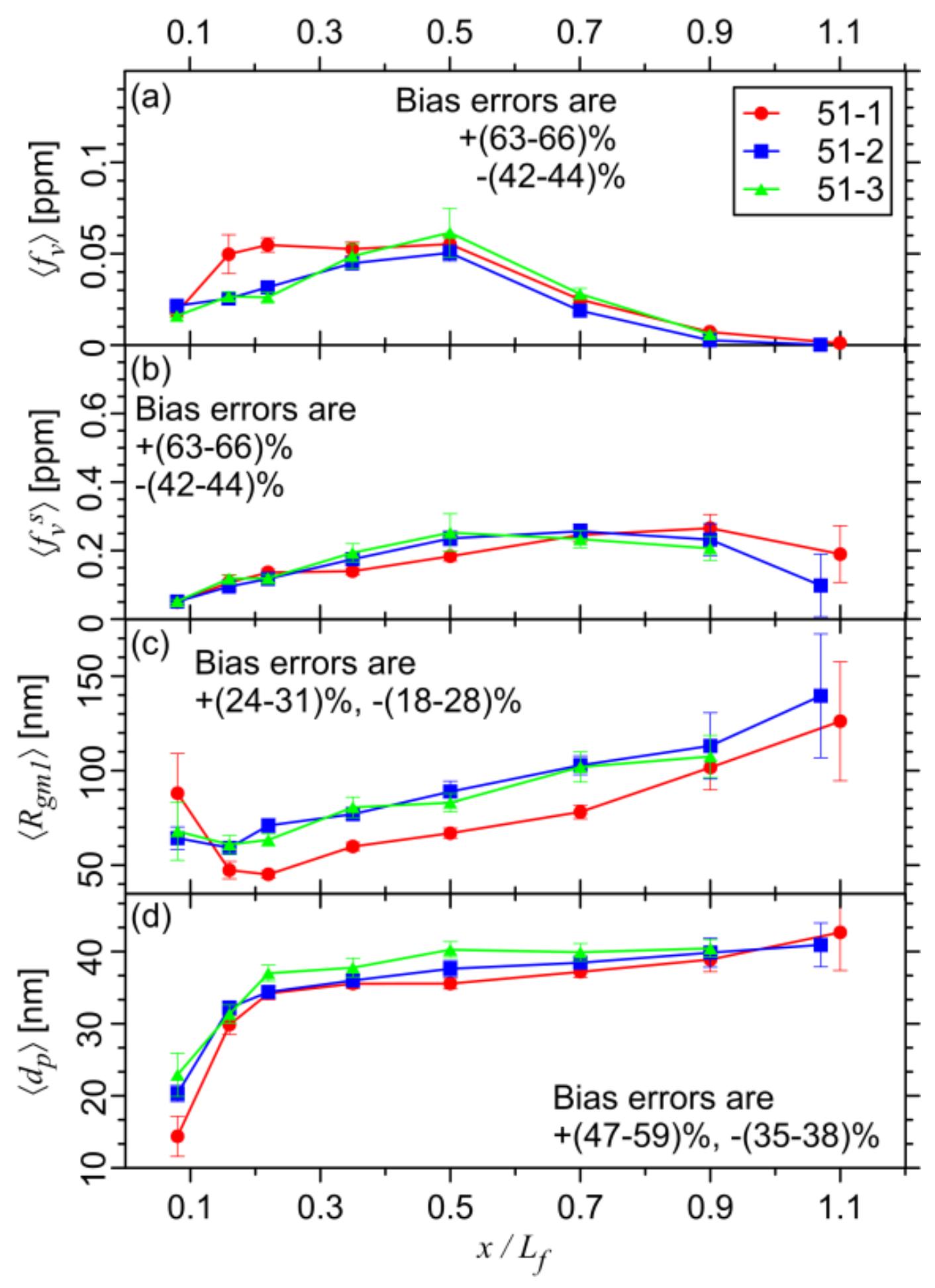

Figure S5.6: Axial profiles of mean a) $f_{v}$, b) $f_{v}^{s}$, c) $R_{g m 1}$ and d) $d_{p}$ at the radial location of maximum $f_{v}$ for the $50.8 \mathrm{~mm}$ nozzle conditions. 


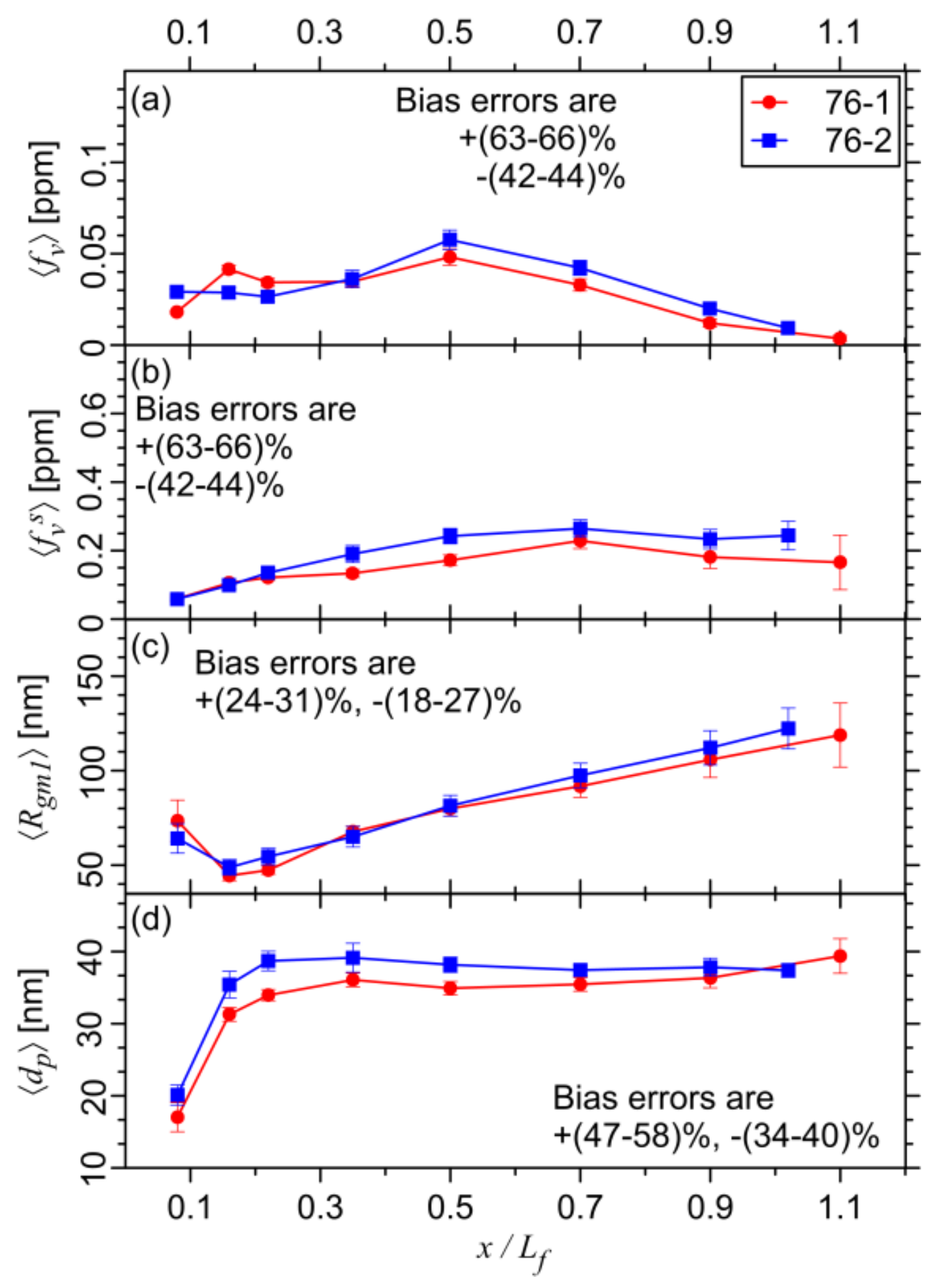

Figure S5.7: Axial profiles of mean a) $f_{v}$, b) $f_{v}^{s}$, c) $R_{g m 1}$ and d) $d_{p}$ at the radial location of maximum $f_{v}$ for the $76.2 \mathrm{~mm}$ nozzle conditions. 


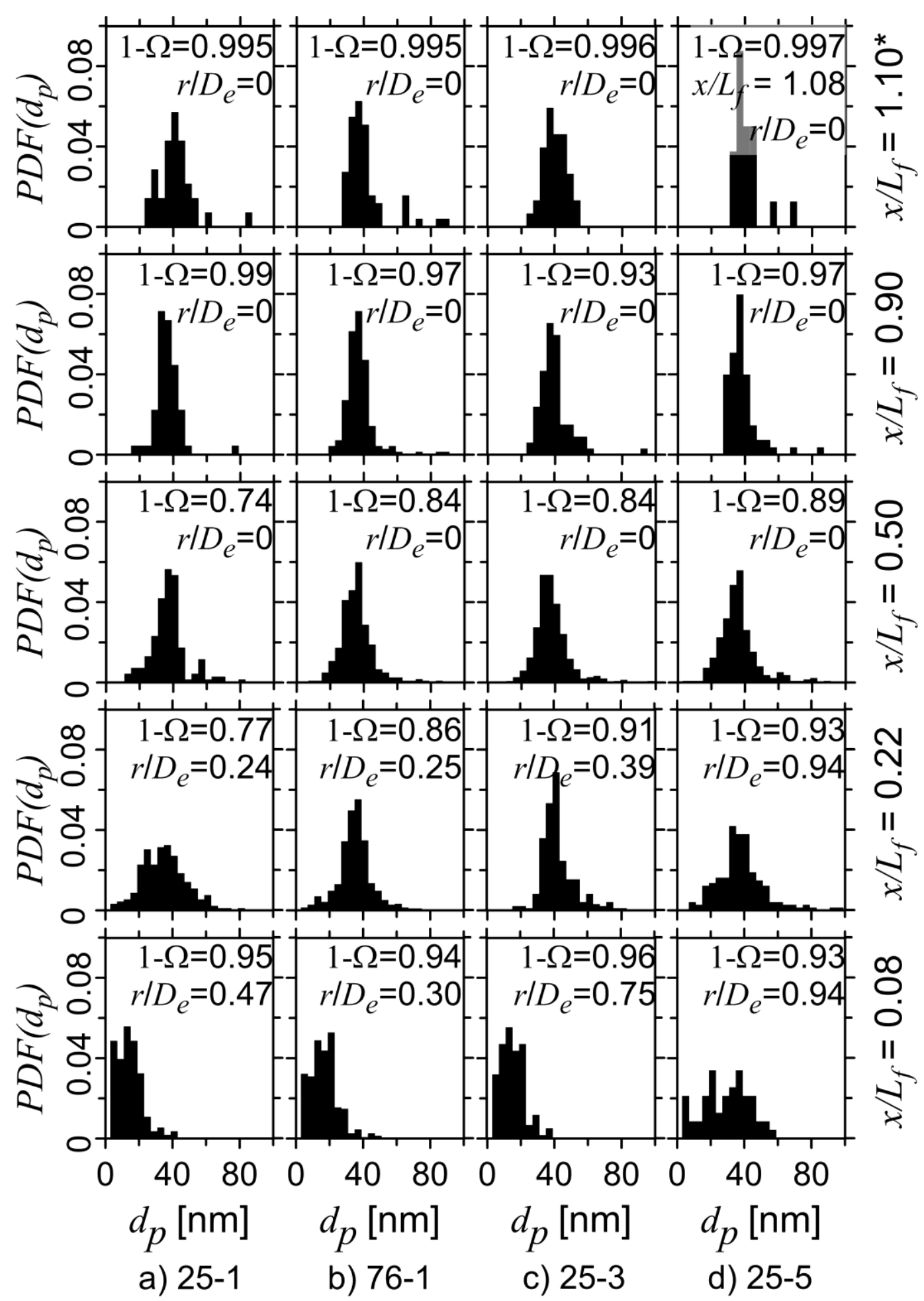

Figure S5.8: PDFs of $d_{p}$ for various flame conditions. 


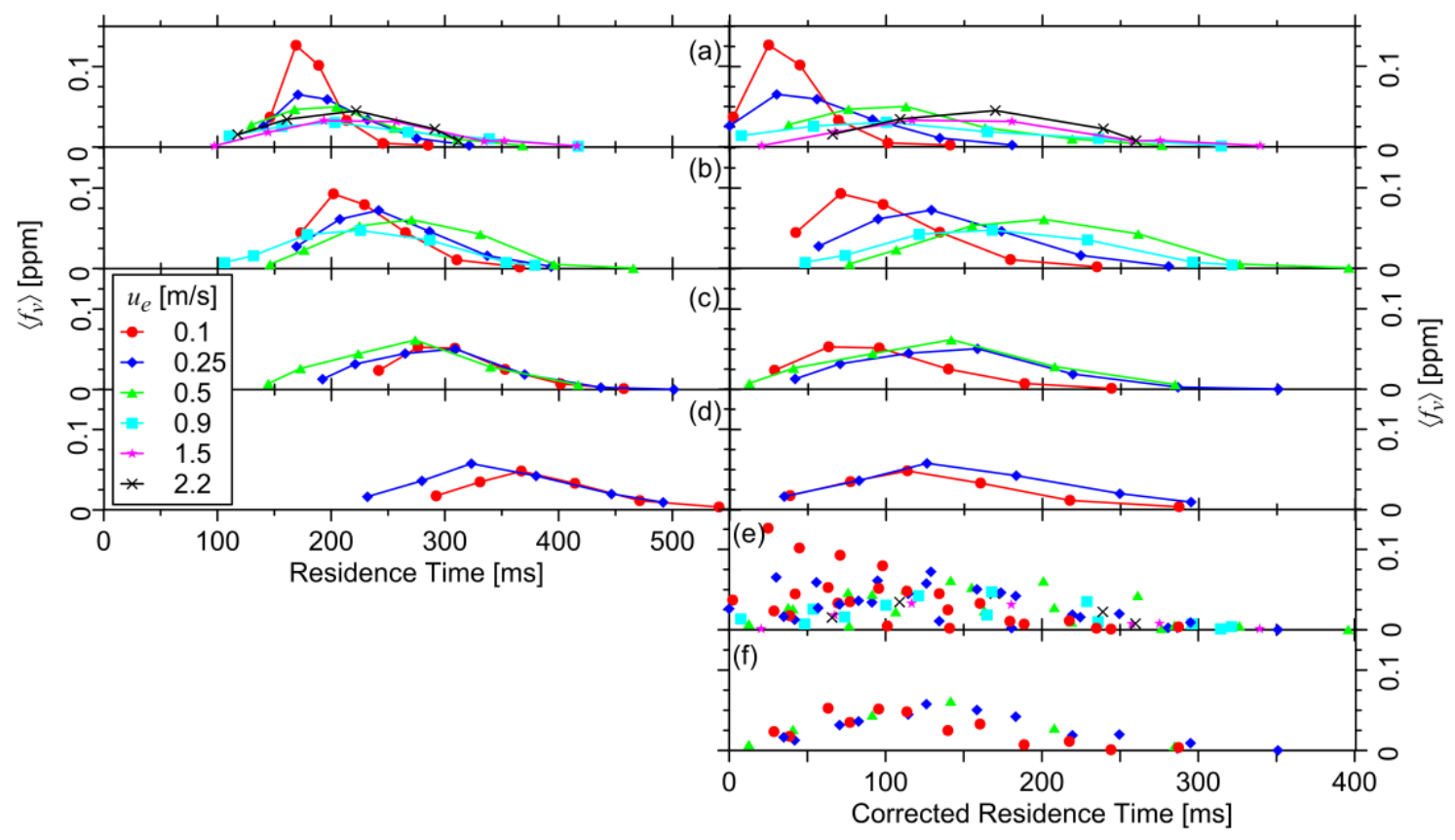

Figure S5.9: Time-averaged soot volume fraction plotted versus residence time starting at the nozzle exit plane (left) and corrected residence (right). (a) $25.4 \mathrm{~mm}$ nozzle, (b) $38.1 \mathrm{~mm}$ nozzle, (c) $50.8 \mathrm{~mm}$ nozzle, (d) $76.2 \mathrm{~mm}$ nozzle, (e) all nozzles, (f) $50.8 \mathrm{~mm}$ and $76.2 \mathrm{~mm}$ diameter nozzles.

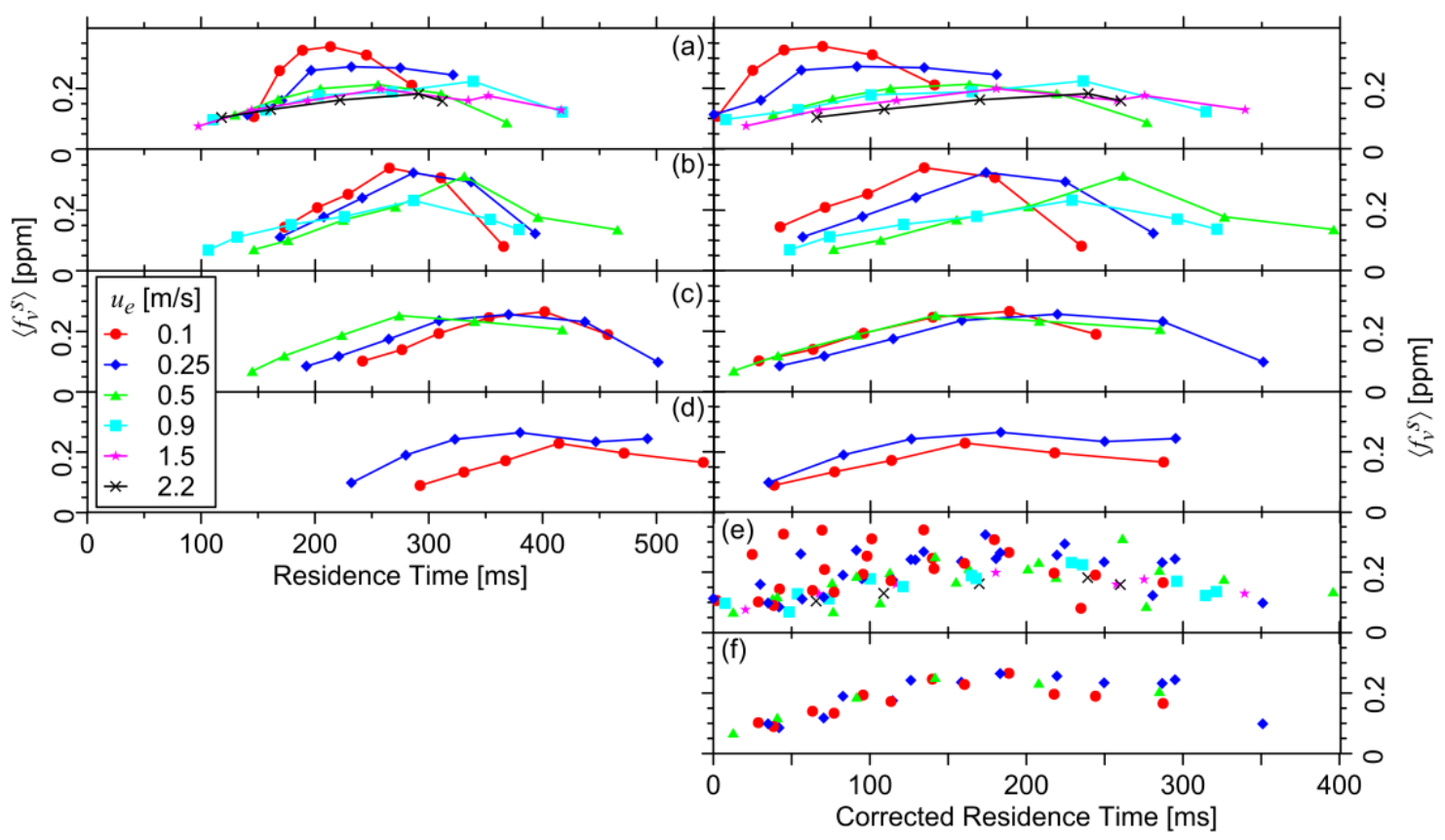

Figure S5.10: Mean soot volume fraction (when soot is present) plotted versus residence time starting at the nozzle exit plane (left) and corrected residence time (right). (a) $25.4 \mathrm{~mm}$ nozzle, (b) $38.1 \mathrm{~mm}$ nozzle, (c) $50.8 \mathrm{~mm}$ nozzle, (d) $76.2 \mathrm{~mm}$ nozzle, (e) all nozzles, (f) $50.8 \mathrm{~mm}$ and $76.2 \mathrm{~mm}$ diameter nozzles. 


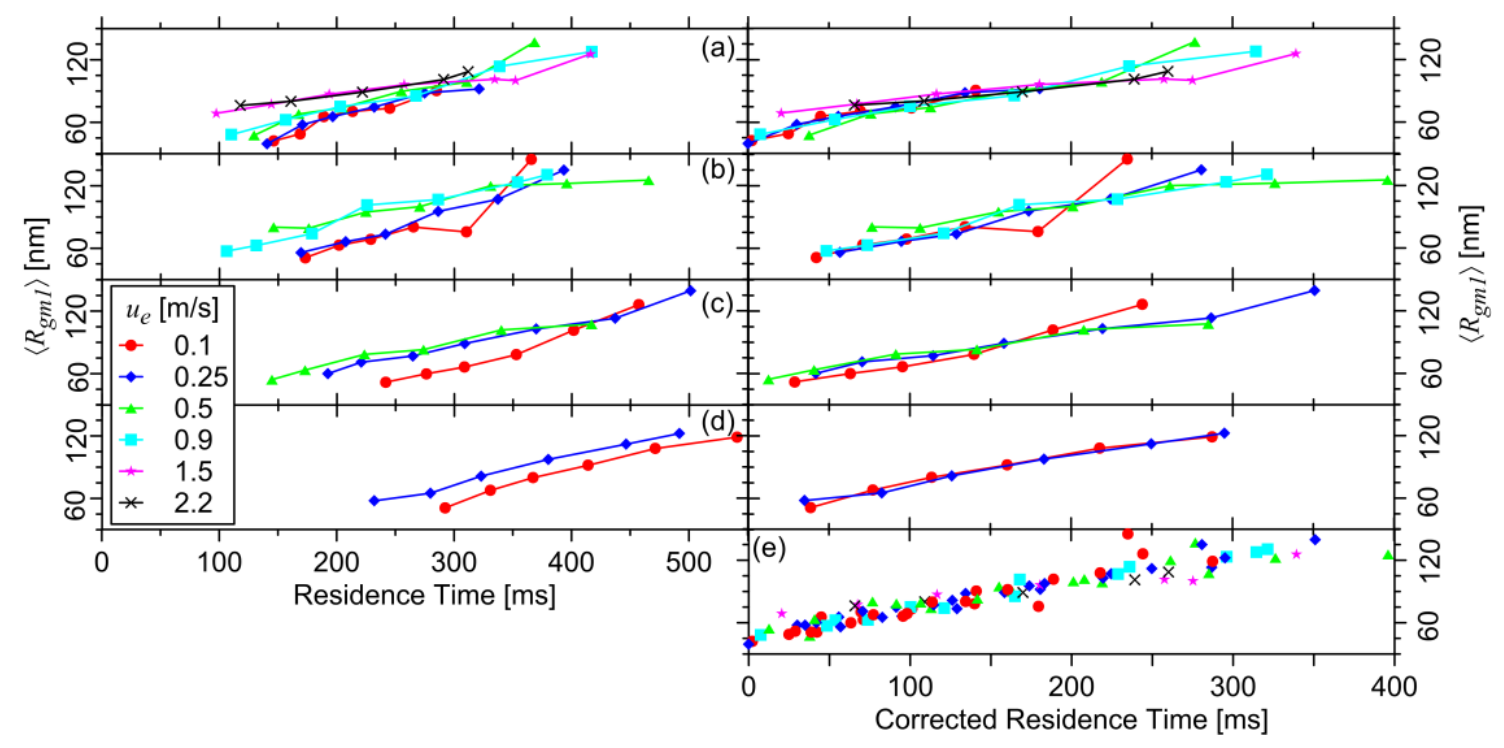

Figure S5.11: Mean effective soot radius of gyration plotted versus residence time starting at the nozzle exit plane (left) and corrected residence time (right). (a) 25.4 mm nozzle, (b) $38.1 \mathrm{~mm}$ nozzle, (c) $50.8 \mathrm{~mm}$ nozzle, (d) $76.2 \mathrm{~mm}$ nozzle, (e) all nozzle diameters.

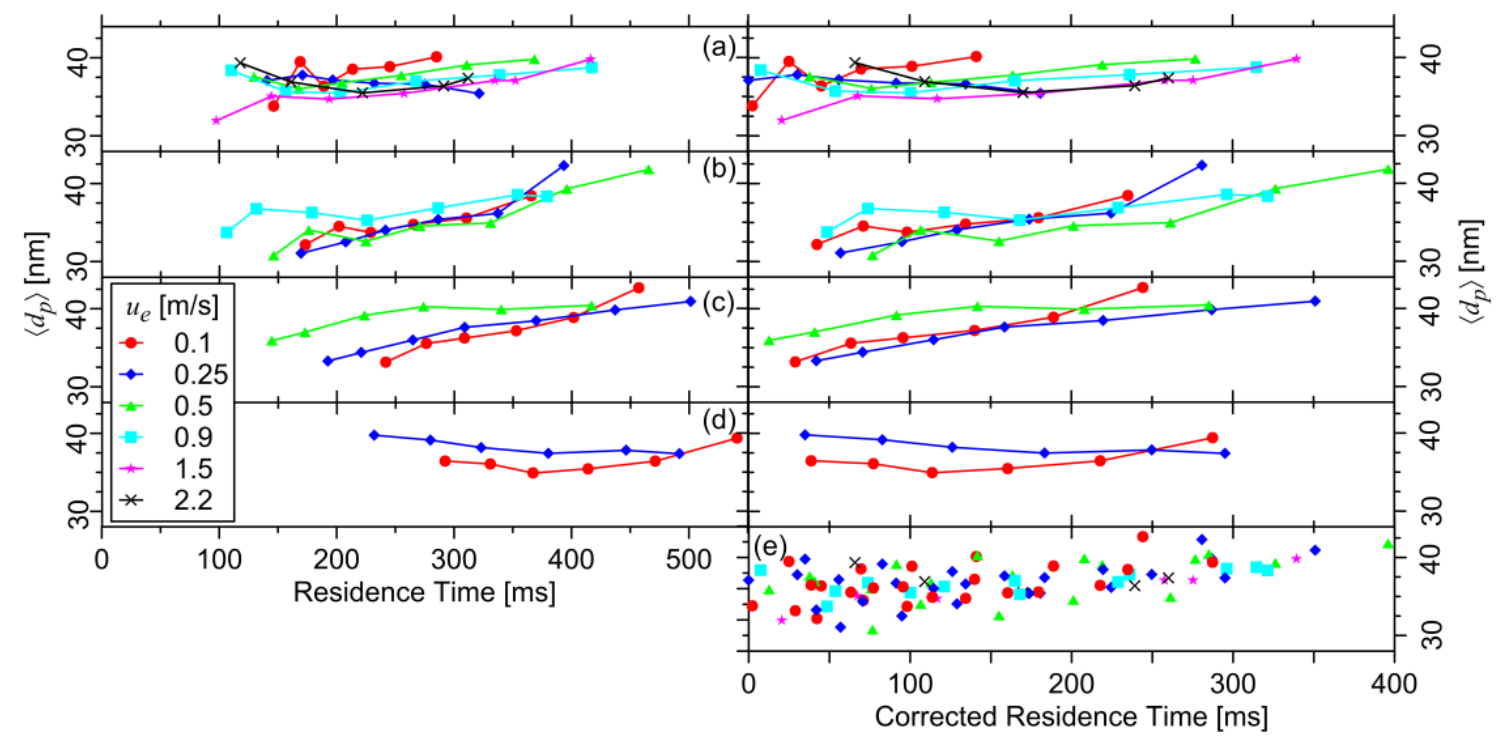

Figure S5.12: Mean soot primary particle diameter plotted versus residence time starting at the nozzle exit plane (left) and corrected residence time (right). (a) 25.4 mm nozzle, (b) $38.1 \mathrm{~mm}$ nozzle, (c) $50.8 \mathrm{~mm}$ nozzle, (d) $76.2 \mathrm{~mm}$ nozzle, (e) all nozzle diameters. 


\section{Chapter 6}

\section{Conclusions \& Recommendations}

\subsection{Conclusions}

This thesis makes important contributions to the development of soot optical diagnostics and to the fundamental investigation of soot formation in turbulent non-premixed flames. The work presented focussed on diagnostic techniques suitable for making instantaneous measurements in turbulent flames and their application to turbulent buoyant non-premixed flames. Throughout the work, particular emphasis was placed on determining the uncertainty of the instantaneous measurements.

While measurement techniques exist for making optical measurements of soot volume fraction and morphology within flames, to the author's knowledge the work presented in this thesis was the first comprehensive examination of the uncertainties associated with applying these approaches to turbulent flames. An uncertainty analysis completed as part of a first demonstration of a novel 2D-ACLII diagnostic identified the major sources of uncertainty as the soot refractive index absorption function and photon shot noise. Drawing on the results of this initial investigation, a new combined LII / ELS diagnostic was developed that enables simultaneous, instantaneous measurements of soot volume faction, primary particle diameter, and aggregate radius of gyration. The ELS component 
of the diagnostic took advantage of a newly-developed method of detector calibration, which in turn allowed simultaneous excitation of ELS and LII without interference from laser-induced fluorescence. A comprehensive uncertainty analysis of the LII/ELS system identified the major sources of uncertainty in soot volume fraction, primary particle diameter and effective radius of gyration as the soot refractive index absorption function, the fractal prefactor, and the width of the distribution of aggregate sizes, respectively. The method and results of the uncertainty analysis also have general implications for the understanding of a broader range of optical measurements of soot properties within flames and will accelerate future diagnostic development by guiding research effort toward the most important sources of uncertainty.

The LII / ELS diagnostic was successfully used in the investigation of soot formation processes within turbulent buoyant non-premixed flames, providing new insights into the processes of soot formation, aggregation, and destruction. The range of flame conditions was chosen as representative of solution gas flares ubiquitous to the upstream oil and gas industry, and covers a gap between strongly buoyant (pool-like) flames and strongly momentum-dominated (jet-like) flames in the literature. Many of the conditions studied were found to be selfsimilar when scaled by flame length, with exceptions for the largest and smallest flames studied.

Data from instantaneous and simultaneous measurements of soot volume fraction, primary particle diameter, and aggregate size enabled by the diagnostic led to four important observations. First, decreases in soot volume fraction 
observed near the flame tip are attributable to an increase in the flame intermittency rather than decreases in soot volume fraction within soot-bearing structures, supporting a recent suggestion from the literature that this could occur in momentum-dominated flames and further extending it to the buoyancydominated flames studied here. Secondly, and contrary to a suggestion in the literature for momentum-dominated flames, the current results indicate that soot-bearing structures oxidize very rapidly or not at all, rather than being preferentially oxidized in structures with low soot volume fraction. Thirdly, soot aggregate size was found to vary linearly with residence time, and trends for a wide range of flames collapsed when residence times were offset to account for implied variations in soot inception height. Finally, considering the large range of flow rates and burner diameters investigated, it is significant that measured quantities among all the turbulent buoyant flame conditions studied were wellcorrelated when scaled in the axial direction by either flame length or residence time.

\subsection{Recommendations for Future Work}

While the instantaneous measurements of soot volume fraction and morphology within turbulent buoyant non-premixed flames presented in the current work have provided new insights, they have also raised several questions that merit further investigation. The most important of these concern scaling. While the lab-scale flares studied in the current work are quite large (with flame lengths up to $1.3 \mathrm{~m}$ ), they are smaller than the majority of flares used by industry. The divergent trends at the very largest and smallest conditions examined 
highlight the need for measurements in full-size flares. The aggregate radius of gyration measurements scale linearly by residence time, but show poor agreement with each other unless the residence time is adjusted to begin at the point of soot inception, which is typically defined based on temperature. Since temperature measurements in the current work were only possible in the presence of soot, determination of the temperature at the point of soot inception was not possible. Spatially-resolved measurements of the gas phase temperature or high-sensitivity measurement of soot volume fraction could be used to determine the average location of soot inception, allowing better adjustment of the residence time measurements and perhaps revealing greater similarities among flame conditions, strengthening the basis for predictive models. Furthermore, high spatial resolution measurements of soot volume fraction and mean or instantaneous temperature throughout the soot inception region, as well as in the oxidation region near the flame tip, would allow determination of the dominant mechanisms and rates of soot formation in these zones and facilitate the development of improved emissions factors models.

In the current work, velocity and thus residence time measurements were only performed on the flame centerline. Since the majority of the growth in primary particle diameter was found to occur in an annular region low in the flame, measurements of velocity, residence time, and temperature along a streakline in the annular region are needed to examine effective radius of gyration and primary particle diameter growth in time. This region is believed to be of particular importance in the most buoyancy-dominated conditions, in 
which soot volume fraction grows much more quickly than for the remaining conditions.

The use of laser-induced incandescence is widespread in the sooting flame research community, where it is common practice to ignore the bias uncertainties that result from the uncertainty in the value of the soot index of refraction absorption function. The detailed uncertainty analyses presented in this thesis have highlighted how these uncertainties can be very large. Accurate modeling of the climate forcing effect of atmospheric black carbon also relies on accurate measurement of the soot index of refraction absorption function. Future development of LII-based diagnostic approaches must concentrate on improved characterization of the soot index of refraction absorption function if these large bias uncertainties are to be reduced. 


\section{References}

ANSI/ASME, 1985. ANSI/ASME PTC 19.1 - Part 1-Measurement Uncertainty, Instruments and Apparatus.

Arana, C.P., Pontoni, M., Sen, S. \& Puri, I.K., 2004. Field measurements of soot volume fractions in laminar partially premixed coflow ethylene/air flames. Combustion and Flame, 138(4), pp.362-372. doi:10.1016/j.combustflame.2004.04.013.

Axelsson, B., Collin, R. \& Bengtsson, P.E., 2000. Laser-induced incandescence for soot particle size measurements in premixed flat flames. Applied Optics, 39(21), pp.3683-90. doi:10.1364/AO.39.003683.

Axelsson, B., Collin, R. \& Bengtsson, P.E., 2001. Laser-induced incandescence for soot particle size and volume fraction measurements using on-line extinction calibration. Applied Physics B, 72(3), pp.367-372. doi:10.1007/s003400100504.

Berry, M. \& Percival, I., 1986. Optics of fractal clusters such as smoke. Optica Acta, 33(5), pp.577-591. doi:10.1080/713821987.

Blacha, T., Domenico, M. \& Köhler, M., 2011. Soot modeling in a turbulent unconfined C2H4/air jet flame. In 49th AIAA Aerospace Sciences Meeting. Orlando, FL, USA:

American Institute of Aeronautics and Astronautics, Inc., pp. 1-10, doi:10.2514/6.2011114.

Bladh, H., Johnsson, J. \& Bengtsson, P.-E., 2008. On the dependence of the laser-induced incandescence (LII) signal on soot volume fraction for variations in particle size. Applied Physics B, 90(1), pp.109-125. doi:10.1007/s00340-007-2826-0.

Bladh, H., Johnsson, J. \& Bengtsson, P.-E., 2009. Influence of spatial laser energy distribution on evaluated soot particle sizes using two-colour laser-induced incandescence in a flat premixed ethylene/air flame. Applied Physics B, 96(4), pp.645656. doi:10.1007/s00340-009-3523-y.

Boiarciuc, A., Foucher, F. \& Mounaïm-Rousselle, C., 2006. Soot volume fractions and primary particle size estimate by means of the simultaneous two-color-time-resolved and 2D laser-induced incandescence. Applied Physics B, 83, pp.413-421.

doi:10.1007/s00340-006-2236-8.

Bond, T.C. \& Bergstrom, R.W., 2006. Light Absorption by Carbonaceous Particles: An Investigative Review. Aerosol Science \& Technology, 40(1), pp.27-67.

doi:10.1080/02786820500421521. 
Bond, T.C., Doherty, S.J., Fahey, D.W., Forster, P.M., Berntsen, T., DeAngelo, B.J., Flanner, M.G., Ghan, S., Kärcher, B., Koch, D., Kinne, S., Kondo, Y., Quinn, P.K., Sarofim, M.C., Schultz, M.G., Schulz, M., Venkataraman, C., Zhang, H., Zhang, S., Bellouin, N., Guttikunda, S.K., Hopke, P.K., Jacobson, M.Z., Kaiser, J.W., Klimont, Z., Lohmann, U., Schwarz, J.P., Shindell, D., Storelvmo, T., Warren, S.G. \& Zender, C.S., 2013. Bounding the role of black carbon in the climate system: A scientific assessment. Journal of Geophysical Research: Atmospheres, 118(11), pp.5380-5552. doi:10.1002/jgrd.50171.

Bouvier, Y., Mihesan, C., Ziskind, M., Therssen, E., Focsa, C., Pauwels, J.F. \& Desgroux, P., 2007. Molecular species adsorbed on soot particles issued from low sooting methane and acetylene laminar flames: A laser-based experiment. Proceedings of the Combustion Institute, 31(1), pp.841-849. doi:10.1016/j.proci.2006.08.036.

Brookes, S.J. \& Moss, J.B., 1999. Measurements of Soot Production and Thermal Radiation From Confined Turbulent Jet Diffusion Flames of Methane. Combustion and Flame, 116, pp.49-61.

Bryce, D.J., Ladommatos, N. \& Zhao, H., 2000. Quantitative investigation of soot distribution by laser-induced incandescence. Applied Optics, 39(27), pp.5012-22. doi:10.1364/AO.39.005012.

Burr, D.W., Daun, K.J., Link, O., Thomson, K.A. \& Smallwood, G.J., 2011. Determination of the soot aggregate size distribution from elastic light scattering through Bayesian inference. Journal of Quantitative Spectroscopy and Radiative Transfer, 112(6), pp.1099-1107. doi:10.1016/j.jqsrt.2010.12.001.

Coderre, A.R., 2009. Spectrally-resolved light absorption properties of cooled soot from a methane flame. M.A.Sc. Thesis. Ottawa: Carleton University, Ottawa, ON, Canada.

Coderre, A.R., Thomson, K.A., Snelling, D.R. \& Johnson, M.R., 2011. SpectrallyResolved Light Absorption Properties of Cooled Soot from a Methane Flame. Applied Physics B, 104(1), pp.175-188. doi:10.1007/s00340-011-4448-9.

Coppalle, A. \& Joyeux, D., 1994. Temperature and Soot Volume Fraction in Turbulent Diffusion Flames: Measurements of Mean and Fluctuating Values. Combustion and Flame, 96, pp.275-285.

Crosland, B.M., Johnson, M.R. \& Thomson, K.A., 2011. Analysis of uncertainties in instantaneous soot volume fraction measurements using two-dimensional, autocompensating, laser-induced incandescence (2D-AC-LII). Applied Physics B, 102, pp.173-183. doi:10.1007/s00340-010-4130-7.

Crosland, B.M., Johnson, M.R. \& Thomson, K.A., 2013. Diffuse surface calibration method to improve accuracy and dynamic range of aerosol elastic light scattering measurements. Applied Physics B, 110(3), pp.315-320. doi:10.1007/s00340-013-5357-x. 
Crosland, B.M., Thomson, K.A. \& Johnson, M.R., 2013. Instantaneous In-Flame Measurement of Soot Volume Fraction, Primary Particle Diameter and Aggregate Radius of Gyration via Auto-Compensating Laser-Induced Incandescence and Two-angle Elastic Light Scattering. Applied Physics B, 112(3), pp.381-393. doi:10.1007/s00340-013-55396.

Dasch, C.J., 1992. One-dimensional tomography: a comparison of Abel, onion-peeling, and filtered backprojection methods. Applied Optics, 31(8), pp.1146-1152. doi:10.1364/AO.31.001146.

Daun, K.J., Stagg, B.J., Liu, F., Smallwood, G.J. \& Snelling, D.R., 2007. Determining aerosol particle size distributions using time-resolved laser-induced incandescence. Applied Physics B, 87(2), pp.363-372. doi:10.1007/s00340-007-2585-y.

Daun, K.J., Thomson, K.A. \& Liu, F., 2008. Simulation of Laser-Induced Incandescence Measurements in an Anisotropically Scattering Aerosol Through Backward Monte Carlo. Journal of Heat Transfer, 130(11), p.112701. doi:10.1115/1.2955468.

Decroix, M.E. \& Roberts, W.L., 2000. Transient Flow Field Effects on Soot Volume Fraction in Diffusion Flames. Combustion Science and Technology, 160(1), pp.165-189. doi:10.1080/00102200008935801.

De Iuliis, S., Cignoli, F., Benecchi, S. \& Zizak, G., 1998. Determination of soot parameters by a two-angle scattering-extinction technique in an ethylene diffusion flame. Applied Optics, 37(33), pp.7865-74. doi:10.1364/AO.37.007865.

De Iuliis, S., Cignoli, F. \& Zizak, G., 2005. Two-color laser-induced incandescence (2CLII) technique for absolute soot volume fraction measurements in flames. Applied Optics, 44(34), pp.7414-23. doi:10.1364/AO.44.007414.

De Iuliis, S., Migliorini, F., Cignoli, F. \& Zizak, G., 2007. 2D soot volume fraction imaging in an ethylene diffusion flame by two-color laser-induced incandescence (2CLII) technique and comparison with results from other optical diagnostics. Proceedings of the Combustion Institute, 31, pp.869-876. doi:10.1016/j.proci.2006.07.149.

De Iuliis, S., Maffi, S., Cignoli, F. \& Zizak, G., 2011. Three-angle scattering/extinction versus TEM measurements on soot in premixed ethylene/air flame. Applied Physics B, 102(4), pp.891-903. doi:10.1007/s00340-010-4344-8.

Delichatsios, M.A., 1993. Transition from momentum to buoyancy-controlled turbulent jet diffusion flames and flame height relationships. Combustion and Flame, 92(4), pp.349-364. doi:10.1016/0010-2180(93)90148-V.

Desgroux, P., Mercier, X., Lefort, B., Lemaire, R., Therssen, E. \& Pauwels, J.F., 2008. Soot volume fraction measurement in low-pressure methane flames by combining laserinduced incandescence and cavity ring-down spectroscopy: Effect of pressure on soot 
formation. Combustion and Flame, 155(1-2), pp.289-301.

doi:10.1016/j.combustflame.2008.05.016.

Dobbins, R.A. \& Megaridis, C.M., 1991. Absorption and scattering of light by

polydisperse aggregates. Applied Optics, 30(33), pp.4747-4754.

doi:10.1364/AO.30.004747.

Dobbins, R.A., Mulholland, G.W. \& Bryner, N.P., 1994. Comparison of a fractal smoke optics model with light extinction measurements. Atmospheric Environment, 28(5), pp.889-897.

Eckbreth, A.C., 1977. Effects of laser-modulated particulate incandescence on Raman scattering diagnostics. Journal of Applied Physics, 48(11), pp.4473-4479.

doi:10.1063/1.323458.

El-Asrag, H. \& Menon, S., 2009. Large eddy simulation of soot formation in a turbulent non-premixed jet flame. Combustion and Flame, 156(2), pp.385-395.

Elvidge, C.D., Ziskin, D., Baugh, K.E., Tuttle, B.T., Ghosh, T., Pack, D.W., Erwin, E.H. \& Zhizhin, M., 2009. A Fifteen Year Record of Global Natural Gas Flaring Derived from Satellite Data. Energies, 2, pp.595-622. doi:10.3390/en20300595.

Fisher, M.E. \& Burford, R.J., 1965. Theory of Critical-Point Scattering and Correlations. I. The Ising Model. Physical Review, 156(2), pp.583-622. doi:10.1103/PhysRev.156.583.

Fuentes, A., Legros, G., El-Rabii, H., Vantelon, J.P., Joulain, P. \& Torero, J.L., 2007. Laser-induced incandescence calibration in a three-dimensional laminar diffusion flame. Experiments in Fluids, 43(6), pp.939-948. doi:10.1007/s00348-007-0364-5.

Greenberg, P.S. \& Ku, J.C., 1997. Soot volume fraction imaging. Applied Optics, 36(22), pp.5514-5522. doi:10.1364/AO.36.005514.

Hansen, J., Sato, M., Ruedy, R., Lacis, A. \& Oinas, V., 2000. Global warming in the twenty-first century: An alternative scenario. Proceedings of the National Academy of Sciences of the United States of America, 97(18), pp.9875-9880.

Hu, B., Yang, K. \& Köylü, Ü.Ö., 2003. Soot measurements at the axis of an ethylene/air non-premixed turbulent jet flame. Combustion and Flame, 134, pp.93-106. doi:10.1016/S0010-2180(03)00085-3.

Hurd, A.J. \& Flower, W.L., 1988. In situ growth and structure of fractal silica aggregates in a flame. Journal of Colloid and Interface Science, 122(1), pp.178-192. doi:10.1016/0021-9797(88)90301-3.

IPCC, 2007. Climate Change 2007: The Physical Science Basis. Contribution of Working Group I to the Fourth Assessment Report of the Intergovernmental Panel on Climate 
Change S. Solomon et al., eds., Cambridge, UK and New York, USA: Cambridge University Press.

Iyer, S.S., Litzinger, T.A., Lee, S.-Y. \& Santoro, R.J., 2007. Determination of soot scattering coefficient from extinction and three-angle scattering in a laminar diffusion flame. Combustion and Flame, 149(1-2), pp.206-216. doi:10.1016/j.combustflame.2006.11.009.

Jacobson, M.Z., 2010. Short-term effects of controlling fossil-fuel soot, biofuel soot and gases, and methane on climate, Arctic ice, and air pollution health. Journal of Geophysical Research, 115(D14209), pp.1-24. doi:10.1029/2009JD013795.

Janesick, J.R., 2001. Scientific charge-coupled devices, Bellingham, WA: SPIE Optical Engineering Press.

Johnson, M.R., Devillers, R.W., Yang, C. \& Thomson, K.A., 2010. Sky-Scattered Solar Radiation Based Plume Transmissivity Measurement to Quantify Soot Emissions from Flares. Environmental Science \& Technology, 44(21), pp.8196-8202. doi:10.1021/es1024838.

Johnson, M.R., Devillers, R.W. \& Thomson, K.A., 2011. Quantitative Field Measurement of Soot Emission from a Large Gas Flare Using Sky-LOSA. Environmental Science \& Technology, 45(1), pp.345-350. doi:10.1021/es102230y.

Johnson, M.R. \& Coderre, A.R., 2012. Compositions and greenhouse gas emission factors of flared and vented gas in the western Canadian sedimentary basin. Journal of the Air \& Waste Management Association, 62(9), pp.992-1002.

doi:10.1080/10962247.2012.676954.

Johnson, M.R., Devillers, R.W. \& Thomson, K.A., 2013. A Generalized Sky-LOSA Method to Quantify Soot/Black Carbon Emission Rates in Atmospheric Plumes of Gas Flares. Aerosol Science and Technology, 47(9), pp.1017-1029. doi:10.1080/02786826.2013.809401.

Jones, A.R., 2006. Light Scattering in Combustion. In A. Kokhanovsky, ed. Light scattering reviews. Berlin: Springer, pp. 393-444.

Julien, R. \& Botet, R., 1987. Aggregation and Fractal Aggregates, World Scientific.

Kent, J.H. \& Bastin, S.J., 1984. Parametric effects on sooting in turbulent acetylene diffusion flames. Combustion and flame, 56, pp.29-42.

Kock, B.F., Tribalet, B., Schulz, C. \& Roth, P., 2006. Two-color time-resolved LII applied to soot particle sizing in the cylinder of a Diesel engine. Combustion and Flame, 147(1-2), pp.79-92. doi:10.1016/j.combustflame.2006.07.009. 
Köhler, M., Geigle, K.-P., Meier, W., Crosland, B.M., Thomson, K.A. \& Smallwood, G.J., 2011. Sooting turbulent jet flame: characterization and quantitative soot measurements. Applied Physics B, 104(2), pp.409-425. doi:10.1007/s00340-011-4373-y.

Köylü, Ü.Ö. \& Faeth, G.M., 1992. Structure of overfire soot in buoyant turbulent diffusion flames at long residence times. Combustion and Flame, 89(2), pp.140-156. doi:10.1016/0010-2180(92)90024-J.

Köylü, Ü.Ö. \& Faeth, G.M., 1994. Optical properties of overfire soot in buoyant turbulent diffusion flames at long residence times. Journal of Heat Transfer, 116(1), pp.152-159. doi:10.1115/1.2910849.

Köylü, Ü.Ö., Xing, Y. \& Rosner, D.E., 1995. Fractal Morphology Analysis of Combustion-Generated Aggregates Using Angular Light Scattering and Electron Microscope Images. Langmuir, 11(12), pp.4848-4854. doi:10.1021/1a00012a043.

Köylü, Ü.Ö. \& Faeth, G.M., 1996. Spectral extinction coefficients of soot aggregates from turbulent diffusion flames. Journal of Heat Transfer, 118(2), pp.415-421. doi:10.1115/1.2825860.

Krishnan, S.S., Lin, K.-C. \& Faeth, G.M., 2000. Optical Properties in the Visible of Overfire Soot in Large Buoyant Turbulent Diffusion Flames. Journal of Heat Transfer, 122(3), pp.517-524. doi:10.1115/1.1288025.

Law, A.M. \& Carson, J.S., 1979. A Sequential Procedure for Determining the Length of a Steady-State Simulation. Operations Research, 27(5), pp.1011-1025. doi:10.1287/opre.27.5.1011.

Lee, S.-Y., Turns, S.R. \& Santoro, R.J., 2009. Measurements of soot, OH, and PAH concentrations in turbulent ethylene/air jet flames. Combustion and Flame, 156, pp.22642275. doi:10.1016/j.combustflame.2009.09.005.

Lemaire, R., Faccinetto, A., Therssen, E., Ziskind, M., Focsa, C. \& Desgroux, P., 2009. Experimental comparison of soot formation in turbulent flames of Diesel and surrogate Diesel fuels. Proceedings of the Combustion Institute, 32(1), pp.737-744.

doi:10.1016/j.proci.2008.05.019.

Lin, M.Y., Lindsay, H.M., Weitz, D.A., Klein, R., Ball, R.C. \& Meakin, P., 1990. Universal diffusion-limited colloid aggregation. Journal of Physics: Condensed Matter, 2(13), pp.3093-3113. doi:10.1088/0953-8984/2/13/019.

Link, O., Snelling, D.R., Thomson, K.A. \& Smallwood, G.J., 2011. Development of absolute intensity multi-angle light scattering for the determination of polydisperse soot aggregate properties. Proceedings of the Combustion Institute, 33(1), pp.847-854. doi:10.1016/j.proci.2010.06.073. 
Liu, F., Thomson, K.A. \& Smallwood, G.J., 2008. Effects of soot absorption and scattering on LII intensities in laminar coflow diffusion flames. Journal of Quantitative Spectroscopy and Radiative Transfer, 109(2), pp.337-348.

doi:10.1016/j.jqsrt.2007.08.027.

Liu, F., Snelling, D.R., Thomson, K.A. \& Smallwood, G.J., 2009. Sensitivity and relative error analyses of soot temperature and volume fraction determined by two-color LII. Applied Physics B, 96(4), pp.623-636. doi:10.1007/s00340-009-3560-6.

Liu, F. \& Smallwood, G.J., 2013. Relationship between soot volume fraction and LII signal in AC-LII: effect of primary soot particle diameter polydispersity. Applied Physics B, 112(3), pp.307-319. doi:10.1007/s00340-012-5330-0.

Martin, J.E. \& Hurd, J.A., 1987. Scattering From Fractals. Journal Of Applied Crystallography, 20(2), pp.61-78. doi:10.1107/S0021889887087107.

McEwen, J.D.N., 2010. Soot Emission Factors from Lab-Scale Flares Burning Solution Gas Mixtures. M.A.Sc. Thesis. Carleton University, Ottawa, ON, Canada.

McEwen, J.D.N. \& Johnson, M.R., 2012. Black Carbon Particulate Matter Emission Factors for Buoyancy Driven Associated Gas Flares. Journal of the Air \& Waste Management Association, 62(3), pp.307-321. doi:10.1080/10473289.2011.650040.

Megaridis, C.M. \& Dobbins, R.A., 1990. Morphological Description of Flame-Generated Materials. Combustion Science and Technology, 71(1-3), pp.95-109.

doi:10.1080/00102209008951626.

Melton, L.A., 1984. Soot diagnostics based on laser heating. Applied Optics, 23(13), pp.2201-2208. doi:10.1364/AO.23.002201.

Mewes, B. \& Seitzman, J.M., 1997. Soot volume fraction and particle size measurements with laser-induced incandescence. Applied Optics, 36(3), pp.709-717.

doi:10.1364/AO.36.000709.

Michelsen, H.A., Witze, P.O., Kayes, D. \& Hochgreb, S., 2003. Time-resolved laserinduced incandescence of soot: the influence of experimental factors and microphysical mechanisms. Applied Optics, 42, pp.557-5590. doi:10.1364/AO.42.005577.

Michelsen, H.A., Liu, F., Kock, B.F., Bladh, H., Boiarciuc, A., Charwath, M., Dreier, T., Hadef, R., Hofmann, M., Reimann, J., Will, S., Bengtsson, P.-E., Bockhorn, H., Foucher, F., Geigle, K.-P., Mounaïm-Rousselle, C., Schulz, C., Stirn, R., Tribalet, B. \& Suntz, R., 2007. Modeling laser-induced incandescence of soot: a summary and comparison of LII models. Applied Physics B, 87(3), pp.503-521. doi:10.1007/s00340-007-2619-5.

Michelsen, H.A., Tivanski, A.V., Gilles, M.K., van Poppel, L.H., Dansson, M.A. \& Buseck, P.R., 2007. Particle formation from pulsed laser irradiation of soot aggregates 
studied with a scanning mobility particle sizer, a transmission electron microscope, and a scanning transmission x-ray microscope. Applied Optics, 46(6), pp.959-977.

Migliorini, F., De Iuliis, S. \& Cignoli, F., 2006. Absorption correction of two-color laserinduced incandescence signals for soot volume fraction measurements. Applied Optics, 45(29), pp.7706-7711.

Migliorini, F., Iuliis, S., Maffi, S., Cignoli, F. \& Zizak, G., 2009. Investigation on the influence of soot size on prompt LII signals in flames. Applied Physics B, 96(4), pp.637643. doi:10.1007/s00340-009-3524-x.

Modest, M.F., 2003. Radiative Heat Transfer Second Edi., Elsevier Science.

Mountain, R.D. \& Mulholland, G.W., 1988. Light scattering from simulated smoke agglomerates. Langmuir, 4(6), pp.1321-1326. doi:10.1021/la00084a021.

Mueller, M., Chan, Q. \& Qamar, N., 2013. Experimental and computational study of soot evolution in a turbulent nonpremixed bluff body ethylene flame. Combustion and Flame, 160(7), pp.1298-1309. doi:10.1016/j.combustflame.2013.02.010.

Narayanan, P. \& Trouvé, A., 2009. Radiation-driven flame weakening effects in sooting turbulent diffusion flames. Proceedings of the Combustion Institute, 32(1), pp.14811489. doi:10.1016/j.proci.2008.06.056.

National Aeronautics and Space Administration, 2010. NASA-HDBK-8739.19-3 -Measurement Uncertainty Analysis Principles and Methods, Washington, D.C.

Ni, T., Pinson, J.A., Gupta, S. \& Santoro, R.J., 1995. Two-dimensional imaging of soot volume fraction by the use of laser-induced incandescence. Applied Optics, 34(30), pp.7083-7091. doi:10.1364/AO.34.007083.

Oh, C. \& Sorensen, C., 1997. The effect of overlap between monomers on the determination of fractal cluster morphology. Journal of Colloid and Interface Science, 193(1), pp.17-25. doi:10.1006/jcis.1997.5046.

Oltmann, H., Reimann, J. \& Will, S., 2010. Wide-angle light scattering (WALS) for soot aggregate characterization. Combustion and Flame, 157(3), pp.516-522.

doi:10.1016/j.combustflame.2009.10.011.

Oltmann, H., Reimann, J. \& Will, S., 2012. Single-shot measurement of soot aggregate sizes by wide-angle light scattering (WALS). Applied Physics B, 106(1), pp.171-183. doi:10.1007/s00340-011-4781-z.

Pasquill, F., \& Smith, F. B. (1983). Atmospheric Diffusion (3rd ed.). Chichester, UK: Ellis Horwood. 
Pastor, J.V., García, J.M., Pastor, J.M. \& Buitrago, J.E., 2006. Analysis of calibration techniques for laser-induced incandescence measurements in flames. Measurement Science and Technology, 17(12), pp.3279-3288. doi:10.1088/0957-0233/17/12/013.

Pope III, C.A., Burnett, R.T., Thun, M.J., Eugenia, E.C., Krewski, D., Ito, K. \& Thurston, G.D., 2002. Lung Cancer, Cardiopulmonary Mortality, and Long-term Exposure to Fine Particulate Air Pollution. JAMA: The Journal of the American Medical Association, 287(9), pp.1132-1141. doi:10.1001/jama.287.9.1132.

Qamar, N.H., Nathan, G.J., Alwahabi, Z.T. \& King, K.D., 2005. The effect of global mixing on soot volume fraction: measurements in simple jet, precessing jet, and bluff body flames. Proceedings of the Combustion Institute, 30(1), pp.1493-1500. doi:10.1016/j.proci.2004.08.102.

Qamar, N.H., Alwahabi, Z.T., Chan, Q.N., Nathan, G.J., Roekaerts, D. \& King, K.D., 2009. Soot volume fraction in a piloted turbulent jet non-premixed flame of natural gas. Combustion and Flame, 156(7), pp.1339-1347.

doi:10.1016/j.combustflame.2009.02.011.

Ramanathan, V. \& Carmichael, G., 2008. Global and regional climate changes due to black carbon. Nature Geoscience, 1(4), pp.221-227. doi:10.1038/ngeo156.

Reimann, J., Kuhlmann, S.-A. \& Will, S., 2009. 2D aggregate sizing by combining laserinduced incandescence (LII) and elastic light scattering (ELS). Applied Physics B, 96(4), pp.583-592. doi:10.1007/s00340-009-3546-4.

Roditcheva, O. \& Bai, X.S., 2001. Pressure effect on soot formation in turbulent diffusion flames. Chemosphere, 42(5-7), pp.811-821. doi:10.1016/S0045-6535(00)00255-1.

Santoro, R. \& Semerjian, H., 1983. Soot particle measurements in diffusion flames. Combustion and Flame, 51, pp.203-218. doi:10.1016/0010-2180(83)90099-8.

Santoro, R., Yeh, T., Horvath, J. \& Semerjian, H., 1987. The Transport and Growth of Soot Particles in Laminar Diffusion Flames. Combustion Science and Technology, 53(23), pp.89-115. doi:10.1080/00102208708947022.

Santos, A. \& Costa, M., 2005. Reexamination of the scaling laws for NOx emissions from hydrocarbon turbulent jet diffusion flames. Combustion and Flame, 142(1-2), pp.160-169. doi:10.1016/j.combustflame.2005.03.004.

Saqr, K.M., Aly, H.S., Sies, M.M. \& Wahid, M. a., 2010. Effect of free stream turbulence on NOx and soot formation in turbulent diffusion $\mathrm{CH} 4$-air flames. International Communications in Heat and Mass Transfer, 37(6), pp.611-617.

doi:10.1016/j.icheatmasstransfer.2010.02.008. 
Sato, Y., \& Yamamoto, K. (1987). Lagrangian measurement of fluid-particle motion in an isotropic turbulent field. Journal of Fluid Mechanics, 175, 183-199.

doi:10.1017/S0022112087000351

Schnaiter, M., Horvath, H., Mohler, O., Naumann, K., Saathoff, H. \& Schock, O., 2003. UV-VIS-NIR spectral optical properties of soot and soot-containing aerosols. Journal of Aerosol Science, 34(10), pp.1421-1444. doi:10.1016/S0021-8502(03)00361-6.

Schoemaecker Moreau, C., Therssen, E., Mercier, X., Pauwels, J.F. \& Desgroux, P., 2004. Two-color laser-induced incandescence and cavity ring-down spectroscopy for sensitive and quantitative imaging of soot and PAHs in flames. Applied Physics B, 78(34), pp.485-492. doi:10.1007/s00340-003-1370-9.

Schraml, S., Dankers, S., Bader, K., Will, S. \& Leipertz, A., 2000. Soot temperature measurements and implications for time-resolved laser-induced incandescence (TIRELII). Combustion and Flame, 120(4), pp.439-450. doi:10.1016/S0010-2180(99)00117-0.

Schulz, C., Kock, B.F., Hofmann, M., Michelsen, H.A., Will, S., Bougie, B., Suntz, R. \& Smallwood, G.J., 2006. Laser-induced incandescence: recent trends and current questions. Applied Physics B, 83(3), pp.333-354. doi:10.1007/s00340-006-2260-8.

Shaddix, C.R., Harrington, J.E. \& Smyth, K.C., 1994. Quantitative Measurements of Enhanced Soot Production in a Flickering Methane Air Diffusion Flame. Combustion and Flame, 99(3-4), pp.723-732. doi:10.1016/0010-2180(94)90067-1.

Shaddix, C.R. \& Smyth, K.C., 1996. Laser-induced incandescence measurements of soot production in steady and flickering methane, propane, and ethylene diffusion flames. Combustion and Flame, 107(4), pp.418-452. doi:10.1016/S0010-2180(96)00107-1.

Sivathanu, Y.R. \& Faeth, G.M., 1990. Temperature / Soot Volume Fraction Correlations in the Fuel-Rich Region of Buoyant Turbulent Diffusion Flames. Combustion and Flame, 81(2), pp.150-165. doi:10.1016/0010-2180(90)90061-U.

Smallwood, G.J., Snelling, D.R., Liu, F. \& Gülder, Ö.L., 2001. Clouds Over Soot Evaporation: Errors in Modeling Laser-Induced Incandescence of Soot. Transactions of the ASME, 123(4), pp.814-818. doi:10.1115/1.1370507.

Snelling, D.R., 1997. Development and application of laser-induced incandescence (LII) as a diagnostic for soot particulate measurements. In Advanced Non-Intrusive Instrumentation for Propulsion Engines AGARD Conference Proceedings. pp. 23.2123.29 .

Snelling, D.R., Thomson, K.A., Smallwood, G.J. \& Gülder, Ö.L., 1999. Twodimensional imaging of soot volume fraction in laminar diffusion flames. Applied Optics, 38(12), pp.2478-85. doi:10.1364/AO.38.002478. 
Snelling, D.R., Liu, F., Smallwood, G.J. \& Gülder, Ö.L., 2000. Evaluation of the nanoscale heat and mass transfer model of the laser-induced incandescence: prediction of the excitation intensity. In Thirty Fourth National Heat Transfer Conference (American Society of Mechanical Engineers). pp. NHTC2000-12132.

Snelling, D.R., Thomson, K.A., Smallwood, G.J., Gülder, Ö.L., Weckman, E.J. \& Fraser, R.A., 2002. Spectrally Resolved Measurement of Flame Radiation to Determine Soot Temperature and Concentration. AIAA Journal, 40(9), pp.1789-1795.

doi: $10.2514 / 2.1855$.

Snelling, D.R., Liu, F., Smallwood, G.J. \& Gülder, Ö.L., 2004. Determination of the soot absorption function and thermal accommodation coefficient using low-fluence LII in a laminar coflow ethylene diffusion flame. Combustion and Flame, 136(1-2), pp.180-190. doi:10.1016/j.combustflame.2003.09.013.

Snelling, D.R., Smallwood, G.J., Liu, F., Gülder, Ö.L. \& Bachalo, W.D., 2005. A Calibration-Independent Laser-Induced Incandescence Technique for Soot Measurement by Detecting Absolute Light Intensity. Applied Optics, 44(31), pp.6773-6785. doi:10.1364/AO.44.006773.

Snelling, D.R., Thomson, K.A., Liu, F. \& Smallwood, G.J., 2009. Comparison of LII derived soot temperature measurements with LII model predictions for soot in a laminar diffusion flame. Applied Physics B, 96(4), pp.657-669. doi:10.1007/s00340-009-3614-9.

Snelling, D.R., Link, O., Thomson, K.A. \& Smallwood, G.J., 2011. Measurement of soot morphology by integrated LII and elastic light scattering. Applied Physics B, 104(2), pp.385-397. doi:10.1007/s00340-011-4394-6.

Sorensen, C.M., Cai, J. \& Lu, N., 1992a. Light-scattering measurements of monomer size, monomers per aggregate, and fractal dimension for soot aggregates in flames. Applied Optics, 31(30), pp.6547-57. doi:10.1364/AO.31.006547.

Sorensen, C.M., Cai, J. \& Lu, N., 1992b. Test of static structure factors for describing light scattering from fractal soot aggregates. Langmuir, 8(8), pp.2064-2069.

doi:10.1021/la00044a029.

Sorensen, C.M., Lu, N. \& Cai, J., 1995. Fractal Cluster Size Distribution Measurement Using Static Light Scattering. Journal of Colloid and Interface Science, 174(2), pp.456460. doi:10.1006/jcis.1995.1413.

Sorensen, C., 2001. Light scattering by fractal aggregates: a review. Aerosol Science \& Technology, 35(2), pp.648-687. doi:10.1080/02786820117868.

Sutton, J.A. \& Driscoll, J.F., 2004. Rayleigh scattering cross sections of combustion species at 266, 355, and $532 \mathrm{~nm}$ for thermometry applications. Optics letters, 29(22), pp.2620-2. doi:10.1364/OL.29.002620. 
Teng, Y. \& Köylü, Ü.Ö., 2006. Optical sizing of aggregated combustion particles: computational development of a two-angle laser scattering technique. Applied Optics, 45(18), pp.4396-403. doi:10.1364/AO.45.004396.

Thomson, K.A., Johnson, M.R., Snelling, D.R. \& Smallwood, G.J., 2008. Diffuse-light two-dimensional line-of-sight attenuation for soot concentration measurements. Applied Optics, 47(5), pp.694-703. doi:10.1364/AO.47.000694.

Tian, K., Liu, F., Thomson, K.A., Snelling, D.R., Smallwood, G.J. \& Wang, D., 2004. Distribution of the number of primary particles of soot aggregates in a nonpremixed laminar flame. Combustion and Flame, 138(1-2), pp.195-198.

doi:10.1016/j.combustflame.2004.04.008.

Trottier, S., Guo, H., Smallwood, G.J. \& Johnson, M.R., 2007. Measurement and modeling of the sooting propensity of binary fuel mixtures. Proceedings of the Combustion Institute, 31(1), pp.611-619. doi:10.1016/j.proci.2006.07.229.

US EPA, 2010. Integrated Science Assessment for Particulate Matter, Research Triangle Park, NC: National Center for Environmental Assessmement-RTP Division, U.S. Environmental Protection Agency.

Vander Wal, R.L. \& Weiland, K.J., 1994. Laser-induced incandescence: Development and characterization towards a measurement of soot-volume fraction. Applied Physics B, 59(4), pp.445-452. doi:10.1007/BF01081067.

Vander Wal, R.L., 1998. Calibration and comparison of laser-induced incandescence with cavity ring-down. Symposium (International) on Combustion, 27(1), pp.59-67. doi:10.1016/S0082-0784(98)80390-1.

Will, S., Schraml, S. \& Leipertz, A., 1995. Two-dimensional soot-particle sizing by timeresolved laser-induced incandescence. Optics Letters, 20(22), p.2342.

doi:10.1364/OL.20.002342.

Williams, T.C. \& Shaddix, C.R., 2007. Simultaneous correction of flat field and nonlinearity response of intensified charge-coupled devices. Review of Scientific Instruments, 78(12), p.123702. doi:10.1063/1.2821616.

Xin, Y. \& Gore, J.P., 2005. Two-dimensional soot distributions in buoyant turbulent fires. Proceedings of the Combustion Institute, 30, pp.719-726.

doi:10.1016/j.proci.2004.08.126.

Xing, Y., Köylü, Ü.Ö. \& Rosner, D.E., 1999. In situ light-scattering measurements of morphologically evolving flame-synthesized oxide nanoaggregates. Applied Optics, 38(12), pp.2686-97. doi:10.1364/AO.38.002686. 
Yang, B. \& Köylü, Ü.Ö., 2005a. Soot processes in a strongly radiating turbulent flame from laser scattering/extinction experiments. Journal of Quantitative Spectroscopy and Radiative Transfer, 93(1-3), pp.289-299. doi:10.1016/j.jqsrt.2004.08.026.

Yang, B. \& Köylü, Ü.Ö., 2005b. Detailed soot field in a turbulent non-premixed ethylene/air flame from laser scattering and extinction experiments. Combustion and Flame, 141, pp.55-65. doi:10.1016/j.combustflame.2004.12.008.

Yon, J., Lemaire, R., Therssen, E., Desgroux, P., Coppalle, A. \& Ren, K.F., 2011. Examination of wavelength dependent soot optical properties of diesel and diesel/rapeseed methyl ester mixture by extinction spectra analysis and LII measurements. Applied Physics B, 104(2), pp.253-271. doi:10.1007/s00340-011-4416-4.

Zerbs, J., Geigle, K.P., Lammel, O., Hader, J., Stirn, R., Hadef, R. \& Meier, W., 2009. The influence of wavelength in extinction measurements and beam steering in laserinduced incandescence measurements in sooting flames. Applied Physics B, 96(4), pp.683-694. doi:10.1007/s00340-009-3550-8. 


\section{Appendix A: Additional Figures Describing the Transfer of the Scattering Calibration between Detectors}

As noted in Chapters 3 and 4 , the diffuse surface calibration constant obtained for the backward scattering detector was transferred to the forward scattering detector using an integrating sphere (SphereOptics Hoffman LLC, Contocook, $\mathrm{NH})$. For the experiments detailed in Chapter 3, the sphere was illuminated by a small CW Nd:YAG laser (Crystalaser GCL532-075-L). The sphere output port was mounted along the axis of detection (i.e. axis of the output port coincident with the axis of detection), first facing the backward scattering detector as shown in Figure A.1(a). The sphere and laser were then repositioned to face the forward scattering detector as shown in Figure A.1(b). The CW laser entered the sphere from the same relative location in each case. 


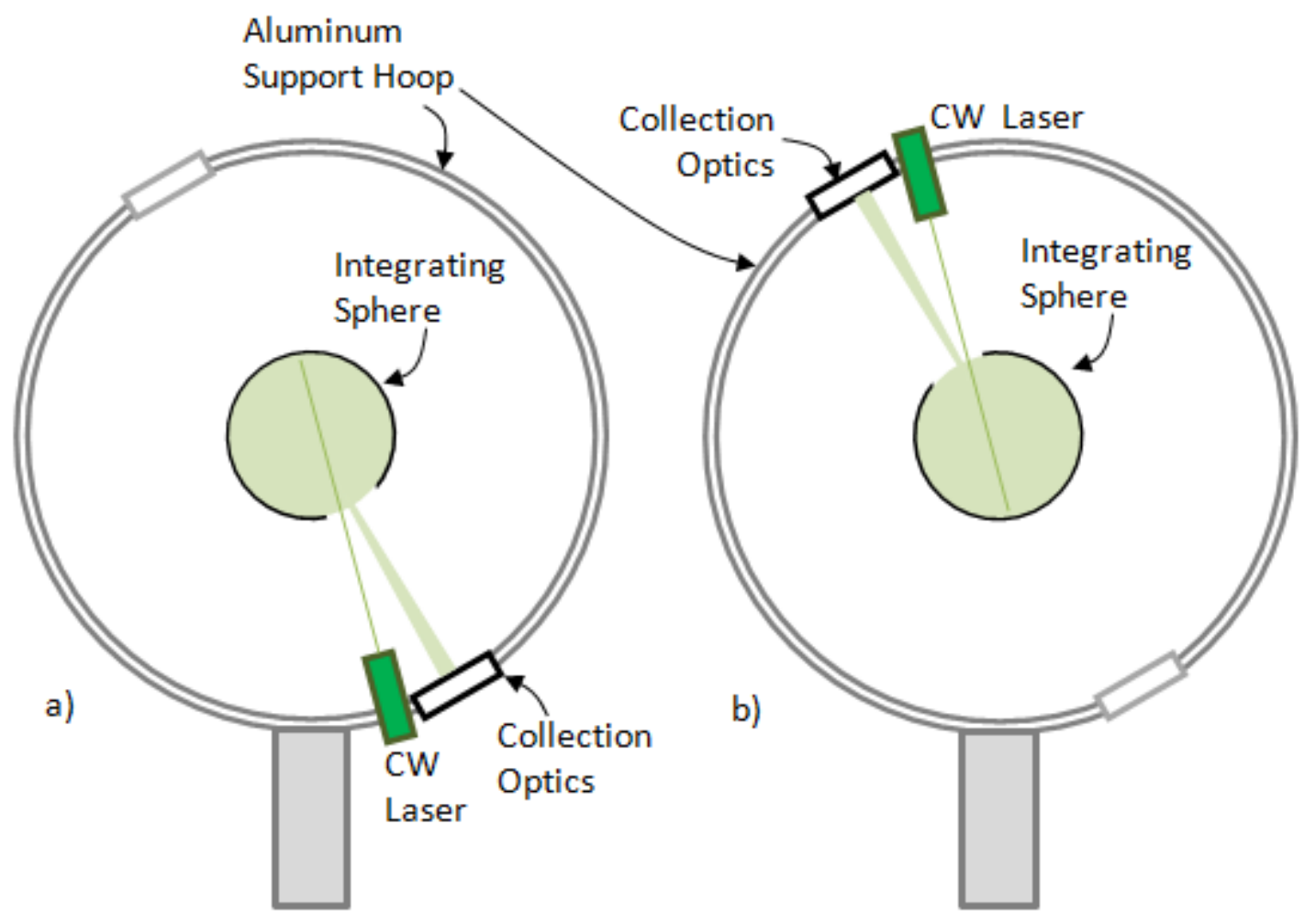

Figure A.1 - Integrating sphere mounted inside the aluminum hoop as viewed from above. In Chapter 3, an integrating sphere illuminated by a $\mathrm{CW}$ laser was used to produce identical calibration signals that overfilled the a) backward scattering and b) forward scattering collection optics.

The apparatus employed in Chapters 4 and 5 did not use a secondary CW laser to transfer the diffuse scattering calibration. Instead, the same pulsed laser used for LII and ELS excitation was used to illuminate an integrating sphere $(150 \mathrm{~mm}$ diameter sphere with a $40 \mathrm{~mm}$ output port) similar to the one described earlier for LII calibration. By measuring the output signal from the laser-illuminated integrating sphere at the backward scattering detector (Figure A.2(a)), and then at the forward scattering detector (Figure A.2(b)), it was possible to obtain a relative calibration between the two detection systems. 


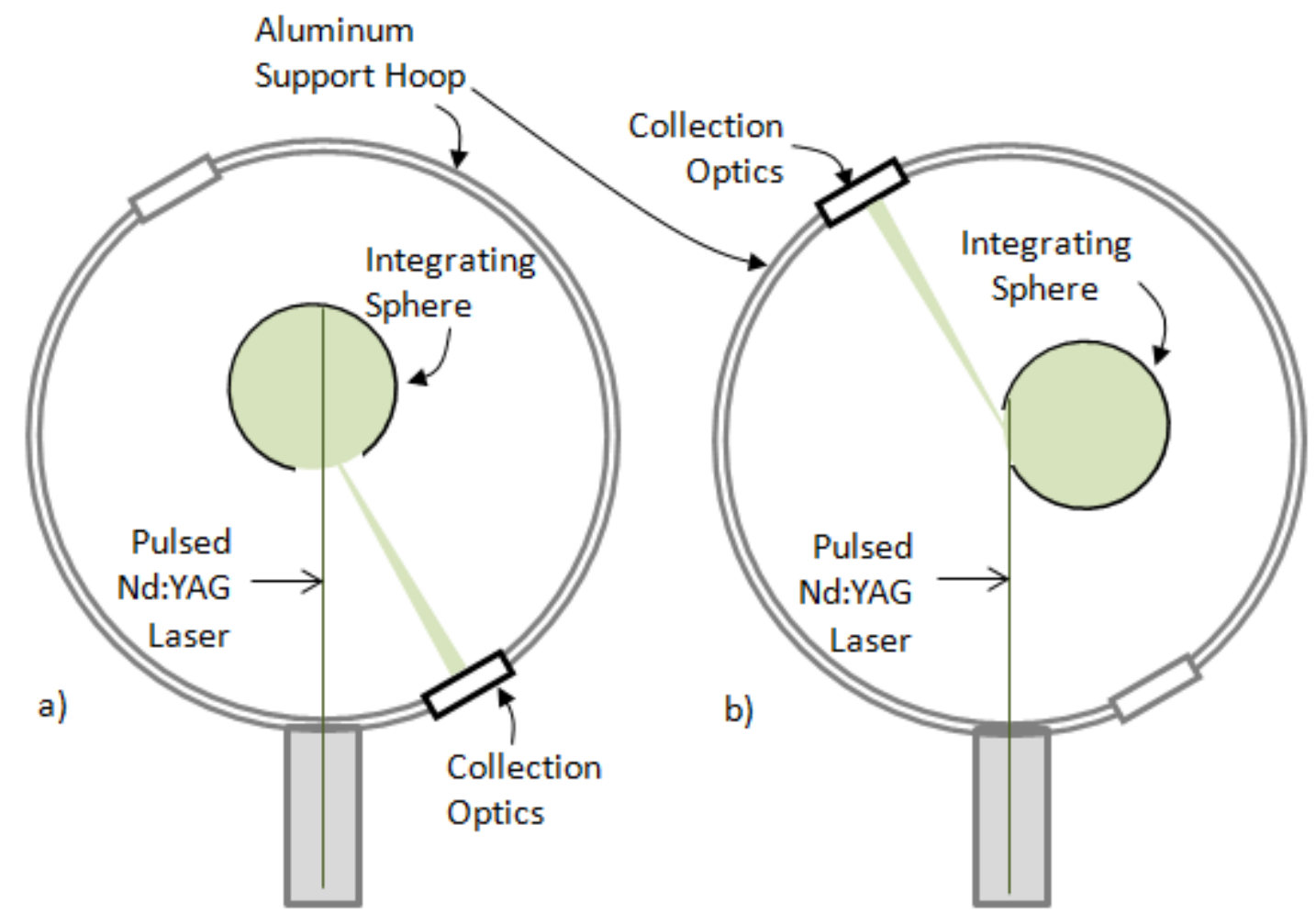

Figure A.2 - Integrating sphere mounted inside the aluminum hoop as viewed from above. In Chapters $4 \& 5$, an integrating sphere illuminated by the same pulsed Nd:YAG laser that was used for LII \& ELS excitation was used to produce identical calibration signals that overfilled the a) backward scattering and b) forward scattering collection optics. 


\section{Appendix B: Supplemental Information and Figures Describing the Experimental Apparatus}

This appendix includes additional figures and photographs to aid a reader's ability to visualize the complex apparatus employed in the thesis as well as additional details about the fuels employed during experiments.

For the experiments presented in Chapter 2-4, Grade 2.5 compressed ethylene gas was used for the fuel stream. Grade 2.5 ethylene has a specified composition of $>99.5 \%$ ethylene. Compressed air from the building supply lines was used for the air stream. The nominal pressure in the lines was 90 psig. Air from these lines was passed through a cyclone filter, pressure regulator, and then a thermal mass flow controller prior to being delivered to the experiment. For the experiments presented in Chapter 5, a fuel mixture was used that was selected to be representative of associated gas flare compositions (McEwen \& Johnson, 2012; Johnson \& Coderre, 2012) which contained 85.3\% $\mathrm{CH}_{4}, 7.1 \%$ $\mathrm{C}_{2} \mathrm{H}_{6}, 3.1 \% \mathrm{C}_{3} \mathrm{H}_{8}, 1.4 \% \mathrm{C}_{4} \mathrm{H}_{10}, 1.9 \% \mathrm{CO}_{2}$ and $1.2 \% \mathrm{~N}_{2}$ by volume.

Due to the size and complexity of the experimental apparatus, additional figures and photographs are included here to assist the reader in visualizing the experimental layout. 


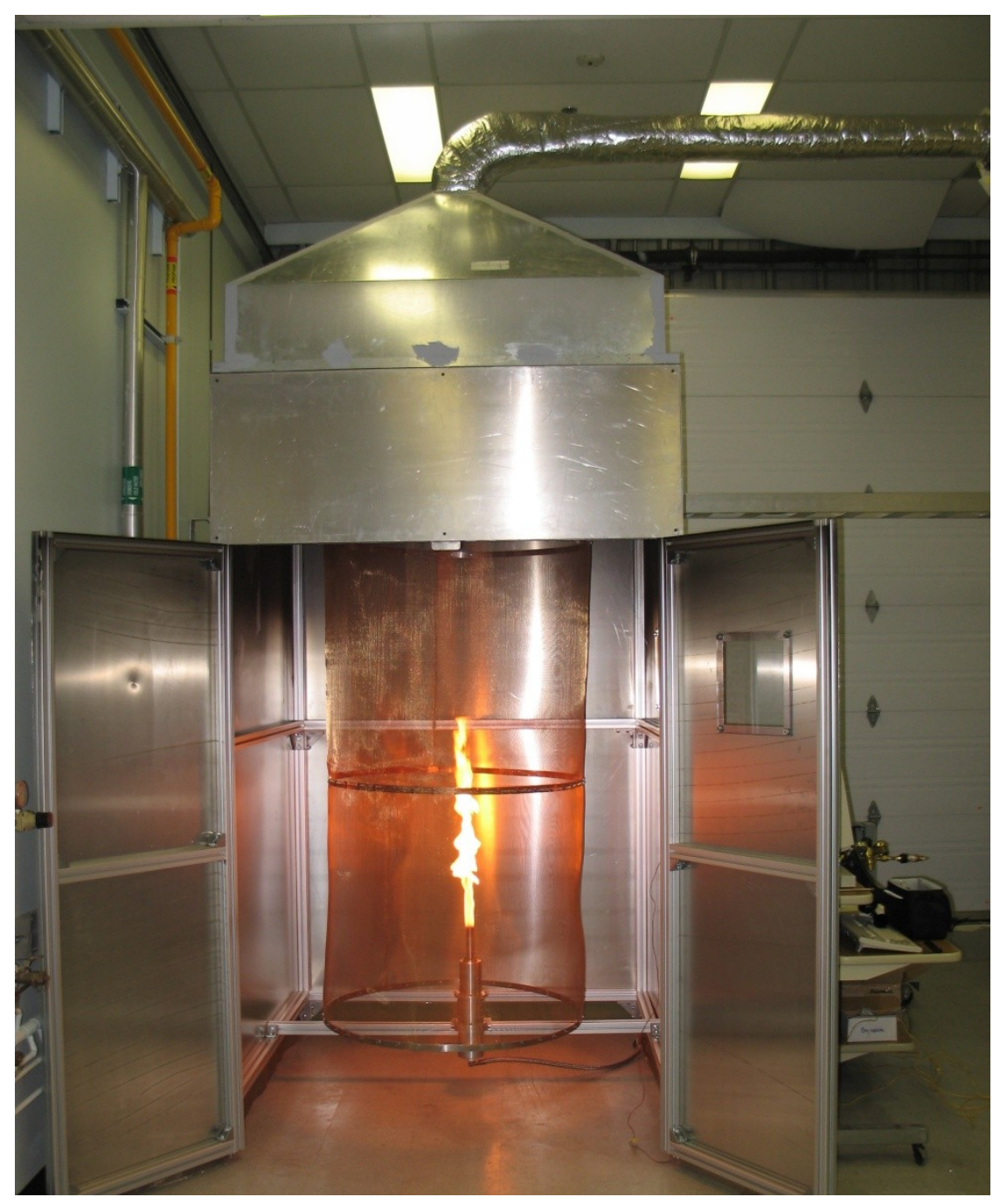

Figure B.1 - The $25.4 \mathrm{~mm}$ diameter burner inside the enclosure with the doors open. 


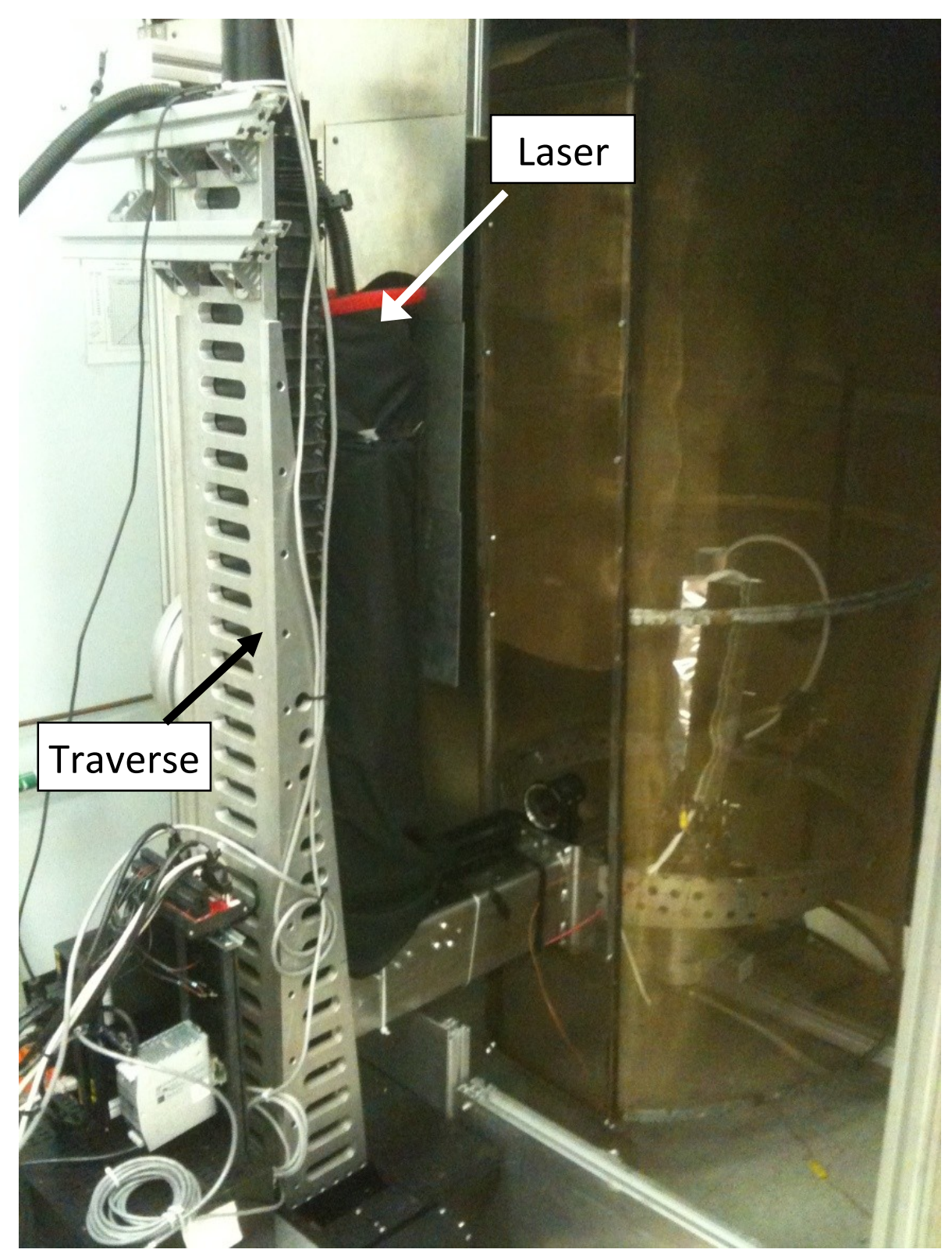

Figure B.2 - The laser was mounted vertically on the vertical axis of the traverse and wrapped in light blocking fabric. 


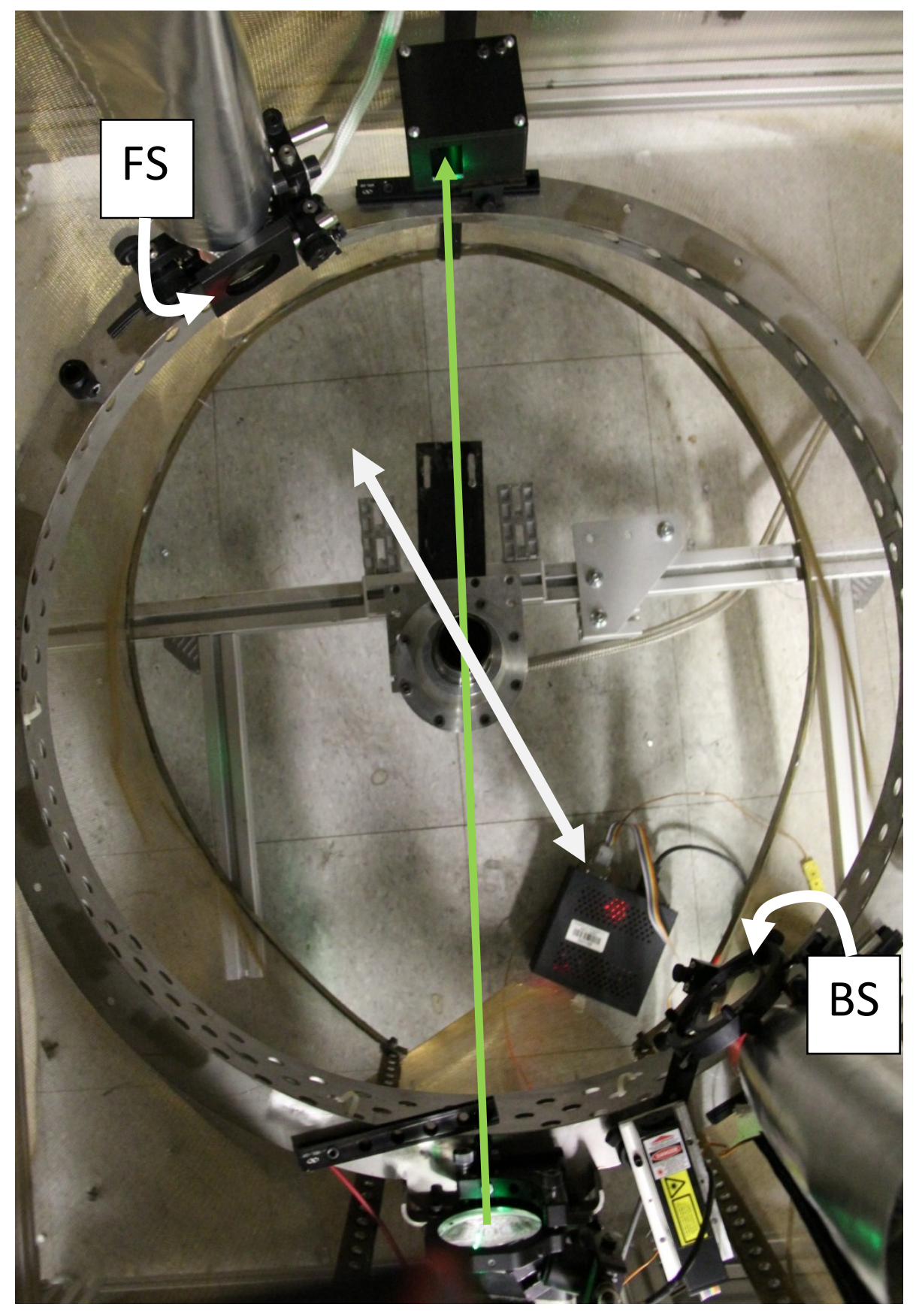

Figure B.3 - The excitation laser beam (shown in green) enters from the bottom of the image. Scattered light is captured by the forward scattering (FS) and backward scattering (BS) collection optics. 


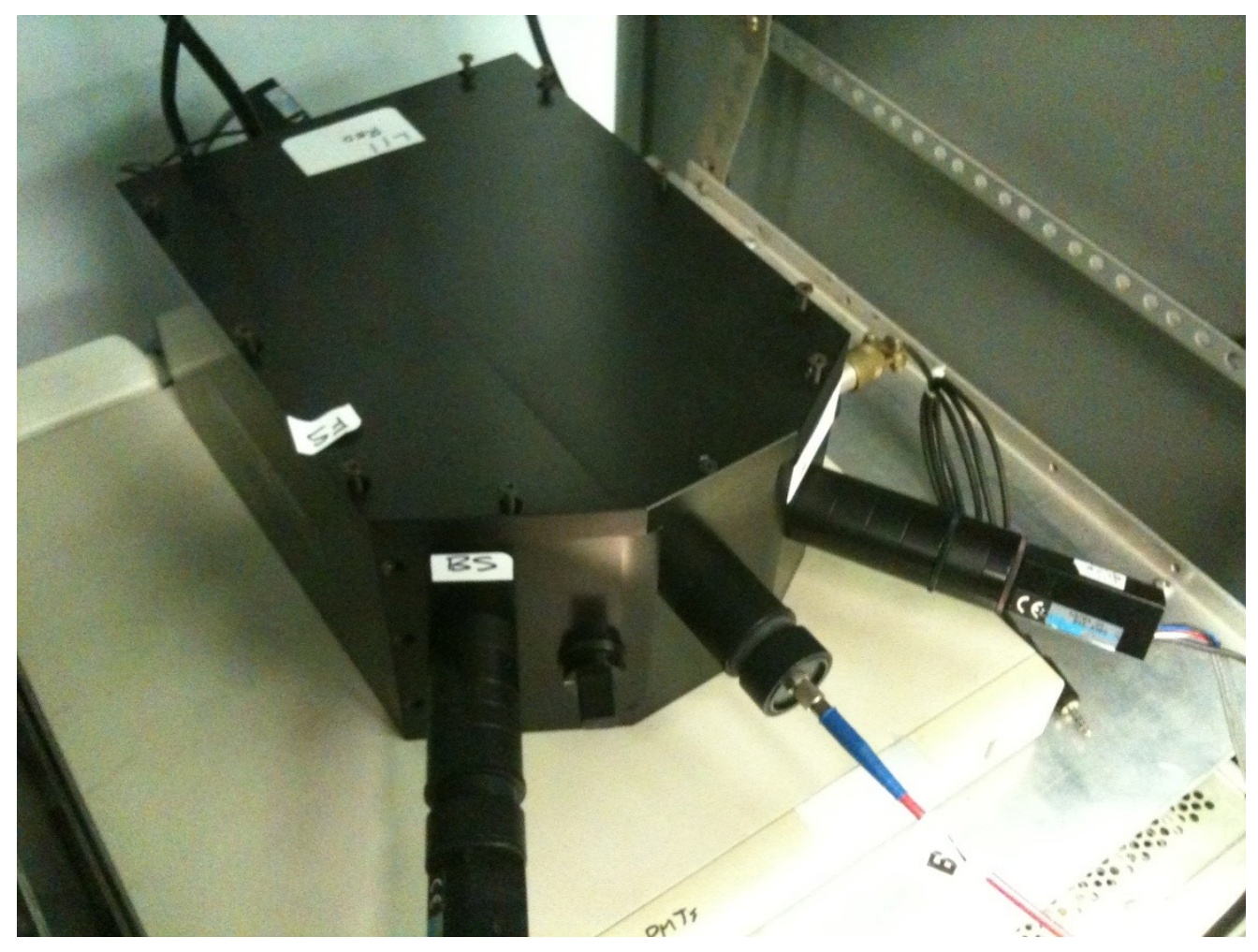

Figure B.3 - The backward scattering signal arrives at the filter box via a $1 \mathrm{~mm}$ diameter fibre. Photomultiplier tubes are mounted at the right and the top left to capture the filtered LII signals, while a photodiode is mounted at the bottom left to capture the filtered scattering signal. 


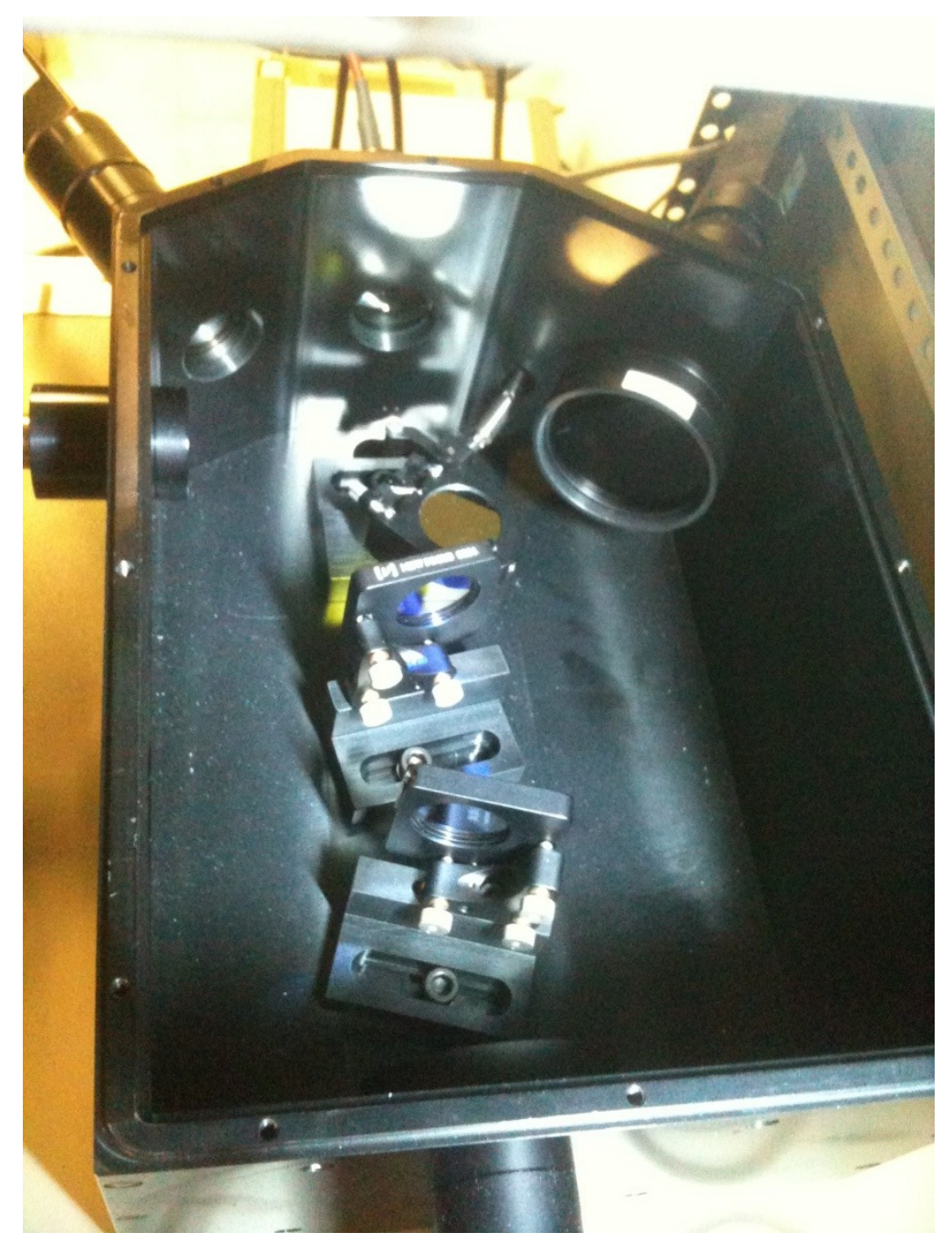

Figure B.4 - The backward scattering signal enters via a $1 \mathrm{~mm}$ diameter fibre and collimating lens at the top centre of the image. Two dichroic mirros in the middle of the filter box direct the shorter wavelength LII and the scattering signals to their detectors at top left and top right, respectively. The longer wavelength LII signal continues through both dichroic mirrors and is captured by a detector at the bottom centre. 


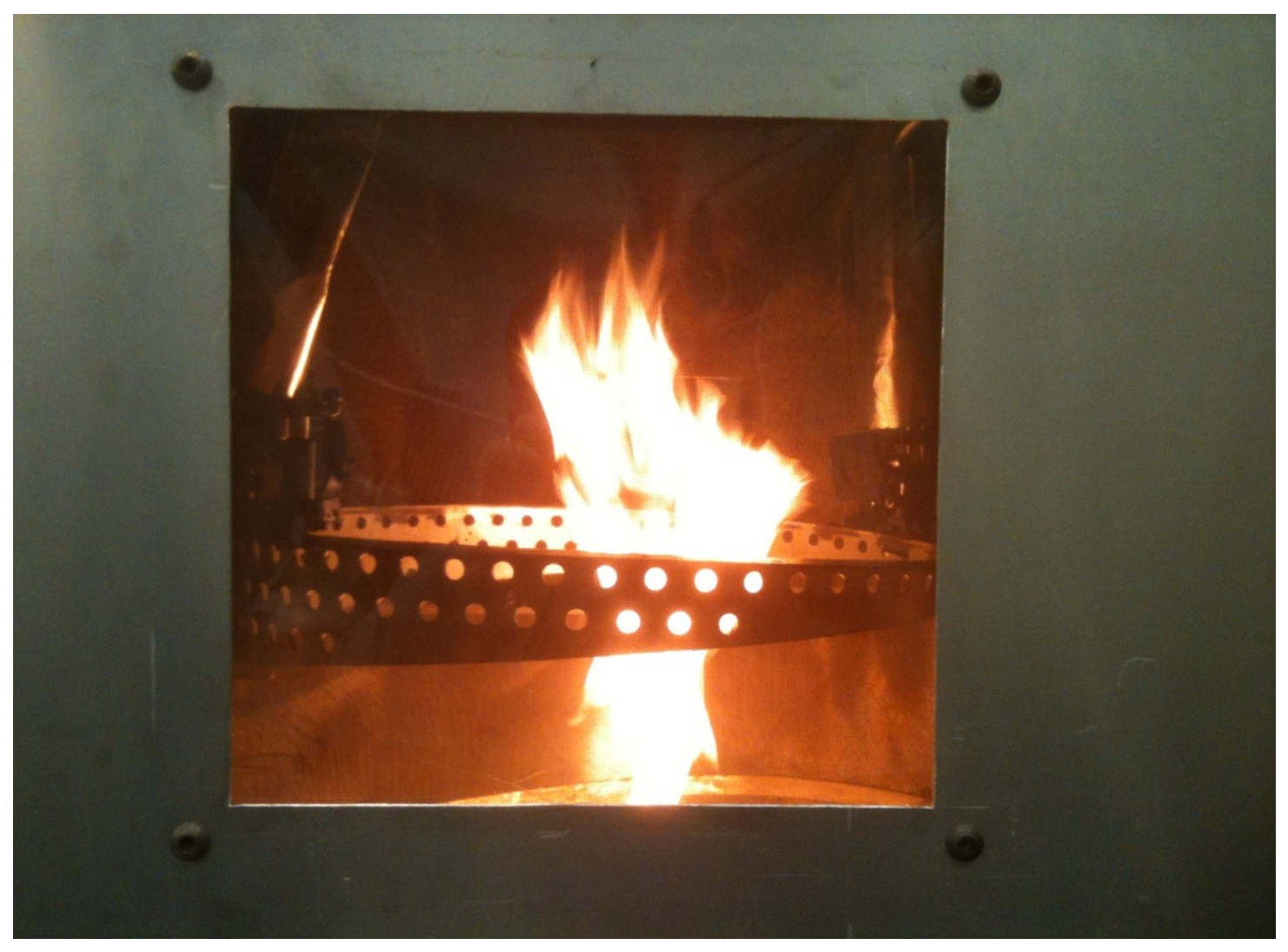

Figure B.5 - The flame as seen through a side window of the enclosure. The detection optics are mounted on the lightweight aluminum hoop. 


\section{Appendix C: Local Soot Flux Estimates}

Velocity measurements in the turbulent buoyant non-premixed flame were also combined with $\mathrm{fv}$ measurements to attempt calculation of the soot mass flux at different axial planes. It became clear during velocity measurements that there were very few seed particles present high in the flame, resulting in very low data acquisition rates. It was decided to restrict velocity measurements to the flame centreline, allowing calculation of a soot mass flux with an assumed radially uniform velocity profile while reducing the total number of velocity measurement locations.

The following figures document the inferred soot mass flux for the flame conditions studied in Chapter 5, where the measured radial soot volume fraction profiles were combined with an assumed radially uniform velocity profile based on the centreline velocity measurements, and an assumed soot density of $1.89 \mathrm{~g} / \mathrm{cm}^{3}$ (Coderre 2009). The assumption of a radially uniform velocity profile is not valid near the nozzle exit where the flame has an annular shape. For this reasons measurements of soot flux begin at a flame-length normalized height above the burner of 0.2. The flame radius is taken from the video measurements made by McEwen et al. (2010) using the same burner apparatus at the same flame conditions.

For a given nozzle exit diameter the soot mass flux throughout the flame generally increases with increasing fuel mass flow rate, as shown in Figure C.1. 
Although the in-flame velocities are fairly similarly among conditions, the increased flame cross-sectional area associated with higher flow rate conditions is such that the inferred soot flux trends are opposite to the trends for soot volume fraction, which indicated a decrease with increasing fuel mass flow rate as shown in Figures 5.1 and $\mathrm{S}_{5.1}$ to $\mathrm{S}_{5} \cdot 3$.

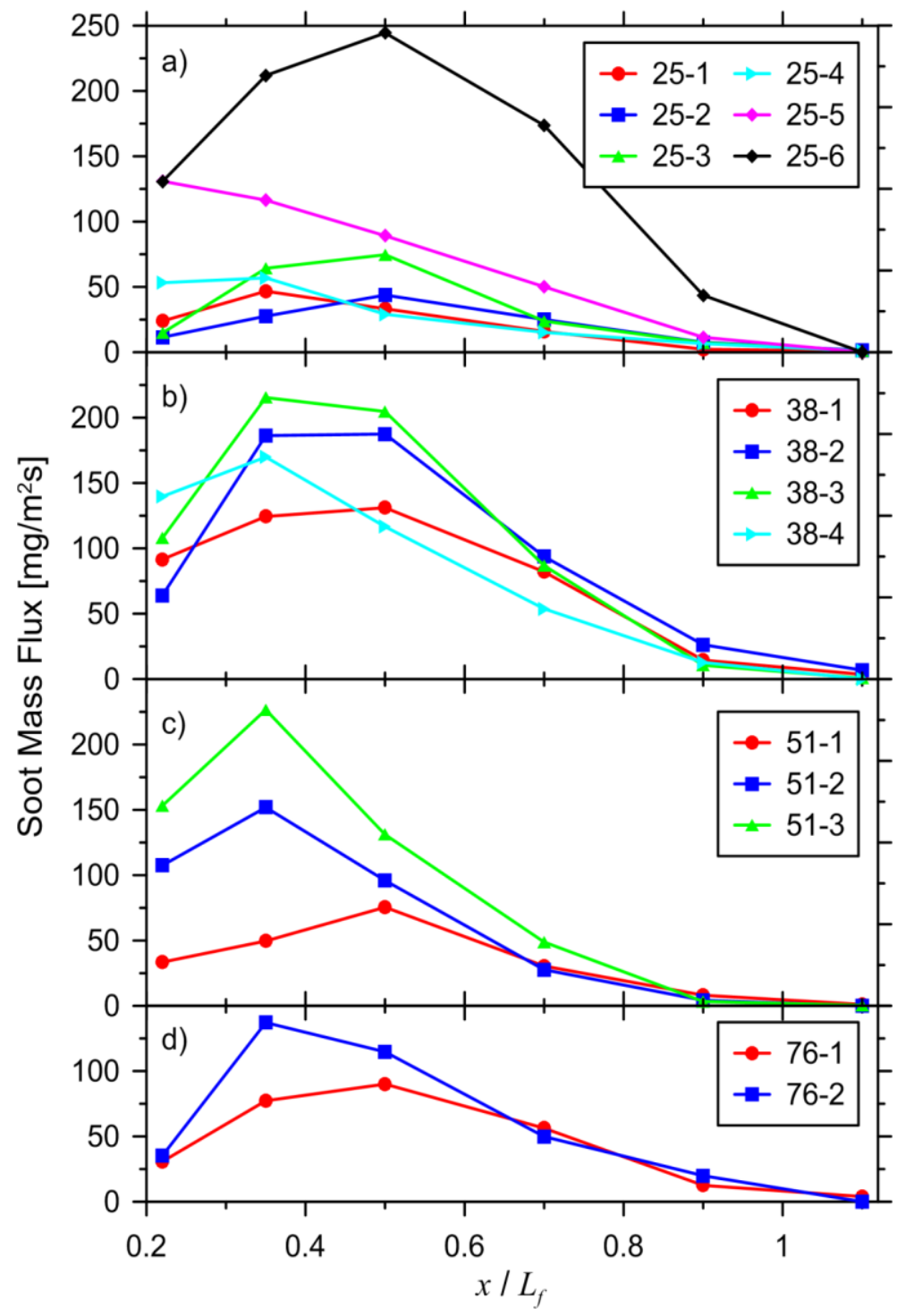

Figure C.1 - Soot mass fluxes in the lab-scale flare estimated using an assumed radially uniform velocity profile and an assumed soot density of $1.89 \mathrm{~g} / \mathrm{cm}^{3}$ (Coderre 2009) for nozzle exit diameters of a) $25.4 \mathrm{~mm}$, b) $38.1 \mathrm{~mm}$, c) $50.8 \mathrm{~mm}$, and d) $76.2 \mathrm{~mm}$. The legend follows the nomenclature described in Table 5.1. 